

\section{Koha 3 Library Management System}

Install, configure, and maintain your Koha installation with this easy-to-follow guide

Savitra Sirohi

Amit Gupta
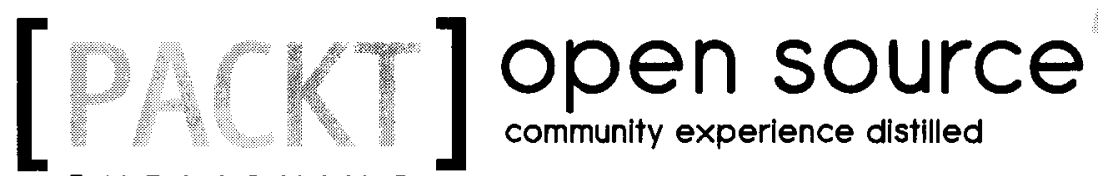

community experience distilled

BIRMINGHAM - MUMBAI

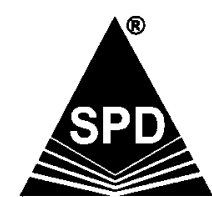

SHROFF PUBLISHERS 


\section{Koha 3 Library Management System}

\section{Copyright (C) 2010 Packt Publishing}

All rights reserved. No part of this book may be reproduced, stored in a retrieval system, or transmitted in any form or by any means, without the prior written permission of the publisher, except in the case of brief quotations embedded in critical articles or reviews.

Every effort has been made in the preparation of this book to ensure the accuracy of the information presented. However, the information contained in this book is sold without warranty, either express or implied. Neither the author, nor Packt Publishing, and its dealers and distributors will be held liable for any damages caused or alleged to be caused directly or indirectly by this book.

Packt Publishing has endeavored to provide trademark information about all of the companies and products mentioned in this book by the appropriate use of capitals. However, Packt Publishing cannot guarantee the accuracy of this information.

Originally published by Packt Publishing Ltd, 32 Lincoln Road, Olton, Birmingham, B27 6PA, UK.

Production Reference: 1091110 ISBN 978-1-849510-82-0 www.packtpub.com

Cover Image by John M. Quick (john.m.quick@gmail.com)

\section{Printing History:}

First published: November 2010

Second Indian Reprint: September 2011

ISBN 13: 978-93-5023-384-9

For sale in the Indian Subcontinent (India, Pakistan, Bangladesh, Sri Lanka, Nepal, Bhutan, Maldives) only. Illegal for sale outside of these countries.

Published by Shroff Publishers and Distributors Pvt. Ltd. C-103, MIDC, TTC Industrial Area, Pawane, Navi Mumbai 400 705, Tel: (91 22) 4158 4158, Fax: (91 22) 4158 4141, e-mail: spdorders@shroffpublishers.com. Printed at Jasmine Art Printers Pvt. Ltd., Navi Mumbai. 


\section{Credits}

Authors

Savitra Sirohi

Amit Gupta

\section{Reviewers}

Kyle M Hall

Vimal Kumar V

Acquisition Editor

Steven Wilding

Development Editor

Wilson D'souza

Technical Editor

Kavita lyer

Indexer

Hemangini Bari
Editorial Team Leader

Akshara Aware

Project Team Leader

Priya Mukherji

Project Coordinator

Srimoyee Ghoshal

Proofreaders

Aaron Nash

Clyde Jenkins

\section{Graphics}

Nilesh Mohite

Production Coordinator

Adline Swetha Jesuthas

Cover Work

Adline Swetha Jesuthas 


\section{About the Authors}

Savitra Sirohi heads Nucsoft OSS Labs (http: //www. osslabs.biz) - a Koha services provider. As part of his work, Savitra has lead several Koha implementations and conducts regular Koha workshops in India. Savitra is an Engineer and has an MBA from the Indian Institute of Management.

We would like to thank Kyle Hall, Vimal Kumar, and Nicole Engard and other members of the Koha community who took the time to review the chapter drafts. Their perspective and expertise helped improve this book immeasurably.

Many thanks are due to Wilson, Kavita, Srimoyee, Steven, and others at Packt for their expertise and hard work and also their patience with these first time authors.

Amit Gupta is the lead Koha specialist at Nucsoft OSS Labs (http: //www. osslabs.biz), a Koha services provider. Amit has played a key role in several Koha implementations, including the one at Delhi Public Library, one of India's biggest Koha projects. Amit has a BSc and a Master's in Computer Applications. 


\section{About the Reviewers}

Kyle M Hall is an IT specialist for the Meadville Public Library and the Crawford County Federated Library System of Pennsylvania is a Free Open Source Software advocate and software developer. His contributions to Koha include bugfixes and new features, as well as the Koha Off-line Circulation system. In addition to his work with Koha, he is also the author of a FOSS Kiosk Management System, Libk (http://libki.org), a cross-platform system for controlling access to computers via logins and time limits.

Vimal Kumar is a library professional with genuine interest in Linux and open source software. He is an active member of Koha community. He has a Master's degree in Library and Information Science from University of Kerala. He has done an evaluative study of open source library management system conducted in 2005 for the completion of MLISc degree project. During the past few years he has been active as a resource person for Koha training programs. He has been working with Mahatma Gandhi University Library and has also presented many papers in national and international conferences. 


\section{Table of Contents}

Preface

Chapter 1: Installing the Software Stack

An orientation to Koha's installation

Koha's architecture

What do we need to install?

Installation tools

Package manager $\quad 9$

Make utility 9

CPAN shell $\quad 9$

Git 9

Choosing between Linux Perl packages and CPAN modules 10

$\begin{array}{ll}\text { Choosing a Linux distribution } & 10\end{array}$

Getting help-Koha's community resources $\quad 10$

Preparing for installation $\quad 11$

Server prerequisites 11

Downloading Koha and switching to a branch 11

Cloning Koha 11

$\begin{array}{ll}\text { Checking out a branch } & 12\end{array}$

Preparing a list of installation packages $\quad 12$

$\begin{array}{ll}\text { System packages } & 13\end{array}$

$\begin{array}{ll}\text { Perl modules } & 13\end{array}$

Debian/Ubuntu package lists $\quad 14$

$\begin{array}{ll}\text { Setting up repositories or sources } & 14\end{array}$

Configuring the CPAN shell $\quad 15$

$\begin{array}{lr}\text { Installing Koha's software stack } & \mathbf{1 6}\end{array}$

$\begin{array}{ll}\text { Installing packages using the package manager } & 16\end{array}$

$\begin{array}{ll}\text { Installing packages from the Linux prompt } & 16\end{array}$

$\begin{array}{ll}\text { Installing packages using shell scripts } & 16\end{array}$ 
Installing packages using dselect

Installing Perl modules using CPAN

Troubleshooting CPAN installations

Setting up Koha's MySQL database

Configuring Koha's installation: Makefile.PL $\quad 20$

$\begin{array}{ll}\text { Completing Koha's installation } & 21\end{array}$

$\begin{array}{ll}\text { Summary } & 21\end{array}$

Chapter 2: Configuring the Apache2 Web Server $\quad 23$

Understanding Apache2 configuration 23

$\begin{array}{ll}\text { About Apache2 } & 23\end{array}$

$\begin{array}{ll}\text { Apache2 virtual hosts } & 24\end{array}$

Name-based or IP-based virtual hosts $\quad 24$

Apache2's configuration folder $\quad 25$

Koha's default Apache2 file $\quad 26$

Koha's virtual hosts $\quad 26$

$\begin{array}{ll}\text { Virtual host configuration } & 27\end{array}$

Preparing for Apache2 configuration $\quad 27$

$\begin{array}{ll}\text { Configuration plan } & 27\end{array}$

Two host names $\quad 28$

Hostname with two ports $\quad 28$

IP address with two ports $\quad 29$

Two IP addresses $\quad 30$

Standalone machine $\quad 30$

$\begin{array}{ll}\text { Configuration prerequisites } & 31\end{array}$

Configuring Apache2 web server $\quad 31$

Creating a symbolic link to koha-httpd.conf 31

Enabling Apache2's Rewrite module $\quad 32$

Configuring the listener $\quad 32$

Editing the OPAC virtual host $\quad 32$

Editing the staff client virtual host $\quad 33$

Enabling Koha's virtual hosts $\quad 33$

Restarting Apache2 $\quad 33$

Troubleshooting configuration problems $\quad 35$

$\begin{array}{ll}\text { Rewrite module not enabled } & 36\end{array}$

$\begin{array}{ll}\text { Incorrect or missing Directory directive } & 36\end{array}$

Unable to connect to MySQL 36

$\begin{array}{ll}\text { Listener not setup } & 37\end{array}$

$\begin{array}{ll}\text { Summary } & \mathbf{3 8}\end{array}$ 
Chapter 3: Installing Koha's Zebra Search Engine

About Zebra

Koha's Zebra related components

Zebrasrv-the Zebra query and retrieval server

Rebuild_zebra.pl-the Zebra index maintenance program

Installing Zebra

Installing Zebra packages

Installing Koha with Zebra

Testing Zebra

Testing zebrasrv

The zebrasrv command

Invoking zebrasrv with Koha's configuration file $\quad 43$

zebrasrv daemon

Zebrasrv daemon on Debian or Ubuntu

Rebuilding Zebra

Creating or recreating indexes

Using Koha without Zebra

Chapter 4: Koha's Web Installer, Crontab, and Other Server

Understanding the web installer's functions

Understanding how to execute the web installer

Understanding optional data available for import 54

Settings for MARC frameworks

Other data

Executing the web installer

Launching Koha

Configuring the crontab

Editing the crontab

Setting up environment variables

Generating advance notices

Generating overdue notices

Sending e-mail messages

Calculating fines

Rebuilding Zebra indexes

More crontab examples

Ensuring Koha starts automatically on server reboot $\quad 60$

Auto-starting Apache2

Auto-starting MySQL

Auto-starting Zebra server 
Configuring the correct SAX parser

Setting up environment variables for the Linux shell

Setting up KOHA_CONF environment variable 63

Setting up PERL5LIB environment variable 64

Setting up persistent environment variables $\quad 64$

Summary

Chapter 5: Configuring the Cataloging Module

A first look at Koha's cataloging configuration tools MARC frameworks

Authority Control

Authorized values

$\begin{array}{ll}\text { Preparing a configuration plan } & 73\end{array}$

$\begin{array}{ll}\text { Identifying Authority Control rules } & 73\end{array}$

$\begin{array}{ll}\text { Identifying frequently cataloged types of material } & 74\end{array}$

Identifying MARC field sets for each type of material $\quad 74$

$\begin{array}{ll}\text { Identifying mandatory fields } & 75\end{array}$

$\begin{array}{ll}\text { Identifying Authority Control rules } & 76\end{array}$

$\begin{array}{ll}\text { Identifying fields to control using authorized values } & 76\end{array}$

$\begin{array}{ll}\text { Implementing our configuration plan } & 77\end{array}$

$\begin{array}{ll}\text { Configuring authorities system preferences } & 78\end{array}$

$\begin{array}{ll}\text { Configuring Authority Types } & 79\end{array}$

$\begin{array}{ll}\text { Configuring authorized values categories } & 80\end{array}$

$\begin{array}{ll}\text { Editing authorized values } & 80\end{array}$

$\begin{array}{ll}\text { Special authorized values } & 81\end{array}$

$\begin{array}{ll}\text { Library } & 82 \\ & 81\end{array}$

Item Type $\quad 82$

$\begin{array}{lc}\text { Configuring MARC frameworks } & 83\end{array}$

Editing MARC framework list $\quad 83$

$\begin{array}{ll}\text { Creating a new framework } & 84\end{array}$

Editing fields and subfields $\quad 85$

Editing labels of fields or subfields $\quad 88$

Making a field or subfield mandatory $\quad \therefore \quad 88$

Advanced constraints $\quad 88$

Hidden fields and subfields $\quad 88$

Bringing fields or subfields under Authorized Value or Authority Control 88

Summary

89

Chapter 6: Configuring the Circulation Module

$\begin{array}{ll}\text { Patron categories } & 91\end{array}$

$\begin{array}{lr}\text { Identifying patron categories } & 92\end{array}$

$\begin{array}{ll}\text { Creating patron categories } & 93\end{array}$ 
Item types

Identifying Item types $\quad 95$

$\begin{array}{lr}\text { Creating Item types } & 96\end{array}$

$\begin{array}{lr}\text { Circulation and fine rules } & 97\end{array}$

Identifying circulation and fine rules $\quad 98$

Creating circulation and fine rules 98

Configuring the calendar and calculation of due date and fines $\quad 99$

$\begin{array}{ll}\text { Calendar and fine calculation } & 99\end{array}$

Calculation of due dates in Koha $\quad 99$

Preparing to configure the calendar and fines and due date calculations 100

$\begin{array}{ll}\text { Editing the calendar } & 100\end{array}$

$\begin{array}{ll}\text { Editing system preferences } & 101\end{array}$

$\begin{array}{ll}\text { Due and overdue notices } & 102\end{array}$

Preparing to configure due and overdue notices 103

$\begin{array}{ll}\text { Editing notices } & 104\end{array}$

Editing notice triggers 106

$\begin{array}{lr}\text { Configuring holds } & 107\end{array}$

$\begin{array}{ll}\text { Preparing to configure holds } & 107\end{array}$

$\begin{array}{ll}\text { Editing holds preferences } & 107\end{array}$

$\begin{array}{lr}\text { Summary } & 109\end{array}$

Chapter 7: Configuring Other System Preferences 111

$\begin{array}{ll}\text { Understanding Koha's system preferences } & 111\end{array}$

Koha's global system preferences module 112

Using system preferences $\quad 113$

Online documentation $\quad 113$

Configuring transactional modules $\quad 113$

$\begin{array}{ll}\text { Configuring patrons preferences } & 114\end{array}$

$\begin{array}{ll}\text { Configuring acquisitions preferences } & 117\end{array}$

$\begin{array}{ll}\text { Configuring serials preferences } & 119\end{array}$

$\begin{array}{lr}\text { Configuring OPAC preferences } & 122\end{array}$

\begin{tabular}{ll} 
Configuring static content & 122 \\
\hline
\end{tabular}

$\begin{array}{ll}\text { Configuring tools for patrons } & 124\end{array}$

$\begin{array}{ll}\text { Configuring patron access control } & 126\end{array}$

$\begin{array}{ll}\text { Configuring enhanced content } & 128\end{array}$

Configuring styling and appearance 132

$\begin{array}{ll}\text { Configuring OPAC styling and appearance } & 133\end{array}$

Configuring staff client styling and appearance 136 
Configuring general preferences

Configuring messaging preferences

Configuring security preferences

Configuring search preferences

Summary

Chapter 8: Test Driving Your Koha Installation

Patrons-create, search, and view patron record

Creating a new patron

Searching for a patron

Cataloging-create, search, and view bibliographic and item record

Creating a bibliographic record

Creating an item record

Searching for the record

Circulation-check-out, check-in, and view circulation history

Checking out

Checking in

Viewing circulation history

Acquisitions-create an order, receive shipment, and view budget utilization

Creating budgets

Creating a vendor

Creating orders

Receiving shipments

Viewing budget utilization

Serials-creating a subscription and receiving the first issue

Creating a subscription

Searching for the subscription

Receiving an issue

Reports-creating a guided report and executing it

Building a report

Using a saved report

OPAC_running a catalog search

Chapter 9: Migrating Catalog Data

An orientation to migrating catalog data

Understanding MARC files

Koha Holdings in tag 952

Holdings in legacy systems

Import tools 
MARCEdit

bulkmarckimport.pl

Koha's GUI import tool

Choosing an import tool

176

Migration process

Preparing to migrate catalog data

Mapping Koha's holdings subfields to subfields in source MARC file

Planning setup of administrative fields in Koha

Migrating catalog data

Setting up values in Koha's administrative fields

Setting up branch codes

Setting up Item types

Setting up collection codes

Setting up shelving locations

Editing the source MARC file using MARCEdit

Swapping subfields

Adding a new subfield

Merging subfields

Importing the MARC file

Using the bulkmarcimport.pl program

Importing catalog records using the GUI tools

\section{Summary}

Koha's mailing lists

Koha's IRC chat

Koha's bug tracker

Koha's Git repository

Apache2 web server is down

MySQL database server is down

Zebra search not returning any results

Zebra index rebuild not working

Parser problems

Overdues e-mail not working

Troubleshooting e-mail problems

Troubleshooting problems with generation of notices

Fines not working 
Software bugs $\quad 211$

Command line programs-environment variables not exported 213

Problems with Internet Explorer $\quad 214$

$\begin{array}{ll}\text { Summary } & 215\end{array}$

\begin{tabular}{lr} 
Chapter 11: Updating Software & 217 \\
\hline
\end{tabular}

$\begin{array}{ll}\text { Orientation to updating software } & 217\end{array}$

$\begin{array}{ll}\text { Understanding Koha's software versions } & 217\end{array}$

$\begin{array}{ll}\text { Branches } & 218\end{array}$

$\begin{array}{ll}\text { Heads } & 218\end{array}$

Tags $\quad 218$

Choosing a version to update to 219

Understanding components of software updates $\quad 219$

$\begin{array}{ll}\text { An overview of the installation process } & 219\end{array}$

$\begin{array}{ll}\text { Updating the software } & \mathbf{2 2 0}\end{array}$

Downloading updates using git pull command 220

$\begin{array}{ll}\text { Switching to a new software version } & 221\end{array}$

Installing the new software version $\quad 222$

Running the Makefile.PL program $\quad 222$

Installing Perl modules $\quad 223$

Completing Koha installation $\quad 223$

$\begin{array}{ll}\text { Configuring Apache2 } & 224\end{array}$

Upgrading the database $\quad 224$

Zebra-rebuilding indexes and restarting the server 225

Rebuilding Zebra indexes $\quad 225$

Restarting zebrasiv $\quad 225$

Summary $\quad 226$

Chapter 12: Customizing Koha Software $\quad 227$

$\begin{array}{ll}\text { An orientation to customizing Koha software } & 227\end{array}$

$\begin{array}{ll}\text { Skills needed } & 228\end{array}$

Understanding Koha's application folder $\quad 228$

Top level folders $\quad 228$

Template files $\quad 229$

Relationships between different types of files $\quad 229$

Understanding Koha's database 230

Browsing Koha's database 230

An overview of important Koha tables $\quad 231$

$\begin{array}{ll}\text { Cataloguing } & 231\end{array}$

Circulation $\quad 231$

$\begin{array}{ll}\text { Patrons } & 231 \\ \text { Admistation } & 231\end{array}$

Administration $\quad 232$

Serials $\quad 232$

Acquisitions 232

Koha's database structure $\quad 232$ 
Using Git to manage software changes

Understanding the software customization process

Customizing Koha software-an example

Creating a development branch

235

Making CSS changes

235

Creating a new JavaScript file

235

Loading the Transliteration JavaScript file

236

Creating a system preference

236

Adding the transliteration tool to the display template

239

Editing the Perl scripts to enable the system preference

239

Committing changes

240

Create a patch using Git

Sending the patch to Koha's release manager

243

Summary

244

Chapter 13: Advanced Topics

245

Creating and using matching rules for use during catalog imports

246

Understanding matching rules

Determining search indexes

More information and examples

Using LDAP with Koha

249

Configuring LDAP

250

Microsoft Active Directory

251

Setting permissions

252

Multiple OPAC interfaces

252

Installing new languages

254

Install Locale::PO module

254

Creating language templates for the OPAC

254

Creating language templates for the staff client

255

System preferences

255

Testing the new language

256

Setting up a public $\mathbf{Z 3 9 . 5 0}$ server

257

Configuring the listen directive

Configuring the server directive

258

Configuring the serverinfo directive

Restarting the Zebra server 


\section{Preface}

Much of what we have written in this book is based on our experiences teaching Koha installation and maintenance of technology and library staff.

We hope this book will help you to quickly install and set up a working Koha installation, complete with catalog data migrated from your current library system. The first nine chapters of this book are devoted to these topics. In the rest of the book we cover topics such as troubleshooting, installing software updates, and customizing Koha, which will be of interest to you when you start to use Koha in earnest.

You will need some Linux expertise. Most Koha users use Debian. However you should feel free to try the installation on your preferred distribution. In the examples in this book, we have demonstrated Debian and openSuSE commands; we think these two are representative of most commonly used Linux distributions.

During the installation process, we would encourage you to seek help from the Koha community via the Koha mailing lists.

\section{What this book covers}

Chapter 1, Installing the Software Stack

In the first chapter our goal will be to install Koha's software stack - the Koha application itself, MySQL database server, Apache2 web server, and the various system and Perl packages Koha uses.

Chapter 2, Configuring the Apache2 Web Server

Next, we will configure Koha's web server-Apache2. Apache2 serves Koha pages to users when they access the OPAC or the staff client. 
Chapter 3, Installing Koha's Zebra Search Engine

In the third chapter we will focus on Zebra-Koha's powerful catalog search engine. We will learn how to install and test Zebra.

\section{Chapter 4, Koha's Web Installer, Crontab, and Other Server Configurations}

In the fourth chapter, we will learn about executing Koha's web installer, setting up Koha's Crontab, and configuring Koha services to start automatically when the machine reboots. At the end of this chapter, we will be able to launch Koha.

\section{Chapter 5, Configuring the Cataloging Module}

This chapter is the first of three application configuration chapters. In this chapter, we will learn how to configure Koha's Cataloging module, which is used to maintain information about items in the library.

\section{Chapter 6, Configuring the Circulation Module}

In this chapter, we will learn how to configure Koha's circulation module. This module is used to loan library items to the patrons. Our goal here will be to map the library's circulation policies to rules and preferences in Koha.

\section{Chapter 7, Configuring Other System Preferences}

In this chapter, we will learn how to configure system preferences related to the rest of Koha's modules - Patrons, Acquisitions and Serials, and Online Public Access Catalog (OPAC). We will also study preferences related to styling and appearance, messaging, security, and search.

\section{Chapter 8, Test Driving Your Koha Installation}

By now we will be in a position to take our Koha installation for a test drive. We will look to complete a transaction cycle in each of the primary Koha modules-Patrons, Cataloging, Circulation, Acquisitions and Serials. We will also test the reports module and catalog search on the OPAC.

\section{Chapter 9, Migrating Catalog Data}

Migrating catalog data from the legacy system is a prerequisite to using Koha for most libraries. In this chapter we will learn how to convert MARC files from legacy systems into Koha compatible files. We will learn about Koha's MARC record import tools. 
Chapter 10, Troubleshooting

In this chapter, we will learn about ways to troubleshoot Koha problems, we will learn about the community tools and resources and take a closer look at ten specific problems.

\section{Chapter 11, Updating Software}

It is good practice to keep your Koha software updated to benefit from new features and bug fixes, but also to avoid migration problems if your version falls too far behind. In this chapter we learn how to download and install software updates.

\section{Chapter 12, Customizing Koha Software}

Most serious Koha users will want to customize the software to suit their needs, perhaps to modify the styling or appearance or to tweak a certain page to show additional information. If you have the skills you can even take on more serious work such as adding new features. In this chapter, we learn how to customize Koha code.

\section{Chapter 13, Advanced Topics}

In this final chapter, we will learn about setting up some less widely used but nevertheless important features of Koha-custom record matching rules, LDAP authentication, custom OPACs for each library, internationalization, and setting up Koha as a Z39.50 source.

\section{What you need for this book}

You will need:

- A computer or a server

- A Linux DVD; we cover Debian \& openSuSE in this book, but other distributions should be fine too

- High speed Internet connection to download software 


\section{Who this book is for}

This book is aimed at Linux System Administrators who need to install and maintain Koha. If you are a system administrator who wants to set up an open source integrated library system, then this book is for you. It will also be useful for system administrators who require help with specific aspects of implementing Koha.

\section{Conventions}

In this book, you will find a number of styles of text that distinguish between different kinds of information. Here are some examples of these styles, and an explanation of their meaning.

Code words in text are shown as follows: "We use the in command to create the symbolic link."

Any command-line input or output is written as follows:

koha@li190-245:/\$ sudo In -s/home/koha/koha-dev/etc/koha-httpd.conf / etc/apache2/sites-available/koha-httpd.conf

New terms and important words are shown in bold. Words that you see on the screen, in menus or dialog boxes for example, appear in the text like this: "To edit these preferences, navigate to Administration | Global system preferences.".

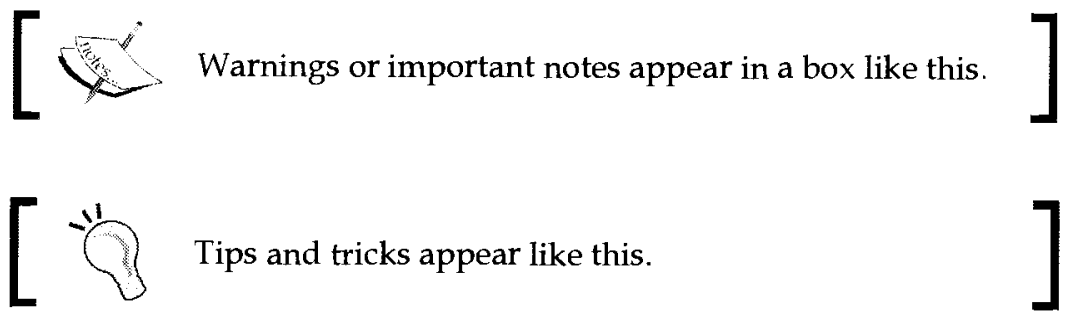

\section{Reader feedback}

Feedback from our readers is always welcome. Let us know what you think about this book - what you liked or may have disliked. Reader feedback is important for us to develop titles that you really get the most out of.

To send us general feedback, simply send an e-mail to feedback@packtpub.com, and mention the book title via the subject of your message.

If there is a book that you need and would like to see us publish, please send us a note in the SUGGEST A TITLE form on www.packtpub . com or e-mail suggest@packtpub.com. 
If there is a topic that you have expertise in and you are interested in either writing or contributing to a book, see our author guide on www. packtpub. com/authors.

\section{Customer support}

Now that you are the proud owner of a Packt book, we have a number of things to help you to get the most from your purchase.

\section{Errata}

Although we have taken every care to ensure the accuracy of our content, mistakes do happen. If you find a mistake in one of our books - maybe a mistake in the text or the code-we would be grateful if you would report this to us. By doing so, you can save other readers from frustration and help us improve subsequent versions of this book. If you find any errata, please report them by visiting http://www. packtpub. $\mathrm{com} /$ support, selecting your book, clicking on the errata submission form link, and entering the details of your errata. Once your errata are verified, your submission will be accepted and the errata will be uploaded on our website, or added to any list of existing errata, under the Errata section of that title. Any existing errata can be viewed by selecting your title from http://www. packtpub. com/support.

\section{Piracy}

Piracy of copyright material on the Internet is an ongoing problem across all media. At Packt, we take the protection of our copyright and licenses very seriously. If you come across any illegal copies of our works, in any form, on the Internet, please provide us with the location address or website name immediately so that we can pursue a remedy.

Please contact us at copyright@packtpub.com with a link to the suspected pirated material.

We appreciate your help in protecting our authors, and our ability to bring you valuable content.

\section{Questions}

You can contact us at questions@packt pub.com if you are having a problem with any aspect of the book, and we will do our best to address it. 



\section{Installing the Software Stack}

In this chapter, our goal will be to install Koha's software stack - the Koha application itself and the various system and Perl packages it uses. Installing the stack in itself is not enough to be able to use Koha, but is an important first step.

This task can be quite challenging, especially for novice Linux users. You will need to get familiar with using the Linux terminal and multiple installation tools. Expect problems with Perl modules, as troubleshooting these can be especially difficult.

We cover the chapter in three stages - first an orientation, next preparatory steps, and finally a demonstration of the installation. Throughout this book we will use two Linux distributions - Debian and openSuSE; the two combined are representative of most other distributions.

\section{An orientation to Koha's installation}

In this section we'll learn about:

- What components we will need to install

- What installation tools to use and when

- The implications of choosing one Linux distribution over another

- Where to get help when you run into installation problems 


\section{Koha's architecture}

First, let us take a quick look at Koha's architecture. Koha runs on the Linux, Apache2, MySQL, Perl (LAMP) platform:

- Linux: The operating system

- Apache2: The web server

- MySQL: The database server

- Perl: Koha is written in the Perl programming language

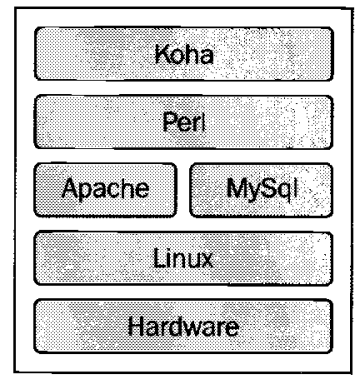

\section{What do we need to install?}

We will install various packages related to:

- The Koha architecture above-Linux, Apache, MySQL, and Perl

- The Koha application itself

- Build and compiler programs that help with the installation

- Various Perl and non Perl packages that Koha uses, along with their own prerequisites

\section{Installation tools}

Let us take a look at the various tools we will use to install Koha's software stack. These tools are:

- Package manager: To install Linux packages

- Make utility: To install Perl modules

- CPAN shell: To install Perl modules that are not available as Linux packages

- Git: To download the Koha application 


\section{Package manager}

A package manager makes installation easy by automatically installing prerequisites, tracking versions and updates, and verifying checksums. Your choice of the package manager will usually depend on the Linux distribution you use. Here are some popular package managers:

- APT: On Debian or Ubuntu

- YaST: On openSuSE

- YUM: On CentOS

\section{Make utility}

Perl programs such as Koha or the various Perl modules it uses can be installed using a series of commands:

- perl Makefile.PL: This command checks for prerequisites and creates a configuration file needed by make

- make: This compiles the software and creates executables

- make test: It runs test cases to ensure proper installation, flags errors, and warnings in case of problems

- make Install: This installs the executable files into proper directories in the server

\section{CPAN shell}

CPAN (Comprehensive Perl Archive Network) - is an archive of Perl modules.

The CPAN shell is a tool that automates the download and installation of Perl modules from the archive including the execution of the perl Makefile.PL, make, make test, and make install commands given above.

Learn more about CPAN here: http ://www. cpan.org/.

\section{Git}

Git is Koha's version control system. Git simplifies and automates the download of software from Koha's online repository. We use Git not only during installation, but also while installing software updates. If you wish to make software changes of your own, Git will help merge those changes with new versions of Koha.

Learn more about Git here: http://git-scm.com/. 


\section{Choosing between Linux Perl packages and CPAN modules}

CPAN is the largest archive of Perl modules. Perl modules are always available on CPAN. Many, but not all of Koha's Perl prerequisites are available as packages in a distribution's sources.

The recommended approach in such a scenario is to use Linux packages where available. If you don't find packages for a certain module, then use CPAN to install it.

The Linux package manager can manage all prerequisites of a module. CPAN only knows about Perl prerequisites, and cannot install any non-Perl prerequisites. For this reason, you will likely have smoother installations with the package manager in comparison to CPAN.

\section{Choosing a Linux distribution}

It appears that Debian is the most popular when it comes to Koha. Some of the installation tasks are simpler in this distribution. Also you might get better community support from a large pool of Debian Koha users.

However, if you are skilled on another distribution, it might make sense to use that. Installation on Ubuntu is very similar to that on Debian. There are many Koha users on Fedora, CentOS, or openSuSE. Installation documents, live CDs, and other sorts of help are becoming available for these distributions as well.

In any case, once you are past the installation stage, it does not really matter distribution you are on.

\section{Getting help-Koha's community resources}

If you face trouble with the installation, Koha's community resources can be of excellent help:

- Mailing lists: Koha's mailing lists are very active and you are likely to get timely help. Join the mailing lists via this page: http://koha-community . org/support/koha-mailing-lists/.

- Mailing lists archives: Many of the discussions are indexed by search engines. If you run into trouble, it is likely someone else had a similar problem before you, so just search for solutions using your favourite search engine.

- IRC chat: Many of Koha's developers are available on this live chat forum. Join here: http: //koha-community.org/support/. 
- Wiki: Koha's wiki might have useful material - http://wiki.kohacommunity.org/.

- Installation documents: Up-to-date installation documents are available in Koha's application folder.

\section{Preparing for installation}

In this section we prepare for the installation-setting up a server, preparing a list of packages for installation and configuring installation tools.

\section{Server prerequisites}

Before we start the installation, we will need a server setup as follows:

\begin{tabular}{ll}
\hline Prerequisites & Description \\
\hline Server & $\begin{array}{l}\text { 2 GB RAM, 40 GB hard disk should be good for most } \\
\text { libraries. }\end{array}$ \\
Internet connection & $\begin{array}{l}\text { High speed Internet connection to download software. } \\
\text { Your preferred distribution installed on the server. }\end{array}$ \\
Linux & $\begin{array}{l}\text { Git port } 9418 \\
\text { Firewall ports opened }\end{array}$ \\
& FTP port 21 \\
HTTP port 80 & Access to the server via SSH, or directly. \\
Access & A Linux user with sudo privileges, in this book we use \\
User & user-koha. \\
Locale & Your locale setup on the server. \\
\hline
\end{tabular}

\section{Downloading Koha and switching to a branch}

One of the first things we do is to download Koha and switch to a version (or a branch) that we want to use. This helps us draw up, as explained in sections below, our package installation list.

\section{Cloning Koha}

To download the Koha application, we need Git. Let us install Git:

koha@li190-245: \$ sudo apt-get install git 
Now we are ready to download Koha, let us change to a folder where we want to install Koha. The user koha must own this folder:

koha@1i190-245: \# cd/home/koha

To clone the application from Koha's git server we use the git clone command:

koha@11190-245: \$ git clone git:://git.koha-community.org/koha.git kohaclone

\section{Checking out a branch}

Before installing Koha, we need to select the software version or branch that we want to use. In production environments, you may want to use the stable version. In test environments you might want to use the latest version-master.

Let us say we want to install the stable version. A quick check on http://git . kohacommunity.org tells us that at the time of writing this chapter, the correct name of the stable branch is v3.00.06.

To use Git, we need to be in the kohaclone folder:

koha@ 11190-245:/home/koha \# cd kohaclone

To switch to this branch, we use the git checkout command:

koha@11190-245: /kohaclone\$ git checkout -b koha-stable v3.00.06

\section{Preparing a list of installation packages}

Preparing a list of installation packages can be a challenge depending on which distribution you are on. At the time of writing, package lists are available for Debian and Ubuntu only. We cannot use the same packages on other distributions-some packages may be named differently, and others may not be available at all. Also some packages that Koha requires may be available on your distribution and not on Debian and Ubuntu. 


\section{System packages}

We use the term system packages for non-Perl modules. Here is a list of system packages that you must have in your installation list; you will need to to look up the right names for each of these from your distribution's sources:

\begin{tabular}{ll}
\hline Package & Description \\
\hline Apache2 & The web server. \\
MySQL & The database server. \\
Make & Programs that helps build and install packages. \\
Gcc & Is the compiler package. \\
Yaz & Is the toolkit used in Z39.50 clients and servers. \\
Libyaz & YAZ related libraries. \\
Libyaz-devel & YAZ related development libraries. \\
\hline
\end{tabular}

On Debian, to look up the name of a package we use the apt-cache search command: koha@1i190-245: -\$ sudo apt-cache search 1ibyaz

On openSuSE, we use the search tool available inside the YaST GUI: koha@1i190-245: -\$ yast

\section{Perl modules}

An accurate list of Perl modules can be drawn up by running Koha's Makefile.PL program. The program checks for the installation status of Koha's Perl module prerequisites and displays warning messages for each missing module.

We run Koha's Makefile. PL program as follows:

koha@li190-245:-/kohaclone\$ perl Makefile.PL

See the section on Makefile. PL below to see how to choose various options, or you can choose default value for now. The missing module prerequisites will be displayed at the end:

[Thu Aug 5 05:07:41 2010] Makefile.PL: Warning: prerequisite PDF : : Reuse: : Barcode 0.05 not found.

[Thu Aug 5 05:07:41 2010] Makefile.PL: Warning: prerequisite SMS : : Send 0.05 not found.

[Thu Aug 5 05:07:41 2010] Makefile.PL: Warning: prerequisite Schedule: : At 1.06 not found.

[Thu Aug 5 05:07:41 2010] Makefile.PL: Warning: prerequisite Text: : CSV : : Encoded 0.09 not found.

[Thu Aug 5 05:07:41 2010] Makefile.PL: Warning: prerequisite 
Text: : CSV XS 0.32 not found.

[Thu Aug 5 05:07:41 2010] Makefile.PL: Warning: prerequisite XML: :RSS

1.31 not found.

Writing Makefile for koha

koha@11190-245: / kohaclone\$

You will need to look up these modules in your distribution's repositories to find corresponding packages. The system packages will usually be named with a prefix "perl-" and will have "-" instead of "::". As an example, the Perl module PDF : : Reuse : :Barcode should have a corresponding Perl package called perl-PDFReuse-Barcode.

If you don't find some of the modules in your distribution's sources, then those modules will need to be installed using CPAN.

\section{Debian/Ubuntu package lists}

Package lists are available for Debian and Ubuntu in the kohaclone folder:

koha@lil90-245: /kohaclone\$ vi install_misc/debian.packages

Or

koha@l1190-245: /kohaclone\$ vi install_misc/ubuntu.packages

If you are on another distribution use the debian.packages or ubuntu.packages lists to look for corresponding modules in your distribution's sources.

It is important to note that these lists may not be completely accurate. This is because software changes all the time; for instance a package that was hitherto unavailable in Debian sources may become available when a new Debian version is released. So it might be a good idea to look for additional Perl packages in your Linux sources before installing them using CPAN.

\section{Setting up repositories or sources}

You might need to configure additional repositories or sources for some of the packages in your installation list.

With Debian you will need to add Index data's sources for YAZ related packages.

Edit the sources file:

koha@1i190-245: \$ sudo vi /etc/apt/sources.list

And add these lines to set up Index data's Debian package sources:

\# Index Data 
deb http://ftp.indexdata.dk/debian lenny main

deb-src http://ftp.indexdata.dk/debian lenny main

With openSuSE 11.2, you will need the Perl repository:

http://download.opensuse.org/repositories/devel:/languages:/perl/ openSUSE_11.2/

We use zypper to add a repository from the command line:

koha@li190-245:-\$ sudo zypper ar http://download.opensuse.org/ repositories/devel:/languages:/perl/openSUSE_11.2/ perl-repository

Don't forget to refresh the package source. On Debian:

koha@li190-245:-\$ sudo apt-get update

On openSuSE:

koha@li190-245:-\$ sudo zypper refresh

\section{Configuring the CPAN shell}

We will need to configure the CPAN shell before we can use it to install Perl modules. To launch the shell we use the cpan command:

koha@linux:/home/koha/kohaclone \# sudo cpan

You can choose to configure CPAN automatically:

Would you like me to configure as much as possible automatically? [yes] yes

Or you can run through the steps manually.

Once the configuration completes, you should be in the CPAN shell:

commit: wrote '/usr/lib/per15/5.10.0/CPAN/Config.pm'

Exiting subroutine via last at/usr/lib/per15/5.10.0/CPAN.pm line 1450, <STDIN> line 1 .

cpan shell -- CPAN exploration and modules installation (vl.9205)

Readline support enabled

cpan $[1]>$ 


\section{Installing Koha's software stack}

In this final section we demonstrate the installation steps on Debian and openSUSE.

\section{Installing packages using the package manager}

We will install most packages using the package manager. Having installed Git in an earlier section, readers are already familiar with the commands used to install individual packages; in this section, we also look at ways of speeding up the process.

\section{Installing packages from the Linux prompt}

You can install the packages one-by-one like this:

koha@li190-245: /kohaclone> sudo apt-get install apache2

On openSuSE, the command would look like this:

koha@1i190-245: /kohaclone> sudo yast -i apache2

Or you can install multiple packages in one statement:

koha@lil90-245: /kohaclone> sudo apt-get install apache2 mysql make gcc

Or:

koha@li190-245: /kohaclone> sudo yast -i apache2 mysql make gcc

\section{Installing packages using shell scripts}

To speed up the installation, you can write a shell script file that looks like this:

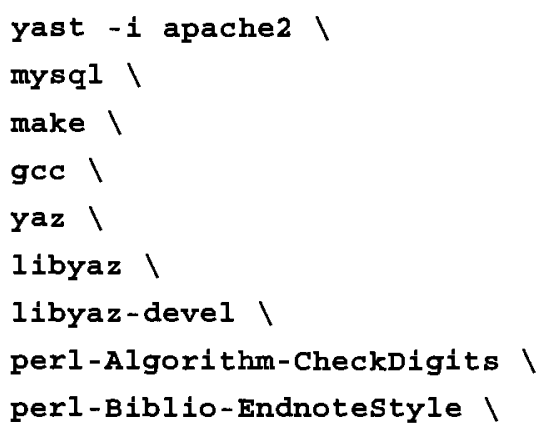

And execute this script using the sh command:

koha@1i190-245: > sudo sh yast-opensuse-perl.sh 


\section{Installing packages using dselect}

Debian and Ubuntu users can use dselect, a convenient way to install package lists.

First we install dselect:

koha@l1190-245: / kohaclone\$ sudo apt-get install dselect

Next, we select what needs to be installed by pointing to the file containing the list of packages:

koha@lil90-245:-/kohaclone\$ sudo dpkg --set-selections < install_misc/ debian.packages

Finally we install the selected packages:

koha@li190-245: / kohaclone\$ sudo dselect

From the dselect screen, we will need to execute the install, configure, and delete options in sequence.

\section{Installing Perl modules using CPAN}

We use the CPAN shell to install only those Perl modules that are not available in your distribution's sources.

We can install such modules from inside the CPAN shell, like this:

koha@1i190-245: /kohaclone\$ sudo cpan

cpan [1] > install HTTP: :OAI

Install multiple modules using a single statement:

cpan[2] > install IPC: :Cnd Net: :LDAP Net: LDAP: :Filter

Net : : z3950 : : zoOM Text : : CSV : : Encoded

Another way of doing it is from the Linux shell:

koha@li190-245: > sudo cpan HTTP::OAI

Here is how we install modules from the Linux shell:

koha@li190-245: > sudo cpan IPC::Cmd Net::LDAP Net::LDAP::Filter

Net: : z3950: : zoOM Text: : CSV: : Encoded 


\section{Troubleshooting CPAN installations}

If CPAN modules don't install successfully, we would see messages like these at the end of install command:

MIRK/Net-z3950-zOOM-1.26.tar.gz : writemakefile No

'/usr/bin/per1 Makefile.PL INSTALLDIRS=site' returned status 512 WRW/Barcode-Code128-2.01.tar.gz : make_test No LARSLUND/PDF-Reuse-Barcode-0 . 05 . tar.gz : make_test No one dependency not OK (Barcode: :Code128) cpan [8] >

From the messages above, we learn that the module Net-z3950-zOOM has failed at the Makefile. PL stage likely due to missing prerequisites.

The module PDF-Reuse-Barcode has failed to install, because one of its prerequisites - Barcode : Code128 has failed at the make test stage.

To troubleshoot such problems we need to look at error messages for clues. Resolve any problems that are found and then install each module manually using the make set of commands.

As an example, let us troubleshoot problems with installing the module Net-z3950-zoOM.

We use the look command to get into a Linux subshell:

cpan [8] > 1ook Net: : z3950:: zooM

Running look for module 'Net::23950::zOOM'

Trying to open a subshell in the build directory...

Working directory is /home/koha/.cpan/build/Net-z3950-zooM-1.26-C9NuSo

We run make clean to start afresh:

sh-3.2\# make clean

make: *** No rule to make target 'clean'. stop.

Next run the Makefile.PL program:

sh-3.2\# per1 Makefile.PI

At this stage we see an error message indicating missing system packages:

ERROR: Unable to call script: yaz-config

If you are using a YAz installation from the Debian package "yaz", you will also need to install "libyaz-dev" in order to build this module. 
This means we need to install YAZ related packages using the package manager, on Debian-yaz and libyaz-dev and on openSUSE-yaz, libyaz, libyaz-devel.

After installing these packages using the package manager, we run the make series of commands to complete the installation:

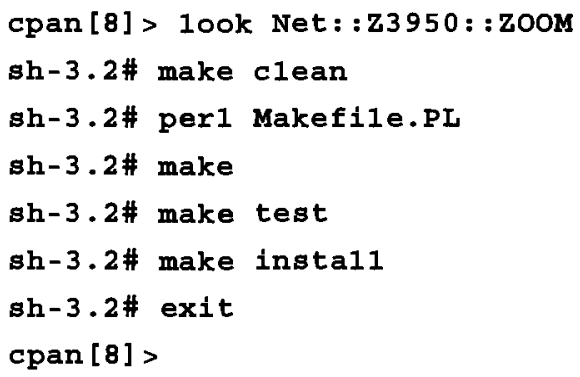

\section{Setting up Koha's MySQL database}

Before we install Koha, we need to setup Koha's MySQL database and a MySQL user with privileges over the database.

Unless you have already done this as part of the installation, we first secure MySQL by configuring a password for the root users:

koha@1i190-245:1inux:/home/koha \# mysqladmin -u root password 'yourdbrootpasswd' ;

Log in to MySQL using root:

koha@11190-245: /kohaclones mysq1 -u root -p

Enter password:

Create Koha's database:

mysq1> create database koha;

Create a MySQL user for Koha's database and grant it privileges. Both actions are accomplished with one command:

mysq1> grant a11 on koha.* to 'kohaadmin'@'localhost' identified by 'katikoan';

mysq1> flush privileges;

mysql> quit 


\section{Configuring Koha's installation: Makefile.PL}

After we have installed required system and Perl packages and set up the database, we are ready to install Koha. The first step is to run Makefile.PL to configure Koha's installation. We will need to supply responses to questions such as mode of installation or database name:

koha@linux:/home/koha/kohaclone \# perl Makefile.PL

Enter responses to configuration questions as follows:

Installation mode should be dev if you wish to use Git to apply patches.

Installation mode (dev, single, standard) [standard] dev

User koha must have write access to the configuration directory to avoid permissions problems:

Configuration directory: [/home/koha/koha-dev]

Choosing mysql, Postgre support in Koha is experimental:

DBMS to use (Pg, mysq1) [mysq1]

Here we specify the name of the database we created in an earlier step:

Please specify the name of the database to be used by Koha [koha]

Specify the MySQL user that has privileges over the database; we created this user in an earlier step:

Please specify the user that owns the database to be used by Koha [kohaadmin]

Specify the password of this user:

Please specify the password of the user that owns the database to be used by Koha [katikoan] katikoan

Say yes to Zebra - Koha's powerful catalog search engine; Although Koha can function without Zebra by using database indexes, Zebra's superior capabilities make it an important part of your installation:

Insta11 the zebra configuration files? (no, yes) [yes]

For other questions, the default value should be fine. Simply press the Return key to proceed to the next step. 
The program display a summary of the configuration at the end, make a note of the details:

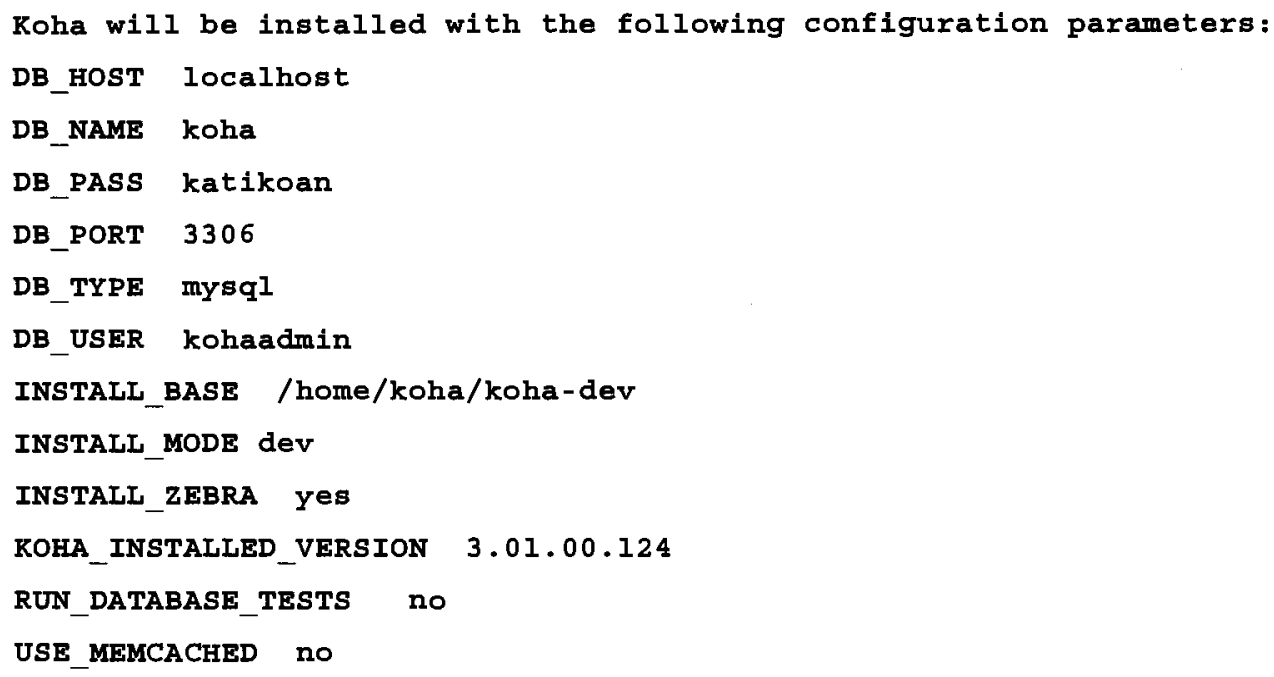

If you have installed all prerequisites you should not see warning messages of missing prerequisites. If you do, you should go back and install any missing modules. Rerun Makefile. PL till all warnings disappear.

\section{Completing Koha's installation}

Run the following commands to complete the installation of Koha:

koha@lil90-245: / kohaclone\$ make

koha@li190-245: /kohaclone\$ make test

koha@lil90-245: /kohaclone\$ sudo make install

\section{Summary}

Here is what we learned in this chapter:

- Using Git to download and use a certain version of Koha

- Preparing an installation list for your distribution

- Installing packages using the package manager

- Installing Perl modules using the CPAN shell 
- Troubleshooting Perl module installations

- Setting up Koha's MySQL database

- Installing Koha using the Make utility

In the next chapter, we will learn how to configure the A pache web server and Koha's web installer. 


\section{2 \\ Configuring the Apache2 Web Server}

In this chapter, our goal will be to configure Apache2. Apache2 is Koha's web server - it serves Koha pages to users when they access the OPAC (Online Public Access Catalog) or the staff client. At the end of the chapter we will be able to launch Koha's OPAC and the staff client interfaces using a web browser. However, the interfaces won't work until we execute Koha's web installer, a topic for Chapter 4.

We cover this chapter in three stages - first an orientation, next the preparatory steps, and finally a demonstration of the configuration. Again, we demonstrate the steps on two Linux distributions-Debian and openSuSE.

\section{Understanding Apache2 configuration}

In this section we try and understand what Apache2 is, how to configure different websites or applications that use it, and how the configuration differs across Linux distributions.

\section{About Apache2}

Apache is the world's most popular web server. It is used to serve static and dynamic pages to web browsers. Apache 2 is a full featured web server. Koha uses it among other things for:

- Setting up two web interfaces, one for the OPAC and the other for the staff client

- Setting up of a host name for Koha, something like http://koha. mylibrary.org/ 
- Securing access to Koha's application folders

- Logging error messages to a file

- Rewriting page URLs

To learn more about Apache, refer to documentation here:

http://httpd.apache.org/docs/2.2/.

\section{Apache2 virtual hosts}

Apache's documentation (http://httpd.apache.org/docs/2.2/vhosts/) defines virtual hosts as follows:

The term Virtual Host refers to the practice of running more than one web site (such as www. company1. com and www. company2 .com) on a single machine. Virtual hosts can be "IP-based", meaning that you have a different IP address for every web site, or "name-based", meaning that you have multiple names running on each IP address. The fact that they are running on the same physical server is not apparent to the end user.

We will have two Koha virtual hosts - one for the OPAC and the other for its staff client.

\section{Name-based or IP-based virtual hosts}

Koha has two interfaces, the OPAC and the staff client. You will need to choose how you want to access these interfaces:

- With the same host name, but different port, say: http://koha.mylibrary. org, http: //koha.mylibrary.org: $8080 /$

- With two host names, say: http://koha-opac.mylibrary.org and http: //koha-staff.mylibrary.org

- With an IP address and different ports, say: http://192.168.1.21 and http://192.168.1.21:8080

- With two IP addresses, say: http://192.168.1.21 and http: //192.168.1.22 
Here are some guidelines to help you work this out:

- Using host names is a better option because they are easier to remember. But if you are not in a position to create host names, you will need to use IP addresses.

- Using Apache2's default port 80 for both interfaces is a better choice. Port 80 is allowed for use on most networks.

- If you are not in a position to create two host names, you can consider using an additional port. Port 8080 is a popular alternative to port 80 and is allowed for use on many networks.

- If you are not in a position to use a second port for the staff client due to network or firewall constraints, you will need to use either two host names or two IP addresses.

- To use two IP addresses you will need a machine with two Network Interface Cards (NICs).

\section{Apache2's configuration folder}

The Apache 2 web server can be configured by editing various files in its configuration folder. On many distributions this folder is named apache2 and is available under the /etc folder.

On other distributions it is named httpd.

It might be useful to browse this folder and get a sense of its contents:

koha@1i190-245:/\$ 1s /etc/apache2/

Or use this command:

koha@1i190-245:/\$1s /etc/httpd/

There are differences in how the Apache 2 folder is organized in various distributions. For instance, on Debian Apache2 ports are configured in the ports . conf file. Let us take a brief look at this file:

koha@11190-245:/\$ sudo vi /etc/apache2/ports.conf

On openSuSE however, this file is called listen. conf.

koha@1i190-245:/\$ sudo vi /etc/apache2/listen.conf

On Debian, virtual host files - essentially configuration files for each website or application that runs on the server-are set up in the folder sites-available:

koha@li190-245:/\$ ls /etc/apache2/sites-available/ 
While on openSuSE such files are created in the folder vhosts.d:

koha@11190-245:/\$1s/etc/apache2/vhosts.d/

\section{Koha's default Apache2 file}

Koha's installation process from the previous chapter creates a default Apache2 configuration file named koha-httpd.conf.

You will find this file under the etc folder inside Koha's configuration folder.

Take a look at this file:

koha@1i190-245:/\$ vi /home/koha/koha-dev/etc/koha-httpd.conf

\section{Koha's virtual hosts}

The file has two Apache2 virtual host blocks - one for Koha's OPAC and the other for its staff client.

This is what the OPAC virtual host looks like:

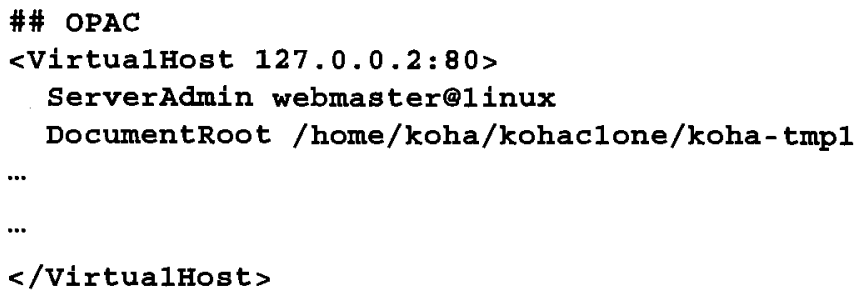

And the staff client virtual host is right below the OPAC block:

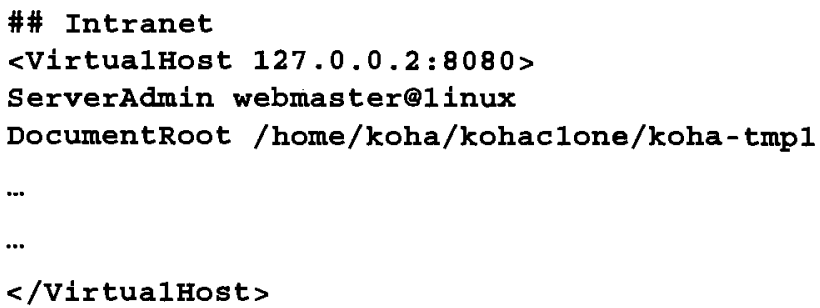

$</$ virtua1Host $>$ 


\section{Virtual host configuration}

Each virtual host block has a set of directives that controls how Apache2 will work with respect to Koha.

You will find that the default koha-httpd. conf file is already configured for the most part, but we may want to modify some of the settings to suit our environment.

Some of the directives we may want to configure are:

\begin{tabular}{|c|c|}
\hline Directive & Description \\
\hline ServerAdmin & $\begin{array}{l}\text { The e-mail address that is displayed when the website does not } \\
\text { function properly. }\end{array}$ \\
\hline ServerName & This is Koha's host name - something like koha. myl ibrary . org. \\
\hline ServerAlias & $\begin{array}{l}\text { Any other domain that users may use, for example, } \\
\text { libcat. mylibrary.org. }\end{array}$ \\
\hline ErrorLog & The file to which Apache2 will write Koha related errors. \\
\hline Directory & $\begin{array}{l}\text { This directive controls what permissions Apache } 2 \text { has on some } \\
\text { of Koha's folders. }\end{array}$ \\
\hline
\end{tabular}

\section{Preparing for Apache2 configuration}

Now that we learned a bit about how to configure Apache2, here are some preparatory steps leading up to the configuration task. First we define a configuration plan; we also look at a list of configuration prerequisites.

\section{Configuration plan}

Here we define host names or IP addresses, ports, and other Apache2 directives for the OPAC and staff client virtual hosts. Here are some sample plans to help you develop your own. 


\section{Two host names}

This is the best way to configure the two interfaces - there are two different host names, both easy to remember and we don't use any non-standard ports.

\begin{tabular}{|c|c|c|}
\hline Item & Value & Comments \\
\hline OPAC IP Address & Any & $\begin{array}{l}\text { We use host based virtual } \\
\text { hosts; we don't need to use } \\
\text { IP based virtual hosts. }\end{array}$ \\
\hline $\begin{array}{l}\text { Staff Client IP } \\
\text { Address }\end{array}$ & Any & $\begin{array}{l}\text { Same as explained in OPAC } \\
\text { IP Address. }\end{array}$ \\
\hline OPAC Host Name & libcat.mylibrary.org & \\
\hline $\begin{array}{l}\text { Staff Client Host } \\
\text { Name }\end{array}$ & libstaff.mylibrary.org & \\
\hline OPAC Port & 80 & $\begin{array}{l}\text { We have the ability to create } \\
\text { host names; we don't need to } \\
\text { use non-standard ports. }\end{array}$ \\
\hline Staff Client Port & 80 & $\begin{array}{l}\text { Same as explained in OPAC } \\
\text { Port. }\end{array}$ \\
\hline OPAC Error Log & $\begin{array}{l}\text { /var/log/apache2/log/ } \\
\text { koha-opac-error_log }\end{array}$ & $\begin{array}{l}\text { We prefer to have all } \\
\text { Apache } 2 \text { logs under /var/ } \\
\text { log/apache2. }\end{array}$ \\
\hline $\begin{array}{l}\text { Staff Client Error } \\
\text { Log }\end{array}$ & $\begin{array}{l}\text { /var/log/apache2/log/ } \\
\text { koha-staff-error_log }\end{array}$ & $\begin{array}{l}\text { Same as explained in OPAC } \\
\text { Error Log. }\end{array}$ \\
\hline $\begin{array}{l}\text { Administrator Email } \\
\text { Address }\end{array}$ & $\begin{array}{l}\text { webmaster@mylibrary. } \\
\text { org }\end{array}$ & \\
\hline
\end{tabular}

\section{Hostname with two ports}

Here we use a single host name but two different ports. As the staff client is usually used within the library, it is best to have that on a non-standard port, while the OPAC remains on port 80.

\begin{tabular}{|c|c|c|}
\hline Item & Value & Comments \\
\hline OPAC IP Address & Any & $\begin{array}{l}\text { We use host based virtual } \\
\text { hosts, we don't need to use } \\
\text { IP addresses to identify } \\
\text { different interfaces. }\end{array}$ \\
\hline $\begin{array}{l}\text { Staff Client IP } \\
\text { Address }\end{array}$ & Any & $\begin{array}{l}\text { Same as explained in } \\
\text { OPAC IP Address. }\end{array}$ \\
\hline OPAC Host Name & library.mylibrary.org & \\
\hline Staff Client Host Name & library.mylibrary.org & \\
\hline
\end{tabular}




\begin{tabular}{lll}
\hline Item & Value & Comments \\
\hline OPAC Port & 80 & $\begin{array}{l}\text { We expect to use the staff } \\
\text { client within our network, } \\
\text { and using a non-standard } \\
\text { port is not a problem for } \\
\text { us. }\end{array}$ \\
\hline
\end{tabular}

\section{IP address with two ports}

If you are not in a position to setup hostnames, you would need to use IP addresses. Here we use a single IP address with two different ports.

\begin{tabular}{lll}
\hline Item & Value & Comments \\
\hline OPAC IP Address & 192.168 .1 .21 & $\begin{array}{l}\text { This is just a test environment; at this } \\
\text { time we can't get a host name and a } \\
\text { DNS entry. } \\
\text { Same as explained in OPAC IP Address. }\end{array}$ \\
$\begin{array}{l}\text { Staff Client IP } \\
\begin{array}{l}\text { Address } \\
\text { OPAC Host Name }\end{array}\end{array}$ & N/A & \\
$\begin{array}{l}\text { Staff Client Host } \\
\text { Name }\end{array}$ & N/A & \\
$\begin{array}{l}\text { OPAC Port } \\
\text { Staff Client Port }\end{array}$ & 8080 & $\begin{array}{l}\text { We expect to use the staff client } \\
\text { within our network, and using a } \\
\text { non-standard port is not a problem } \\
\text { for us. }\end{array}$ \\
\hline
\end{tabular}




\section{Two IP addresses}

This is IP based virtual hosts. We use two IP addresses, one for the OPAC and the other for the staff client. Your Koha server needs to have at least two Network Interfaces cards.

\begin{tabular}{|c|c|c|}
\hline Item & Value & Comments \\
\hline OPAC IP Address & 192.168 .1 .21 & $\begin{array}{l}\text { This is just a test environment; here we } \\
\text { can't get a host name and a DNS entry. }\end{array}$ \\
\hline $\begin{array}{l}\text { Staff Client IP } \\
\text { Address }\end{array}$ & 192.168 .1 .22 & $\begin{array}{l}\text { Our server has or we can setup two IP } \\
\text { addresses. }\end{array}$ \\
\hline OPAC Host Name & $\mathrm{N} / \mathrm{A}$ & \\
\hline $\begin{array}{l}\text { Staff client Host } \\
\text { Name }\end{array}$ & $\mathrm{N} / \mathrm{A}$ & \\
\hline OPAC Port & 80 & \\
\hline Staff client Port & 80 & $\begin{array}{l}\text { In our organization, it is difficult getting } \\
\text { firewalls opened for non-standard port } \\
8080 \text {. }\end{array}$ \\
\hline
\end{tabular}

\section{Standalone machine}

If you intend to use Koha on a standalone machine, then the plan is fairly straight forward. We use the machine's localhost address or the corresponding local loop IP address -127.0.0.1. As the machine is not networked, it is easy to use port 8080 or any other port for that matter.

\begin{tabular}{lll}
\hline Item & Value & Comments \\
\hline OPAC IP Address & 127.0 .0 .1 & $\begin{array}{l}\text { We intend to use Koha on a standalone } \\
\text { Computer, so we use the local loop IP address. } \\
\text { Staff Client IP }\end{array}$ \\
$\begin{array}{l}\text { Address } \\
\text { OPAC Host Name }\end{array}$ & $\begin{array}{l}\text { localhost } \\
\text { localhost }\end{array}$ \\
$\begin{array}{l}\text { Name Client Host } \\
\text { OPAC Port }\end{array}$ & 80 & \\
Staff Client Port & 8080 & $\begin{array}{l}\text { Standalone computer; there are no problems } \\
\text { using a non-standard port. }\end{array}$ \\
\hline
\end{tabular}




\section{Configuration prerequisites}

Here is a list of prerequisites that you might want to take care of; some of these may not apply to your situation depending on the sort of configuration plan you have.

\begin{tabular}{ll}
\hline Item & Description \\
\hline Open Firewall ports & $\begin{array}{l}\text { If you are using ports other port 80, you might } \\
\text { need to open those ports on network firewalls or } \\
\text { routers. } \\
\text { If you intend to use host names, you will have to } \\
\text { purchase or set them up. }\end{array}$ \\
Domain Name Service (DNS) & $\begin{array}{l}\text { If you use host names, you will have to set them up } \\
\text { in a DNS to route requests to the Koha server. } \\
\text { If you are using IP based virtual hosts, you will } \\
\text { nedresses }\end{array}$ \\
& $\begin{array}{l}\text { need to ensure network cards are installed on your } \\
\text { server. }\end{array}$ \\
\hline
\end{tabular}

\section{Configuring Apache2 web server}

Now that we have our configuration plan in place, let us get started with Apache2 configuration. We will edit the OPAC and staff client virtual hosts in Koha's Apache2 configuration file. We will also configure Apache2 to listen on the staff client port8080 and we will enable its Rewrite module. To make all this work we will point Apache2 to Koha's Apache2 configuration file using a symbolic link.

\section{Creating a symbolic link to koha-httpd.conf}

1. First we create a symbolic link in Apache2's virtual host's folder pointing to Koha's Apache2 file. A symbolic link is just a pointer to the actual Koha file.

2. We can copy the koha-httpd. conf file into the virtual host's folder, but it is better to create a symbolic link as this helps when new versions of the file are created during software upgrades.

3. We use the in command to create the symbolic link. The syntax is: In -s <path to koha-httpd.conf> <path to symbolink link name>

4. On Debian the command would be:

koha@li190-245:/\$ sudo ln -s/home/koha/koha-dev/etc/koha-httpd. conf /etc/apache2/sites-available/koha-httpd.conf

5. And on openSuSE, the command would look like this:

koha@li190-245:/\$ sudo In -s/home/koha/koha-dev/etc/koha-httpd. conf /etc/apache2/vhosts.d/koha-httpd.conf 


\section{Enabling Apache2's Rewrite module}

Koha uses Apache2's Rewrite module to manipulate URLs. To allow this we need to enable the module using the azenmod command:

koha@1i190-245:/\$ sudo a2enmod rewrite

\section{Configuring the listener}

If you intend to use ports other than 80 , you will need to configure the Listen directive. On Debian we add this directive to the ports . conf file:

koha@1il90-245:/\$ sudo vi /etc/apache2/ports.conf

And on openSuSE, we add this to the file listen.conf:

koha@1i190-245:/\$ sudo vi /etc/apache2/1isten.conf

We add the directive in this manner:

Listen 8080

\section{Editing the OPAC virtual host}

Now we modify Koha's virtual hosts file to include elements of our configuration plan. First we set the IP address in the first line of the Virtual Host block. Something like this:

\#\# OPAC

$\langle$ VirtualHost 192.168.1.21:80>

If you want to use any IP address on the server, use "1*":

\#\# OPAC

$\langle$ VirtualHost *:80>

Next we setup Koha's host name in the ServerName directive.

ServerName 1ibcat.mylibrary.org

If are not using a host name, leave this Directive untouched.

Next, we add the Directory directive. Make sure you add these lines just before the $</ v i r t u a l$ host $>$ tag. Note that this step is not required on Debian.

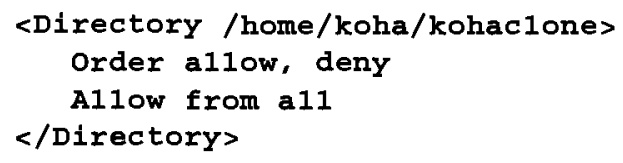


In a similar manner, we set other directives:

ServerAdmin webmaster@mylibrary.org

ErrorLog /var/log/apache2/log/koha-opac-error_log

\section{Editing the staff client virtual host}

Next we edit the staff client virtual host block; we will need to repeat the steps above for this virtual host.

If you need to change the port we edit the first line of the virtual host:

\#\# Intranet

<VirtualHost $127 \cdot 0 \cdot 0.2: 8080\rangle$

If the port needs to be port 80 , we change the line as follows:

\#\# Intranet

$\langle$ VirtualHost $127 \cdot 0 \cdot 0.2: 80\rangle$

\section{Enabling Koha's virtual hosts}

On some distributions we need to enable the new virtual host file. For instance on Debian, we run the azensite command to do this:

koha@li190-245:/etc/apache2/sites-available\$ sudo a2ensite koha-httpd. conf

Enabling site koha-http.conf.

The azensite command creates a symbolic link in the sites-enabled folder pointing to the Apache2 configuration file in the sites-available folder.

This step is not required openSuSE.

\section{Restarting Apache2}

Finally we restart Apache2 to load the new configuration changes:

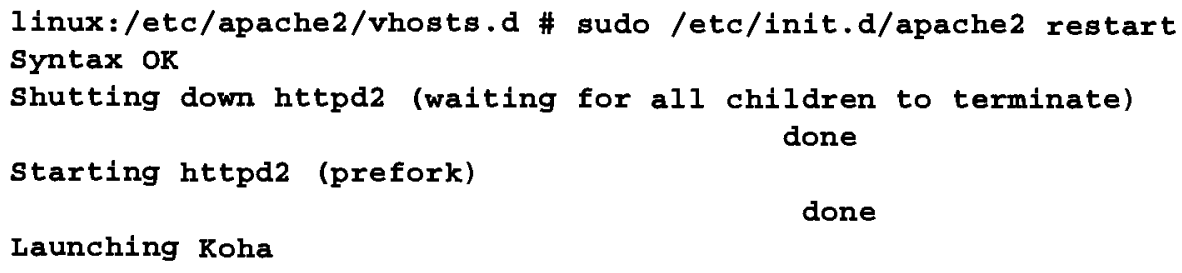


Once we complete the Apache2 configuration, we are ready to test Koha. To navigate to the OPAC, type the URL for the OPAC in your favorite browser.

Depending on your configuration, you may access the site via the host name, something like this:

http://libcat .mylibrary.org

Or using an IP address, like this:

http://192.168.1.21

If you are on a standalone machine, you would use a local loop IP address or the name localhost:

http://localhost or http://127.0.01

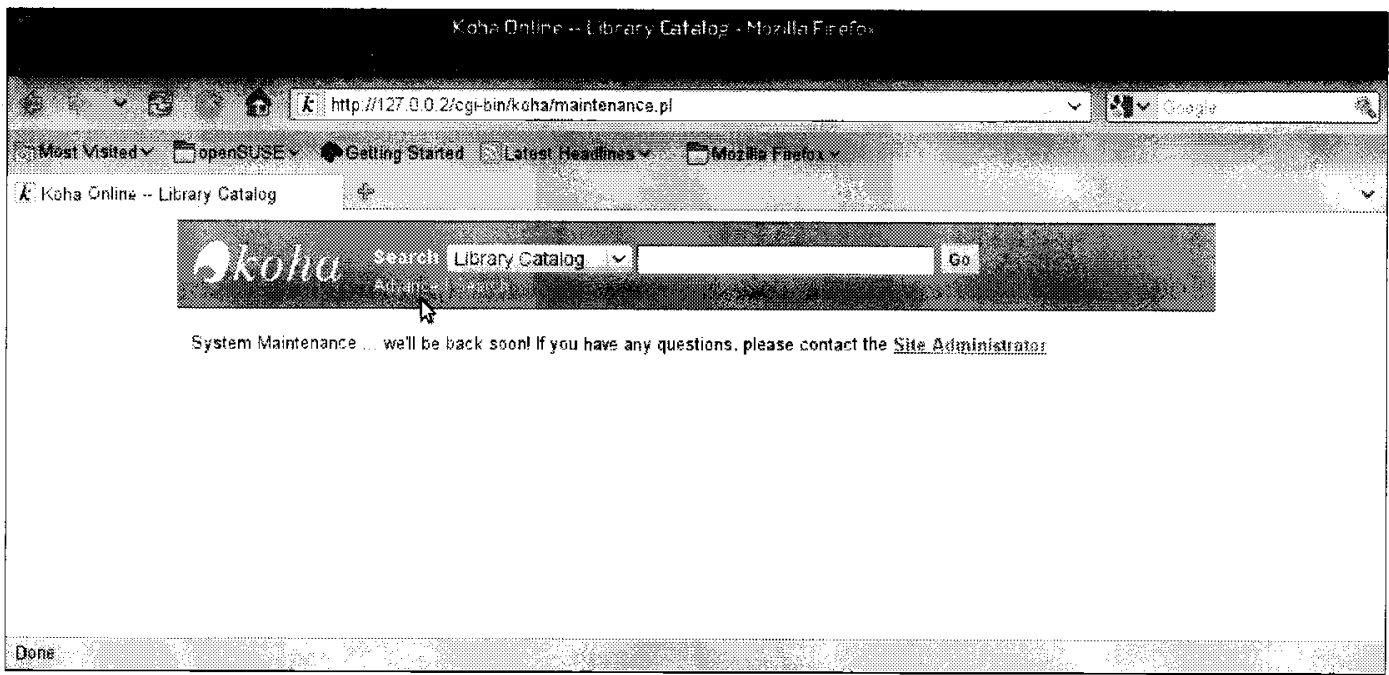

On the OPAC you will see a System Maintenance message; this is because we have not configured Koha's web installer yet.

To navigate to the staff client, type the URL for Koha's staff client:

http://libstaff.mylibrary.org/

Or if you are using a port 8080, something like this: http: // library.mylibrary . org: $8080 /$

Or if you are using an IP address with port 8080:

http://192.168.1.21:8080/ 
Or if have a dedicated IP address:

http://192.168.1.22/

Or if you are on a standalone machine:

http://localhost: 8080 or http://127.0.0.1:8080/

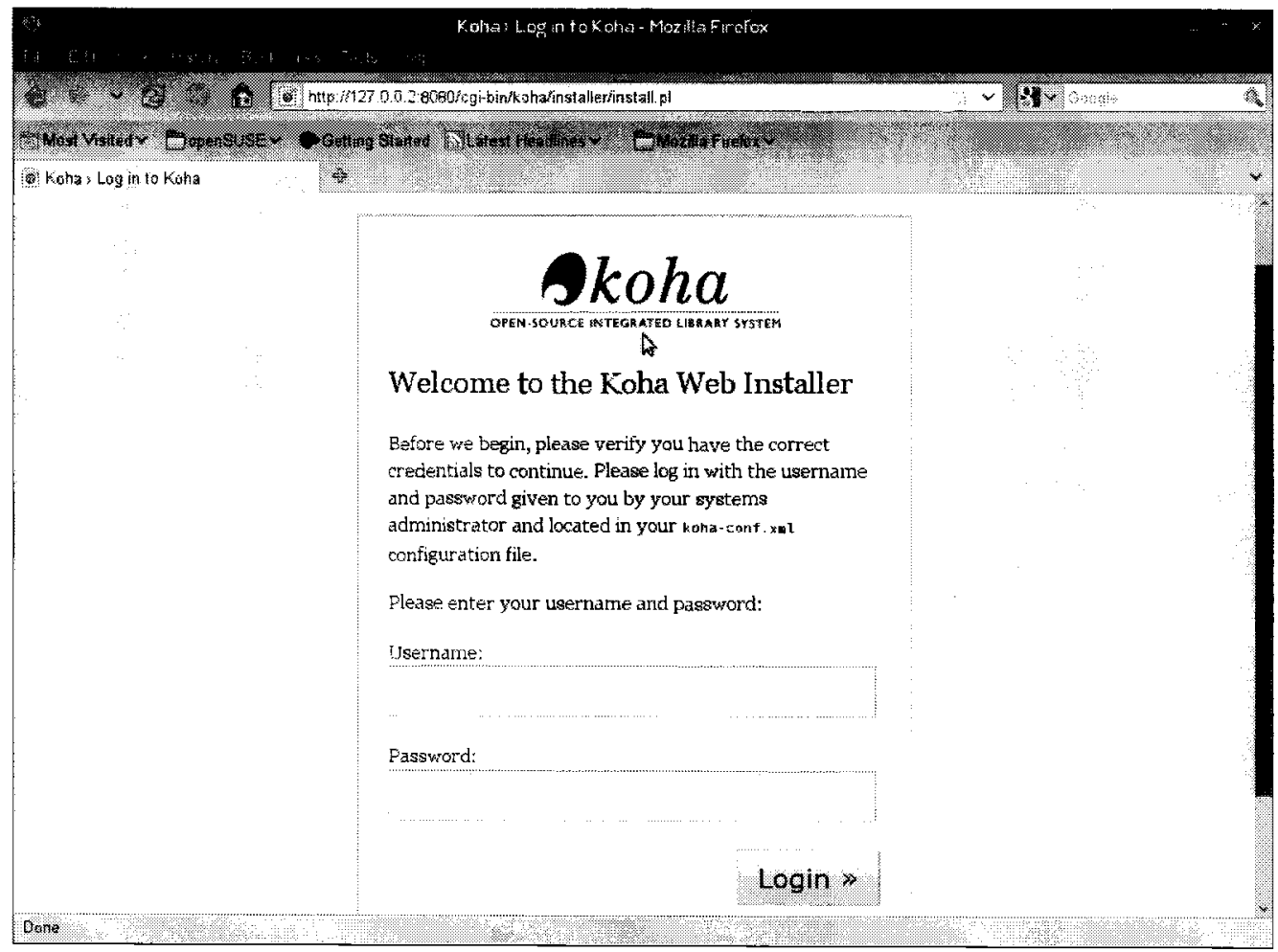

This screen means we have successfully configured Apache2. In the next chapter, we will look at how to execute this web installer.

\section{Troubleshooting configuration problems}

Here is an explanation of some common problems with Apache2 configuration. 


\section{Rewrite module not enabled}

If you have not enabled Apache2's Rewrite module, you will see this error when starting Apache2:

linux:/etc/apache2/vhosts.d \# sudo /etc/init.d/apache2 restart

Syntax error on line 28 of /etc/apache2/vhosts.d/koha-httpd.conf:

Invalid command 'RewriteEngine', perhaps misspelled or defined by a module not included in the server configuration

\section{Incorrect or missing Directory directive}

On distributions such as openSuSE, if you have not added the Directory directive, you will see this error when you try to access Koha's OPAC or the staff client. This means Apache2 does not have permission to access Koha's folders.

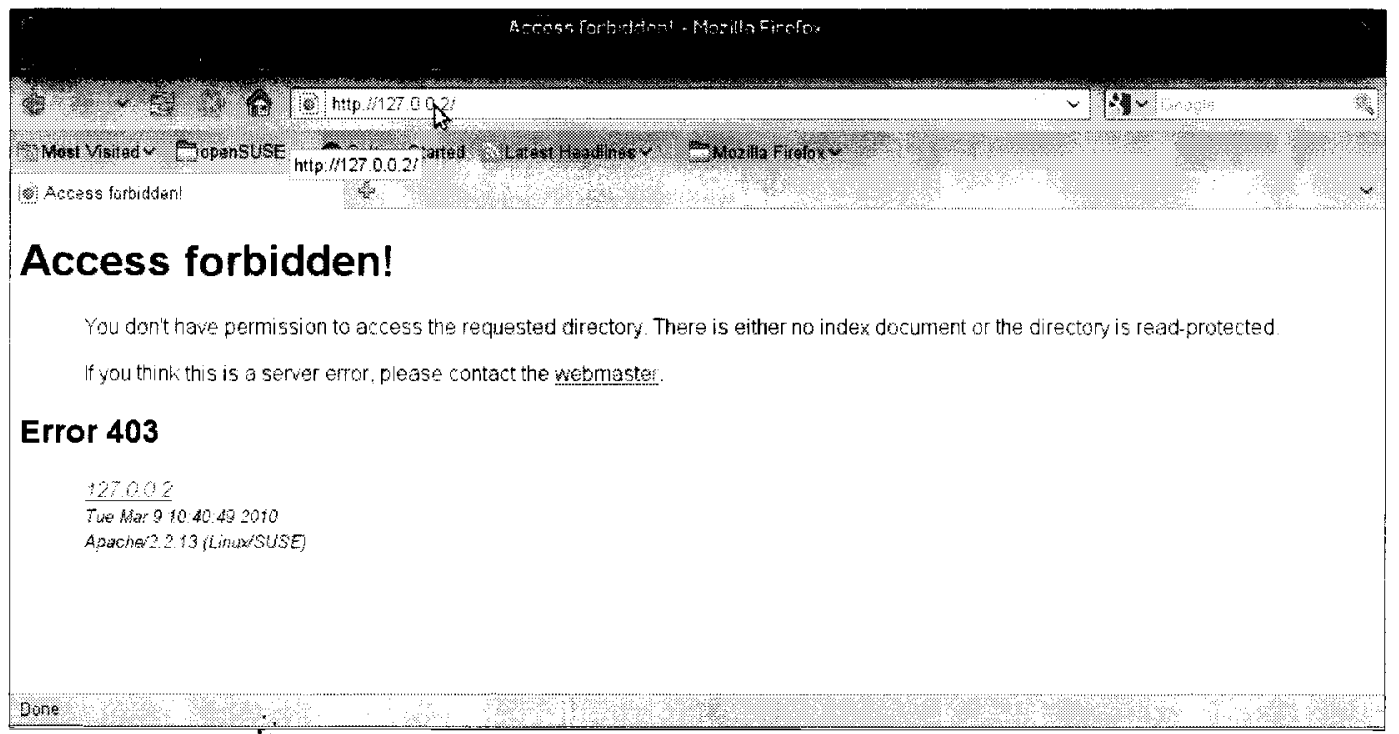

\section{Unable to connect to MySQL}

If the MySQL server is down or you dont have the Koha database set up properly, Koha and Apache2 will not be able to connect to the database and you will see this type of error: 


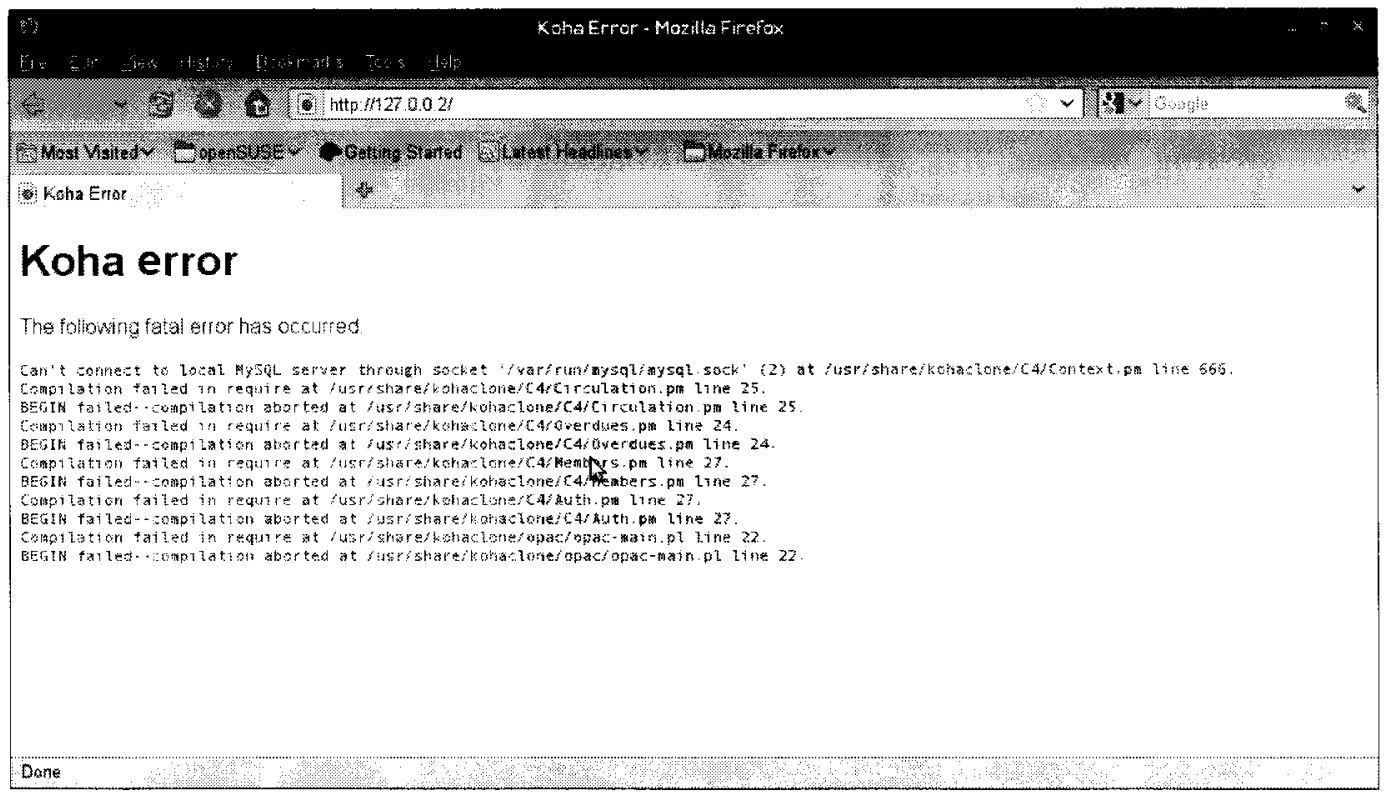

\section{Listener not setup}

If you do not setup the Apache2 listener for the staff client port, you will see this error when you try to connect to Koha's staff client:

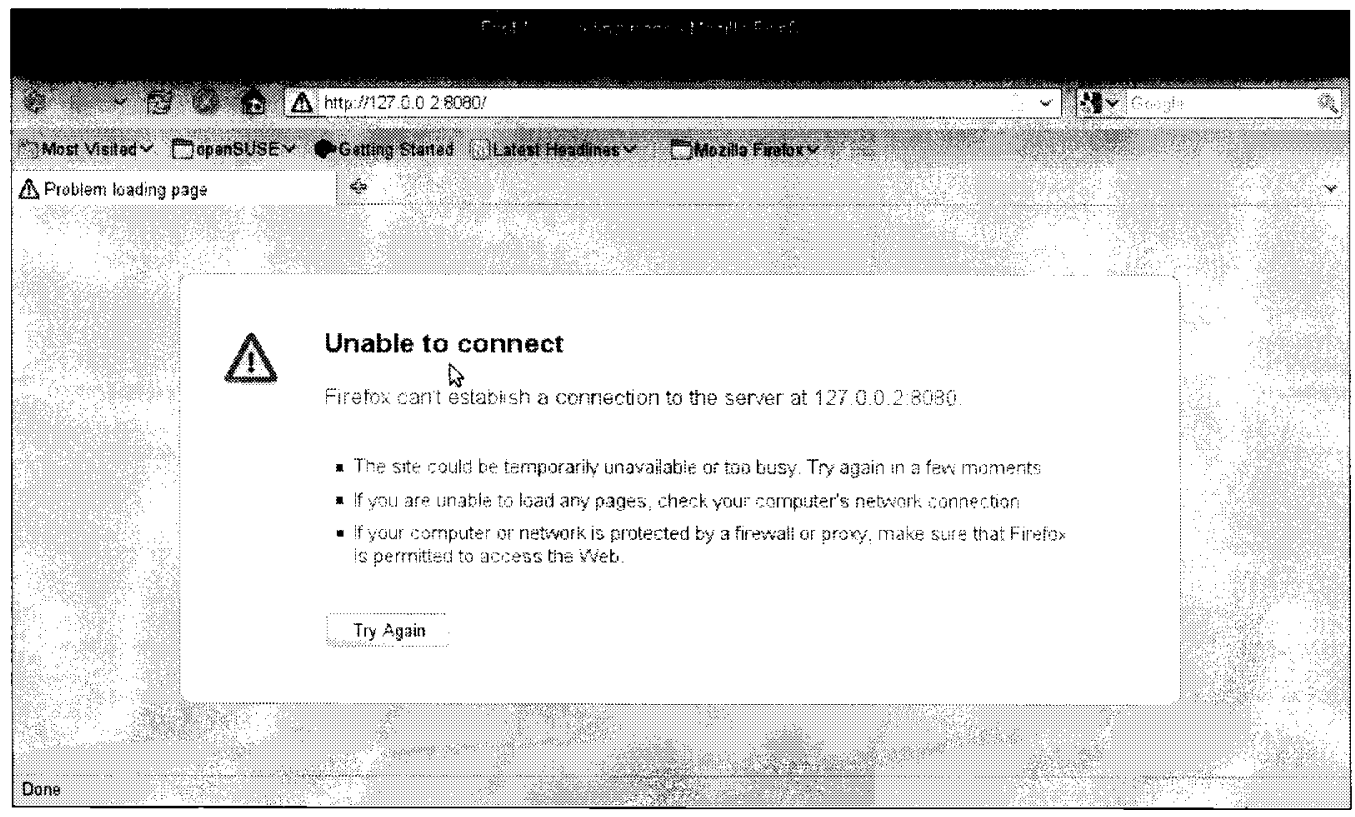




\section{Summary}

Here is what we learned in this chapter on configuring Apache2:

- Setting up a symbolic link to Koha's Apache2 configuration file

- Enabling Apache2's Rewrite module

- Configuring an IP address in Koha's virtual hosts

- Configuring host names in Koha's virtual hosts

- Setting up Apache2 to listen on the staff client port

- Configuring the Directory directive in a virtual host

- Launching Koha's OPAC and staff client

In the next chapter, we will install and test Koha's Zebra search engine. 


\section{3 \\ Installing Koha's Zebra Search Engine}

You will need to use Koha's Zebra search engine if you have more than say 10,000 catalog records. Without Zebra, catalog search results may be too slow.

If you have a small catalog you can use Koha without Zebra, in fact earlier versions of Koha did not have Zebra. Without Zebra both installation and ongoing maintenance will be simpler. However you should consider using Zebra even for small catalog sizes because of Zebra's superior capabilities.

In this chapter we will learn more about Zebra and how to install and test it.

\section{About Zebra}

From the website of Indexdata, the organization behind Zebra:

"Zebra is a high-performance, general-purpose structured text indexing and retrieval engine. It reads structured records in a variety of input formats (eg. email, $X M L, M A R C$ ) and allows access to them through exact boolean search expressions and relevance-ranked free-text queries."

In our experience with Koha, we find Zebra to be an excellent search engine:

- It is fast and efficient

- It can index large databases

- It can index bibliographic, authority, and holdings records

- It is Unicode compliant and can work with any language

- It is highly configurable; you can index any MARC field, set up numeric, word, or phrase indexes, or configure ranking and sorting 
- It can be queried using complex search expressions such as AND and OR operators

- It allows for additional features on Koha such as search limits, and refining searches that are otherwise not available

- It has sophisticated features such as approximate matching, and spelling correction

- It can be queried by any Z39.50 or SRU/W client

Learn more about Zebra here:

http://www. indexdata.com/zebra/.

Documentation on Zebra is available here:

http://www. indexdata.com/zebra/doc/.

\section{Koha's Zebra related components}

Before we install and test Zebra with Koha, let us understand a couple of key Zebra related components that we will use frequently as Koha administrators.

\section{Zebrasrv-the Zebra query and retrieval server}

This is a Zebra component that is responsible for serving results to search requests coming from Koha's OPAC or staff client. Here are some key points to note about zebrasrv:

- For search to function, the zebrasrv process must be running on the Koha server

- The process can be started by using the zebrasrv command from the Linux shell

- zebrasrv is usually run in the background as a service or a daemon

- To make zebrasrv work with our Koha installation, we will need to invoke the process by pointing it to use Koha's configuration file 


\section{Rebuild_zebra.pl-the Zebra index maintenance program}

This is a Perl program that is used to create and maintain Zebra's search indexes. Here are some key points about this program:

- This is a Koha program that uses Zebra's zebraidx index maintenance utility

- The program can be used to build indexes in full or in an incremental fashion

- The program can be run form the Linux shell

- For ongoing index maintenance the program is usually scheduled to run in the Crontab

\section{Installing Zebra}

To get Koha working with Zebra we will need to install Zebra packages and then install Koha. You can skip this section if you have already installed Zebra, and have installed Koha by selecting the Zebra option during the Makefile. PL step.

\section{Installing Zebra packages}

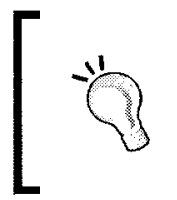

You might have already installed Zebra packages. These packages are part of the Debian and Ubuntu packages lists that we covered in Chapter 1 . If you have indeed installed Zebra, you can skip this section.

On Debian we would install Zebra packages as follows:

koha@1i190-245: /kohaclone> sudo apt-get instal1 idzebra-2.0-common idzebra-2.0-doc idzebra-2.0 idezebra-2.0-utils

On openSuSE, the package names are different, so the installation command would look like this:

koha@1il90-245: /kohaclone> sudo yast -i idzebra idzebra-doc idzebradeve1 idzebra-debuginfo 


\section{Installing Koha with Zebra}

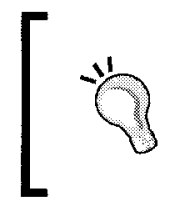

You might have already installed Koha with Zebra. If you had installed Zebra packages before installing Koha and had selected yes to the question Install the Zebra configuration files?, then you can skip this section.

Once Zebra packages are installed we need to install Koha. This installation process creates Zebra related configuration files and installs them in Koha's configuration folder, in our case /etc/koha-dev/.

To install Koha with Zebra, we run Koha Makefile. PL program:

koha@linux:/home/koha/kohaclone \# perl Makefile.PL

Say yes to this question on installing Zebra configuration files:

Install the zebra configuration files? (no, yes) [yes]

We then run the other make commands complete the installation of Koha with Zebra:

koha@lil90-245: / kohaclone\$ make

koha@1i190-245: / kohaclone\$ make test

koha@li190-245:-/kohaclone\$ sudo make install

If you have had to reinstall Koha, you may need to reconfigure Apache2 (see Chapter 2) as the Koha installation process may have overwritten the Apache2 configuration file you created.

\section{Testing Zebra}

Now that we have installed Zebra, let us try out the zebrasrv command and the rebuild_zebra.pl program.

We will learn how to execute the zebrasrv command from the Linux shell and as a daemon. On production systems zebrasrv is usually run as a daemon that runs silently in the background.

The rebuild_zebra.pl command can also be executed from the Linux shell.

On production systems however the program is scheduled to run in the crontab. 


\section{Testing zebrasrv}

The zebrasrv program is usually installed under/usr/bin and you should be able to invoke it from any folder location.

\section{The zebrasrv command}

To learn more about how zebrasrv is used, we run the command with the -help or -h option:

linux-4yut:/home/koha \# sudo zebrasrv - -help

Usage: zebrasrv [ - a <pdufile> -v <loglevel> - l <logfile> -u <user> -c

<config> - $t$ <minutes> - $k$ <kilobytes> - d <daemon> - p <pidfile> - C

certfile -ziDSTl -m <time-format> -w <directory> <listener-addr>...]

To learn more about each option, use the man command:

linux-4yut:/home/koha \# man zebrasrv

\section{Invoking zebrasrv with Koha's configuration file}

To make zebrasrv use Koha's configuration file we use the - $f$ option:

linux-4yut:/home/koha \# sudo zebrasrv -f /etc/koha-dev/etc/koha-conf.xml

The process starts in the shell foreground and waits for search queries to serve:

$\cdots$

$14: 25: 24-22 / 04$ [log] Loaded filter module

/usr/lib/idzebra-2.0/modules/mod-text . so

$14: 25: 24-22 / 04$ [server] Adding dynamic listener on

unix:/etc/koha-dev/var/run/zebradb/bibliosocket id=l

14:25:24-22/04 [server] Adding dynamic listener on

unix:/etc/koha-dev/var/run/zebradb/authoritysocket id=2

$14: 25: 24-22 / 04$ [server] starting server zebrasrv pid=11088

To stop the server and to exit to the Linux shell, use $C t r l+C$ to:

${ }^{\wedge}$

linux-4yut: /home/koha \# 


\section{zebrasrv daemon}

The Zebra Server is usually run in the background as a daemon. In this section we learn how to setup zebrasrv as a daemon and how to set it up as a service that can be included in the system's start-up profile. Once again, we see how things are easier on Debian or Ubuntu than on openSuSE.

\section{Zebrasrv daemon on Debian or Ubuntu}

Koha ships with a script, koha-zebra-ctl. sh that can run zebrasrv in the background as a daemon. This script uses the daemon command to start, stop, or restart Zebra.

You will need to ensure that the daemon package is installed:

linux-4yut:/home/koha \# sudo apt-get install daemon

The script koha-zebra-ctl.sh can be found under the bin folder under Koha's configuration folder:

linux-4yut:/home/koha \# cd/etc/koha-dev/bin/

linux-4yut:/etc/koha-dev/bin \#vi koha-zebra-ctl.sh

Koha's Zebra daemon script can be set up as a service and configured in the system start-up profile. This way we ensure that zebrasrv starts automatically when the machine reboots. To set up the script as a service we create a symbolic link to it from the /etc/init.d/ folder:

linux-4yut:/home/koha \# sudo ln -s/etc/koha-dev/bin/koha-zebra-ctl.sh / etc/init.d/koha-zebra-daemon

Let us test this zebrasrv service by starting it:

linux-4yut:/home/koha \# sudo /etc/init.d/koha-zebra-daemon start starting zebra server

Let us try a restart:

linux-4yut:/home/koha \# sudo /etc/init.d/koha-zebra-daemon restart Restarting the zebra server

And finally let us try a stop operation:

linux-4yut:/home/koha \# sudo/etc/init.d/koha-zebra-daemon stop stopping zebra Server

To setup this service in the start-up profile, we use the update-rc.d command: linux-4yut:/home/koha \# sudo update-rc.d koha-zebra-daemon defaults 


\section{zebrasrv daemon on openSuSE}

The daemon command is not available on openSuSE. This is because the corresponding package daemon is not included in openSuSE repositories for copyright reasons.

However there are alternatives to the daemon command:

- startproc: For starting a process

- killproc: For stopping a process

We can modify the koha-zebra-ctl. sh file to work on openSuSE by replacing the daemon command with startproc and killproc and suitably modifying the options supplied to the commands.

The modified statements in koha-zebra-ctl. sh script may look like this:

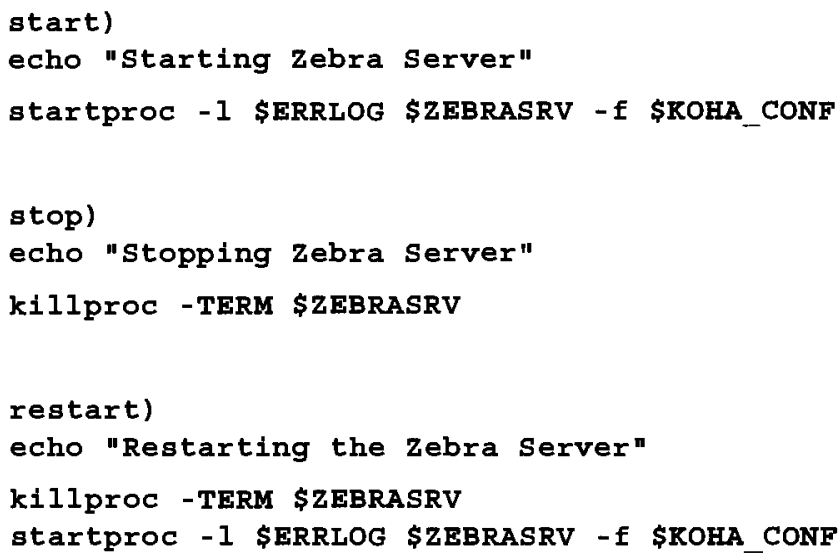

You will need to reinstall Koha once you have modified the script to ensure that the modified koha-zebra-ct 1 . sh file is installed in Koha's configuration folder-/etc/koha-dev/bin/.

Once the script is modified and installed, we can set it up as a service by creating a symbolic link to it from the /etc/init.d folder:

linux-4yut:/home/koha \# sudo ln -s /etc/koha-dev/bin/koha-zebra-ctl.sh / etc/init.d/koha-zebra-daemon 
To ensure that zebrasrv starts when the machine reboots we use the chkconfig command:

linux-4yut:/home/koha \# sudo chkconfig koha-zebra-daemon on

\section{Rebuilding Zebra}

Let us now test the second key Zebra related component - rebuild_zebra.pl. This program is used to maintain Zebra's search indexes.

The program can be found in the folder $\mathrm{misc} / \mathrm{migration}$ tools under the kohaclone folder:

linux-4yut:/usr/share/kohaclone \# cd misc/migration_tools/

linux-4yut:/usr/share/kohaclone/misc/migration_tools/ \# vi rebuildzebra. pl

To learn about the usage of this program, run it with the - -help or - -h option:

linux-4yut:/home/koha \# sudo ./rebuild zebra.pl --help

./rebuild zebra.pl: reindex MARC bibs and/or authorities in zebra.

Use this batch job to reindex all biblio or authority records in your Koha database. This job is useful only if you are using Zebra; if you are using the 'NoZebra' mode, this job should not be used.

\begin{tabular}{|c|c|}
\hline Parameters & Description \\
\hline$-\mathrm{b}$ & Index bibliographic records. \\
\hline$-\mathbf{a}$ & Index authority records. \\
\hline$-z$ & $\begin{array}{l}\text { Select only updated and deleted records marked in the zebraqueue } \\
\text { table. Cannot be used with }-r \text { or }-s \text {. }\end{array}$ \\
\hline$-r$ & Clear Zebra index before adding records to index. \\
\hline$-d$ & $\begin{array}{l}\text { Temporary directory for indexing. If not specified, one is automatically } \\
\text { created. The export directory is automatically deleted unless you supply } \\
\text { the }-k \text { switch. }\end{array}$ \\
\hline$-\mathrm{k}$ & Do not delete export directory. \\
\hline$-s$ & $\begin{array}{l}\text { Skip export. Used if you have already exported the records in a previous } \\
\text { run. }\end{array}$ \\
\hline- noxml & $\begin{array}{l}\text { Index from ISO MARC blob instead of MARC XML. This option is } \\
\text { recommended only for advanced user. }\end{array}$ \\
\hline$-\mathrm{x}$ & $\begin{array}{l}\text { Export and index as XML instead of is } 02709 \text { (biblios only). Use this if you } \\
\text { might have records }>99,999 \text { chars. }\end{array}$ \\
\hline
\end{tabular}




\begin{tabular}{|c|c|}
\hline Parameters & Description \\
\hline -nosanitize & $\begin{array}{l}\text { Export biblio/authority records directly from DB marcxml field without } \\
\text { sanitizing records. It speed up dump process but could fail if } \mathrm{DB} \\
\text { contains badly encoded records. Works only with }-\mathrm{x} \text {. }\end{array}$ \\
\hline$-\mathrm{w}$ & Skip shadow indexing for this batch. \\
\hline$-y$ & $\begin{array}{l}\text { Does NOT clear zebraqueue after indexing; normally, after doing batch } \\
\text { indexing, zebraqueue should be marked done for the affected record } \\
\text { type(s) so that a running zebraqueue_daemon doesn't try to reindex } \\
\text { the same records - specify -y to override this. Cannot be used with - } z \text {. }\end{array}$ \\
\hline$-\mathrm{v}$ & $\begin{array}{l}\text { Increase the amount of logging. Normally only warnings and errors } \\
\text { from the indexing are shown. }\end{array}$ \\
\hline $\begin{array}{l}\text {-munge- } \\
\text { config }\end{array}$ & Deprecated option to try to fix Zebra config files. \\
\hline - -help or $-\mathrm{h}$ & Show this message. \\
\hline
\end{tabular}

Here are some key points about the options available with the rebuild_zebra.pl program:

- The most commonly used options are $-b,-a,-r,-z,-v$, and $-x$.

- We use either $-r$ or $-z$, not both.

- Both - $b$ and - $a$ can be used in the same statement.

- If we expect at least some MARC records to have large sizes we use $-x$, for instance if the number of holdings is very large.

- The -v option can be used to troubleshoot problems with the program.

- The -r option is typically used when the server is setup and catalog data has been migrated.

- The - $r$ option should also be used if Zebra configuration is changed, for instance if a new field is to be indexed.

- The $-\mathrm{z}$ option should be used when the rebuild program is scheduled in the crontab. This option only indexes updates to the catalog.

Let us look at some examples to learn how to run this program. 


\section{Creating or recreating indexes}

To create or recreate the complete index of all bibliographic records in the database, we would run the command as follows:

1inux-4yut:/usr/share/kohaclone/misc/migration_tools \# sudo ./rebuild_ zebra.pl -b -r -v

To index bibliographic records incrementally, we could set up the command as follows:

1inux-4yut:/usr/share/kohaclone/misc/migration_tools \# sudo./rebuild zebra.p1 -b -z -v

To index both bibliographic and authority records incrementally, we would set up the command as follows:

1inux-4yut:/usr/share/kohaclone/misc/migration_tools \# sudo//rebuild zebra.p1 -b $-a-z-v$

If you have at least some records of large sizes, it is recommended that we use the $-x$ option:

linux-4yut:/usr/share/kohaclone/misc/migration_tools \# sudo ./rebuild zebra.p1 -b $-a-z-x-v$

\section{Using Koha without Zebra}

If you decide that you do not want to use Zebra, you will need to ensure that the system preference NoZebra is turned on. We will learn about Koha's system preferences in subsequent chapters. 


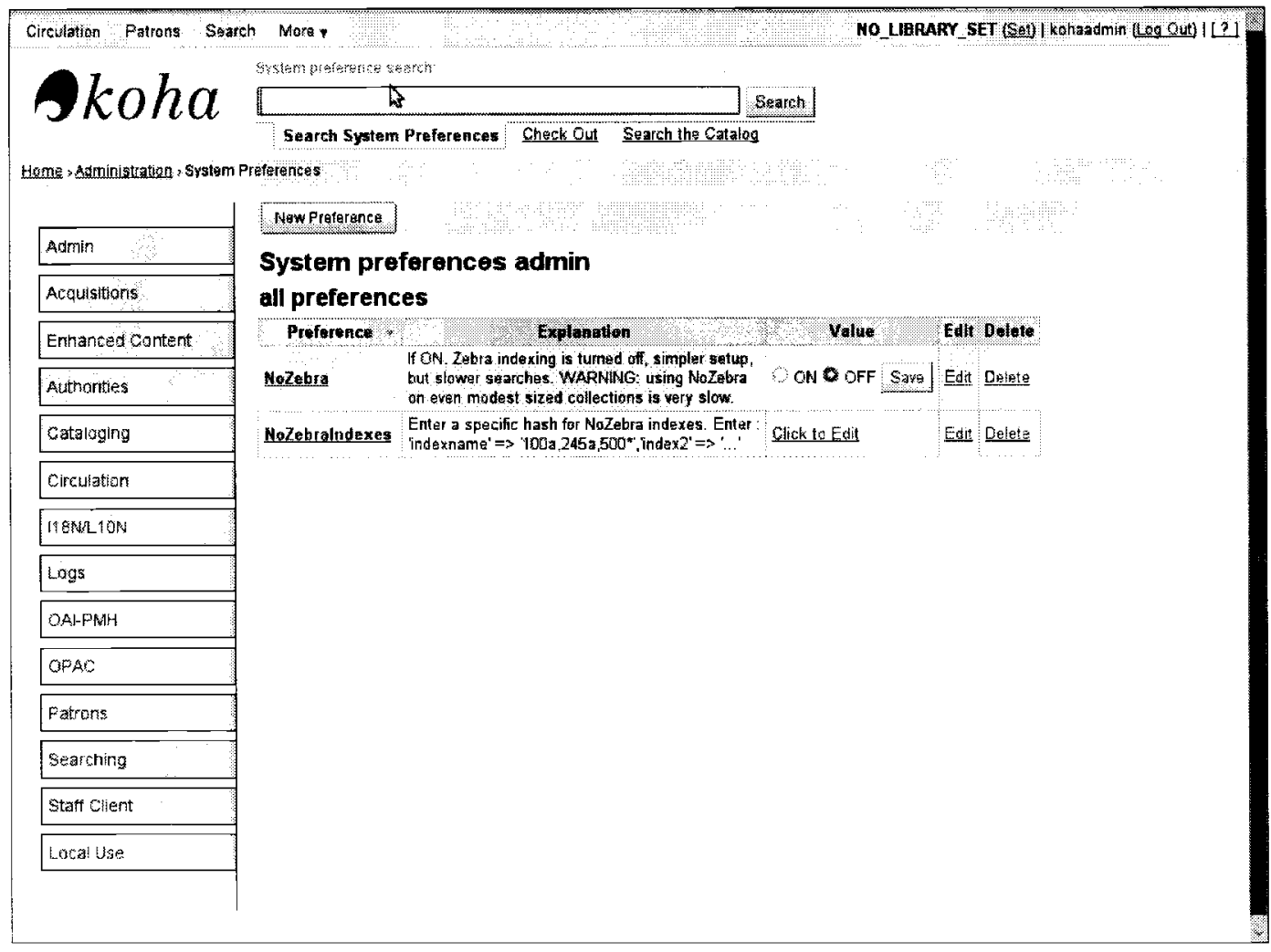

If you have installed Koha with Zebra and you want to stop using it, you will need to run a Koha program rebuild_nozebra.pl. This needs to be run just once when you start to use Koha without Zebra. The command is executed as follows:

linux-4yut:/usr/share/kohaclone/misc/migration_tools \#./rebuild_nozebra. pl 


\section{Summary}

Here is what we learned in this chapter:

- Installing Zebra packages

- Installing or reinstalling Koha to work with Zebra

- Invoking the zebrasrv program from the Linux shell

- Running the zebrasrv as a daemon

- Setting up the zebrasrv daemon as a service

- Including the zebrasrv service in the start-up profile

- Executing the rebuild_zebra.pl program with different options

- Turning off Zebra

In the next chapter, we will complete the installation process by executing Koha's web installer and configuring the Crontab to schedule Zebra and other programs. 


\section{4 \\ Koha's Web Installer, \\ Crontab, and Other Server \\ Configurations}

In this chapter, we will complete Koha's installation and system configuration tasks. First we will execute Koha's web installer to populate the Koha database structure and some important administrative settings. This will allow us to launch Koha's staff interface and its OPAC.

We will set up the koha user's crontab to schedule periodic execution of Koha programs such as those that generate overdue notices or calculate fines.

We will also set up an XML parser suitable for use with Koha.

Finally we will make sure Koha related services start automatically when the machine reboots.

\section{Executing Koha's web installer}

In this section of the chapter, we will learn how to execute Koha's web installer. The web installer performs several important functions such as creating Koha's database structure or populating mandatory administrative settings. It can also populate optional settings and sample data such as MARC frameworks or patron categories. The installer is launched from the staff client interface using Koha's MySQL user and is a series of interactive steps. At the end of the process we will be able to launch Koha's staff interface and its OPAC. 


\section{Understanding the web installer's functions}

Koha's web installer performs the following functions:

- Checks for the existence of Koha's database, the connectivity to the database, and if the database user has the required privilege on the Koha database

- Creates Koha's database structure - its tables, relationships between tables, database constraints, and other rules

- Accepts user input on important configuration questions such as Language or MARC flavor

- Populates the Koha database with several mandatory administrative settings such as the default system preferences

- Populates the Koha database with several optional administrative settings and sample data such as MARC bibliographic frameworks, sample libraries, or sample patron categories

- Configures Koha catalog search to use Zebra or to use database indexing

\section{Understanding how to execute the web installer}

Here are some important points to note about executing Koha's web installer: 


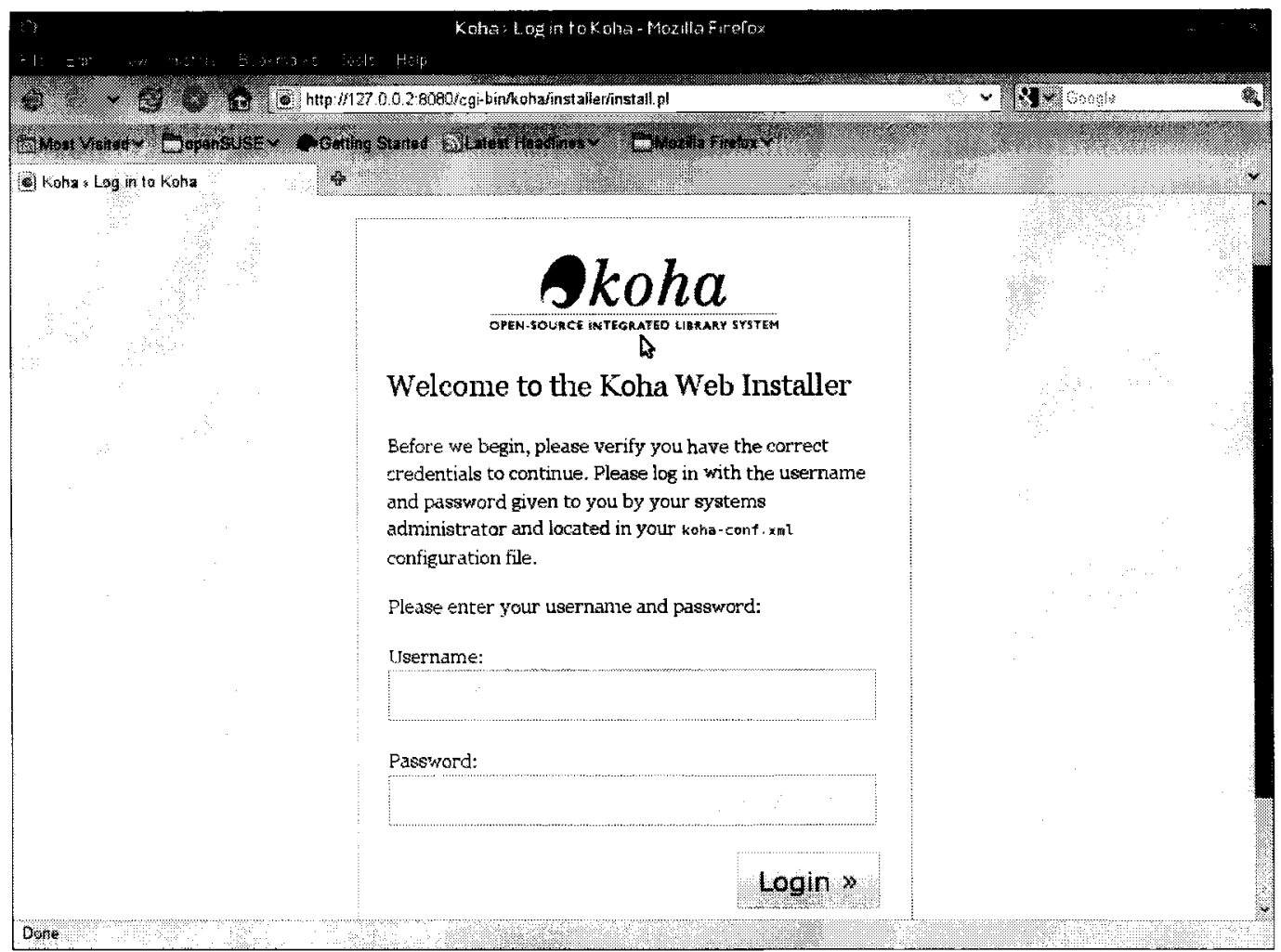

- The web installer is launched from the staff interface.

- We use a MySQL database user and password to login into the installer; this user must have privileges over Koha's database.

- Choosing the correct MARC flavor-MARC21 or UNIMARC is very important; it is not possible to change this configuration once the database is created.

- If you are evaluating or testing Koha, you should choose to import most or all of the optional settings and sample data. This way you can start using Koha right away.

- The optional settings and sample data can be deleted or edited from Koha's staff client at any time, but this can be significant amount of work.

- If you have made a mistake in the configuration settings and want to start over, simply drop and recreate Koha's database from the MySQL prompt; you will be able to launch the web installer once again. 


\section{Understanding optional data available for import}

Let us understand some of the optional setting and sample data that we can choose to install using the web installer.

\section{Settings for MARC frameworks}

MARC frameworks define how data is captured for different types of material. The frameworks control things such as, which MARC fields are used, which of these fields is mandatory, or which fields are under authority control.

The installer has three sets of optional settings that we can import:

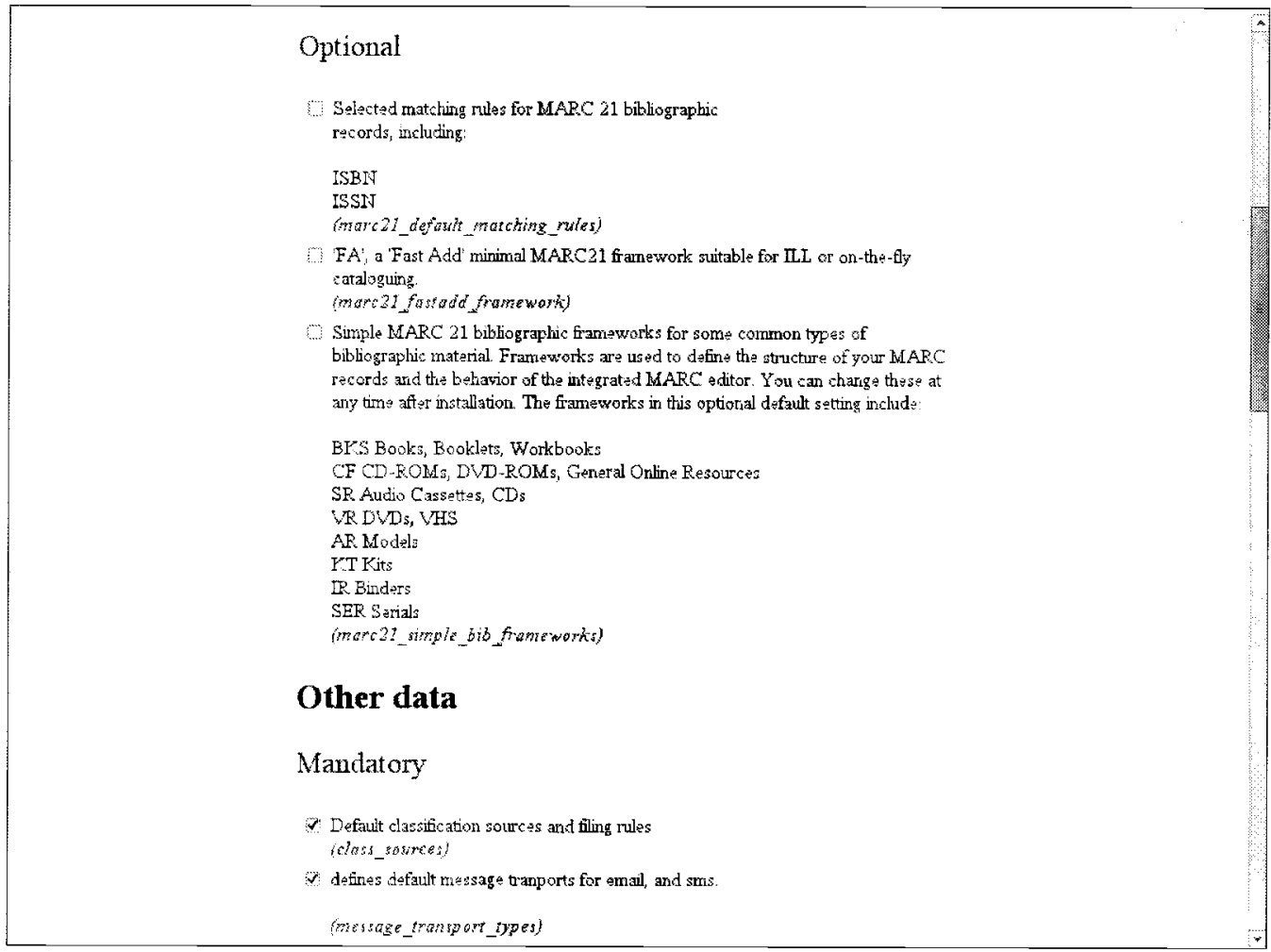

- Matching rules: Matching rules are used during import of catalog records to match incoming records to those already in the database. Further action can be taken on matched records such as overwriting old records or adding holdings records. Two matching rules are available: one matches on ISBN and other on ISSN. 
- Fast Add framework: This framework is designed for quickly adding catalog records; it has fewer fields when compared to other frameworks.

- Simple MARC 21 Bibliographic frameworks: A set of bibliographic frameworks for common types of material such as books, CDs, or serials.

\section{Other data}

Here is a listing of data we can import under the Other data section:

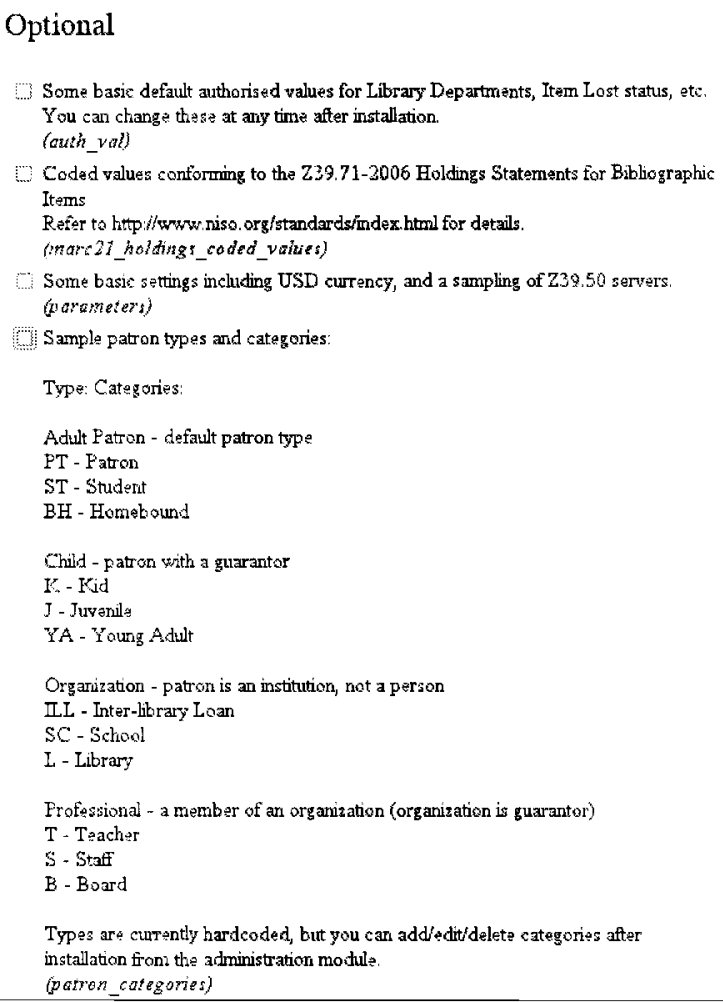

- Authorized values: Authorized values are lists of values that control data entry into catalog fields. Here we can import lists along with sample values for fields such as collections, shelving locations, or item statuses.

- Currencies: A set of currencies with sample exchange rates for use in Koha's Acquisitions module.

- Sample patron types and categories: A set of sample patron categories such as Student, Teacher, or Staff. Patron categories are used to define rules such as membership duration; the categories are also used to define circulation policy such as loan period. 
- Sample Label and Patron Card Data: A set of sample layouts and templates for use in Koha's label and patron card generation, and printing tool.

- Sample Holidays: A sample set of holidays for use in Koha's calendar. The calendar is used in Koha's circulation module to calculate due dates and fines.

- Default Item Types: A sample set of item types. Item types are used to define circulation policy such as loan period or fine amount.

- Sample Libraries: A sample set of libraries, patrons, catalog items, circulation rules are linked to libraries.

- Sample News Items: A set of sample news items, for display on the OPAC and the staff interface.

- Default messages or notices: A set of sample notices. These are used in various Koha modules, for instance the Overdue notice can be configured to be sent to patrons with overdue items.

- Sample Patrons: A set of patron records.

- Sample Z39.50 servers: A sample set of Z39.50 servers such as that of the Library of Congress. These servers are used in Koha's cataloging module for copy catalog records into Koha.

\section{Executing the web installer}

Here are step-by-step instructions on executing the web installer:

1. Log in using the MySQL user and password; in this book we have used the user kohaadmin.

2. In Step 1, choose your language; you should see just one option here-en for English or fr for French.

3. In Step 2, the installer checks the database connectivity and user privileges.

4. In Step 3, the installer populates the database with tables before prompting the user to install basic configuration settings.

5. Select your MARC flavor-Unimarc or MÄRC 21. It is important to make the right choice here. Consult with your library staff if you are unsure of what to choose.

6. Choose to import optional data related to MARC frameworks.

7. Choose to import other optional data such as authorized values, currencies, or patron categories.

8. Click on Import to install the settings and sample data.

9. Choose to use Zebra or the regular database indexing.

10. Click on Finish to complete the execution of the web installer. 


\section{Launching Koha}

Once the installer finishes it should automatically redirect to the staff interface:

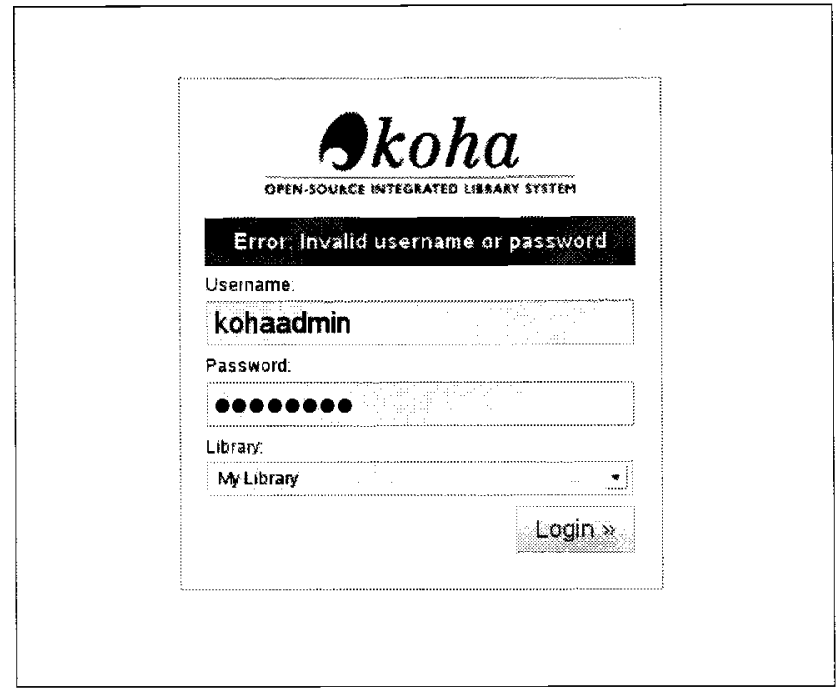

Log in using the MySQL user and you should see Koha's staff interface home page:

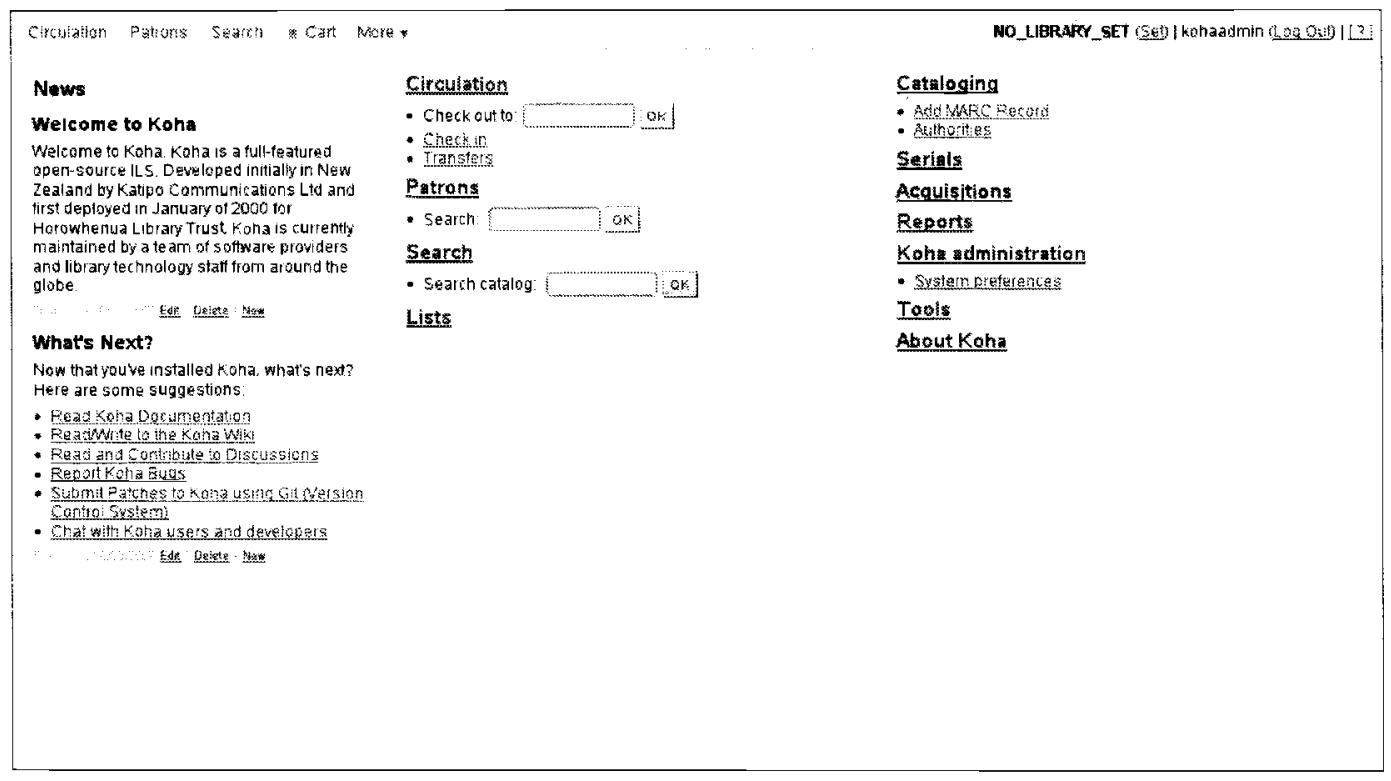


To launch the OPAC navigate to the OPAC url and you should see a screen such as this:

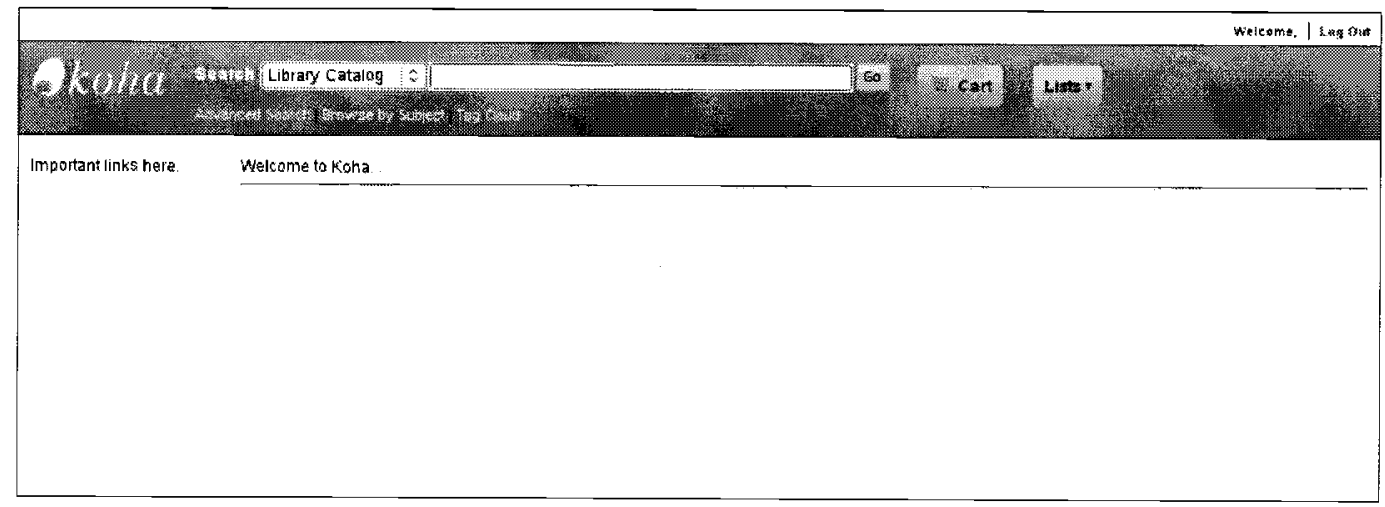

\section{Configuring the crontab}

Several Koha programs need to be run periodically. These programs calculate fines, generate overdue notices, send out e-mails, or build Zebra indexes.

We use Linux's Cron utility to schedule the execution of these programs.

\section{Editing the crontab}

The cronjobs are set up under the koha user's crontab. To edit the crontab we run the command crontab with the -e option:

koha@koha@linux: > crontab -e

To save and exit, we use the vi command wq:

:wq

\section{Setting up environment variables}

The first thing we need to do is to set Koha related environment variables in the crontab; without these none of the cronjobs will execute. Add these lines in the crontab, somewhere at the top:

PERL5LIB=/home/koha/kohaclone

KOHA_CONF=/etc/koha-dev/etc/koha-conf .xml 


\section{Generating advance notices}

Advance notices are sent to patrons when items are due. To generate such notices, we need to script advanced_notices.pl as a cronjob. Add a line to the crontab as follows:

$495 *$ * * perl /home/koha/kohacone/bin/cronjobs/advance_notices.pl -c

This cronjob will execute at 5:49 AM every day and generate and queue advance notices messages to patrons.

\section{Generating overdue notices}

Overdue notices are sent to patrons when items are past due. To generate such notices, we need to script overdue_notices.pl as a cronjob. Add a line to the crontab as follows:

$455 *$ * * perl /home/koha/kohaclone/bin/cronjobs/overdue notices.pl -t

This cronjob will execute at 5:45 AM every day and generate and queue overdue notices messages to patrons.

\section{Sending e-mail messages}

To send e-mails to patrons we will need to script process_messages.pl in the crontab:

$306 * *$ * perl/home/koha/kohaclone/bin/cronjobs/process_message_queue. pl

The process_messages.pl program sends out the queued messages via e-mail. This is the reason it should be scheduled after the advance notices and overdue notices cronjobs. In this example, we have scheduled the program to run at 6:30 AM every day.

\section{Calculating fines}

To calculate fines we script $f$ ines.$p l$ as follows:

$07 *$ * * perl /home/koha/kohaclone/bin/cronjobs/fines.pl

The fines.pl program calculates fines on overdue items based on circulation rules setup in Koha. 


\section{Rebuilding Zebra indexes}

In Chapter 3, Installing Koha's Zebra Search Engine, we learned how to rebuild Zebra indexes by passing different parameters to the rebuild_zebra.pl program. To schedule index rebuilds, we script a cronjob as follows:

*/1 * * * * perl/home/koha/kohaclone/misc/migration_tools/rebuild zebra.pl -b -a -z $\gg /$ dev/null $2>\& 1$

Note the following about this cronjob:

- The $* / 1$ at the beginning the cronjob signifies that the command will be executed every minute

- The output of the command is being redirected to the /dev/null, which means nowhere

- The expression $2>\& 1$ means, that the command's error messages (2) and its standard output (1) will both be redirected to the same place, in this case /dev/null

To redirect the output and error messages to a log file, we setup the cronjob as follows:

*/1 * * * * perl/home/koha/kohaclone/misc/migration_tools/rebuild zebra.pl -b -a -z >/home/koha/logs/zebra.log $2>\& l$

Note the use of the file /home/koha/logs/zebra.log instead of / dev/null.

\section{More crontab examples}

There are several other programs that can be set up in the crontab depending on your requirements. Take a look at the $/ \mathrm{misc} / \mathrm{cronj}$ obs/crontab.example file for more information:

koha@koha@linux: > vi /home/koha/kohaclone/misc/cronjobs/crontab.example

\section{Ensuring Koha starts automatically on server reboot}

To make sure that Koha runs smoothly after a server reboot, we need to make sure that Apache2, MySQL, and Zebra server start up automatically. In this section, we demonstrate how to set this on Debian and openSuSE. 


\section{Auto-starting Apache2}

On Debian, Apache2 is configured by default to start automatically on server reboot. In openSuSE, however, this is not the case. We use the chkconfig program to configure Apache2 to auto-start on reboot:

koha@koha@1inux: > sudo chkconfig apache2 on

Let us test if the command was successful; we run the command as follows:

koha@koha@1inux: > sudo chkconfig apache2

apache 2 on

\section{Auto-starting MySQL}

Again on Debian, MySQL is already configured to start automatically on server reboot. In openSuSE, we use chkconfig to configure it to auto-start on reboot: koha@koha@1inux: > sudo chkconfig mysq1 on

To test the configuration, we use chkconfig as follows:

koha@koha@linux: $>$ sudo chkconfig mysql

mysq1 on

\section{Auto-starting Zebra server}

We need to configure the service koha-zebra-daemon to start up automatically on server reboot.

On Debian, we use the chkconfig equivalent command-update-rc.d to accomplish this:

koha@koha@1inux: > sudo update-rc.d koha-zebra-daemon defau1ts

On openSuSE, we use chkconfig as follows:

koha@koha@1inux: > sudo chkconfig koha-zebra-daemon on

On openSuSE, if you are not using the koha-zebra-daemon service, you can setup the zebrasrv command in the /etc/init.d/boot. local file.

Edit the boot. local file:

koha@koha@linux: > sudo vi /etc/init.d/boot.loca1 
Add the zebrasrv command to the file somewhere near the end of the file as follows:

\# script with local commands to be executed from init on system startup

$\#$

\# Here you should add things, that should happen directly after booting

\# before we're going to the first run level.

$\#$

/usr/bin/zebrasrv -f /etc/koha-dev/etc/koha-conf.xm1\&

Note the use of the \& character at the end of the zebrasrv command; this tells the command to run silently in the background.

\section{Configuring the correct SAX parser}

Koha uses Simple API for XML (SAX) parsers to process XML data. It is possible that multiple XML parsers are installed on the server. We need to use the LibXML : : SAX : : Parser. The other parsers such as XML : : SAX : : PurePerl or XML : : SAX : : Expat are known to have bugs with certain character types.

First we run a test to check which parser is setup on the server. To print the parser that is in use, we run the Koha program /misc/sax_parser_print.pl:

koha@koha@1inux: > cd /home/koha/kohaclone/misc/

koha@1inux:/home/koha/kohaclone/misc \# ./sax_parser_print.p1

Koha wants something like:

XML : : LibXML : : SAX : : Parser =HASH $(0 \times 81 \mathrm{fe} 220)$

You have:

XML : : L IbXML : : SAX=HASH ( $0 \times 834$ fea 4$)$

Looks bad, check INSTALI.* documentation.

That error, $100 \mathrm{ks} \mathrm{bad}$, indicates that the configured parser is not suitable for Koha use. We will need to edit the initialization file of the parser and change its configuration.

First we locate the file ParserDetails ini:

koha@linux:/home/koha/kohaclone/misc \# locate ParserDetails.ini /usr/1ib/per15/vendor_per1/5.10.0/XML/SAX/ParserDetails.ini

We edit this file replace [XML: :SAX : :PurePerl] or [XML: :SAX : :Expat] as the case may be with [XML: :LibXML: : SAX: : Parser] . 
koha@linux:/home/koha/kohaclone/misc \# cd

/usr/1ib/per15/vendor_per1/5.10.0/XML/SAX/

koha@1inux:/usr/1ib/per15/vendor_per1/5.10.0/XML/SAX \# vi ParserDetails. ini

[XML : : LibXML : : SAX : : Parser]

http: //xm1.org/sax/features/namespaces $=1$

Let us test the parser configuration again; a correct file will result in an output like this:

koha@1inux:/home/koha/kohaclone/misc \# ./sax_parser_print.p1

Koha wants something like:

XML : : LibXML : : SAX : : Parser=HASH $(0 \times 81 \mathrm{fe} 220)$

You have:

XML : : LibXML : : SAX : : Parser =HASH (0x834fC94)

Looks good.

\section{Setting up environment variables for the Linux shell}

To run any of the Koha's programs from the Linux shell we need to set up up two environment variables properly - KOHA_CONF and PERL5LIB. Koha's Perl programs look at these variables to determine the location of the installation's configuration file-koha-conf . $\mathrm{xml}$ and the location of the application folder - kohaclone. In this section, we demonstrate how to setup these variables up for a single session and how to set these up to be persistent across sessions.

\section{Setting up KOHA_CONF environment variable}

The KOHA_CONF environment variable should point to Koha's configuration directory; in this book we have used/etc/koha-dev/etc/koha-conf .xml. To set up this variable, we use the export command:

koha@1inux:/home/koha/kohaclone \# export KOHA_CONF=/etc/koha-dev/etc/koha-conf .xm1

Let us test to make sure the variable is set correctly:

koha@1ibux:/home/koha/kohac1one \# echo \$KOHA_CONF /etc/koha-dev/etc/koha-conf.xm1 


\section{Setting up PERL5LIB environment variable}

The PERL5LIB environment variable points to the kohaclone folder. To set up this variable, we use the export command as follows:

koha@linux:/home/koha/kohaclone\# export PERL5LIB=/home/koha/kohaclone

Let us test to make sure the variable is set correctly:

koha@l inux:/home/koha/kohaclone\# echo \$PERL5LIB

/home/koha/kohaclone

\section{Setting up persistent environment variables}

To make sure the variables are persistent across sessions, we will need to export these variables in a bash configuration file.

On Debian, we set these up in the /etc/bash.bashrc file:

koha@linux:/home/koha \#vi /etc/bash.bashrc

On openSuSE, we use the /etc/bash.backrc. local file:

koha@linux:/home/koha \# vi /etc/bash.bashrc.local

We add these lines to the file:

export KOHA_CONF=/etc/koha-dev/etc/koha-conf.$x m l$

export PERL5LIB=/usr/share/kohaclone

To test if the configuration is successfully setup, we open a new terminal session and run the echo command:

koha@linux: > echo \$KOHA_CONF

/etc/koha-dev/etc/koha-conf.xml

koha@koha@linux: > echo \$PERL5LIB

$\because /$ home/koha/kohaclone

koha@linux: > 


\section{Summary}

Here is what we learned in this chapter:

- Executing Koha's web installer to populate the database structure and mandatory administrative settings

- Configuring the crontab to schedule Koha's batch programs

- Configuring the necessary XML SAX parser

- Configuring Apache2, MySQL, and Zebra server to start automatically on reboot

We have now completed the installation and server configuration phase of the book. In the next set of chapters we will use Koha's staff interface to configure the various Koha modules. In the next chapter, we will configure the cataloging module. 
$\therefore$ 


\section{5 \\ Configuring the Cataloging Module}

In this chapter, we will learn how to configure Koha's Cataloging module. This module is used to maintain information about items in the library. Cataloging is an important function - a good catalog helps patrons find and evaluate items easily.

Our goals in this chapter will be to:

- Make cataloging screens simpler to use

- Control the fields to prevent errors to bring about consistency and quality

To do this we will need to study three of Koha's cataloging configuration tools:

- MARC Frameworks

- Authority Control

- Authorized values

To configure these tools effectively we will need to first develop a configuration plan based on an understanding of the library's needs and circumstances. 


\section{A first look at Koha's cataloging configuration tools}

Before we create our cataloging configuration plan let us understand Koha's configuration tools:

- MARC frameworks are cataloging templates for different types of material in the library

- Authority Control allows us to control data entry in certain fields. Authority Control is used for title, name, and subject fields

- Authorized values offer an additional way to control data entry. These are used mainly for item or local use fields.

\section{MARC frameworks}

Koha's MARC frameworks are a way to simplify catalog data entry, also to control what gets entered. Think of these as cataloging templates for different types of material in the library.

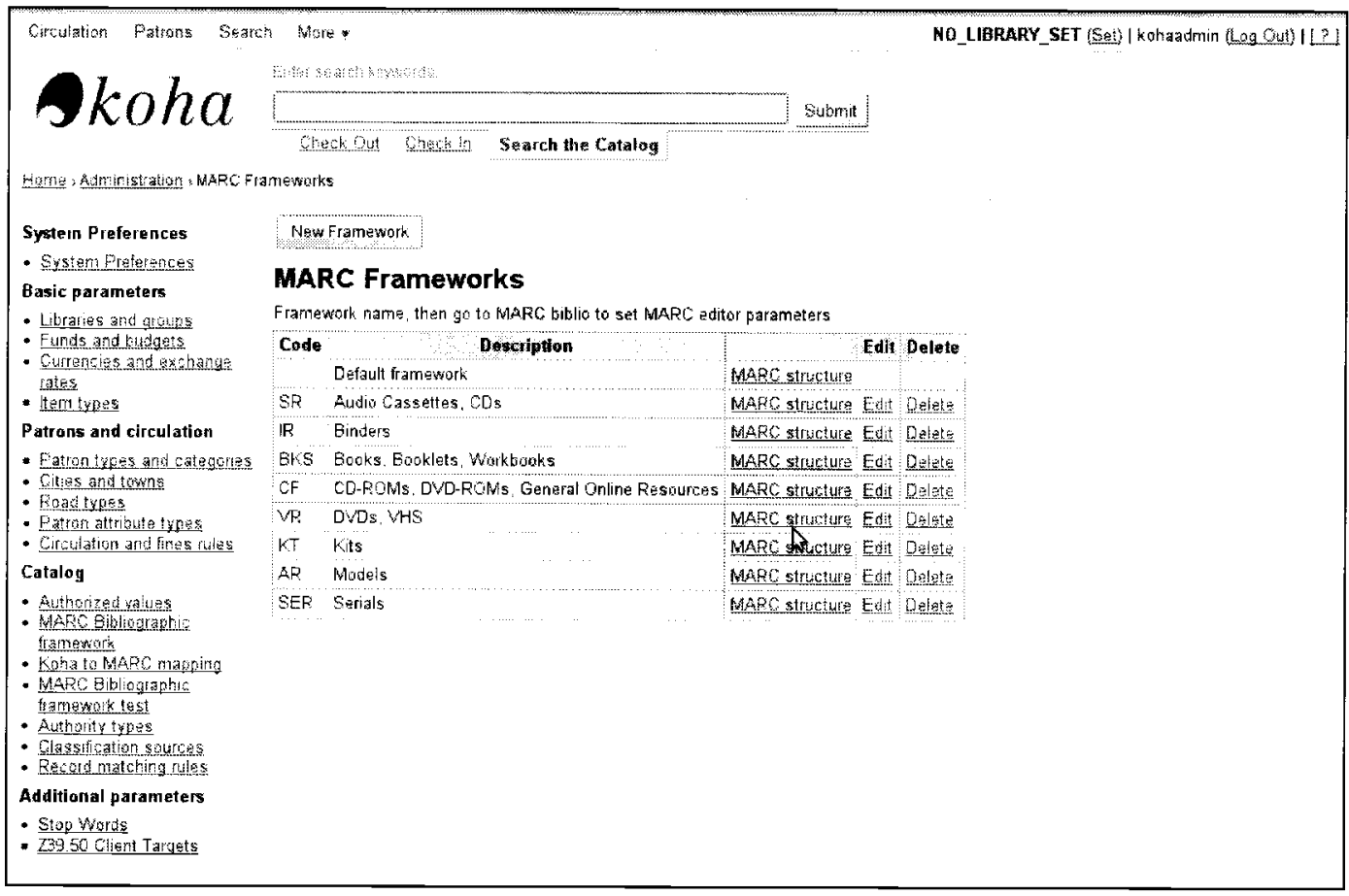


Here are some notes on frameworks:

- While installing Koha you can choose to install a set of frameworks for commonly used material types

- New frameworks can be created by modelling them on existing ones

- Frameworks can be edited or deleted at any time

- The default framework has a broad set of fields and can be used for material that doesn't fit into any other framework

- Frameworks control how a catalog record is entered and displayed in the cataloging screens

- Frameworks have no impact on records that are imported via Koha's import or Z39.50 copy cataloging tools

With MARC frameworks, for each type of material, we can define what fields and subfields are:

- Available for data entry

- Mandatory

To control data entry, we can also bring some of these fields or subfields under:

- Authority Control

- Authorized Values Control

\section{Authority Control}

Data entry into bibliographic fields can be controlled using Authority Control. Bibliographic cataloguers cannot enter text in fields under Authority Control; they can only pick values from the list of authority records.

This text from Wikipedia (http://en.wikipedia.org/wiki/Authority_control) describes the purpose of authority control well:

Authority control fulfils two important functions.

First, it enables catalogers to disambiguate items with similar or identical headings. For example, two authors who happen to have published under the same name can be distinguished from each other by adding middle initials, birth and/or death (or flourished, if these are unknown) dates, or a descriptive epithet to the heading of one (or both) authors. 
Second, authority control is used by catalogers to collocate materials that logically belong together, although they present themselves differently. For example, authority records are used to establish uniform titles, which can collocate all versions of a given work together even when they are issued under different titles.

Authority records are usually created for name, title, and subject headings. Some bibliographic fields that are can be brought under authority control are:

- 100\$a: Personal name

- 110\$a: Corporate name

- 111\$a: Meeting name

- 139\$a: Uniform title

- 600\$a: Subject: Personal name

- 610\$a: Subject: Corporate name

- 611\$a: Subject: Meeting name

- 650\$a: Subject: Topic

- 651\$a: Subject: Geographic name

- 655\$a: Subject: Genre/Form

In Koha, Authority Control is implemented using:

- Authorities system preferences

- Authority types

Authorities related system preferences control:

- Whether Authority Control is used or not

- Whether new bibliographic records result in automatic creation of authority records

- Whether updates to authority records should update linked bibliographic records

Some key points on Authority Types are:

- Authority Types are MARC frameworks for authority headings

- While installing Koha you can choose to install a set of commonly used authority types

- New Authority Types can be created, these can be edited or deleted at any time 
- Authority Types are mapped to fields in Bibliographic MARC frameworks

- Authority Types control how an authority record is entered and displayed in the authorities cataloging screens as shown in the following screenshot:

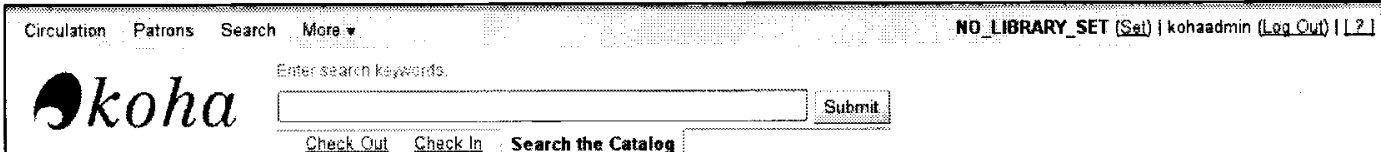

- Sistem Praferences

Basic paraneters

- Libraries and grouns

- Funds and budgets

- Currancios and exchande

rates

- Itemtyos

Patrons and circulation

- Pation lypes and categories

- Cities and towns

- Road tupes

- Fatron attributia tupes

- Circulation and fines rules

Catalog

- Authonzadralus

- MARC Bibliographt

Iraniewopk

- Kona to MARC mapeina

- MARC Jiblingraphic

framework 1est

Alsthority tayes

- Clasification sourices

- Fecord matching rules

Additional parameters

- Stop Words

- 2050 gilent Targats

New Authority Type

\section{Authority Types}

Define authority types, then authority MARC structure in the same way you define itemtypes afld biklio MARC tag structure. Authurity values are managed through plugins

\begin{tabular}{|c|c|c|c|c|c|c|}
\hline Code & Description & Sumnan & Why fidld copled & & Edit & Delete \\
\hline & Defautt & & & WARC structure & Edjt & Delata \\
\hline CHFON_TERM & Chronologizal Term & Chronological Term & 148 & MARG structure & Endt & Qelote \\
\hline CORPO_NAME & Corporate Name & Corporate Names & 110 & MARC structufe & Edit & Delate \\
\hline GEWRE FORM & Genrafform Term & Genreiform Torm & 155 & MARC structure & Edit & Dentete \\
\hline GEOGR_NAME & Geographic Name & Geographic Name & 151 & MARC sturcture & Edt & Delete \\
\hline MEEFI_NAME & Meeting Name & Meeting Name & 111 & MARC structure & Edit & Delete \\
\hline PERSO_NAME & Fersonal Plame & Personal Names & 100 & MARC structure & Edt & Qelats \\
\hline TOFIC TEFM & Topical Term & Topical Terrm & 150 & MARC structure & Edt & Daste \\
\hline UNVF_TITLE & Uniform Title & Unifom Title & 130 & MAPQ structure & Edit & Delet: \\
\hline
\end{tabular}

s

\section{Authorized values}

Koha provides an additional way to control data entry - authorized values. These are simple lists of values that can be linked to any bibliographic field or subfield. 
Catalogers will not be able to enter free text in fields that are controlled via authorized values; they will only be able to pick values from a list. Like Authority Control, authorized values help reduce errors and bring about consistency in catalog records.

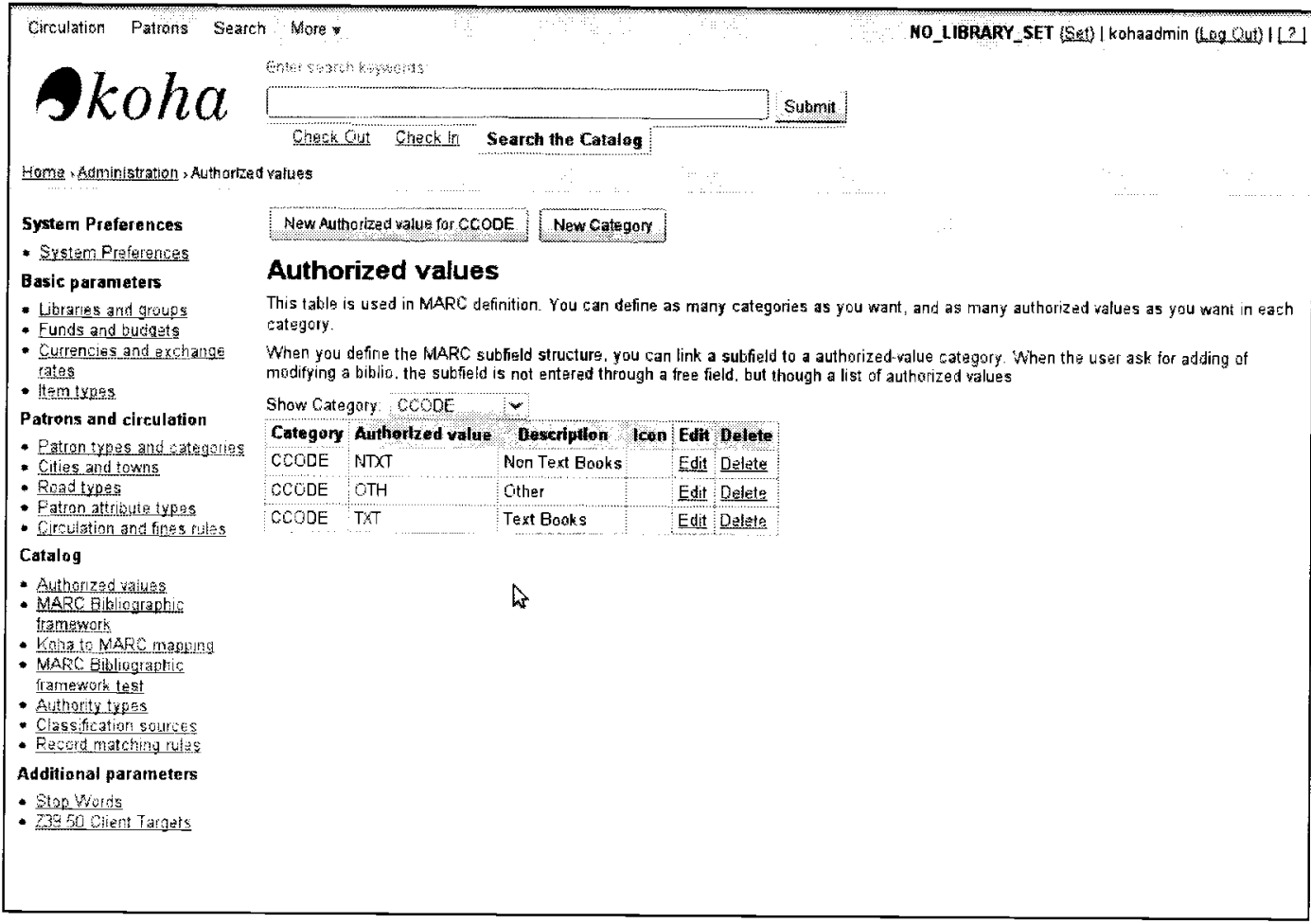

Item or Local use fields are usually controlled using authorized values. Some of these fields are:

- 952\$2: Shelving scheme

- 952\$8: Collection code

- 952\$a: Home branch

- $952 \$ c:$ Shelving location

- $952 \$$ j: Shelving control number

- 952\$y: Item type 
And here are some key points about authorized values:

- While installing Koha you can choose to install a set of commonly used authorized values categories along and corresponding values

- New Authority values categories and values can be created, edited, or deleted

- Authorized values categories can be mapped to fields in Bibliographic MARC frameworks

- Some authorized values such as branch and item type are special and they are configured under Koha's Administration screens

\section{Preparing a configuration plan}

Before we configure Koha's cataloging module, we will need to develop a plan based on the library's needs and circumstances. We will need to identify how to use Koha's Authority Control, what types of material we would want to catalog, and what fields and subfields we will need for each material type. We will also need to define which of these fields and subfields will be mandatory, which ones will be controlled using Authority Control or Authorized Values Control.

\section{Identifying Authority Control rules}

We will first need to decide how to use Koha's Authority Control, if at all.

Using Authority Control has cost implications; you will need staff to maintain your authority files, or you may outsource this work. You may have to purchase authority records from the Library of Congress or other sources.

You will also need to establish a process for using Authority Control. Will you create authority records during the creation of bibliographic records, or after? What process will you follow when authority headings are updated? 
Based on this you can develop a plan that looks something like this:

\begin{tabular}{ll}
\hline Question & Plan \\
\hline Use Authority Control? & Yes \\
$\begin{array}{l}\text { Create authority records before bibliographic records } \\
\text { are created, or after they are created }\end{array}$ & $\begin{array}{l}\text { After bibliographic records } \\
\text { are created }\end{array}$ \\
$\begin{array}{l}\text { Do you want bibliographic records to be automatically } \\
\text { updated when authority records are updated? }\end{array}$ & Yes \\
\hline
\end{tabular}

\section{Identifying frequently cataloged types of material}

Create a list of materials that are cataloged often and have distinct bibliographic characteristics, in terms of fields and subfields that are commonly used.

Our list might look something like this:

- Books

- Serials

- Visual materials

- Reports/Dissertations

- Electronic material

You will need to create a Bibliographic framework for each item in this list.

\section{Identifying MARC field sets for each type of material}

For each type of material above, we will list the fields and subfields that will be used during cataloging. For instance, for books, we might want a field set similar to this:

- 020: ISBN

- 082: Call number

- 1XX: Author fields

- 245: Title

- 260\$a: Place of publication

- 260\$b: Publisher 
- 260\$c: Date of publication

- 300: Physical description

- 500: General note

- 505: Formatted contents note

- 6XX: Various subject fields

- 7XX: Other authors

- 952\$a: Home branch

- 952\$d: Date acquired

- 952\$p: Barcode

- 952\$y: Item type

\section{Identifying mandatory fields}

Next, for each field and subfield we will indicate if it needs to be mandatory. If data for a certain field is always available, and the field helps patrons find or evaluate an item, it might be a good idea to make it mandatory. Our configuration plan for books now looks like this:

\begin{tabular}{ll}
\hline Tag/Subfield & Mandatory? \\
\hline 020: ISBN & No \\
082: Call number & No \\
1XX: Author fields & No \\
245: Title & Yes \\
260\$a: Place of publication & Yes \\
260\$b: Publisher & Yes \\
260\$c: Date of publication & Yes \\
300: Physical description & Yes \\
500: General note & No \\
505: Formatted contents note & No \\
6XX: Various subject fields & Yes \\
7XX: Other authors & No \\
952\$a: Home branch & Yes \\
952\$d: Date acquired & Yes \\
952\$p: Barcode & Yes \\
952\$y: Item type & Yes \\
\hline
\end{tabular}




\section{Identifying Authority Control rules}

Here will need to decide which bibliographic fields will be under Authority Control. The usual name, title, and subject fields are natural choices, but you can consider other fields too.

Let us add an Authority Control column to our example:

\begin{tabular}{lll}
\hline Tag/Subfield & Mandatory? & Authority Control \\
\hline 020: ISBN & No & \\
082: Call number & No & \\
1XX: Author fields & Yes & Yes \\
245: Title & Yes & \\
260\$a: Place of publication & Yes & \\
260\$b: Publisher & Yes & Yes \\
260\$c: Date of publication & Yes & \\
300: Physical description & Yes & \\
500: General note & Yes & \\
505: Formatted contents note & No & \\
6XX: Various subject fields & Yes & Yes \\
7XX: Other authors & No & Yes \\
952\$a: Home branch & Yes & \\
952\$d: Date acquired & Yes & \\
952\$p: Barcode & Yes & \\
952\$y: Item type & Yes & \\
\hline
\end{tabular}

\section{Identifying fields to control using authorized values}

Some fields such as branch and item type are controlled by default. Other fields that can be populated by short lists of fixed or infrequently changing values are also good candidates.

Let us add an authorized values control column to our example: 


\begin{tabular}{llll}
\hline Tag/Subfield & Mandatory? & Authority Control & $\begin{array}{l}\text { Authorized } \\
\text { values control }\end{array}$ \\
\hline 020: ISBN & No & & \\
082: Call number & No & Yes & \\
1XX: Author fields & Yes & & Yes \\
245: Title & Yes & & \\
260\$a: Place of & Yes & Yes & \\
publication & & & \\
260\$b: Publisher & Yes & & \\
260\$c: Date of & Yes & & \\
publication & & & \\
300: Physical & Yes & & \\
description & & & \\
500: General note & Yes & Yes & \\
505: Formatted & No & & \\
contents note & & Yes & Yes \\
6XX: Various subject & Yes & & Yes \\
fields & & & \\
7XX: Other authors & No & & \\
952\$a: Home branch & Yes & Yes & \\
952\$d: Date acquired & Yes & & \\
952\$p: Barcode & Yes & & \\
952\$y: Item Type & & & \\
\hline
\end{tabular}

This completes our configuration plan for books. You can create similar plans for other types of material.

\section{Implementing our configuration plan}

Now that we have a configuration plan in place, let us look at how to implement it in Koha. We will first setup Authority Control and authorized values and then use them in a new MARC framework. 


\section{Configuring authorities system preferences}

We will need to set two system preferences:

- BiblioAddsAuthorities: Turn this Off, if you expect to have authority records available for use during creation of bibliographic records. If this is set to On, authority control is turned off; Catalogers can enter the data in the field, and Koha automatically creates authority records based on what is entered in the corresponding bibliographic field.

- dontmerge: Set this to On, if you want linked bibliographic records to be automatically updated when an authority records is updated.

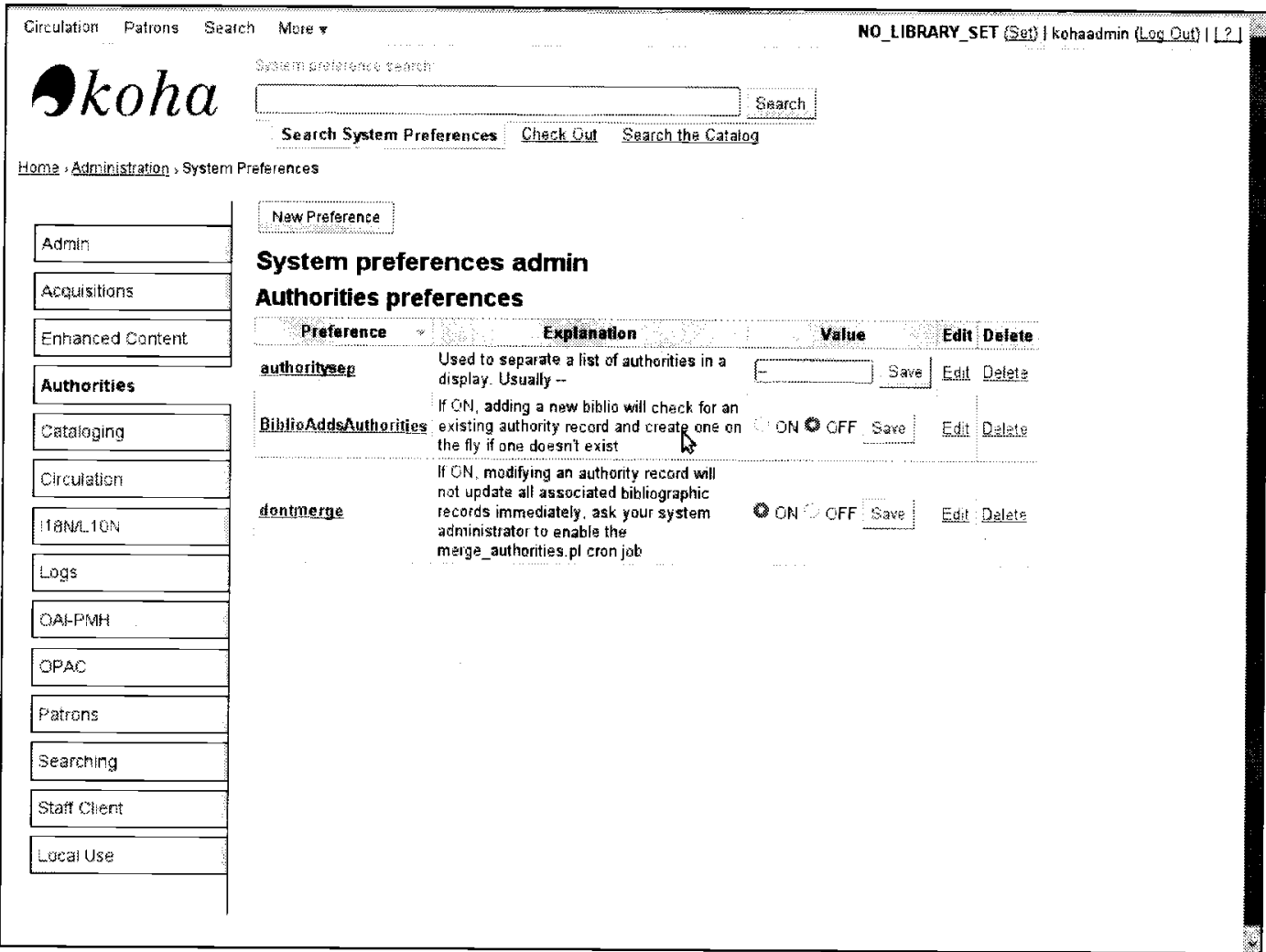

To edit these preferences, navigate to Administration | Global system preferences. Search for the system preference by its name to find it. 


\section{Configuring Authority Types}

Authority Types are MARC frameworks for authority records. Commonly used Authority Types are available with the default installation of Koha. You can create new ones if you want to bring fields other than name and subject headings under Authority Control.

To create a new authority type, follow these steps:

1. We find Authority Types screens in the Catalog section under Administration.

2. Click on New Authority Type button.

3. Enter an Authority Type code, Description, and Summary.

4. The field Authority field to copy is most important we enter the tag in the authority record that should be copied into the bibliographic record. Look at the existing Authority Types for reference.

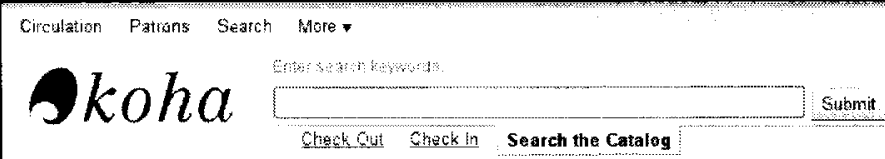

NO_LIBRARY_SET Get) I kohadmin (Lag Qut) $14 ?$

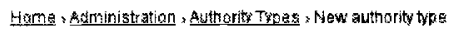

System Piaferences

- Sustam Prifancices

Basic parameters

- Libraries and gralips

- Funds and buridets

- Currencles and exchange

taies

- tembrass

Patrons and circulation

- Fatron types and categones

- Citras and torris

- Roajtypes

- Eatron attribute :yees

- Circulation and fines rulas

Catalog

- Authorzed values

- MARC Gibliogravhic

iramesch

- Atia to VYAEC magring

- NARE Eibliograplic

framenork test

- Autharity voss

- Classification suzrises

- Record matching rules

A

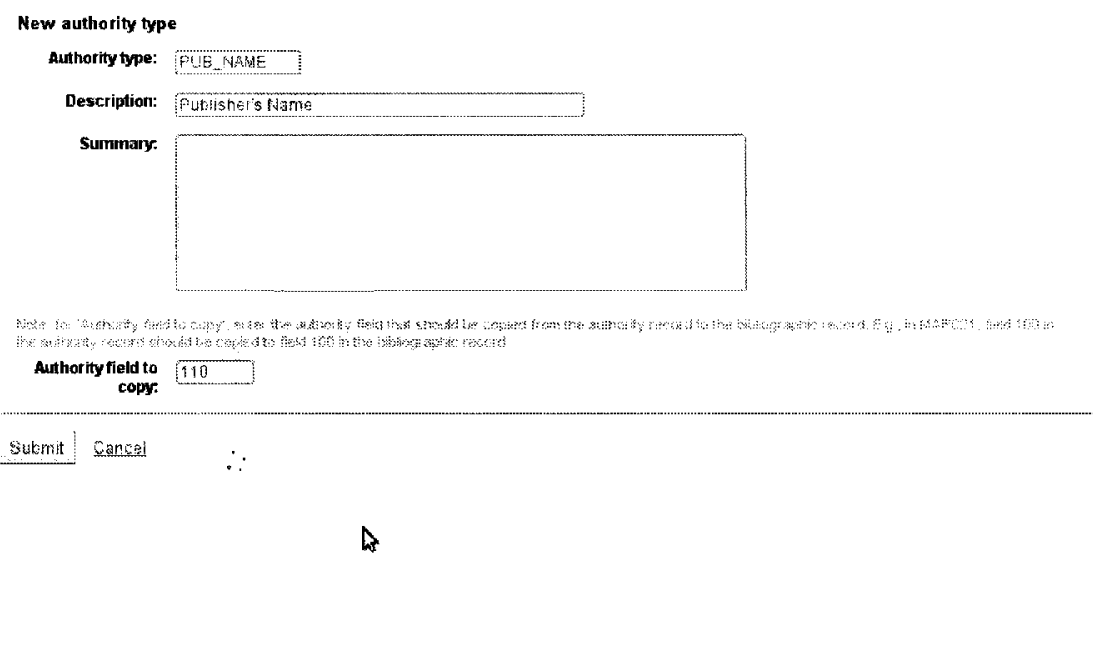

- stop Morde

- 209 5u clent Targets 


\section{Configuring authorized values categories}

We will need an authorized values category for each field we want to control using authorized values.

Find Authorized Values screens in the Catalog section under Administration. The pre-configured set of categories is listed in the Show Category list of values.

To create new categories, we use the New Category button.

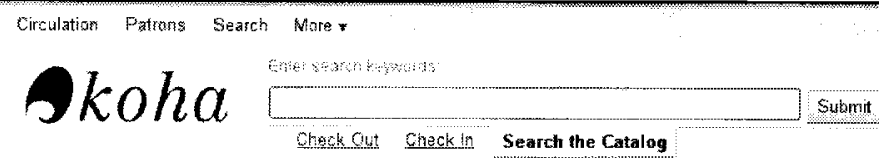

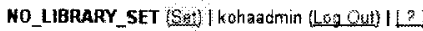

Hame Administration, Authorized vialues: New categon

System Preferences

- Exstem Preferentras

Basic parameters

- Librarip and gucues

- Funds and butsyots

- Currencies and exchange

rates

- item types

Patrons and circulation

- Fatuon types and categoles

- Cities and towns

- Foadtypes

- Fatron atribut types

- Sirculgtion andines rules

Catalog

- Aluthrized kailizs

- MARE Eifliojraphic

framenom.

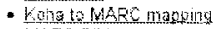

- MARC G blengraptir

iramentoptest

- Ajtharity tyoss

- Classifiatian sources

- Racord matching rules

Additional parameters

- Stog zrons

- 79050 Client Targers
New category

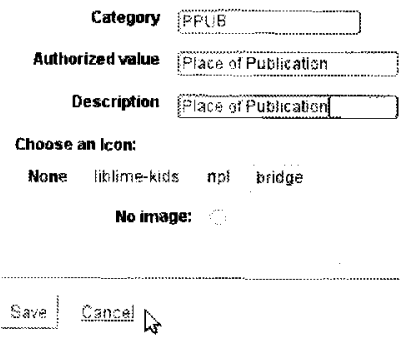

\section{Editing authorized values}

To edit the list of values in a category, we first select the category from the Show category list of values. 


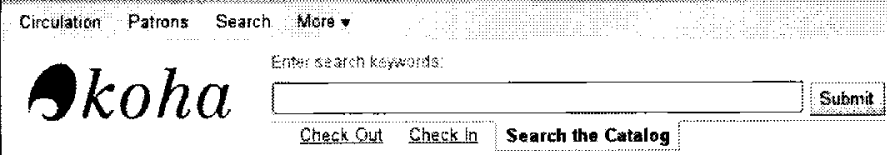

thome , Administration a guthorizgd values, Medify authorized value

Syatem Preferences

- Srstem Preferences

Basic parameters

- Litraries and grougs

- Funds and budgets

- Currencias and exchange

catess

- Itemtyotes

Patrons and circulation

- Fatron types and categrisas

- Clies and toswris

- Foad trpes

- Paspos attributa tymes

- Eirculation and fines rulas

Catalog

- Authorized xalues

- MARC Bililiographir

framework

- Kaha te MAR mapping

- MARC Bibliggarab

framewark test

- Authority traes

- Classification ssurces

- Record matchirg rules

Additlonal parameters

- Stop Words

- Zj 50 client Tagets
NO LLBRARY_SET (SHD I Kohaadmin (LGQ CUI) I ? ]

Modify authorized value

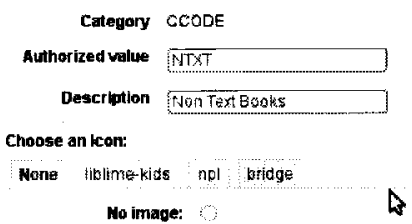

Save Cancis

We use the button New Authorized value for <Category Name $>$ to create new values.

\section{Special authorized values}

Some authorized values categories are maintained in the Administration section directly. We'll look at these now: 


\section{Library}

Libraries can be maintained in Libraries and groups section in the Basic parameters section under Administration.

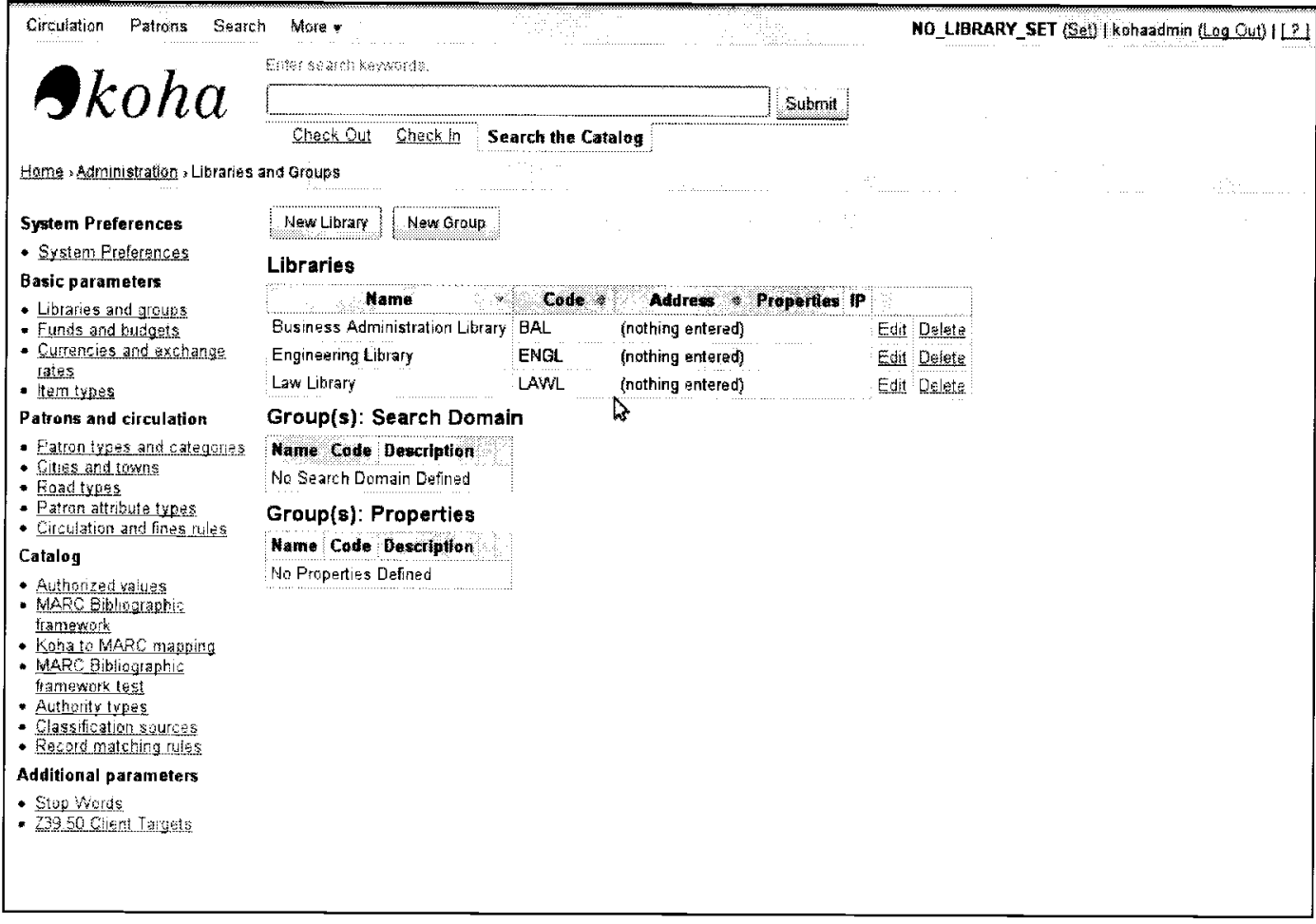

\section{Item Type}

Item Types can be maintained in Item Types $\mathbf{n}$ the Basic parameters section under Administration. 


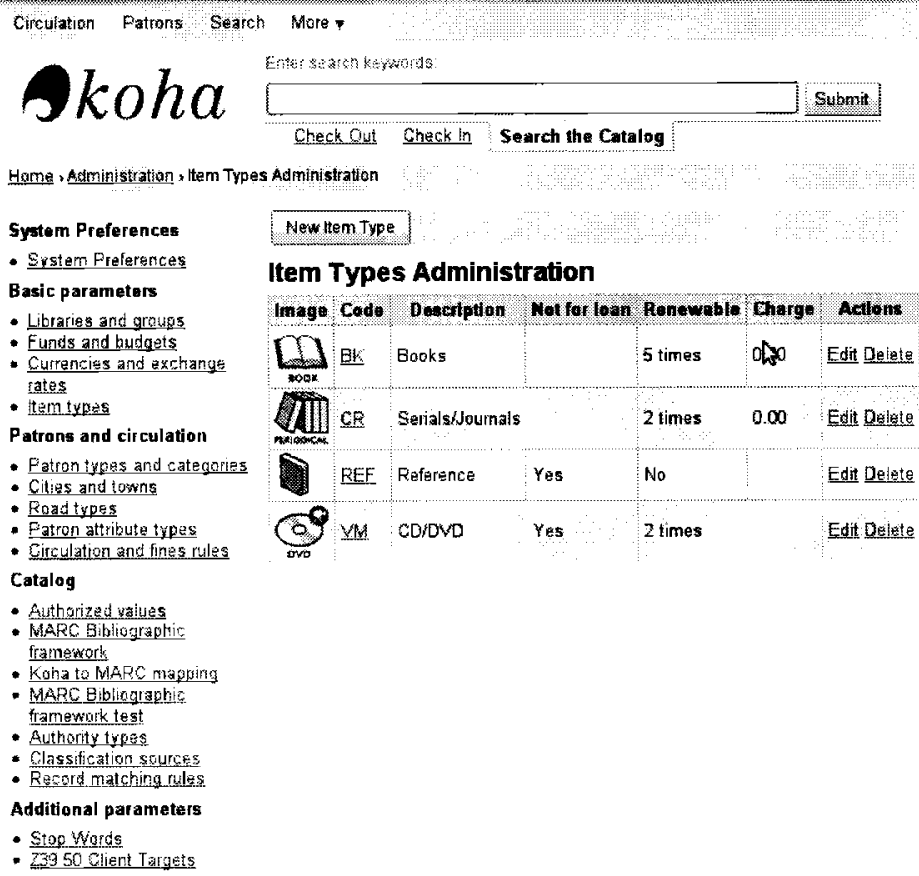

- Stop Words

- Tag 50 client Talgets

\section{Configuring MARC frameworks}

Now that we have Authority Types and Authorized Values Categories set up, let us look at editing our MARC framework list, and configuring the fields and subfields in a framework.

\section{Editing MARC framework list}

We use the New Framework button to create, the Edit link to edit, and the Delete link to delete frameworks.

Key points to remember:

- Try not to edit or delete any preconfigured frameworks, at least initially

- Create new frameworks, Koha allows you to model new frameworks on existing ones

- Only once your own frameworks are fully ready, should you consider consider removing the preconfigured ones

- You should retain the default framework for material types that have no frameworks 


\section{Creating a new framework}

To create a new framework, we use the New Framework button. Once the

Framework Code and Description is saved, we click on the MARC structure link.

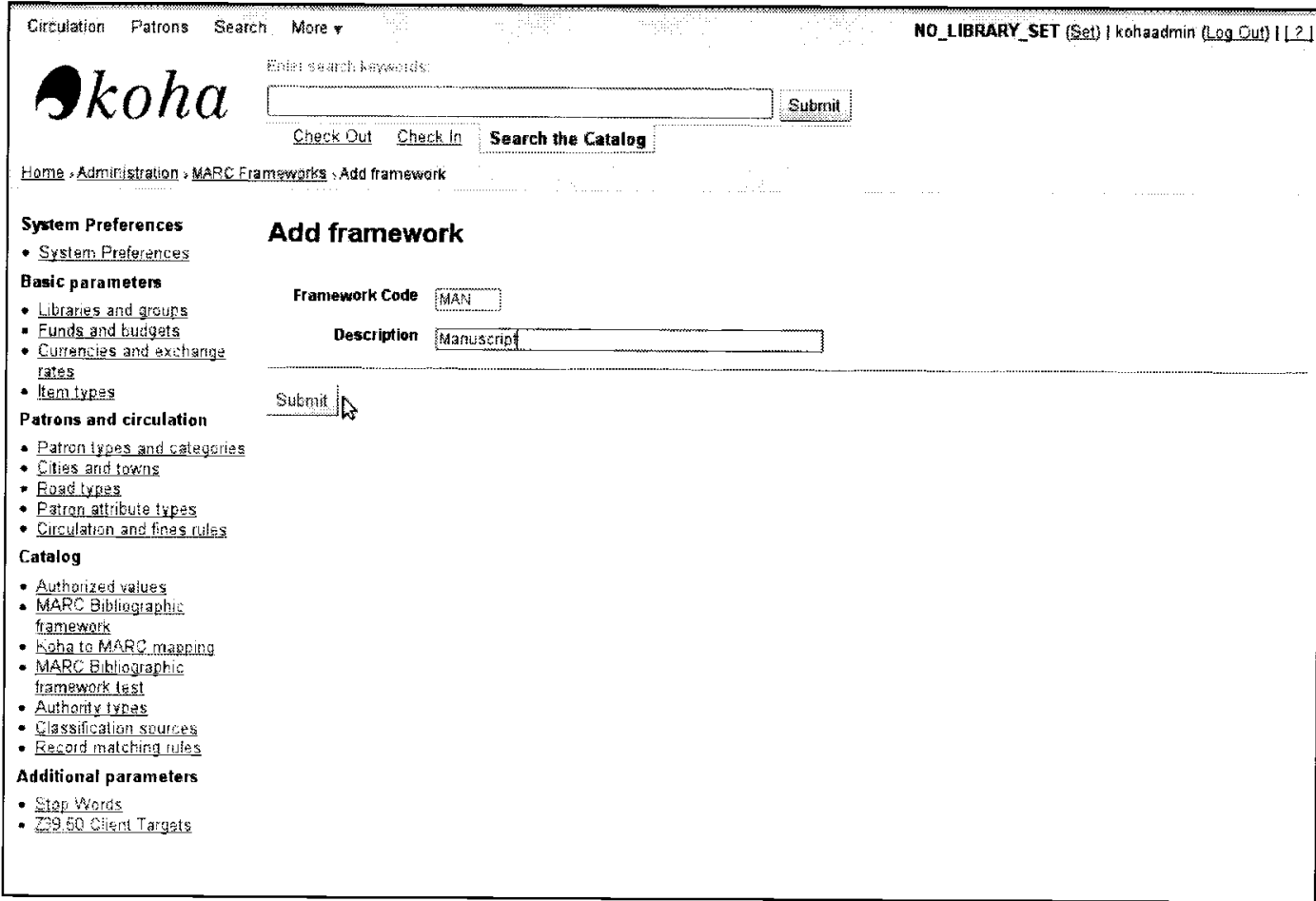

At this stage, we choose an existing framework as a model for the new one. Choosing the right framework in this step will save a lot of effort. 


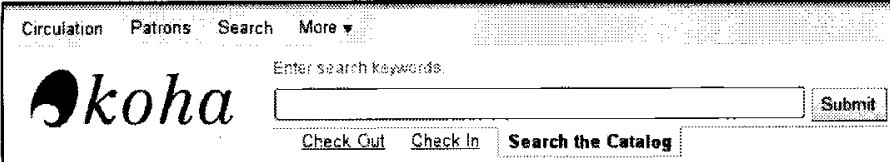

Mo LIBRARY SET (SOt) | kohaadmin (Lag OUt) I [?]

Harne : Administration .

Syatem Proferences

- Bystem Preferences

Basic parameters

MARC Framework for Manuscript (MAN)

- Bibraries and greups

- Funds and hudgets

- Currencies and axthange

rates

- liem types

t

trons and circulation

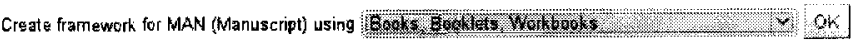

- Patron typus and categernes

- Cities and towns

- Bojad types

- Patron attribute types

- Circulation andinas rules

Catalog

- Autharized vaiues

- MARC Bibliggraptrio

framenoris

- Kotna to MARC mapring

- MaRC Bibliographí

fiamework test

- Authority tweses

- Classificatian sounces

- Resora matching rulis.

Additional parameters

- Siop Wuards

- 3950 Client Targets

\section{Editing fields and subfields}

Let us now edit the fields and subfields in the new framework.

Remember that Bibliographic tags are numbered from 0XX through 8XX. Item or local use data is stored in tag 952. 
Use the Search for tag feature to navigate to the field you wish to edit. Use the Display only used Tags/Subfields checkbox as a navigation aid.

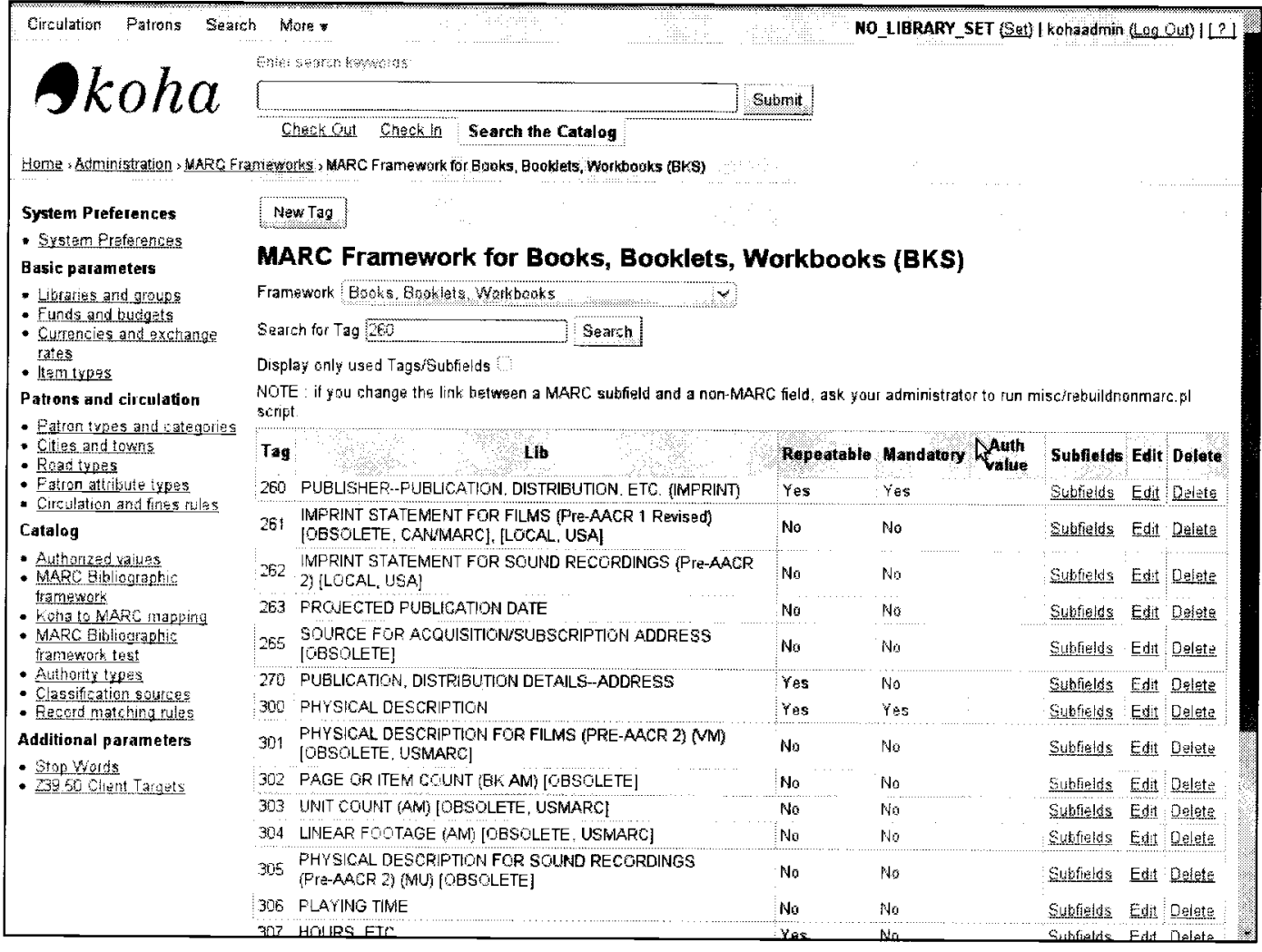

To edit the field, click on Edit. To edit subfields click on Subfields, and click on the Edit Subfields button at the bottom of the page. 


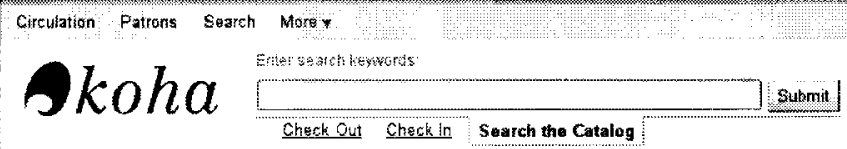

Hame, Auministiation, MARC Framewerks, BKS Framewofk strukture, Tag 260 sutfield structure

\section{MARC subfield structure admin for 260 (framework BKS)}

\begin{tabular}{|c|c|c|c|}
\hline subliteld & Tont & Constratins & Delote \\
\hline 6 & Linkage & Tab:2, Nat repeatable, Not mandatory, hidden, & Delets \\
\hline 8 & Field link and sequence number & Tak:2. Repeatable. Not mandatory, hidden. & Delate \\
\hline a & Place of publication, distribution, etc & $\begin{array}{l}\text { Tab:2: I Koha field: kiblioitems place, } \\
\text { Repeatable, Mandatory. }\end{array}$ & Qeletz \\
\hline b & Name of publisher, distributor, etc & $\begin{array}{l}\text { Tah:2. I Koha field: bibicioitems publishercode, } \\
\text { Repeatable, Mandatory. }\end{array}$ & Delet: \\
\hline ¿ & Date of copyright, publication, distribution. & $\begin{array}{l}\text { Tab:2, I koha field: tiklia copylight date. } \\
\text { Repeatable. Mandatory. }\end{array}$ & Delate \\
\hline$d$ & $\begin{array}{l}\text { Plate or publisher's number for music (PreAACR 2) } \\
{[\text { OOSOLETE, GAN/4/4ARC], [LOCAL, USA] }}\end{array}$ & Tab:2. Not repeatable, Not mandatory, hidden, & Qelete \\
\hline 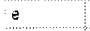 & Place of manufacture & Tab:2, Repeatable, Not mandatory, hidden: & Qulete \\
\hline$f$ & Manufacturer & Tats 2. Repeatable, Net mandatory, hidden. & Delete \\
\hline 9 & Date of manufacture & Tab:2, Not repeat able, Not mandatory, hidden, & Delets \\
\hline k & $\begin{array}{l}\text { Identification/man ffacturer number [OESOLETE. } \\
\text { CAN/MARC] }\end{array}$ & Tab:2, Not repeatable, Not mandatory, kidden: & Delete \\
\hline 1 & Matrix andios take number [QBSOLETE. CANBMARC] & Tab:2. Not repeatable, Not mandatory hidden, & Delets \\
\hline
\end{tabular}

Navigate to the specific subfield you wish to edit by clicking on the appropriate tab at the top.

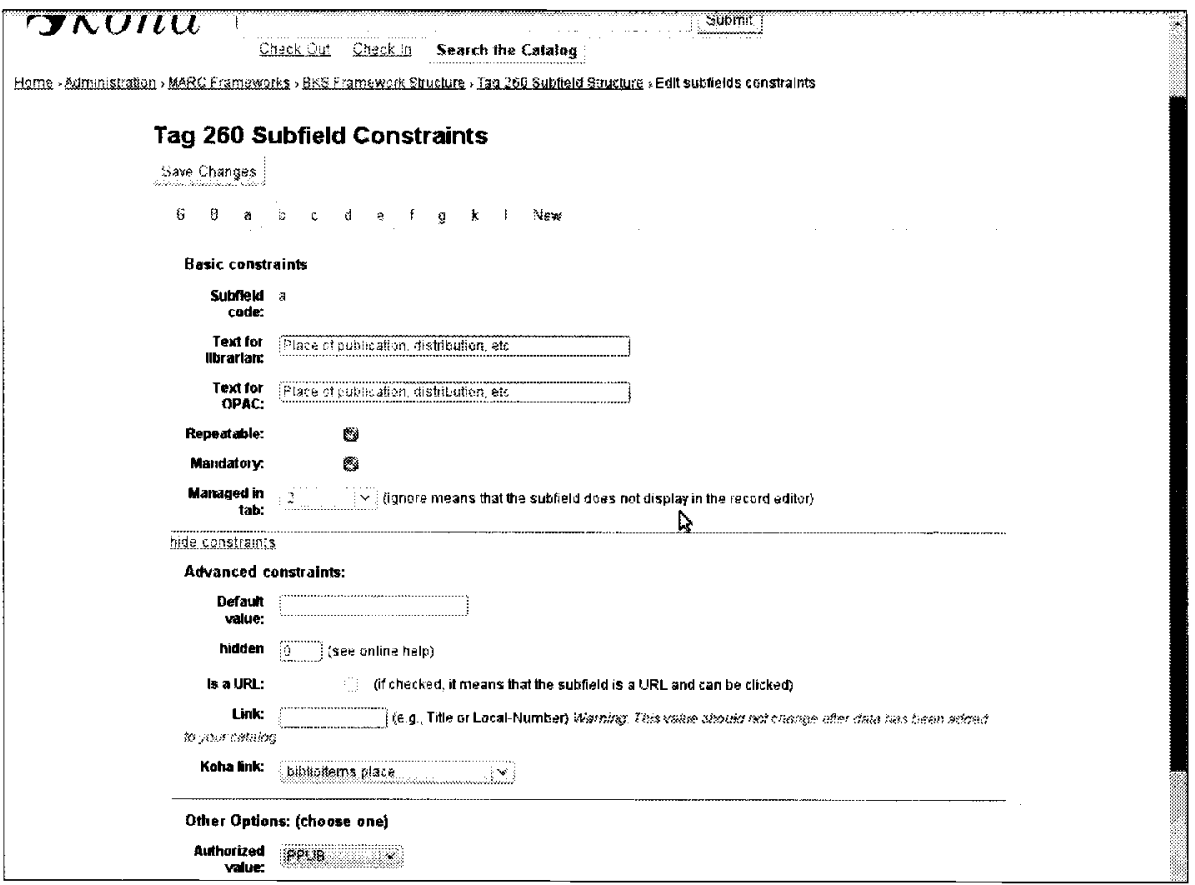




\section{Editing labels of fields or subfields}

To edit how a tag or subfields is labeled in the cataloging screens, edit the field Text for librarians.

\section{Making a field or subfield mandatory}

To make a tag or subfield mandatory simply check the box Mandatory in the Basic Constraints block.

\section{Advanced constraints}

Click on the link Display more constraints below the Basic constraints block to display Advanced constraints.

\section{Hidden fields and subfields}

This field controls if a tag or subfield is displayed in the MARC editor, and if yes, in what form - collapsed or not.

The field can have several values, for the purposes of cataloging; you will need to learn these:

- 0: Displayed, not collapsed

- -1: Displayed, collapsed

- 2: Not displayed

\section{Bringing fields or subfields under Authorized Value or Authority Control}

You can bring the field under Authorized Values control OR under Authority Control. It does not make sense to use both.

To use Authorized Values, select the appropriate Category from the Authorized value list of values.

To use Authority Control, select the appropriate type from the Thesaurus list of values. 


\section{Summary}

In this chapter, we used three tools to make cataloging simpler and to control data entry:

- MARC Frameworks

- Authority Control

- Authorized values

Developing an effective configuration plan in advance is important.

There are cost implications to using Authority Control. You will need to incorporate your process of using Authority Control in the configuration plan.

You will need to develop a MARC framework for each material type that you catalog frequently, for the rest you can use the default framework. Within each framework you will need to configure which fields and subfields are available, and which of those are mandatory. Some of the fields can be brought under Authority Control; others may be controlled using authorized values.

In the next chapter, Configuring the Circulation Module, we will learn how to map the library's circulation policies to rules and preferences in Koha. 
$\therefore$ 


\section{6 \\ Configuring the Circulation Module}

In this chapter, we will learn how to configure Koha's circulation module. This module is used to loan library items to the patrons. Our goal will be to map the library's circulation policies to rules and preferences in Koha.

A library's circulation policies govern loan periods, renewals, membership duration, fines, holds, reference material, and so on.

To map these in Koha, we will study the following Koha features:

- Patron categories

- Item types

- Circulation and fine rules

- Notices and triggers

- Calendar

- Circulation system preferences

\section{Patron categories}

We create a patron category for each group or class of patrons that has distinct characteristics or needs.

Patron categories are a very important part of Koha's circulation module. 
You can find the Patron Category Administration screen in the Patrons and Circulation section in Koha's Administration module.

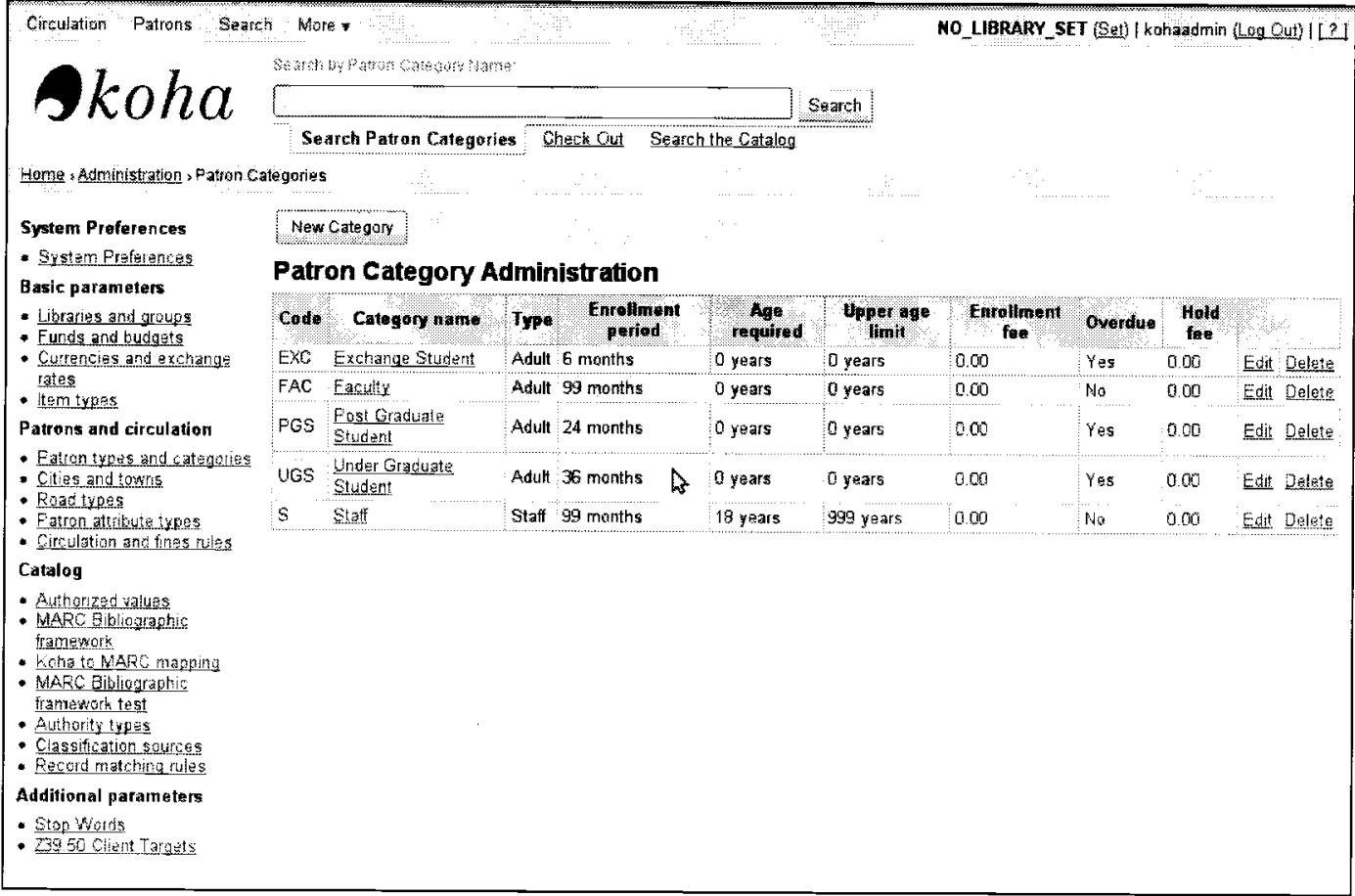

\section{Identifying patron categories}

Unless your library is just starting up, you will already have your list of patron categories. However, you might consider modifying the list to take advantage of some of Koha's capabilities.

The key question here is do you have, or anticipate groups of patrons that have distinct characteristics. We need to assess if these groups are different in one or more of following ways:

- Enrolment duration

- Enrolment fee

- Age restrictions

- Loan periods

- Maximum checkouts allowed

- Fine amounts 
Here are some examples for different types of libraries:

- Public library: In a public library, these categories might be suitable:

$\begin{array}{ll}\text { - } & \text { Adult } \\ \text { - Child } \\ \text { - Student } \\ \text { - Staff } \\ \text { - Institution }\end{array}$

- Academic library: In an academic library, these categories might be suitable:

- Under graduate student

- Post graduate student

- Faculty

- Commercial library: In a commercial library, you might create categories like these:

- Plan A: Rs. 250 a month

- Plan B: Rs. 500 a month

- Plan C: Rs. 1,000 a month

\section{Creating patron categories}

To create a new category we use the New Category button. Use this table as a guide to create or edit patron categories:

\begin{tabular}{|c|c|c|c|}
\hline Field & Mandatory? & Instructions & Comments \\
\hline Category Code & Yes & $\begin{array}{l}\text { Enter short code } \\
\text { for the category, for } \\
\text { example, UGS. }\end{array}$ & \\
\hline Description & Yes & $\begin{array}{l}\text { Enter description of } \\
\text { category, for example, } \\
\text { under graduate } \\
\text { Student. }\end{array}$ & \\
\hline $\begin{array}{l}\text { Enrolment } \\
\text { Period }\end{array}$ & No & $\begin{array}{l}\text { Enter enrolment } \\
\text { period in months. }\end{array}$ & $\begin{array}{l}\text { Field used to autocalculate } \\
\text { membership expiry date. }\end{array}$ \\
\hline Age Required & No & Enter lower age limit. & \\
\hline
\end{tabular}




\begin{tabular}{|c|c|c|c|}
\hline Field & Mandatory? & Instructions & Comments \\
\hline $\begin{array}{l}\text { Upper Age } \\
\text { Limit }\end{array}$ & No & Enter upper age limit. & \\
\hline Enrolment Fee & No & Enter fee amount. & $\begin{array}{l}\text { This fee will be charged when } \\
\text { first enrolled. }\end{array}$ \\
\hline $\begin{array}{l}\text { Overdue } \\
\text { Notice } \\
\text { Required }\end{array}$ & No & $\begin{array}{l}\text { Select or deselect the } \\
\text { checkbox. }\end{array}$ & $\begin{array}{l}\text { Controls if due and overdue } \\
\text { notices will be sent to patrons } \\
\text { of this category. }\end{array}$ \\
\hline Hold Fee & No & Enter Fee Amount. & $\begin{array}{l}\text { This fee will be charged every } \\
\text { time a patron of this category } \\
\text { places a hold on an item. }\end{array}$ \\
\hline \multirow[t]{2}{*}{ Category Type } & Yes & $\begin{array}{l}\text { Choose from list of } \\
\text { values. }\end{array}$ & $\begin{array}{l}\text { Child: requires an adult } \\
\text { guarantor. }\end{array}$ \\
\hline & & & $\begin{array}{l}\text { Staff: have additional } \\
\text { privileges, only for library } \\
\text { staff. }\end{array}$ \\
\hline
\end{tabular}

\section{Item types}

Item types are groups of items of material in the library that are circulated in different ways.

Item types are also a very important part of Koha's circulation module.

You can find the types screen in the Patrons and Circulation section in Koha's Administration module. 


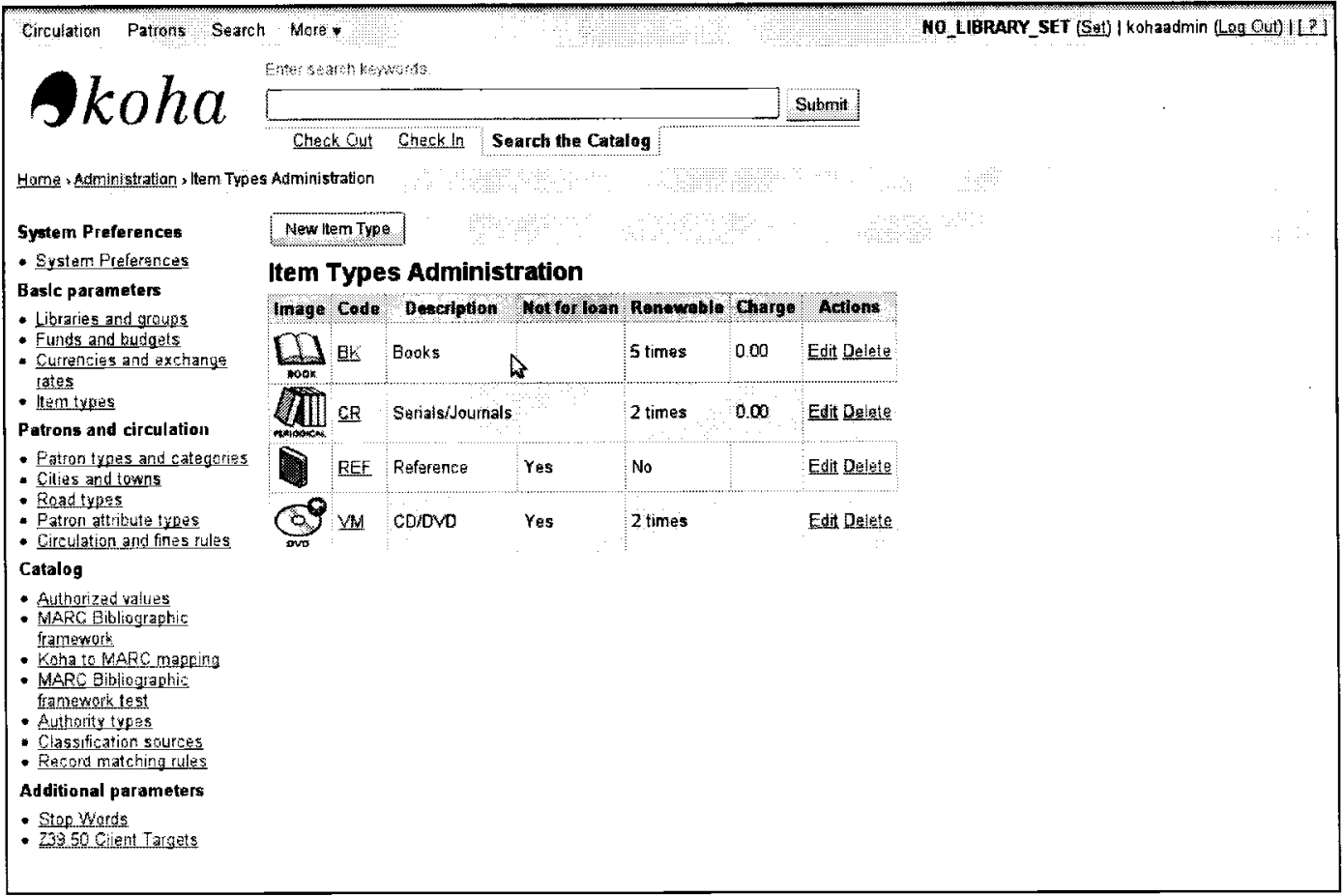

\section{Identifying Item types}

Unless your library is just starting up, you will already have your list of Item types. Just like with patron categories you might consider modifying the item type list to take advantage of some of Koha's capabilities.

We will need to consider what types of material in the library have have distinct characteristics. We need to assess if types of material are different in one or more of following ways:

- Renewal policies

- Not for loan policies

- Loan period

- Maximum checkouts

- Fine amount

- Rental charge 
Here's a good example of Koha's default Item type list:

- Books

- Reference

- Journals

- Reports

- CD/DVDS

\section{Creating Item types}

To create a new item type we use the New Item Type button. Use this table as a guide to create or edit an item type:

\begin{tabular}{|c|c|c|c|}
\hline Field & Mandatory? & Instructions & Comments \\
\hline Item Type & Yes & $\begin{array}{l}\text { Enter short code for the } \\
\text { category, for example, } \\
\text { BK }\end{array}$ & \\
\hline Description & Yes & $\begin{array}{l}\text { Enter description of } \\
\text { item type, for example, } \\
\text { Books }\end{array}$ & \\
\hline Images & No & $\begin{array}{l}\text { Choose image from } \\
\text { available list or provide } \\
\text { a URL to a image on an } \\
\text { external server }\end{array}$ & \\
\hline Not for Loan & No & $\begin{array}{l}\text { Select or deselect the } \\
\text { checkbox }\end{array}$ & $\begin{array}{l}\text { If this option is checked, } \\
\text { items of this type cannot be } \\
\text { checked out. }\end{array}$ \\
\hline Renewals & No & Enter number & $\begin{array}{l}\text { Number will indicate } \\
\text { maximum number of } \\
\text { renewals possible on items } \\
\text { of this type. Leave blank } \\
\text { or enter } 0 \text { to indicate no } \\
\text { renewals allowed. }\end{array}$ \\
\hline Rental Charge & No & $\begin{array}{l}\text { Enter rental charge } \\
\text { amount }\end{array}$ & $\begin{array}{l}\text { Amount will be charged each } \\
\text { time an item of this type is } \\
\text { checked out. }\end{array}$ \\
\hline Summary & No & Enter free text & \\
\hline
\end{tabular}




\section{Circulation and fine rules}

In Koha, for a combination of library or branch, patron category and item type, you can specify:

- Loan period

- Fine amount

- Maximum checkouts

In addition, for a combination of library or branch and patron category, you can also specify:

- Maximum checkouts

The second type of rule is used to constrain the total number of checkouts across all item types.

You can find the Circulation and Fine Rules screens in the Patrons and Circulation section under Koha's Administration module.

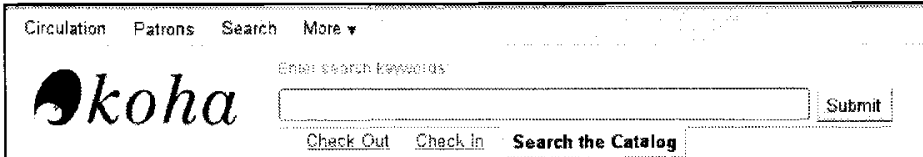

Home, Adrimistration, is suing Rules

System Preferences

- Sxstem Praferences

Basie parameters

- Lbranes ant groups

- Funds and budigats

- Currencies ana

- Lem tyoes

Patroris and circulation

- Patron tyoes and

Gatayolies

- Citirs and towns

- Road types

- Fatrun attribute syoes

- Crculation and fines

sules

Catalog

- Authorizad yalues

- MARC Biblingrablic

tramewolk

- kota to MARC mapping

- MARC Bikilographic

rameyouk test

- Authority troes

- Classification saurea

- Fecord matching rules

Additional parameters

- Stag Words

- 39.50 client Targets

\section{Defining default issuing rules}

The rules are applied from most specific to less specific, using the first found in this order:

- same library, same patron type, same item Iype

- same library. same patron type default item type

- same likrary, default patron type, same item type

- same library, default patron type, defaut item type

- default library. same patron typo, same itern type

- defautu litrary, same patron type, delaut item type

- default library, default patrun type, same item type

- default likrary, default patron type. default item type

To modify a rule, create a new one with the sane pation type and item type.

Select a fibrary: Defaut

\begin{tabular}{|c|c|c|c|c|c|c|c|c|}
\hline Patron Catogory & Ham Type & $\begin{array}{l}\text { Fine } \\
\text { Amount }\end{array}$ & $\begin{array}{l}\text { Fine } \\
\text { Doys }\end{array}$ & $\begin{array}{l}\text { Fine } \\
\text { frase } \\
\text { polod }\end{array}$ & $\begin{array}{c}\text { Fine } \\
\text { Charging } \\
\text { Interval }\end{array}$ & $\begin{array}{l}\text { Curront } \\
\text { Chectouss } \\
\text { Allowed }\end{array}$ & $\begin{array}{l}\text { Loan } \\
\text { Period }\end{array}$ & \\
\hline Defaut & Eooks & $\$ 5.00$ & & & 1 day(s) & 5 & 14 day (s) & alpte \\
\hline Defauls & CDRDVD & 5.00 & & & I day(s) & 2 & 7 day $(s)$ & Belale \\
\hline Eetadik & Serials/J dournals & $\$ 5.00$ & & & 1 day(s) & 1 & 2 day $(s)$ & Dellete \\
\hline Default & Detauk & 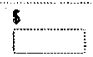 & & & $d x y(s)$ & & $\operatorname{day}(s)$ & Ascid \\
\hline
\end{tabular}

For this library. you can specify the maximum number of loans that patron of a given category can make, regardless of the iteny type. If the tatal amount loanable for a given patron category is left biank, na limit applies, except possibly for a limit you define for a specific item type.

\begin{tabular}{|c|c|c|}
\hline Patran Categary & Total Current Chackout Alowod & \\
\hline Faculty & 8 & Dofleste \\
\hline Defaut & 5 & Delote \\
\hline Defantit & 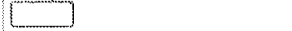 & Add \\
\hline
\end{tabular}




\section{Identifying circulation and fine rules}

Unless your library is just starting up, you will already have your list of circulation and fine rules. However, you might consider modifying the list to take advantage of some of Koha's capabilities.

Based on your current circulation and fine policies, record data in a table in the following fashion:

\begin{tabular}{llllll}
\hline $\begin{array}{l}\text { Library or } \\
\text { branch }\end{array}$ & $\begin{array}{l}\text { Patron } \\
\text { category }\end{array}$ & Item Type & Loan Period & Fine Amount & $\begin{array}{l}\text { Current } \\
\text { Checkout } \\
\text { Allowed }\end{array}$ \\
\hline Library A & Student & Books & 21 & 5 & 5 \\
Library B & Student & Books & 21 & 5 & 5 \\
Library C & Student & Books & 14 & 10 & 3 \\
Library A & Student & CDs & 21 & 5 & 5 \\
Library B & Student & CDs & 21 & 5 & 5 \\
Library C & Student & CDs & 14 & 10 & 3 \\
\hline
\end{tabular}

And this table as well:

\begin{tabular}{lll}
\hline Library or Branch & Patron Category & $\begin{array}{l}\text { Total Current Checkouts } \\
\text { Allowed }\end{array}$ \\
\hline Library A & Student & 5 \\
Library B & Student & 5 \\
Library C & Student & 5 \\
\hline
\end{tabular}

\section{Creating circulation and fine rules}

If you take all combinations of library or branch, patron category and item type the number of rules to configure and maintain would be very large.

Thankfully, Koha allows us to use the value "Default" to denote all values. This way you need to configure a small number of default rules and another small number of rules for exceptions.

This is best explained using the example in the previous section. The example we just saw can be translated to following rules for Koha: 


\begin{tabular}{llllll}
\hline $\begin{array}{l}\text { Library or } \\
\text { branch }\end{array}$ & $\begin{array}{l}\text { Patron } \\
\text { category }\end{array}$ & Item Type & Loan Period & Fine Amount & $\begin{array}{l}\text { Current } \\
\text { Checkout } \\
\text { Allowed }\end{array}$ \\
\hline Default & Student & Default & 21 & 5 & 5 \\
Library C & Student & Default & $\mathbf{1 4}$ & 10 & 3 \\
\hline
\end{tabular}

The first rule above can apply to Library $\mathrm{C}$ as well; however Koha will use the second rule for Library $\mathrm{C}$, as it is more specific.

Similarly the total current checkout table can be configured as follows:

\begin{tabular}{lll}
\hline Library or branch & Patron category & $\begin{array}{l}\text { Total Current Checkouts } \\
\text { Allowed }\end{array}$ \\
\hline Default & Default & 5 \\
\hline
\end{tabular}

\section{Configuring the calendar and calculation of due date and fines}

In this section we will learn about Koha's calendar module and how to configure fines and due date calculations.

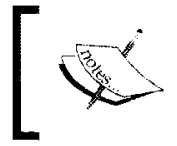

\section{Koha holidays}

It is important to note that in Koha, a holiday is any day when the library is closed.

\section{Calendar and fine calculation}

You can choose to have Koha ignore the Calendar. If the calendar is ignored fines are calculated every day, even if the day is a holiday.

\section{Calculation of due dates in Koha}

Koha offers three options for due date calculations:

- You can choose to have Koha ignore the calendar; the due date will be calculated as check out date plus loan period, even if this date is a holiday.

- You can have Koha exclude holidays from the loan period. So in this case the due date will be calculated as check out date plus loan period plus number of holiday during loan period. 
- If you have Koha include holidays in the loan period, the due date will be calculated as checkout date plus loan period, if this date falls on a holiday, Koha will move the due date forward to the next working day.

\section{Preparing to configure the calendar and fines and due date calculations}

Before we can start the configuration, you will need to gather this information:

- Holiday list for the year

- Whether Saturdays are holidays

- Whether Sundays are holidays

- Your library's policy on fines calculation with regards to holidays

- Your library's policy on due date calculation with regards to holidays

\section{Editing the calendar}

The calendar module is available in the Tools section.

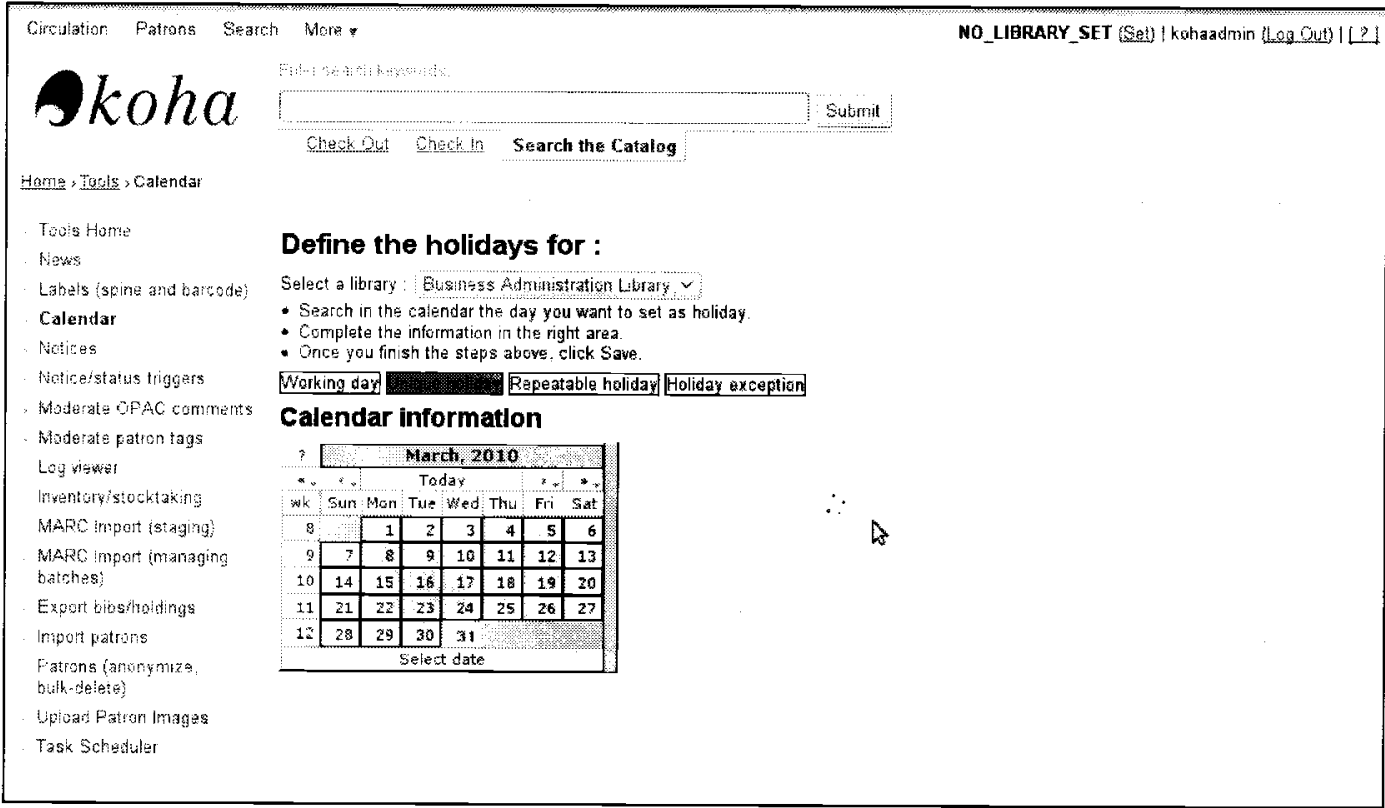


To configure the calendar, we follow these steps:

1. If Sundays are holidays, click on the nearest Sunday in the calendar and choose option Holiday repeated every same day of the week.

2. If Saturdays are holidays, click on the nearest Saturday in the calendar and choose options Holiday repeated every same day of the week.

3. For holidays that repeat every year on the same date (for example, Christmas), click on the date and choose option Holiday repeated yearly on the same date.

4. For other holidays, click on the date and choose the option Holiday only on this day.

\section{Editing system preferences}

There are three System Preferences you will need to set:

- finesmode

- Set this to production; without this Koha will not accrue fines.

- finesCalendar

- Choose noFinesWhenClosed if you don't want fines to accrue on holidays.

- Choose ignoreCalendar if you want fines to accrue on holidays.

- useDaysMode

- Choose Calendar if you want due date to be check out date plus loan period plus number of holidays during loan period.

- Choose Days if you want due date to be checkout date plus loan period. Holidays are ignored.

- Choose Datedue if you want due date to be check out date plus loan period. Due date is moved forward only if it falls on a holiday. 


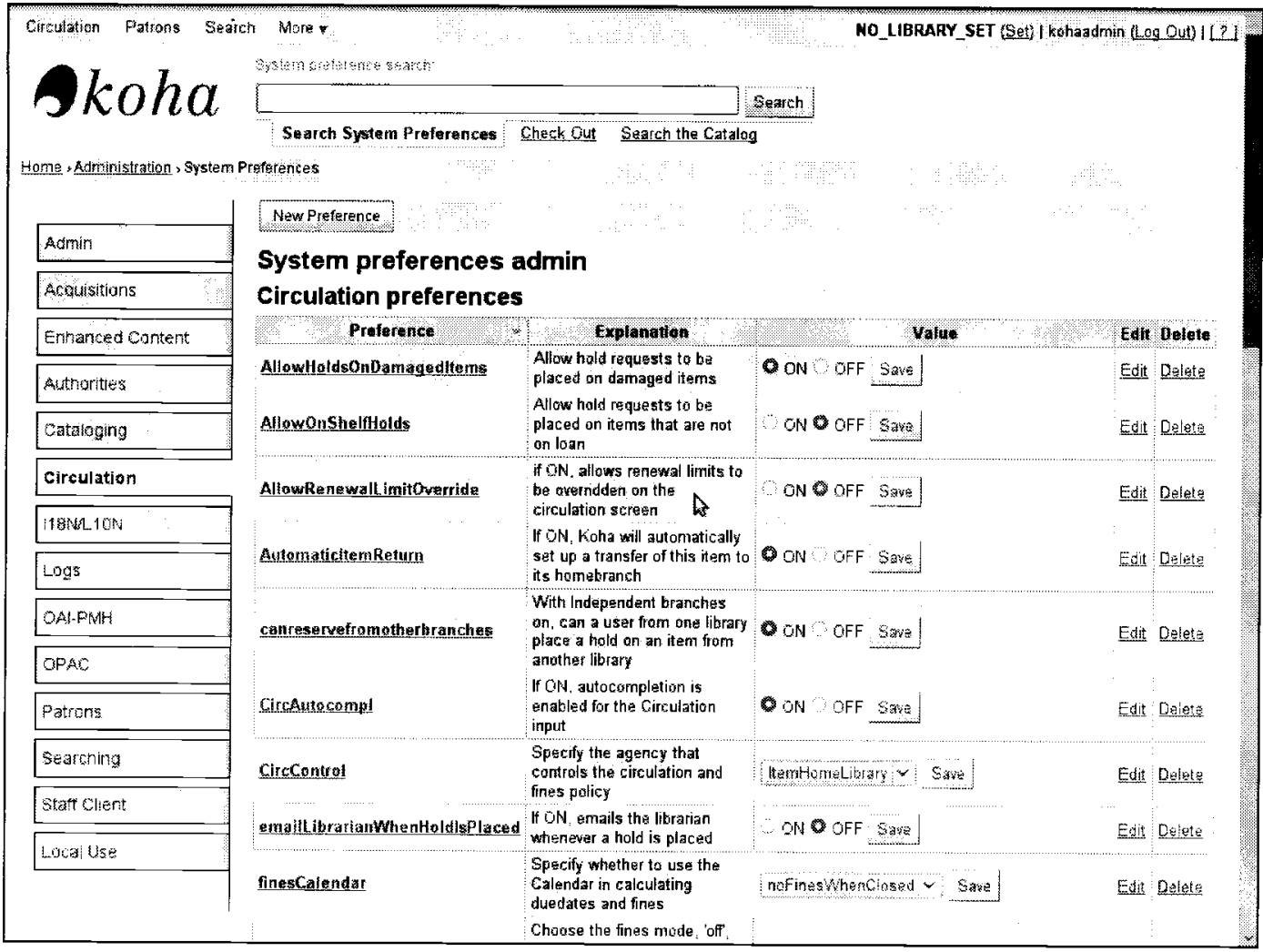

\section{Due and overdue notices}

Koha can automatically generate and e-mail due and overdue notices.

We will need to define:

- Templates: Text to be included in the notices, along with fields that will be populated dynamically

- Triggers: Definitions of when each type of notice should be sent for each patron category 


\section{Preparing to configure due and overdue notices}

To configure due and overdue notices, we will need to prepare a plan. We will need to identify which patron categories will receive notices, how many notices will be sent and when, and what the content will be in each notice. Our plan may look like this:

\begin{tabular}{lllllll}
\hline $\begin{array}{l}\text { Patron } \\
\text { category }\end{array}$ & \multicolumn{2}{l}{ First notice } & \multicolumn{2}{l}{ Second notice } & \multicolumn{2}{l}{ Third notice } \\
\hline \multicolumn{1}{c}{ Delay } & Template & Delay & Template & Delay & Template \\
$\begin{array}{l}\text { Exchange } \\
\text { Student }\end{array}$ & 1 & $\begin{array}{l}\text { Item Due } \\
\text { Reminder }\end{array}$ & 3 & $\begin{array}{l}\text { Overdue } \\
\text { Notice } 1\end{array}$ & 5 & Overdue \\
Under & 1 & Item Due & 3 & Overdue & 5 & Notice 2 \\
$\begin{array}{l}\text { Graduate } \\
\text { Student }\end{array}$ & & Reminder & & Notice 1 & & Overdue \\
$\begin{array}{l}\text { Post } \\
\text { Graduate } \\
\text { Student }\end{array}$ & 1 & Item Due & 3 & Overdue & 5 & Overdue \\
\hline
\end{tabular}

For each template in the plan, we will need to prepare the text:

- Item due reminder

- Item overdue notice 1

- Item overdue notice 2 


\section{Editing notices}

The Notices screen can be found in the Tools section. The following screenshot shows the notices templates:

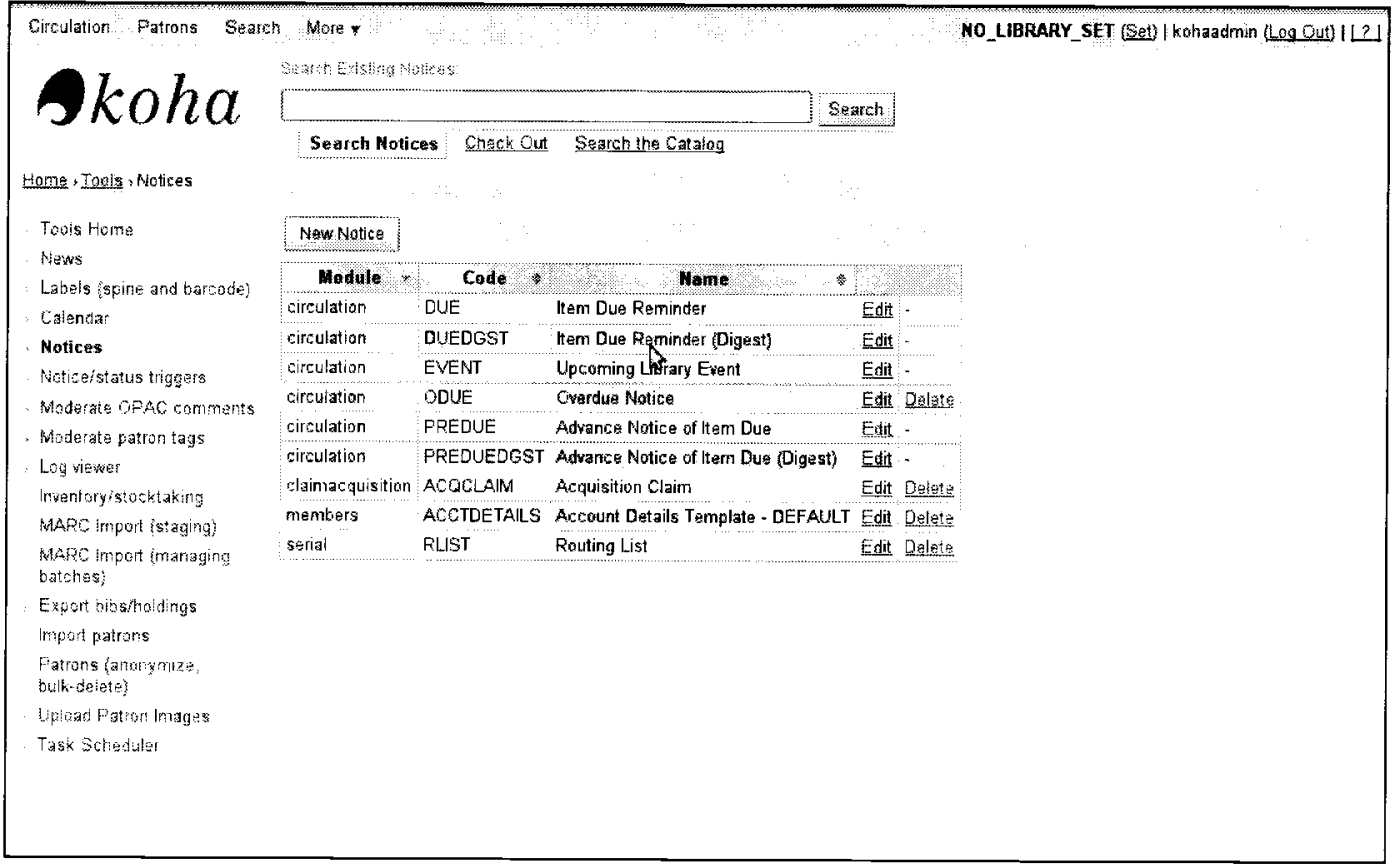

To create a new notice or template we use the button New Notice, and to edit an existing notice we use the Edit link.

We write the text of the notice in the Message Body. Some content, such as a borrower's name, will be dynamically populated by Koha when the notices are e-mailed to patrons. You can select the fields that you want from the box on the left. Use the >> button to move the selected fields into the message body. 


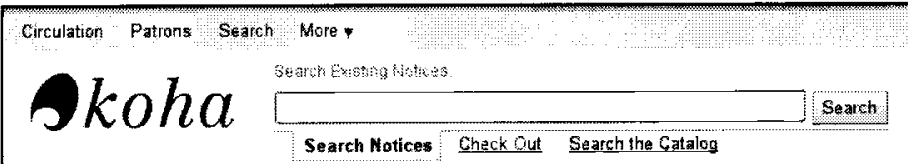

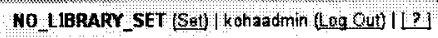

Hame , Toos , Natices * Matily notice

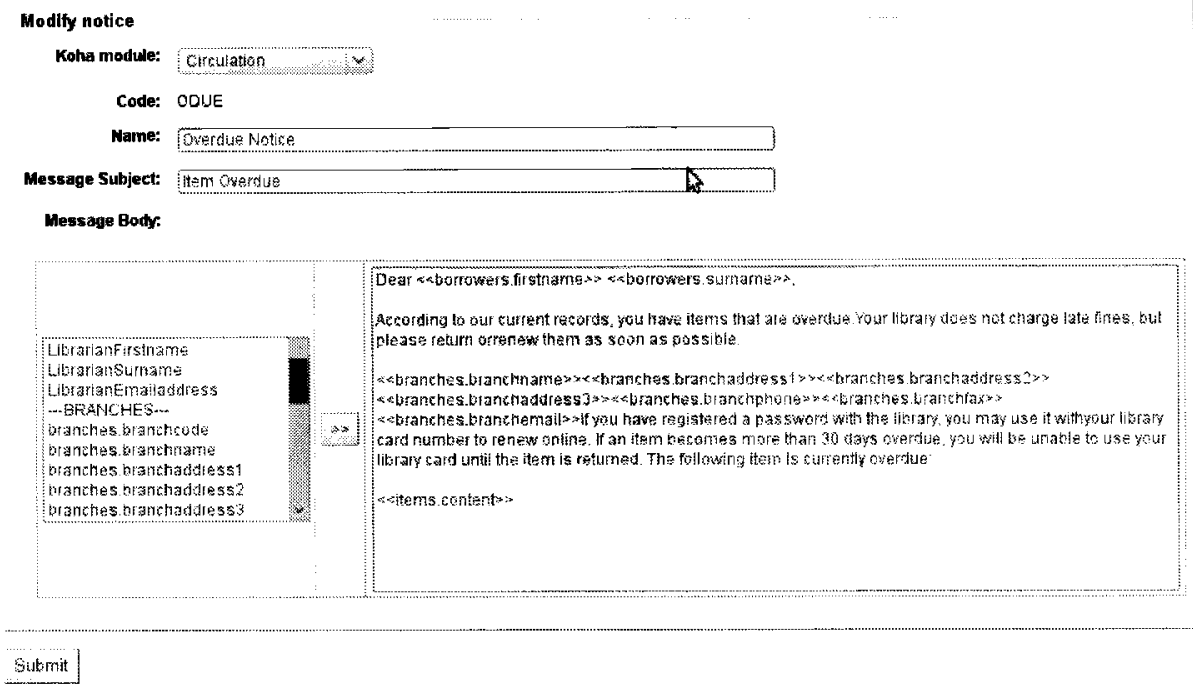

Once notice templates are created, we can configure notice triggers. 


\section{Editing notice triggers}

Notice triggers screens can be found in the Tools section. Here we configure, for each patron category when each notice should be e-mailed.

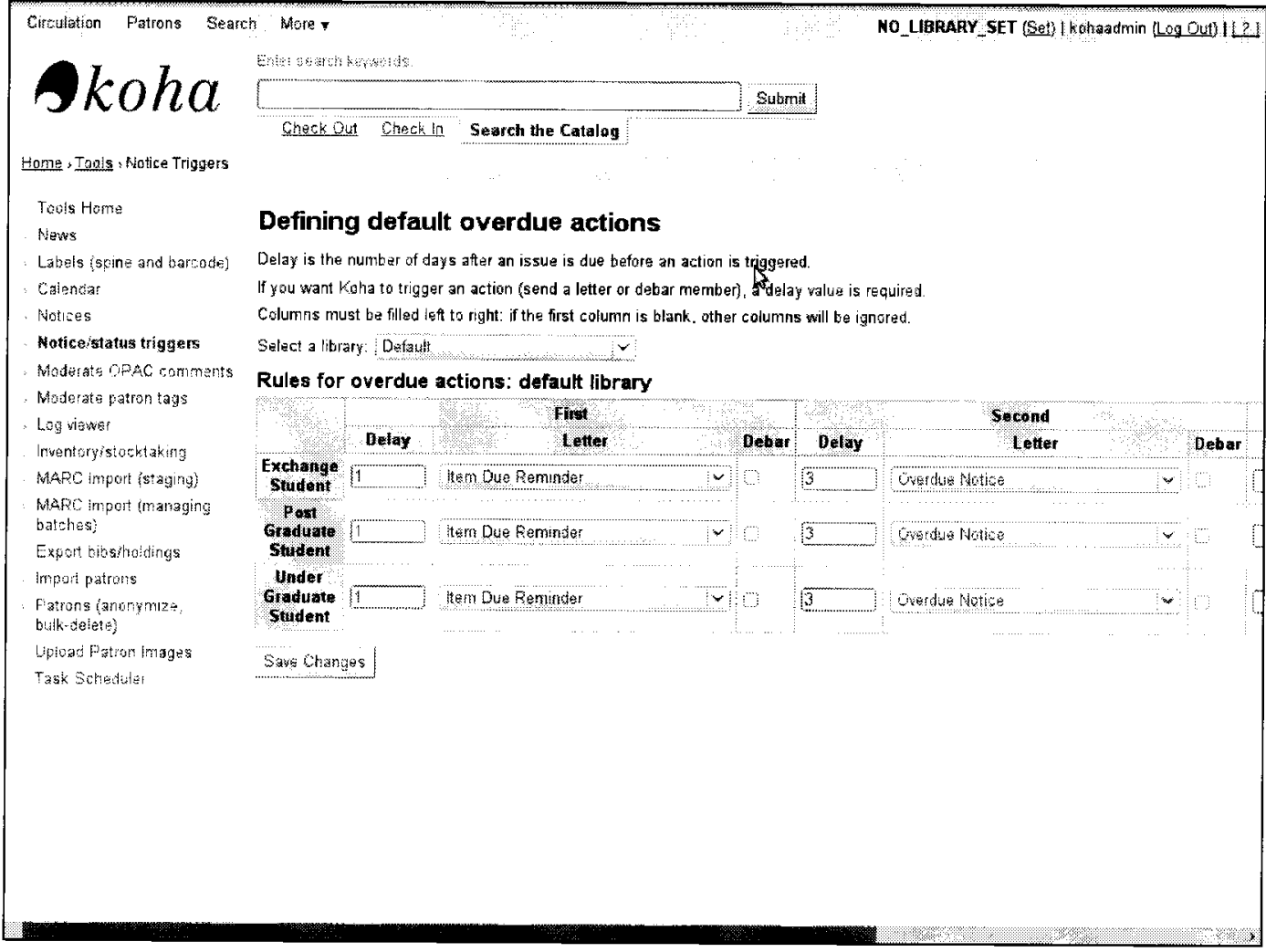

For each patron category define the delay and the template to be used in the first, second, and third letter boxes.

Some points to note:

- If you don't see a patron category listed in the screen, you will need to edit that patron category from the Administration section, and select the checkbox Overdue Notice Required.

- You do not need to have all three letters configured.

- If you don't configure any letters, notices will be not be sent out for that patron category.

- If you do need notices to be sent out, make sure you have the first letter configured properly. 


\section{Configuring holds}

Replace this with "Finally, let us turn our attention to holds. Using Koha's holds feature, patron can request that certain items be reserved for them. Holds are usually placed on items that checked out. Once an item is placed on hold for a patron, the patron needs to pick up the item from the library within a specified number of days failing which the hold is cancelled and the item is made available for circulation.

We configure holds in Koha using system preferences."

\section{Preparing to configure holds}

Based on your library reserves or holds policy, you should prepare a plan such as this:

\begin{tabular}{|c|c|}
\hline Reserves policy & Value \\
\hline Maximum number of holds per patron & 5 \\
\hline Maximum delay in picking up an item on hold & 7 \\
\hline Whether to allow holds on items not on loan & No \\
\hline Number of days before a hold is cancelled & 7 \\
\hline $\begin{array}{l}\text { Maximum fee or fine amount outstanding before } \\
\text { ability to place holds is blocked }\end{array}$ & 50 \\
\hline $\begin{array}{l}\text { Whether to allow patron of one library to request a } \\
\text { hold on an item in another library }\end{array}$ & No \\
\hline
\end{tabular}

\section{Editing holds preferences}

Most of the holds related System preferences are in the Circulation tab. You can also search for these using words hold or reserve. 


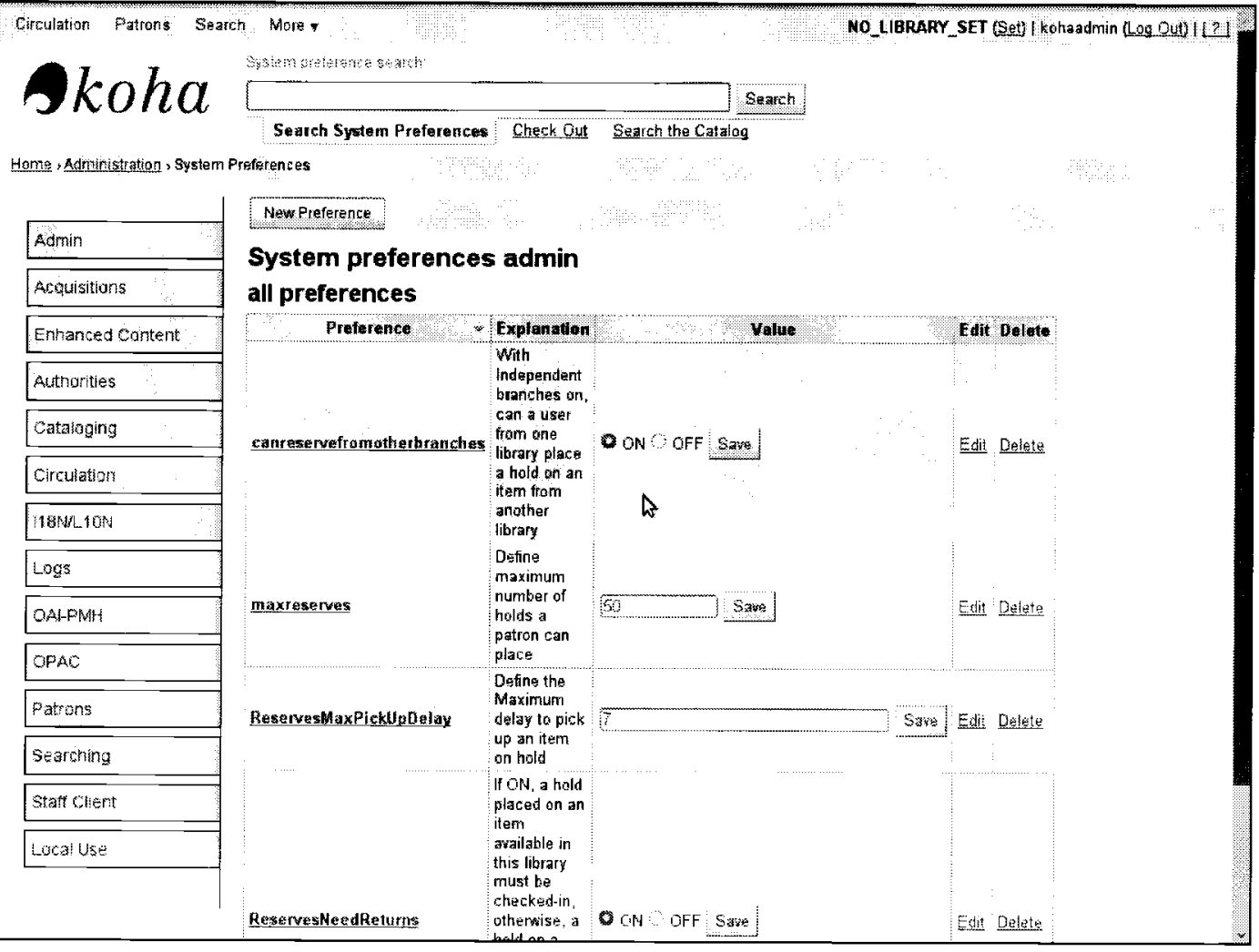

Here is a complete list of preferences:

- AllowHoldsOnDamagedItems

- AllowOnShelfHolds

- canreservefromotherbranches

- emailLibrarianWhenHoldIsPlaced

- holdCancelLength

- maxoutstanding

- maxreserves

- RandomizeHoldsQueueWeight

- ReservesMaxPickUpDelay

- ReservesNeedReturns

- StaticHoldsQueueWeight 


\section{Summary}

Circulation is arguably the most important function in a library. In this chapter, we learned:

- How to map a library's policies to Koha's rules and system preferences.

- Patron categories control enrolment duration, age restrictions, and circulation and fine policies for different groups of patrons.

- Item types control renewals, not for loan, and circulation and fine policies for different types of material in the library.

- Koha's circulation and fines rules configuration module is used to set loan period, maximum checkout, and fine rules for combinations of patron categories, item types, and libraries or branches.

- You will help yourself by learning how to keep the number of rules to a small number using "Default" values.

- Holds are controlled mainly via system preferences. The preferences control among other things maximum reserves per patron, maximum duration before a reserve is cancelled, and the maximum delay in picking up an item on hold.

In the next chapter, our last on application configuration, we learn how to configure system preferences related to acquisitions, serials, the OPAC, and the staff client. 
$\therefore$ 


\section{7 \\ Configuring Other System Preferences}

In this chapter, our goal will be to complete the application configuration and be in a position to use Koha in a test or production environment. We will learn to configure system preferences related to:

- The rest of the transactional modules - patrons, acquisitions, and serials

- The Online Public Access Catalog (OPAC)

- Styling and appearance of the OPAC and the staff client

- Messaging, security, and search

Koha has dozens of system preferences, some more important than others. We will focus on the important ones in this chapter. Readers should refer to Koha's online user manual for latest information on other preferences.

\section{Understanding Koha's system preferences}

System preferences are essentially choices that each Koha library makes about how the Koha should function. In this first section of the chapter, let us learn about Koha's system preferences module, the nature, and organization of the preferences. We share tips on using these preferences and finding information on these online. 


\section{Koha's global system preferences module}

The Global system preferences module can be found under Koha Administration.

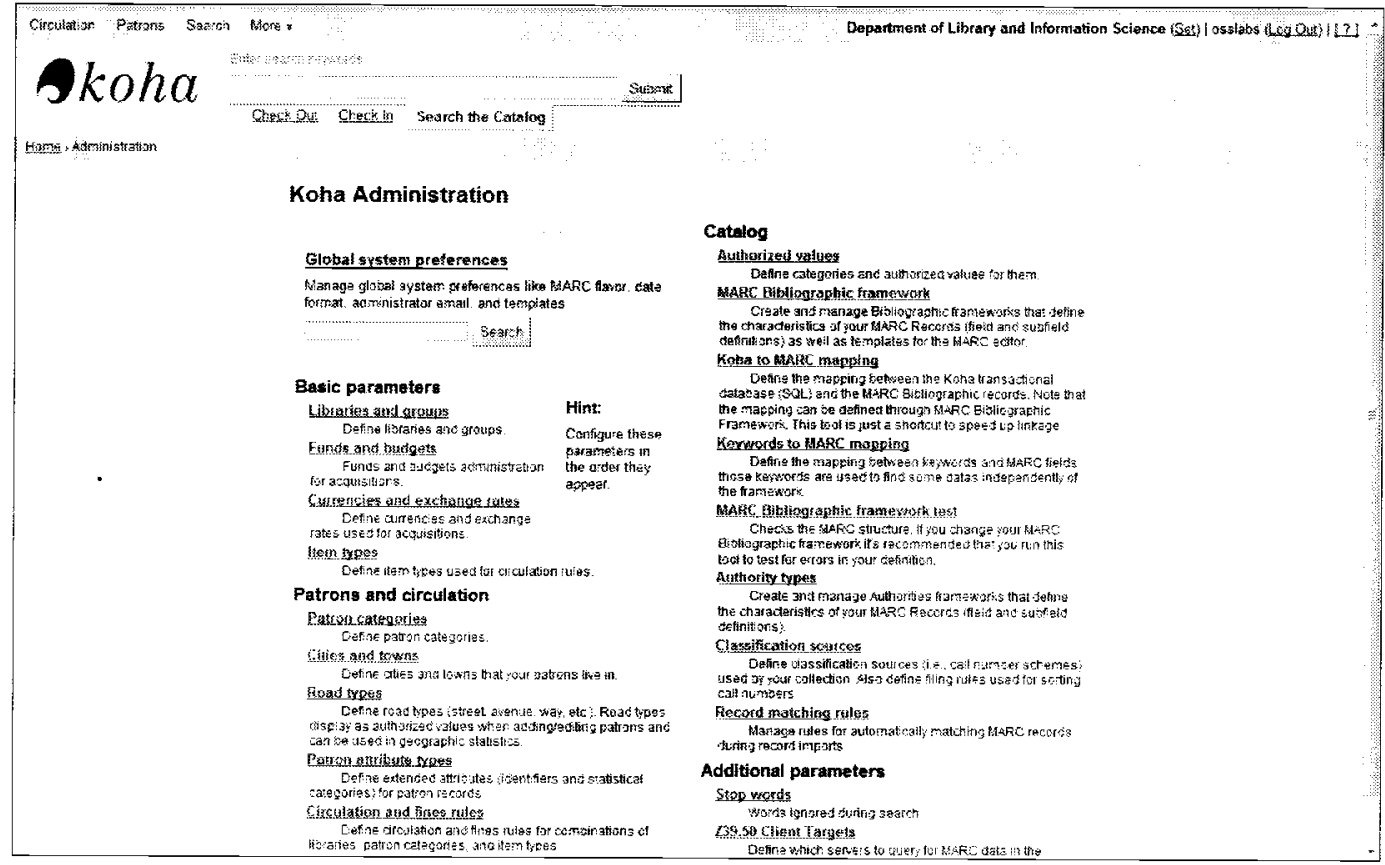

Here are the key points to note about this module:

- There are several dozen preferences, and these are organized by categories.

- These preference control system behavior such as whether budgets will be used in Acquisitions, or whether the patron card number will be auto-calculated.

- A handy search tool is available to find specific preferences.

- Preferences are of many types, from simple on/off switches to more complex list of values.

- Many preferences have default values set. You can change the values at any time.

- Some system preferences are set based upon choices you made during Koha's installation. 


\section{Using system preferences}

Here are some key points to note about using these preferences:

- These preferences apply to the whole system; it is not possible to have different choices for different libraries, patron categories, or other types of divisions with your library.

- Access to system preferences should be controlled. Changes to these preferences can significantly alter system behavior.

- You will probably want to set a few preferences when you start using the system, especially those related to cataloging, patrons, or circulation.

- System preferences can be changed at any time, as you become familiar with the system over time you can set other preferences to tailor Koha to your needs.

\section{Online documentation}

We will not be able to cover all the preferences in this chapter or other places in this book. Besides, system preferences change, new ones are added all the time, some preferences are deprecated or their categorization or values may change. Refer to Koha's online user manual for the latest information.

The Koha 3.0 user manual is here:

http://koha.org/documentation/manual/3.0/administration/globalsystem-preferences/.

And the Koha 3.2 manual is here:

http://koha-community.org/documentation/3-2-manual/.

\section{Configuring transactional modules}

In earlier chapters we have learned how to configure cataloging and circulation. In this section we learn about system preferences that control the functioning of some of the other transactional modules - patrons, acquisitions, and serials modules:

- Patrons preferences control how patrons' records are created

- Acquisitions preferences relate to budgeting and taxes

- Serials preferences relate to routing lists, subscriptions renewals, and display of subscription history 


\section{Configuring patrons preferences}

Let us start by learning about patrons-related system preferences. These preferences can be found under the Patrons tab.

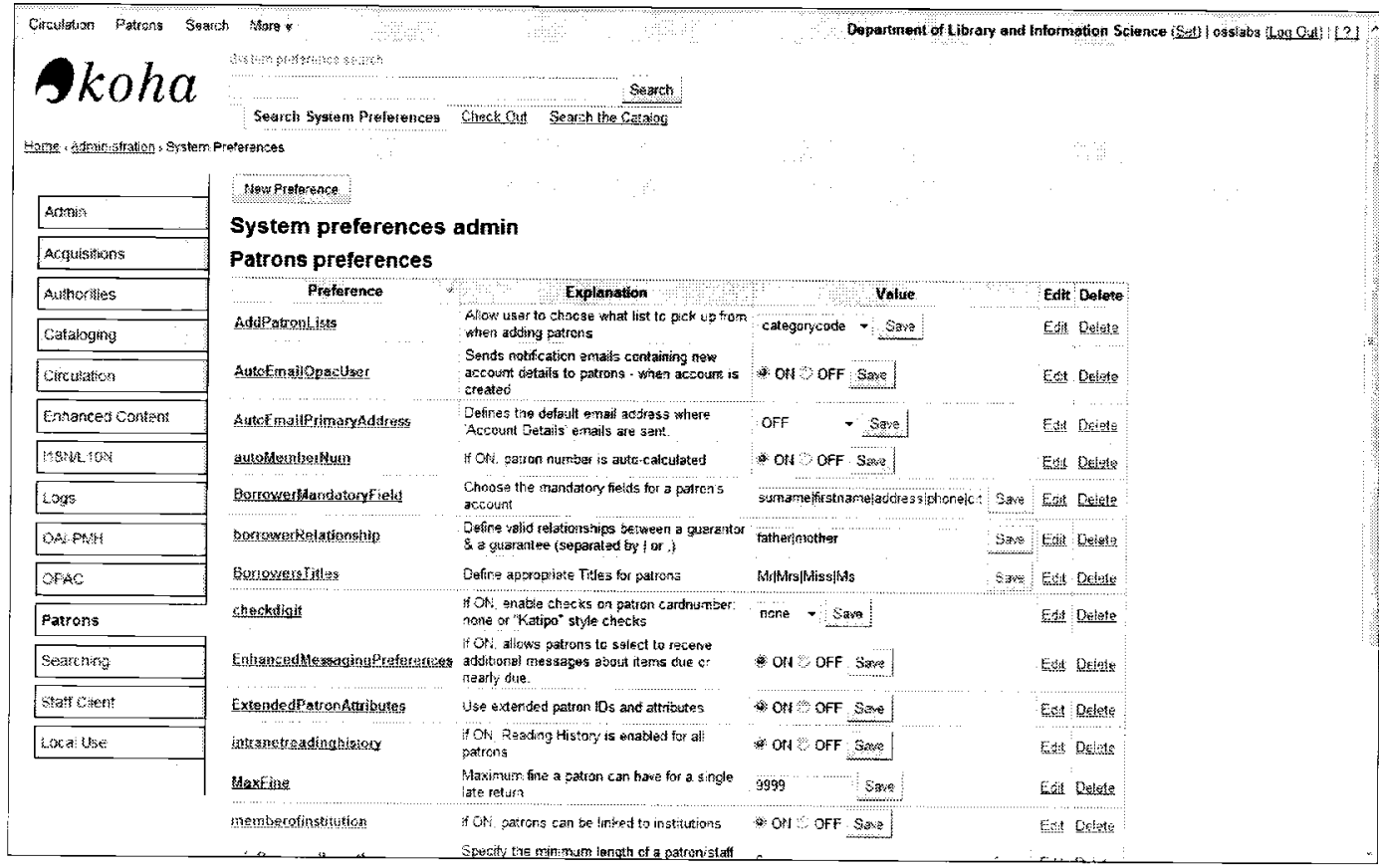

The Patrons module is as important as Cataloging or Circulation because a library cannot function without patron records.

Some of the functions of the module are to:

- Categorize patrons

- Capture useful information about them

- Generate unique identifiers for each patron to use in circulation

We have already learnt about creating patron categories in earlier chapters.

The following preferences help manage patron records: 


\begin{tabular}{|c|c|c|c|c|}
\hline System preference & $\begin{array}{l}\text { System } \\
\text { preferences } \\
\text { tab }\end{array}$ & Description & $\begin{array}{l}\text { Default } \\
\text { values }\end{array}$ & Instructions \\
\hline \multirow[t]{2}{*}{ BorrowerMandatoryField } & Patrons & $\begin{array}{l}\text { Mandatory } \\
\text { fields when } \\
\text { creating a } \\
\text { patron record }\end{array}$ & $\begin{array}{l}\text { zipcode | } \\
\text { surname | } \\
\text { cardnumber }\end{array}$ & $\begin{array}{l}\text { It is important to } \\
\text { pay attention to } \\
\text { this preference. } \\
\text { Ensure that } \\
\text { fields that you } \\
\text { will need, e-mail } \\
\text { address for } \\
\text { instance, are } \\
\text { made mandatory. } \\
\text { This way you } \\
\text { will not have to } \\
\text { correct patron } \\
\text { records at a later } \\
\text { date. }\end{array}$ \\
\hline & & & & $\begin{array}{l}\text { Add fields } \\
\text { separated by } \\
\text { "|". Fields are } \\
\text { column names } \\
\text { in database table } \\
\text { "borrowers". } \\
\text { To look up the } \\
\text { names log on } \\
\text { to mysql and } \\
\text { describe the } \\
\text { borrowers table. } \\
\text { mysql> desc } \\
\text { borrowers; }\end{array}$ \\
\hline ExtendedPatronAttributes & Patrons & $\begin{array}{l}\text { Create new } \\
\text { attribute } \\
\text { fields for } \\
\text { patrons }\end{array}$ & Off & $\begin{array}{l}\text { Set up patron } \\
\text { attributed in } \\
\text { section Patron } \\
\text { Attribute Types: } \\
\text { under block } \\
\text { Patrons and } \\
\text { Circulation } \\
\text { under Koha } \\
\text { Administration. }\end{array}$ \\
\hline
\end{tabular}




\begin{tabular}{|c|c|c|c|c|}
\hline System preference & $\begin{array}{l}\text { System } \\
\text { preferences } \\
\text { tab }\end{array}$ & Description & $\begin{array}{l}\text { Default } \\
\text { values }\end{array}$ & Instructions \\
\hline autoMemberNum & Patrons & $\begin{array}{l}\text { Whether to } \\
\text { auto calculate } \\
\text { the patron } \\
\text { number }\end{array}$ & On & $\begin{array}{l}\text { Koha generates a } \\
\text { running sequence } \\
\text { of numbers. } \\
\text { If you wish to } \\
\text { generate card } \\
\text { numbers outside } \\
\text { of Koha turn } \\
\text { this preference } \\
\text { Off. If you don't } \\
\text { turn this off, in } \\
\text { some cases you } \\
\text { may forget to } \\
\text { populate the } \\
\text { external number, } \\
\text { and Koha will } \\
\text { record the default } \\
\text { auto generated } \\
\text { number for this } \\
\text { patron. }\end{array}$ \\
\hline borrowerRelationship & Patrons & $\begin{array}{l}\text { Relationships } \\
\text { between } \\
\text { guarantee } \\
\text { and } \\
\text { guarantor, } \\
\text { used for } \\
\text { Child patron } \\
\text { type. }\end{array}$ & $\begin{array}{l}\text { father I } \\
\text { mother }\end{array}$ & $\begin{array}{l}\text { Enter names } \\
\text { separated by } \\
\text { "I". This set of } \\
\text { values becomes } \\
\text { available for } \\
\text { selection in the } \\
\text { Guarantor field } \\
\text { when creating a } \\
\text { patron record of } \\
\text { type Child. }\end{array}$ \\
\hline
\end{tabular}




\begin{tabular}{|c|c|c|c|c|}
\hline System preference & $\begin{array}{l}\text { System } \\
\text { preferences } \\
\text { tab }\end{array}$ & Description & $\begin{array}{l}\text { Default } \\
\text { values }\end{array}$ & Instructions \\
\hline \multirow[t]{3}{*}{ memberofinstitution } & Patrons & $\begin{array}{l}\text { Whether } \\
\text { patrons can } \\
\text { be linked to } \\
\text { Institutions }\end{array}$ & Off & $\begin{array}{l}\text { Turn this } \\
\text { preference } \\
\text { On, to link } \\
\text { patrons of type } \\
\text { Professionals } \\
\text { to specific } \\
\text { institutions. }\end{array}$ \\
\hline & & & & $\begin{array}{l}\text { You will need to } \\
\text { set up a patron } \\
\text { category for } \\
\text { institutions, } \\
\text { and then create } \\
\text { patron records } \\
\text { for various } \\
\text { institutions. }\end{array}$ \\
\hline & & & & $\begin{array}{l}\text { When adding } \\
\text { a patron } \\
\text { record for type } \\
\text { Professional, } \\
\text { you will be able } \\
\text { to select such } \\
\text { institutions to } \\
\text { link to the patron. }\end{array}$ \\
\hline patronimages & Patrons & $\begin{array}{l}\text { Whether to } \\
\text { allow use } \\
\text { of patron } \\
\text { images }\end{array}$ & Off & $\begin{array}{l}\text { Turn this off } \\
\text { if you have } \\
\text { privacy concerns } \\
\text { or don't want to } \\
\text { store images on } \\
\text { the server due } \\
\text { to disk space } \\
\text { constraints. }\end{array}$ \\
\hline
\end{tabular}

\section{Configuring acquisitions preferences}

Koha's Acquisitions module is used to acquire Library items, usually through purchases. Koha's acquisitions module allows:

- Creation of vendors and budgets

- Management of purchase suggestions

- Creation of orders

- Receipt of ordered items 
- Tracking of late or missing orders

- Generation of claim letters

Unlike Cataloging and Circulation, relatively fewer libraries use Koha's Acquisitions module, instead they prefer to manage the process manually or on some other system.

Perhaps for this reason, Koha's Acquisitions module is a simple module and has few system preferences. These preferences can be found under the Acquisitions tab.

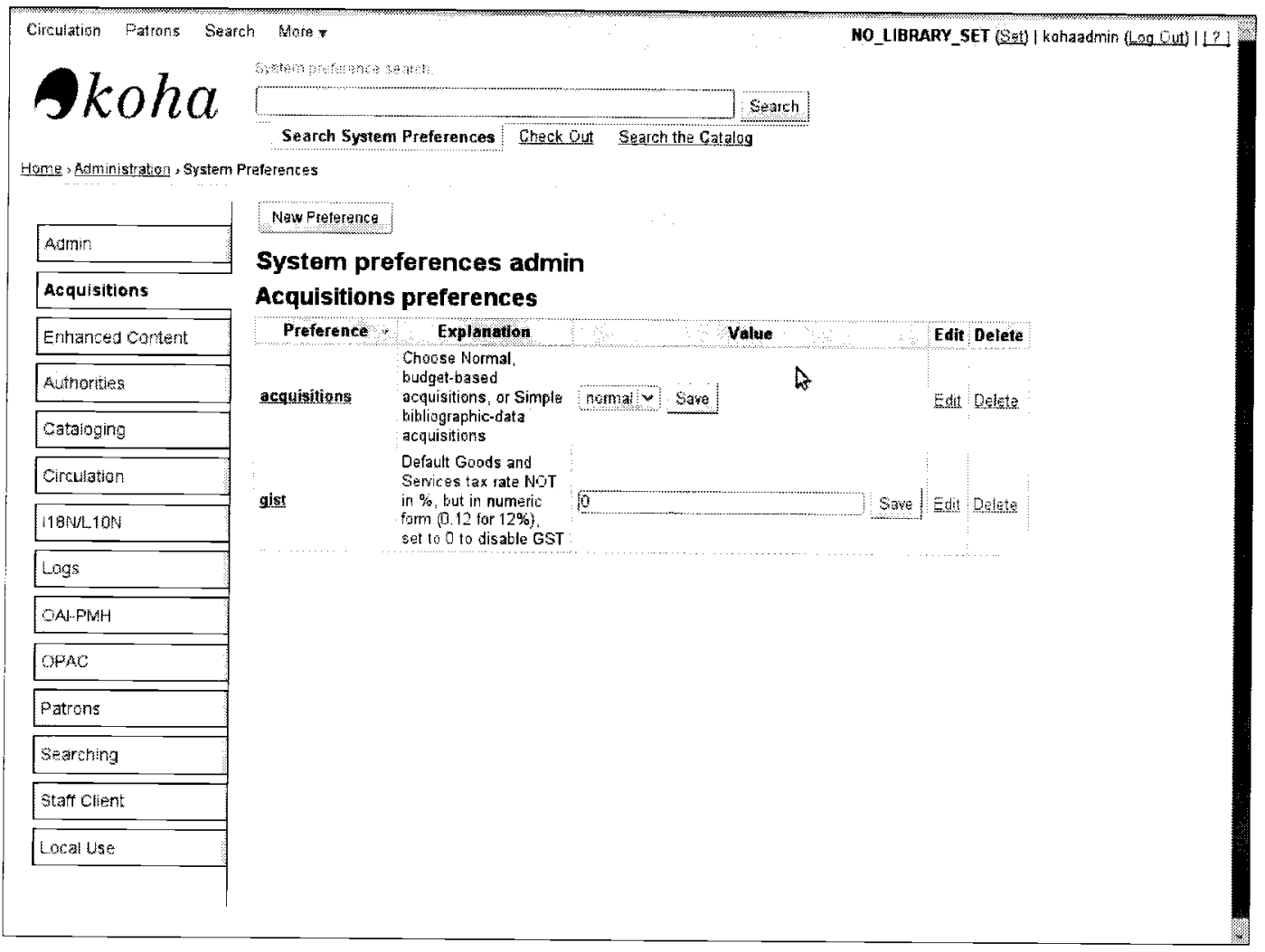


Here is an explanation of the Acquisitions preferences with instructions on how to configure them:

\begin{tabular}{|c|c|c|c|c|}
\hline System preference & $\begin{array}{l}\text { System } \\
\text { preferences } \\
\text { tab }\end{array}$ & Description & $\begin{array}{l}\text { Default } \\
\text { value }\end{array}$ & Instructions \\
\hline acquisitions & Acquisitions & $\begin{array}{l}\text { Whether to } \\
\text { use budgets } \\
\text { or not }\end{array}$ & normal & $\begin{array}{l}\text { Set to "normal" to } \\
\text { use budgets. Set to } \\
\text { "simple" to make } \\
\text { acquisitions without } \\
\text { budgets. }\end{array}$ \\
\hline emailPurchaseSuggestions & Acquisitions & $\begin{array}{l}\text { Whether } \\
\text { to have } \\
\text { purchase } \\
\text { suggestions } \\
\text { e-mailed to } \\
\text { the Koha } \\
\text { admin or } \\
\text { to use the } \\
\text { Manage } \\
\text { suggestions } \\
\text { module } \\
\text { within Koha }\end{array}$ & Off & $\begin{array}{l}\text { Turn "On" to use } \\
\text { e-mail. The e-mail will } \\
\text { be sent to the e-mail } \\
\text { address set up for the } \\
\text { system preference } \\
\text { KohaAdminEmail } \\
\text { Address. }\end{array}$ \\
\hline gist & Acquisitions & $\begin{array}{l}\text { Defaults } \\
\text { Goods and } \\
\text { Services Tax } \\
\text { Rate }\end{array}$ & 0 & $\begin{array}{l}\text { " } 0 \text { " means GST is } \\
\text { disabled. To use GST } \\
\text { set to a numeric value, } \\
\text { for example. } 0.12 \text { for } \\
12 \% \text {. }\end{array}$ \\
\hline
\end{tabular}

\section{Configuring serials preferences}

Koha's Serials module is used to manage subscriptions to periodicals. The module is used to:

- Create subscriptions with start dates and frequencies

- Receive issues when they arrive at the library

- Track missing or late issues

- Track renewals of subscription

- Generate claim letters for missing or late issues

- Maintain routing lists to notify specific patrons when new issues are received at the library

Like Acquisitions, relatively fewer libraries use this simple module, and there are fewer system preferences here as well. 
In version 3.02 there is no serials or subscriptions category. You can find related system preferences by searching for the term subscriptions.

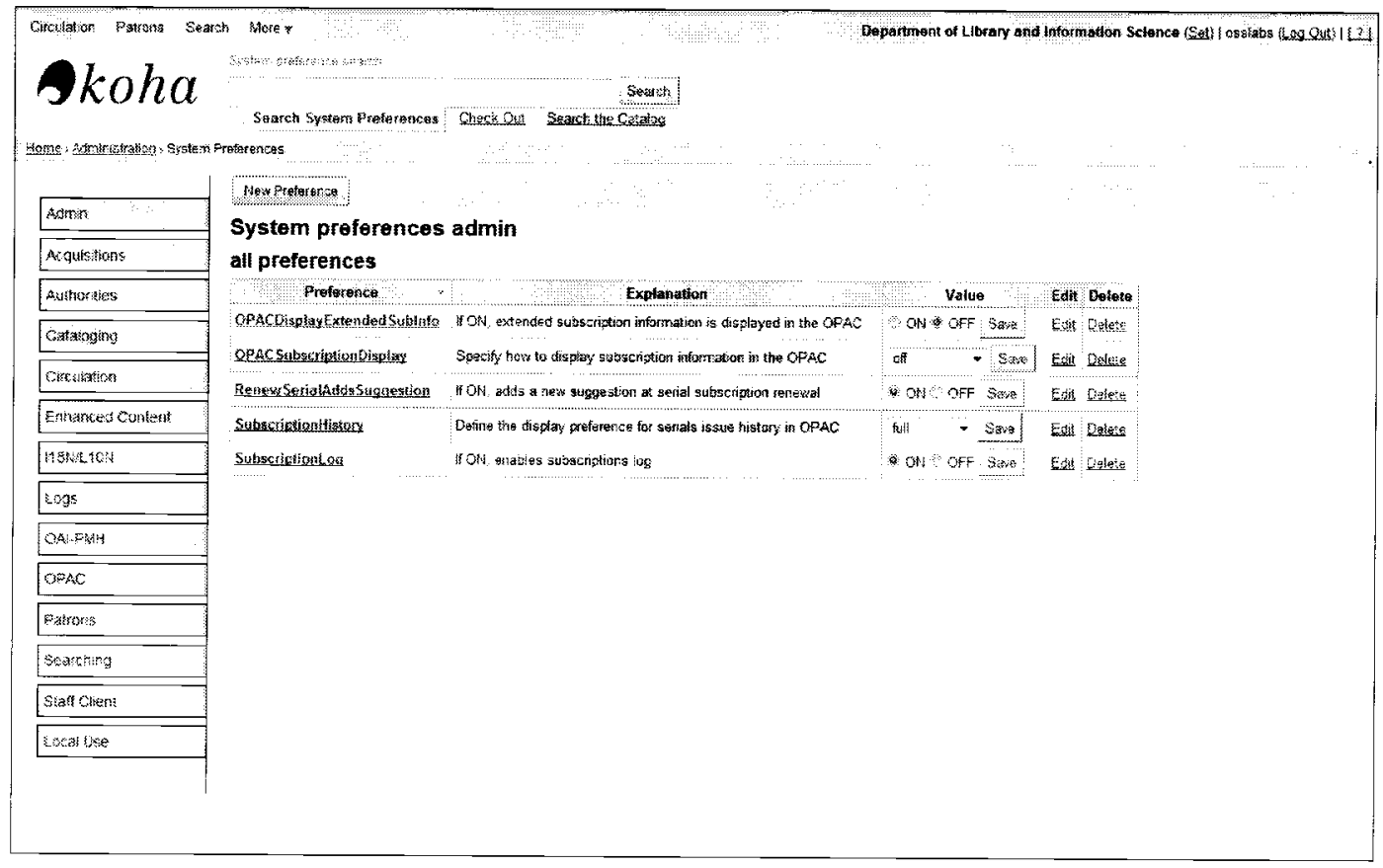

Here is an explanation of the Serials preferences with instructions on how to configure them:

\begin{tabular}{lllll}
\hline System preference & $\begin{array}{l}\text { System } \\
\text { preferences tab }\end{array}$ & Description & $\begin{array}{l}\text { Default } \\
\text { value }\end{array}$ & $\begin{array}{l}\text { Additional } \\
\text { information }\end{array}$ \\
\hline RoutingSerials & Cataloging & $\begin{array}{l}\text { Whether } \\
\text { to turn on } \\
\text { routing lists }\end{array}$ & On & $\begin{array}{l}\text { With this } \\
\text { preference } \\
\text { On, you can } \\
\text { setup routing }\end{array}$ \\
& $\therefore$ & & $\begin{array}{l}\text { lists in Serials } \\
\text { subscriptions. } \\
\text { Routing lists } \\
\text { are ordered }\end{array}$ \\
& & & & $\begin{array}{l}\text { set of names } \\
\text { that each issue } \\
\text { should be } \\
\text { circulated to. }\end{array}$ \\
& & & & \\
& & &
\end{tabular}




\begin{tabular}{|c|c|c|c|c|}
\hline System preference & $\begin{array}{l}\text { System } \\
\text { preferences tab }\end{array}$ & Description & $\begin{array}{l}\text { Default } \\
\text { value }\end{array}$ & $\begin{array}{l}\text { Additional } \\
\text { information }\end{array}$ \\
\hline \multirow[t]{2}{*}{ RenewSerialAddsSuggestion } & Serials & $\begin{array}{l}\text { Whether to } \\
\text { add a new } \\
\text { purchase } \\
\text { suggestion } \\
\text { when } \\
\text { renewing a } \\
\text { serial }\end{array}$ & Off & $\begin{array}{l}\text { Turn this on, } \\
\text { if you want } \\
\text { a way to } \\
\text { remind the } \\
\text { acquisition } \\
\text { staff to } \\
\text { renew the } \\
\text { subscription } \\
\text { with the } \\
\text { vendor. A } \\
\text { new purchase } \\
\text { suggestion } \\
\text { will be listed } \\
\text { in the Manage } \\
\text { suggestions } \\
\text { module under } \\
\text { Acquisitions. }\end{array}$ \\
\hline & & & & $\begin{array}{l}\text { With this } \\
\text { preference } \\
\text { Off, the } \\
\text { subscription } \\
\text { will get } \\
\text { renewed in } \\
\text { Koha, but } \\
\text { you will need } \\
\text { to manually } \\
\text { ensure that } \\
\text { it is indeed } \\
\text { renewed with } \\
\text { the vendor. }\end{array}$ \\
\hline SubscriptionHistory & Serials & $\begin{array}{l}\text { The default } \\
\text { subscription } \\
\text { history } \\
\text { view in the } \\
\text { OPAC- } \\
\text { simplified or } \\
\text { full }\end{array}$ & Simplified & $\begin{array}{l}\text { Turn to full if } \\
\text { you want to } \\
\text { show a full } \\
\text { listing of the } \\
\text { subscription } \\
\text { history in } \\
\text { the OPAC by } \\
\text { default. }\end{array}$ \\
\hline
\end{tabular}




\section{Configuring OPAC preferences}

Koha's Online Public Access Catalog (OPAC) is not just an online catalog; it is also a self service tool for the patrons. Patrons can use the Koha OPAC to:

- Find items by entering search terms or by browsing categories

- Select items based on descriptions, ratings, reviews, and other useful material

- Place holds on items that are not available at the time

- Renew items they have borrowed

- Make purchase suggestions

- Review their borrowings, reading history, or fines

- Request changes to their address and other personal information

- Create and share reading lists

- Learn about library policies or upcoming events or News

Koha offers an extensive set of OPAC preferences that control:

- The static content on OPAC home page, from the page header to the content in the main block of the home page

- Tools that help patrons find, select, and manage their borrowings, such as virtual shelves or listing of most popular items

- Enhanced content that help patron select items, from Google jackets to Amazon reviews

- Patron access to features such as place holds or renew items

\section{Configuring static content}

We first configure the static content on the OPAC - the page header and footer, the content in the main body, the navigation bar, and the logo. 
These preferences allow us to change OPAC content without having to edit the files on the server. It will help to have some HTML skills to maintain this set of preferences. With HTML you can format the content with color, emphasis, fonts, and font sizes.

Here is an explanation of these preferences with instructions on how to configure them:

\begin{tabular}{|c|c|c|c|c|}
\hline System preference & $\begin{array}{l}\text { System } \\
\text { preferences } \\
\text { tab }\end{array}$ & Description & Default value & Instructions \\
\hline LibraryName & OPAC & $\begin{array}{l}\text { Name that } \\
\text { appears } \\
\text { in the } \\
\text { browser's } \\
\text { title bar }\end{array}$ & & $\begin{array}{l}\text { Enter your } \\
\text { Library's name, } \\
\text { something like: } \\
\text { Tailorbird } \\
\text { Children's Library. }\end{array}$ \\
\hline opaccredits & OPAC & $\begin{array}{l}\text { Contents at } \\
\text { the bottom } \\
\text { of the } \\
\text { OPAC page }\end{array}$ & & $\begin{array}{l}\text { Enter HTML } \\
\text { contents, } \\
\text { something like: } \\
<p \\
\text { style="text- } \\
\text { align: center" > } \\
\text { My OPAC } \\
\text { Credits } / \mathrm{p}>\end{array}$ \\
\hline
\end{tabular}




\begin{tabular}{|c|c|c|c|c|}
\hline System preference & $\begin{array}{l}\text { System } \\
\text { preferences } \\
\text { tab }\end{array}$ & Description & Default value & Instructions \\
\hline opacheader & OPAC & $\begin{array}{l}\text { Contents at } \\
\text { the top of } \\
\text { the OPAC } \\
\text { page }\end{array}$ & & $\begin{array}{l}\text { Enter HTML } \\
\text { contents, } \\
\text { something like: } \\
<\text { h3 }>\text { Welcome to } \\
\text { my library</ } \\
\text { h } 3>\end{array}$ \\
\hline OpacMainUserBlock & OPAC & $\begin{array}{l}\text { Contents in } \\
\text { the middle } \\
\text { of OPAC } \\
\text { home page }\end{array}$ & $\begin{array}{l}\text { Welcome to } \\
\text { Koha... < hrs }\end{array}$ & $\begin{array}{l}\text { Enter HTML } \\
\text { contents. }\end{array}$ \\
\hline OpacNav & OPAC & $\begin{array}{l}\text { Contents } \\
\text { in the } \\
\text { navigation } \\
\text { block to the } \\
\text { left of the } \\
\text { page in the } \\
\text { OPAC }\end{array}$ & $\begin{array}{l}\text { Important links } \\
\text { here. }\end{array}$ & $\begin{array}{l}\text { Enter HTML } \\
\text { contents, } \\
\text { something like: } \\
\text { <a href= "www. } \\
\text { mywebsite. } \\
\text { com" >My } \\
\text { Website</a> }\end{array}$ \\
\hline opacsmallimage & OPAC & $\begin{array}{l}\text { Web URL } \\
\text { of an image } \\
\text { to replace } \\
\text { default } \\
\text { logo in the } \\
\text { OPAC }\end{array}$ & & $\begin{array}{l}\text { Enter full path of } \\
\text { the logo, something } \\
\text { like: } \\
\text { http: //mysite. } \\
\text { com/logos/ } \\
\text { logo.png } \\
\text { Logo's size should } \\
\text { be } 120 p{ }^{*} 40 p x \text { or } \\
\text { less. }\end{array}$ \\
\hline
\end{tabular}

\section{Configuring tools for patrons}

Koha's OPAC has several tools that help patrons find, select, and manage items they want to borrow. These tools include-Browse by Subject, Listing of most popular items, virtual shelves, or reading lists, Book bag or cart, and a tool to allow online browsing of shelves. 
Lay in to Your Aceourt

My OPAC Header

Skoha

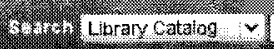

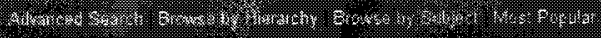

Here are the preferences along with instructions on how to use them:

\begin{tabular}{|c|c|c|c|c|}
\hline System preference & $\begin{array}{l}\text { System } \\
\text { preferences } \\
\text { tab }\end{array}$ & Description & $\begin{array}{l}\text { Default } \\
\text { value }\end{array}$ & Instructions \\
\hline OpacAuthorities & OPAC & $\begin{array}{l}\text { Whether } \\
\text { to display } \\
\text { "Browse by } \\
\text { Subject" link } \\
\text { below the } \\
\text { Search box on } \\
\text { the OPAC }\end{array}$ & On & $\begin{array}{l}\text { This will allow you to } \\
\text { search the Authorities } \\
\text { records. } \\
\text { This will work when } \\
\text { you have authority } \\
\text { records entered and } \\
\text { indexed in the system. }\end{array}$ \\
\hline opacbookbag & OPAC & $\begin{array}{l}\text { Whether to } \\
\text { display the } \\
\text { "cart" or book } \\
\text { bag in the } \\
\text { mast head of } \\
\text { the OPAC }\end{array}$ & On & $\begin{array}{l}\text { The cart feature allows } \\
\text { users to maintain } \\
\text { a list of they want } \\
\text { to borrow and also } \\
\text { e-mail the list out. } \\
\text { You will need to } \\
\text { configure a mail } \\
\text { server to send the } \\
\text { e-mail out. }\end{array}$ \\
\hline
\end{tabular}




\begin{tabular}{|c|c|c|c|c|}
\hline System preference & $\begin{array}{l}\text { System } \\
\text { preferences } \\
\text { tab }\end{array}$ & Description & $\begin{array}{l}\text { Default } \\
\text { value }\end{array}$ & Instructions \\
\hline OpacTopissue & OPAC & $\begin{array}{l}\text { Whether } \\
\text { to display } \\
\text { the "Most } \\
\text { Popular" link } \\
\text { below the } \\
\text { Search box on } \\
\text { the OPAC }\end{array}$ & Off & $\begin{array}{l}\text { The link will display } \\
\text { a listing of items that } \\
\text { are circulated most } \\
\text { often. }\end{array}$ \\
\hline virtualshelves & OPAC & $\begin{array}{l}\text { Whether to } \\
\text { display the } \\
\text { "Lists" button } \\
\text { in the mast } \\
\text { head of the } \\
\text { OPAC }\end{array}$ & On & $\begin{array}{l}\text { To create and manage } \\
\text { lists use the Lists } \\
\text { module in the staff } \\
\text { client. Patrons can also } \\
\text { create and share their } \\
\text { reading lists. }\end{array}$ \\
\hline OPACShelfBrowser & OPAC & $\begin{array}{l}\text { Whether to } \\
\text { enable the } \\
\text { "Browse } \\
\text { Shelf" feature } \\
\text { in the call } \\
\text { number } \\
\text { column in the } \\
\text { holdings table }\end{array}$ & Off & $\begin{array}{l}\text { For this to work, you } \\
\text { will need to have call } \\
\text { numbers entered in } \\
\text { field } 952 \$ 0 .\end{array}$ \\
\hline
\end{tabular}

\section{Configuring patron access control}

In this section we'll learn how to control what patrons can and cannot do on the OPAC. These preferences control whether patrons can log on to the OPAC, change their passwords, place holds online, renew items online, write book reviews, or make purchase suggestions.

In general, most of these features are good to have and should be turned on. But if your OPAC is not available to most patrons, then it might not make sense to take on the burden of maintaining patron user IDs and passwords.

Here is a listing of these preferences along with instructions on how to set these up: 


\begin{tabular}{|c|c|c|c|c|}
\hline System preference & $\begin{array}{l}\text { System } \\
\text { preferences } \\
\text { tab }\end{array}$ & Description & $\begin{array}{l}\text { Default } \\
\text { value }\end{array}$ & Instructions \\
\hline opacuserlogin & OPAC & $\begin{array}{l}\text { Whether to } \\
\text { allow user } \\
\text { login in the } \\
\text { OPAC }\end{array}$ & On & $\begin{array}{l}\text { If you turn } \\
\text { this on, you } \\
\text { will need to } \\
\text { shoulder the } \\
\text { burden of } \\
\text { administering } \\
\text { user names } \\
\text { and passwords. } \\
\text { Initial } \\
\text { passwords } \\
\text { will have to be } \\
\text { distributed in a } \\
\text { secure manner. } \\
\text { You might } \\
\text { get ongoing } \\
\text { password reset } \\
\text { requests. }\end{array}$ \\
\hline OpacPasswordChange & OPAC & $\begin{array}{l}\text { Whether to } \\
\text { allow patrons } \\
\text { to change their } \\
\text { passwords on } \\
\text { the OPAC }\end{array}$ & On & $\begin{array}{l}\text { Set to Off if } \\
\text { you use LDAP } \\
\text { authentication. } \\
\text { In this case } \\
\text { passwords are } \\
\text { not maintained } \\
\text { in Koha, but } \\
\text { on the LDAP } \\
\text { database. }\end{array}$ \\
\hline OpacRenewalAllowed & OPAC & $\begin{array}{l}\text { Whether } \\
\text { to allow } \\
\text { renewals via } \\
\text { the OPAC }\end{array}$ & Off & $\begin{array}{l}\text { Some of the } \\
\text { scenarios where } \\
\text { you might want } \\
\text { this turned } \\
\text { off are, if you } \\
\text { maintain hold } \\
\text { requests outside } \\
\text { of Koha. If you } \\
\text { allow online } \\
\text { renewals, the } \\
\text { system will } \\
\text { allow renewals } \\
\text { even on items } \\
\text { where there are } \\
\text { pending hold } \\
\text { requests. }\end{array}$ \\
\hline
\end{tabular}




\begin{tabular}{|c|c|c|c|c|}
\hline System preference & $\begin{array}{l}\text { System } \\
\text { preferences } \\
\text { tab }\end{array}$ & Description & $\begin{array}{l}\text { Default } \\
\text { value }\end{array}$ & Instructions \\
\hline RequestOnOpac & OPAC & $\begin{array}{l}\text { Whether to } \\
\text { allow patron } \\
\text { holds on the } \\
\text { OPAC }\end{array}$ & On & $\begin{array}{l}\text { You might want } \\
\text { to turn this off } \\
\text { if most of your } \\
\text { patrons do not } \\
\text { have access to } \\
\text { the OPAC and } \\
\text { you maintain } \\
\text { hold requests } \\
\text { outside of } \\
\text { Koha. }\end{array}$ \\
\hline reviewson & OPAC & $\begin{array}{l}\text { Whether to } \\
\text { allow patron } \\
\text { reviews } \\
\text { of catalog } \\
\text { records on the } \\
\text { OPAC }\end{array}$ & On & $\begin{array}{l}\text { Reviews } \\
\text { entered by } \\
\text { patron will } \\
\text { be sent for } \\
\text { moderation by } \\
\text { the staff. The } \\
\text { comments can } \\
\text { moderated in } \\
\text { the Comments } \\
\text { section under } \\
\text { Tools. }\end{array}$ \\
\hline suggestion & OPAC & $\begin{array}{l}\text { Whether } \\
\text { to allow } \\
\text { purchase } \\
\text { suggestions } \\
\text { to be made on } \\
\text { the OPAC }\end{array}$ & On & $\begin{array}{l}\text { Patron purchase } \\
\text { suggestions can } \\
\text { be managed } \\
\text { via the Manage } \\
\text { suggestions } \\
\text { section under } \\
\text { Acquisitions. }\end{array}$ \\
\hline
\end{tabular}

\section{Configuring enhanced content}

Koha's enhanced content features help patrons select items by displaying content such as book jackets, book reviews, and ratings. This content is in addition to the regular catalog record data such as Title, Author, or Subject that is available on the OPAC, hence the term enhanced content. 
Log in te Your Atecount

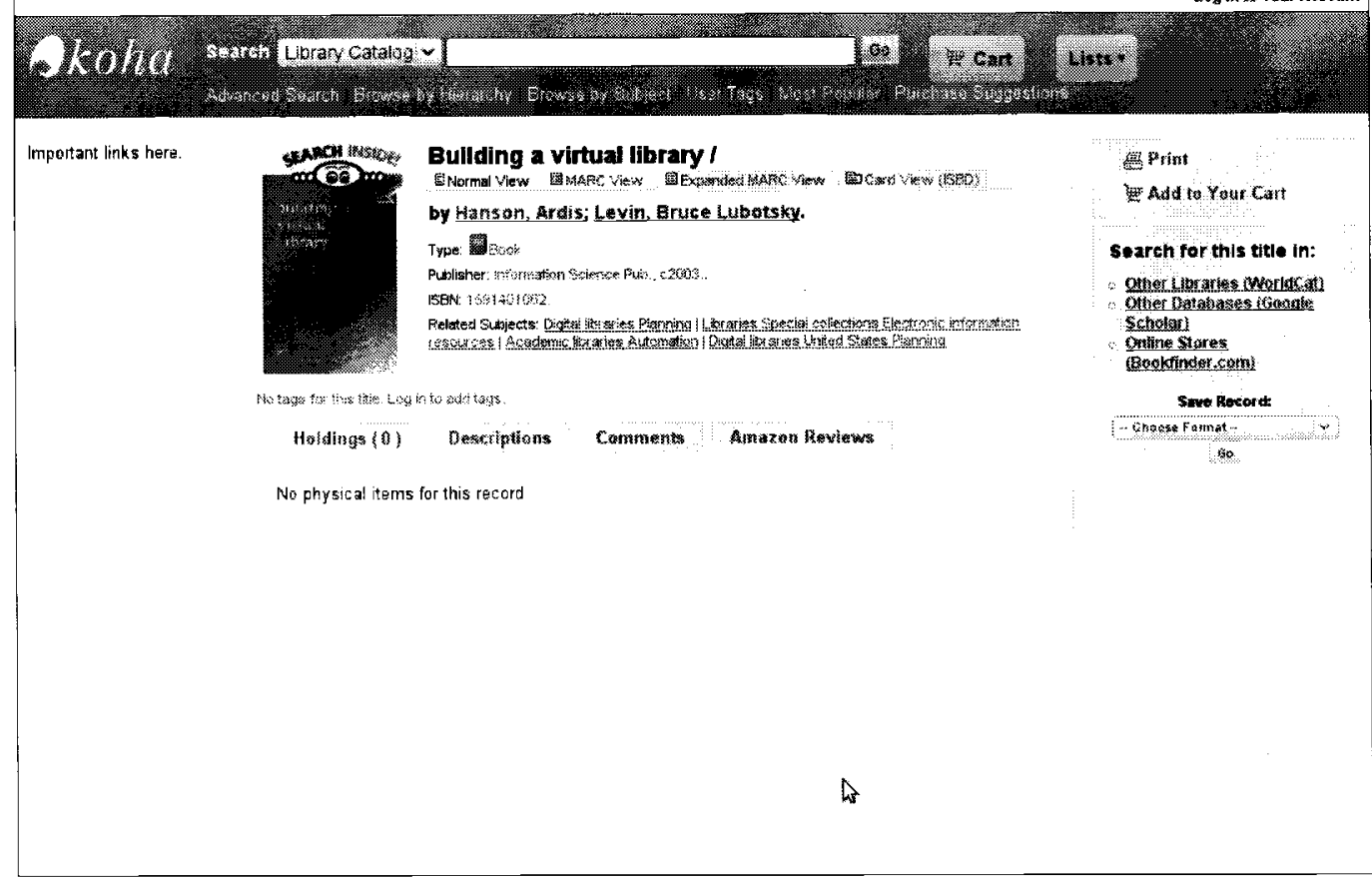

Koha integrates with Web Services such as those provided by Amazon and Google to display such content. Most of these preferences are On or Off switches; others, especially Amazon-related preferences, require the appropriate keys or IDs to be set up. Some of these services are paid subscriptions; some may require login credentials to be configured. 
Here is a listing of select enhanced content preferences along with instructions on how to set these up:

\begin{tabular}{|c|c|c|c|c|}
\hline OPACFRBRizeEditions & $\begin{array}{l}\text { System } \\
\text { preferences } \\
\text { tab }\end{array}$ & Description & $\begin{array}{l}\text { Default } \\
\text { value }\end{array}$ & Instructions \\
\hline OPACAmazonEnabled & $\begin{array}{l}\text { Enhanced } \\
\text { Content }\end{array}$ & $\begin{array}{l}\text { Whether to } \\
\text { display Book } \\
\text { Jackets and } \\
\text { reviews from } \\
\text { Amazon }\end{array}$ & Off & $\begin{array}{l}\text { To get this to work, } \\
\text { you will need } \\
\text { to set values for } \\
\text { the preferences } \\
\text { AWSAccess } \\
\text { KeyID and } \\
\text { AmazonAssoc } \\
\text { Tag. Get the key and } \\
\text { tag from here: } \\
\text { http://aws. } \\
\text { amazon.com. }\end{array}$ \\
\hline OPACAmazonCoverImages & $\begin{array}{l}\text { Enhanced } \\
\text { Content }\end{array}$ & $\begin{array}{l}\text { Whether to } \\
\text { display book } \\
\text { jackets from } \\
\text { Amazon }\end{array}$ & Off & $\begin{array}{l}\text { To get this to work, } \\
\text { you must turn on } \\
\text { OPACAmazon } \\
\text { Enabled. } \\
\text { Use either Google } \\
\text { or Amazon book } \\
\text { jackets. }\end{array}$ \\
\hline OPACAmazonSimilarItems & $\begin{array}{l}\text { Enhanced } \\
\text { Content }\end{array}$ & $\begin{array}{l}\text { Whether } \\
\text { to display } \\
\text { Amazon's } \\
\text { similar items } \\
\text { feature }\end{array}$ & Off & $\begin{array}{l}\text { To get this to work, } \\
\text { you must turn on } \\
\text { OPACAmazon } \\
\text { Enabled. }\end{array}$ \\
\hline GoogleJackets & $\begin{array}{l}\text { Enhanced } \\
\text { Content }\end{array}$ & $\begin{array}{l}\text { Whether to } \\
\text { display Book } \\
\text { Jackets from } \\
\text { Google Books }\end{array}$ & Off & $\begin{array}{l}\text { Use either Google } \\
\text { or Amazon book } \\
\text { jackets. }\end{array}$ \\
\hline
\end{tabular}




\begin{tabular}{|c|c|c|c|c|}
\hline OPACFRBRizeEditions & $\begin{array}{l}\text { System } \\
\text { preferences } \\
\text { tab }\end{array}$ & Description & $\begin{array}{l}\text { Default } \\
\text { value }\end{array}$ & Instructions \\
\hline OPACFRBRizeEditions & $\begin{array}{l}\text { Enhanced } \\
\text { Content }\end{array}$ & $\begin{array}{l}\text { Whether to } \\
\text { display an } \\
\text { editions tab in } \\
\text { the item details } \\
\text { page }\end{array}$ & Off & $\begin{array}{l}\text { To get this to work } \\
\text { you will need one } \\
\text { of the FRBR Web } \\
\text { Services listed } \\
\text { below turned on. } \\
\text { Here is a definition } \\
\text { of FRBR from } \\
\text { Wikipedia: } \\
\text { "Functional } \\
\text { Requirements } \\
\text { for Bibliographic } \\
\text { Records-or } \\
\text { FRBR, sometimes } \\
\text { pronounced } \\
\text { /f3rber/-is a } \\
\text { conceptual entity- } \\
\text { relationship model } \\
\text { developed by } \\
\text { the International } \\
\text { Federation } \\
\text { of Library } \\
\text { Associations and } \\
\text { Institutions (IFLA) } \\
\text { that relates user } \\
\text { tasks of retrieval } \\
\text { and access in online } \\
\text { library catalogues } \\
\text { and bibliographic } \\
\text { databases from a } \\
\text { user's perspective. } \\
\text { It represents a more } \\
\text { holistic approach to } \\
\text { retrieval and access } \\
\text { as the relationships } \\
\text { between the entities } \\
\text { provide links to } \\
\text { navigate through } \\
\text { the hierarchy of } \\
\text { relationships." }\end{array}$ \\
\hline
\end{tabular}




\begin{tabular}{|c|c|c|c|c|}
\hline OPACFRBRizeEditions & $\begin{array}{l}\text { System } \\
\text { preferences } \\
\text { tab }\end{array}$ & Description & $\begin{array}{l}\text { Default } \\
\text { value }\end{array}$ & Instructions \\
\hline ThingISBN & $\begin{array}{l}\text { Enhanced } \\
\text { Content }\end{array}$ & $\begin{array}{l}\text { Whether to use } \\
\text { the ThingISBN } \\
\text { web service to } \\
\text { populate the } \\
\text { editions tab }\end{array}$ & Off & $\begin{array}{l}\text { To use this system } \\
\text { preference you will } \\
\text { need to first turn on } \\
\text { OPACFRBRize } \\
\text { Editions. }\end{array}$ \\
\hline XISBN & $\begin{array}{l}\text { Enhanced } \\
\text { Content }\end{array}$ & $\begin{array}{l}\text { Whether to } \\
\text { use the OCLC } \\
\text { xISBN Web } \\
\text { Service to } \\
\text { populate the } \\
\text { editions tab }\end{array}$ & Off & $\begin{array}{l}\text { To use this system } \\
\text { preference you will } \\
\text { need to first turn on } \\
\text { OPACFRBRize } \\
\text { Editions. }\end{array}$ \\
\hline PINSEISBN & $\begin{array}{l}\text { Enhanced } \\
\text { Content }\end{array}$ & $\begin{array}{l}\text { Whether to } \\
\text { use the OINES } \\
\text { OISBN Web } \\
\text { Service to } \\
\text { populate the } \\
\text { editions tab }\end{array}$ & Off & $\begin{array}{l}\text { To use this system } \\
\text { preference you will } \\
\text { need to first turn on } \\
\text { OPACFRBRize } \\
\text { Editions. }\end{array}$ \\
\hline TagsEnabled & $\begin{array}{l}\text { Enhanced } \\
\text { Content }\end{array}$ & $\begin{array}{l}\text { Whether to } \\
\text { allow tagging } \\
\text { of items in the } \\
\text { OPAC }\end{array}$ & On & $\begin{array}{l}\text { It is important } \\
\text { to consider if } \\
\text { you need tags to } \\
\text { be moderated, } \\
\text { see preference } \\
\text { TagsModeration } \\
\text { below. }\end{array}$ \\
\hline TagsModeration & $\begin{array}{l}\text { Enhanced } \\
\text { Content }\end{array}$ & $\begin{array}{l}\text { Whether tags } \\
\text { entered by } \\
\text { patrons need to } \\
\text { be moderated } \\
\text { by Library staff }\end{array}$ & Off & $\begin{array}{l}\text { Tags can be } \\
\text { moderated via the } \\
\text { Tags section under } \\
\text { Tools. }\end{array}$ \\
\hline
\end{tabular}

\section{Configuring styling and appearance}

In this section we will learn about preferences that control the styling and appearance-colors, fonts, font size, or background image of the Koha OPAC and its staff client.

Most libraries certainly want their OPAC to have a polished look, but it might be worth doing up staff client as well, as the default staff client pages are very plain.

Koha has several system preferences that control styling and appearance, with more options for the OPAC and fewer for the staff client. 
These preferences related to:

- Themes or templates: These are a broad set of elements - style sheets, JavaScript programs, or header and footer programs - that control not just styling and appearance but also the behavior of the screens.

- Stylesheets: Stylesheets are CSS files, and in some cases XSLT files that relate to a narrower set of styling and appearance elements - font, color, font size, or background images.

To use these preferences effectively you will need some HTML and CSS skills.

\section{Configuring OPAC styling and appearance}

Let us look at OPAC related preferences. These preferences relate to OPAC themes, CSS style sheets, and some XSLT style sheets that control the display of MARC data.

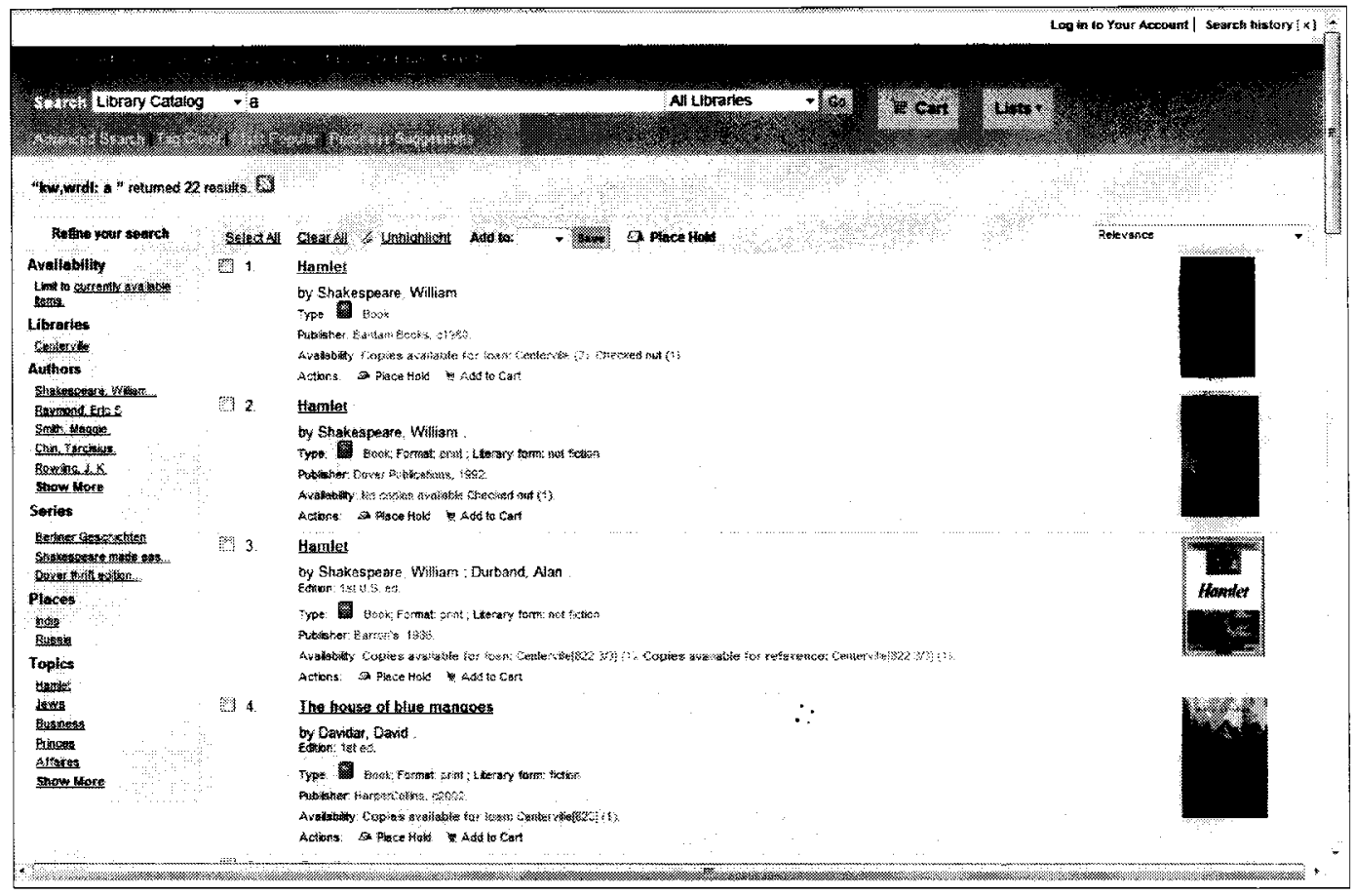

In general, to set up new themes of style sheets you will need access to the Koha server. But you also have the option of using a style sheet that is available on the web or writing CSS within the system preference. 
Here is a listing of OPAC styling-related preferences along with instructions on how to set them up:

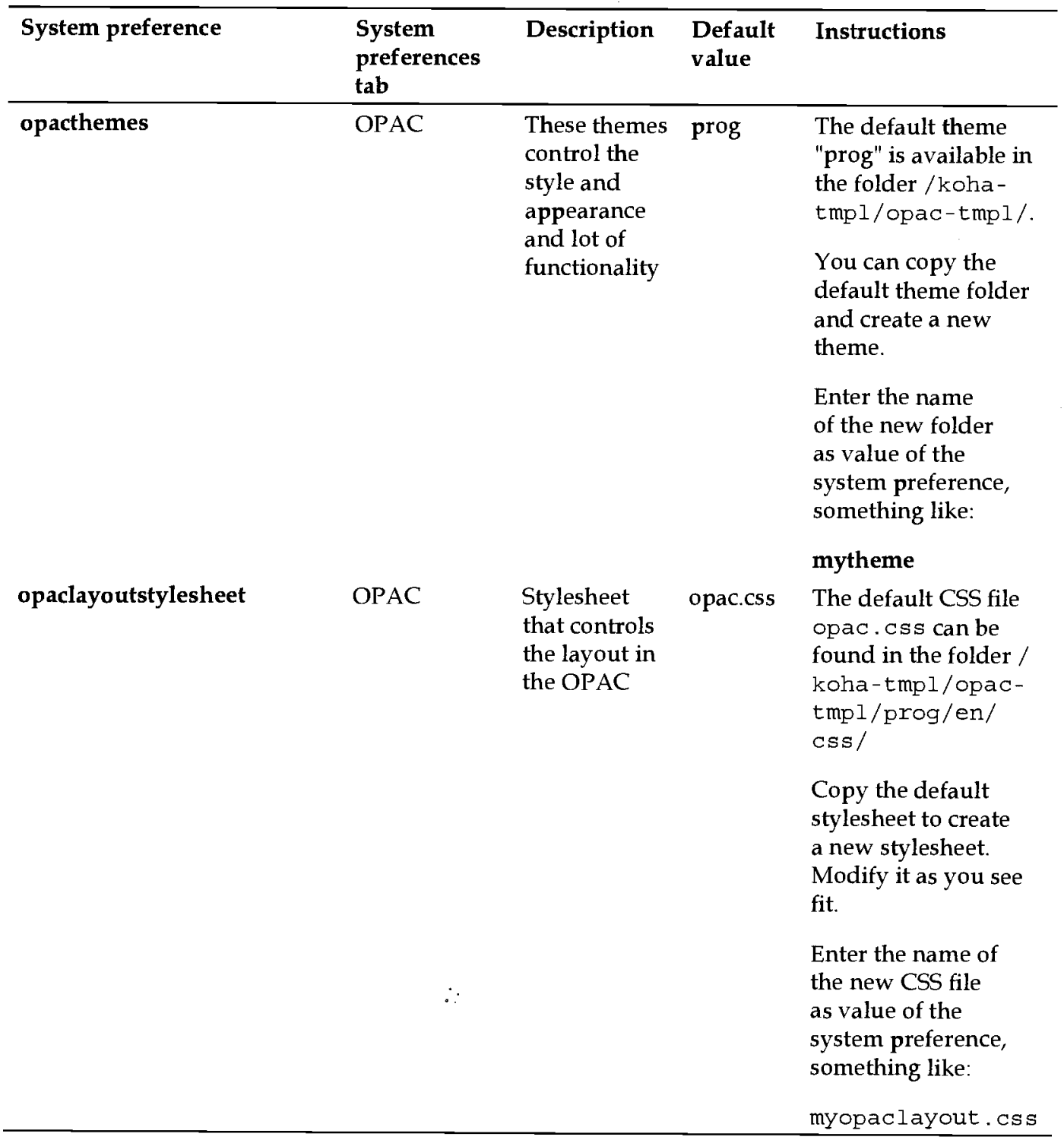




\begin{tabular}{|c|c|c|c|c|}
\hline System preference & $\begin{array}{l}\text { System } \\
\text { preferences } \\
\text { tab }\end{array}$ & Description & $\begin{array}{l}\text { Default } \\
\text { value }\end{array}$ & Instructions \\
\hline opacstylesheet & OPAC & $\begin{array}{l}\text { This contains } \\
\text { the Web } \\
\text { URL of a } \\
\text { stylesheet } \\
\text { that will } \\
\text { override } \\
\text { the default } \\
\text { stylesheets of } \\
\text { Koha }\end{array}$ & & $\begin{array}{l}\text { This is useful if the } \\
\text { stylesheet you want } \\
\text { to use is maintained } \\
\text { on a different server. } \\
\text { Specify the full } \\
\text { URL including the } \\
\text { http://, something } \\
\text { like: } \\
\text { http://mysite. } \\
\text { com/css/ } \\
\text { mystylesheet. } \\
\text { css. }\end{array}$ \\
\hline OPACUserCSS & OPAC & $\begin{array}{l}\text { This contains } \\
\text { the CSS code } \\
\text { that will } \\
\text { override } \\
\text { default CSS } \\
\text { settings }\end{array}$ & & $\begin{array}{l}\text { This is useful if you } \\
\text { want to make minor } \\
\text { modification to the } \\
\text { style without having } \\
\text { to edit the files on the } \\
\text { server. } \\
\text { Simply enter } \\
\text { the code in the } \\
\text { value box of the } \\
\text { system preference, } \\
\text { something like: } \\
\text { body \{ } \\
\text { background: } \\
\text { grey; } \\
\text { \} }\end{array}$ \\
\hline XSLTDetailsDisplay & OPAC & $\begin{array}{l}\text { This } \\
\text { preference } \\
\text { allows us } \\
\text { to decide } \\
\text { whether to } \\
\text { use XSLT } \\
\text { stylesheets } \\
\text { or regular } \\
\text { CSS ones } \\
\text { to control } \\
\text { display } \\
\text { of MARC } \\
\text { record } \\
\text { details }\end{array}$ & Off & $\begin{array}{l}\text { XSLT stylesheets are } \\
\text { a more powerful way } \\
\text { of formatting the } \\
\text { content. } \\
\text { The corresponding } \\
\text { XSLT stylesheet can } \\
\text { be found at / koha- } \\
\text { tmpl/opac-tmpl/ } \\
\text { prog/en/xslt/. } \\
\text { The file name is: } \\
\text { MARC2lslim2OPAC } \\
\text { Detail.xsl. }\end{array}$ \\
\hline
\end{tabular}




\begin{tabular}{|c|c|c|c|c|}
\hline System preference & $\begin{array}{l}\text { System } \\
\text { preferences } \\
\text { tab }\end{array}$ & Description & $\begin{array}{l}\text { Default } \\
\text { value }\end{array}$ & Instructions \\
\hline XSLTResultsDisplay & OPAC & $\begin{array}{l}\text { This } \\
\text { preference } \\
\text { allows you } \\
\text { to decide } \\
\text { whether to } \\
\text { use XSLT } \\
\text { stylesheets } \\
\text { or regular } \\
\text { CSS ones } \\
\text { to control } \\
\text { display of } \\
\text { record search } \\
\text { results }\end{array}$ & Off & $\begin{array}{l}\text { The XSLT stylesheet } \\
\text { can be found at / } \\
\text { koha-tmp1/opac- } \\
\text { tmpl/prog/en/ } \\
\text { xs1t/. } \\
\text { The file name is: } \\
\text { MARC2 1s1im2OPAC } \\
\text { Results.xs1. }\end{array}$ \\
\hline
\end{tabular}

\section{Configuring staff client styling and appearance}

Let us look at staff-related preferences. As with OPAC preferences, to set up new themes or templates you will need access to the Koha server, but you also have an option of pointing to an externally hosted CSS file.

These system preferences can be found under the Staff Client tab. 


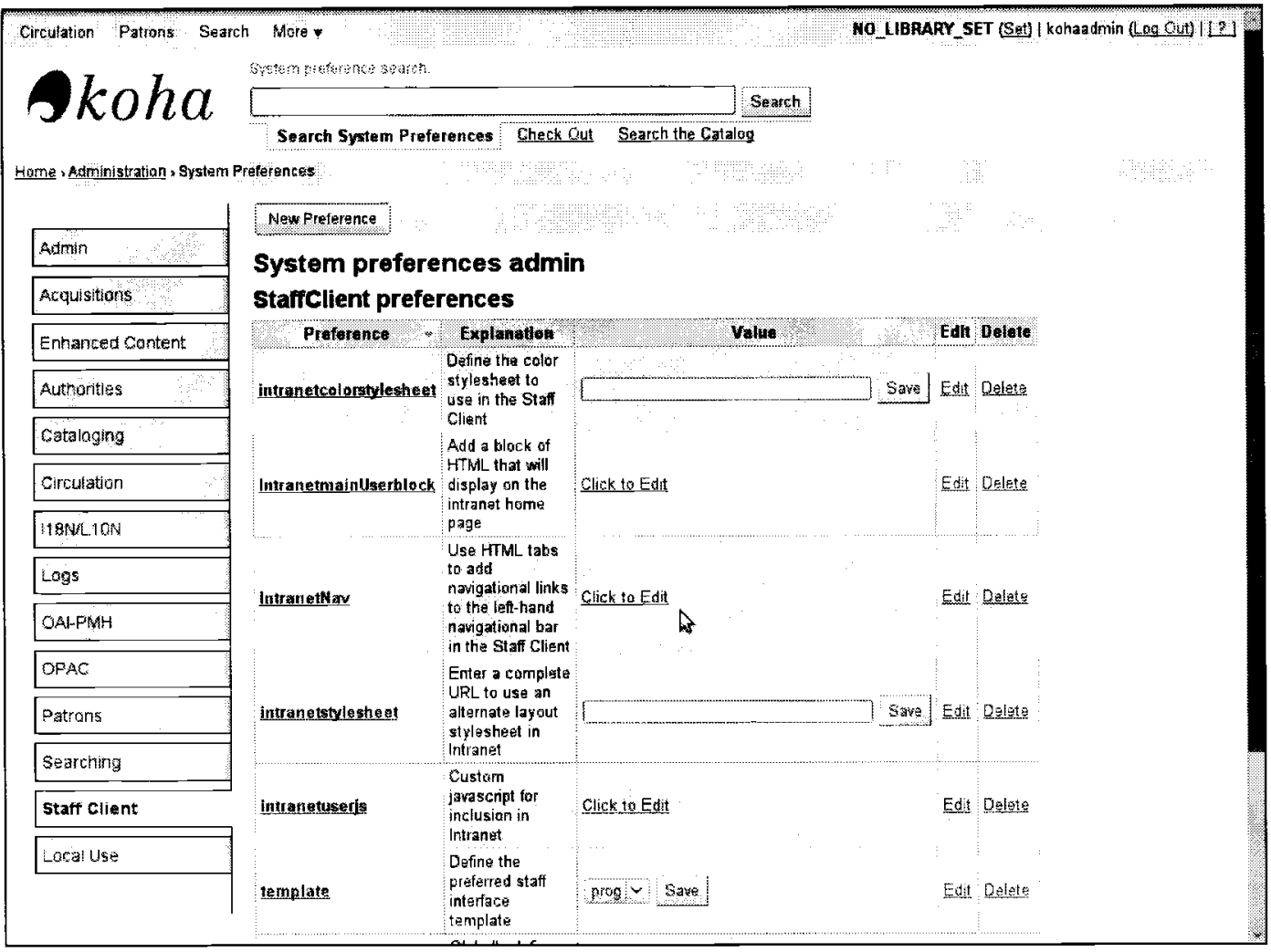

Here is a listing of preferences related to the styling of the staff client, along with instructions on how to set them up:

\begin{tabular}{|c|c|c|c|c|}
\hline System preference & $\begin{array}{l}\text { System } \\
\text { preferences } \\
\text { tab }\end{array}$ & Description & $\begin{array}{l}\text { Default } \\
\text { value }\end{array}$ & Additional information \\
\hline template & $\begin{array}{c}\text { Staff Client } \\
\therefore\end{array}$ & $\begin{array}{l}\text { Similar to } \\
\text { a theme } \\
\text { for OPAC. } \\
\text { Templates } \\
\text { control style, } \\
\text { appearance, } \\
\text { and some } \\
\text { functionality } \\
\text { in the staff } \\
\text { client. }\end{array}$ & Prog & $\begin{array}{l}\text { The default theme } \\
\text { "prog" is available in the } \\
\text { folder / koha-tmpl/ } \\
\text { intranet-tmpl/. } \\
\text { You can copy the default } \\
\text { template folder and } \\
\text { create a new template. } \\
\text { Enter the name of the } \\
\text { new folder as value of } \\
\text { the system preference. }\end{array}$ \\
\hline
\end{tabular}




\begin{tabular}{|c|c|c|c|c|}
\hline System preference & $\begin{array}{l}\text { System } \\
\text { preferences } \\
\text { tab }\end{array}$ & Description & $\begin{array}{l}\text { Default } \\
\text { value }\end{array}$ & Additional information \\
\hline intranetstylesheet & Staff Client & $\begin{array}{l}\text { It contains the } \\
\text { Web URL of a } \\
\text { stylesheet that } \\
\text { will override } \\
\text { the default } \\
\text { stylesheets of } \\
\text { Koha. }\end{array}$ & & $\begin{array}{l}\text { This is useful if the } \\
\text { stylesheet you want to } \\
\text { use is maintained on a } \\
\text { different server. } \\
\text { Specify the full url } \\
\text { including the http://, } \\
\text { something like: } \\
\text { http: //mysite. } \\
\text { com/css/ } \\
\text { mystaffstylesheet. } \\
\text { css. }\end{array}$ \\
\hline
\end{tabular}

\section{Configuring general preferences}

And finally we turn our attention to configuring other general Koha features:

- Messaging: Is related to how Koha communicates with patrons

- Security: How access to the OPAC and the staff client is secured

- Search: How catalog search can be tailored to a Library's needs

\section{Configuring messaging preferences}

Libraries need to communicate with patrons for a variety of reasons - to inform them of account creation, or of upcoming events, or to remind them of overdue items.

Sometimes patrons too need to communicate with libraries, for instance to request a change in their address, or to make a purchase suggestion. 
Koha can send messages to patrons via e-mail or SMS. Most Koha libraries use e-mail. We are already familiar with setting up overdue notices and trigger from previous chapters. In addition to overdue notices Koha can send other types of messages on upcoming events, when holds are fulfilled, or when items are nearly due. Libraries can choose to allow patrons to set their individual messaging preferences or the Library staff can set these up for patrons.

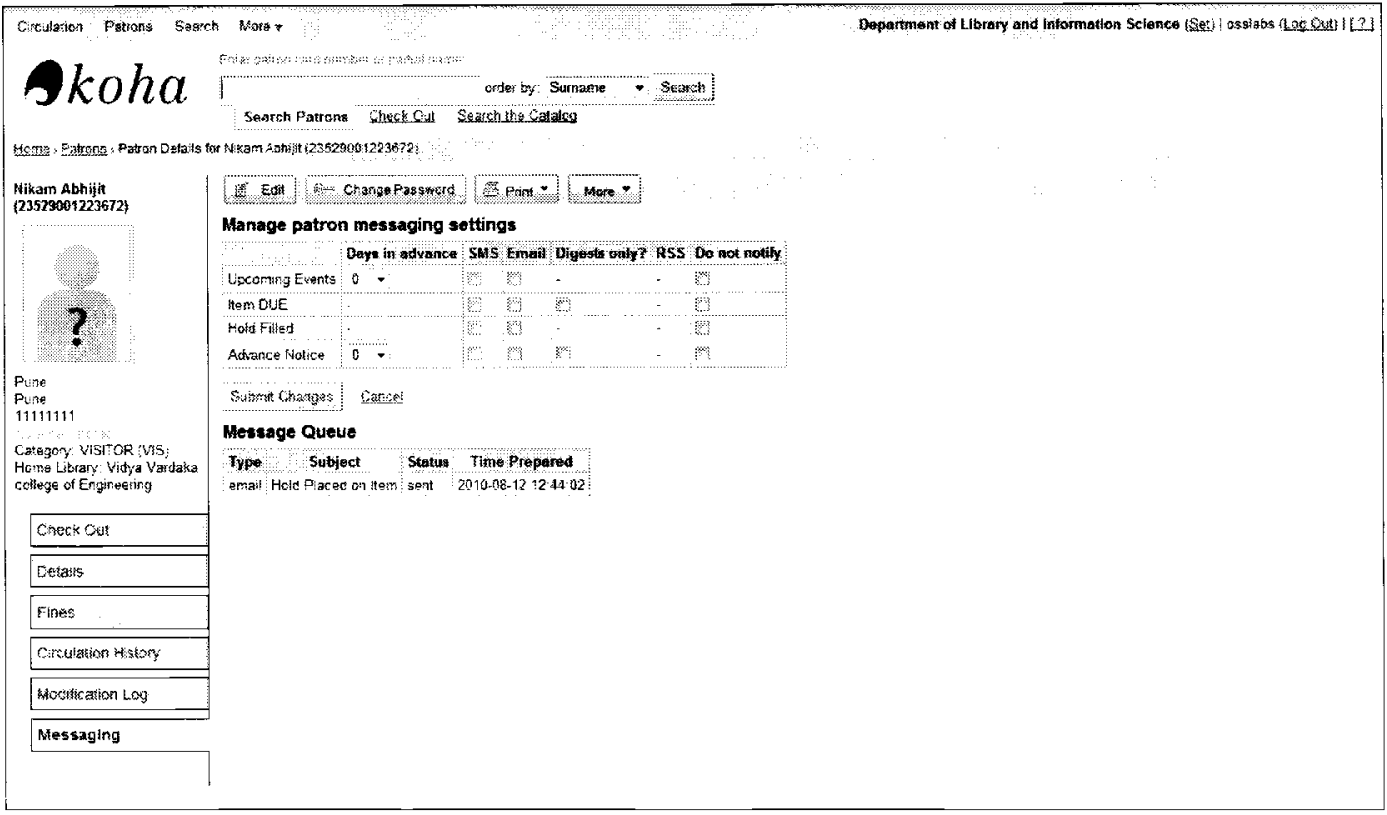


Here is a listing of messaging-related preferences along with instructions on how to set then up:

\begin{tabular}{|c|c|c|c|c|}
\hline System preference & $\begin{array}{l}\text { System } \\
\text { preferences } \\
\text { tab }\end{array}$ & Description & $\begin{array}{l}\text { Default } \\
\text { value }\end{array}$ & $\begin{array}{l}\text { Additional } \\
\text { information }\end{array}$ \\
\hline EnhancedMessagingPreferences & Patrons & $\begin{array}{l}\text { Whether } \\
\text { to allow } \\
\text { enhanced } \\
\text { messaging } \\
\text { preferences }\end{array}$ & Off & $\begin{array}{l}\text { With this turned } \\
\text { on, an additional } \\
\text { Messaging tab } \\
\text { becomes available } \\
\text { in the OPAC and } \\
\text { the staff client. } \\
\text { Patrons or Staff } \\
\text { can choose to } \\
\text { receive messages } \\
\text { on events, nearly } \\
\text { due items, or } \\
\text { holds that are } \\
\text { filled. }\end{array}$ \\
\hline AutoEmailOpacUser & Patrons & $\begin{array}{l}\text { Whether } \\
\text { to send an } \\
\text { e-mail to a } \\
\text { patron upon } \\
\text { account } \\
\text { creation } \\
\text { with } \\
\text { account } \\
\text { details }\end{array}$ & Off & $\begin{array}{l}\text { Set this to On, if } \\
\text { you have a mail } \\
\text { server configured } \\
\text { and in general } \\
\text { you have patron } \\
\text { e-mail addresses } \\
\text { handy when } \\
\text { creating patron } \\
\text { accounts. }\end{array}$ \\
\hline emailLibrarianWhenHoldIsPlaced & Circulation & $\begin{array}{l}\text { Whether } \\
\text { to send an } \\
\text { e-mail to } \\
\text { the library } \\
\text { e-mail } \\
\text { address } \\
\text { when a hold } \\
\text { is placed }\end{array}$ & Off & $\begin{array}{l}\text { Turn this On } \\
\text { if library staff } \\
\text { monitor e-mails } \\
\text { more often than } \\
\text { the Koha holds } \\
\text { reports. }\end{array}$ \\
\hline
\end{tabular}




\begin{tabular}{|c|c|c|c|c|}
\hline System preference & $\begin{array}{l}\text { System } \\
\text { preferences } \\
\text { tab }\end{array}$ & Description & $\begin{array}{l}\text { Default } \\
\text { value }\end{array}$ & $\begin{array}{l}\text { Additional } \\
\text { information }\end{array}$ \\
\hline \multirow[t]{7}{*}{ AutoEmailPrimary Address } & Patrons & $\begin{array}{l}\text { The default } \\
\text { patron } \\
\text { email } \\
\text { address to } \\
\text { use when } \\
\text { sending } \\
\text { messages }\end{array}$ & Off & $\begin{array}{l}\text { A patron record } \\
\text { may have one } \\
\text { or more e-mail } \\
\text { addresses. This } \\
\text { preference } \\
\text { controls how the } \\
\text { e-mail address is } \\
\text { selected. }\end{array}$ \\
\hline & & & & $\begin{array}{l}\text { Select email if you } \\
\text { want the home } \\
\text { e-mail to be used. }\end{array}$ \\
\hline & & & & $\begin{array}{l}\text { Select emailpro } \\
\text { if you want the } \\
\text { office e-mail to be } \\
\text { used. }\end{array}$ \\
\hline & & & & $\begin{array}{l}\text { Select B_email } \\
\text { if you want the } \\
\text { alternate e-mail to } \\
\text { to be used. }\end{array}$ \\
\hline & & & & $\begin{array}{l}\text { Select } \\
\text { cardnumber if } \\
\text { you have e-mail } \\
\text { addresses in the } \\
\text { card number field. }\end{array}$ \\
\hline & & & & $\begin{array}{l}\text { In above cases if } \\
\text { the field does not } \\
\text { have an e-mail } \\
\text { address, notices } \\
\text { will not be sent. }\end{array}$ \\
\hline & & & & $\begin{array}{l}\text { Select "Off" if you } \\
\text { want the first } \\
\text { available address } \\
\text { to be used, the } \\
\text { system checks } \\
\text { email, emailpro, } \\
\text { and B_email in } \\
\text { that order. }\end{array}$ \\
\hline
\end{tabular}




\begin{tabular}{|c|c|c|c|c|}
\hline System preference & $\begin{array}{l}\text { System } \\
\text { preferences } \\
\text { tab }\end{array}$ & Description & $\begin{array}{l}\text { Default } \\
\text { value }\end{array}$ & $\begin{array}{l}\text { Additional } \\
\text { information }\end{array}$ \\
\hline KohaAdminEmailAddress & Admin & $\begin{array}{l}\text { This } \\
\text { address } \\
\text { is used to } \\
\text { both send } \\
\text { and receive } \\
\text { e-mails }\end{array}$ & $\begin{array}{l}\text { root@ } \\
\text { localhost }\end{array}$ & $\begin{array}{l}\text { Make sure this } \\
\text { is set to a valid } \\
\text { e-mail address. } \\
\text { It is also a good } \\
\text { practice to set up } \\
\text { e-mail addresses } \\
\text { for each library } \\
\text { in Libraries, } \\
\text { Branches and } \\
\text { Groups under } \\
\text { Administration. }\end{array}$ \\
\hline
\end{tabular}

\section{Configuring security preferences}

Securing access to the OPAC and especially the staff client is important to any library. Koha's offers several ways of securing access:

- Requires valid login ID and password for both OPAC and the staff client

- Only staff users can access the staff client

- Staff access to modules with the staff client can be restricted using granular permissions

- Access to the staff client can be restricted to IP address ranges

- In multi-library installations, access to other libraries patron, circulation, and catalog data can be prevented

Most security-related preferences are under the Admin tab. 


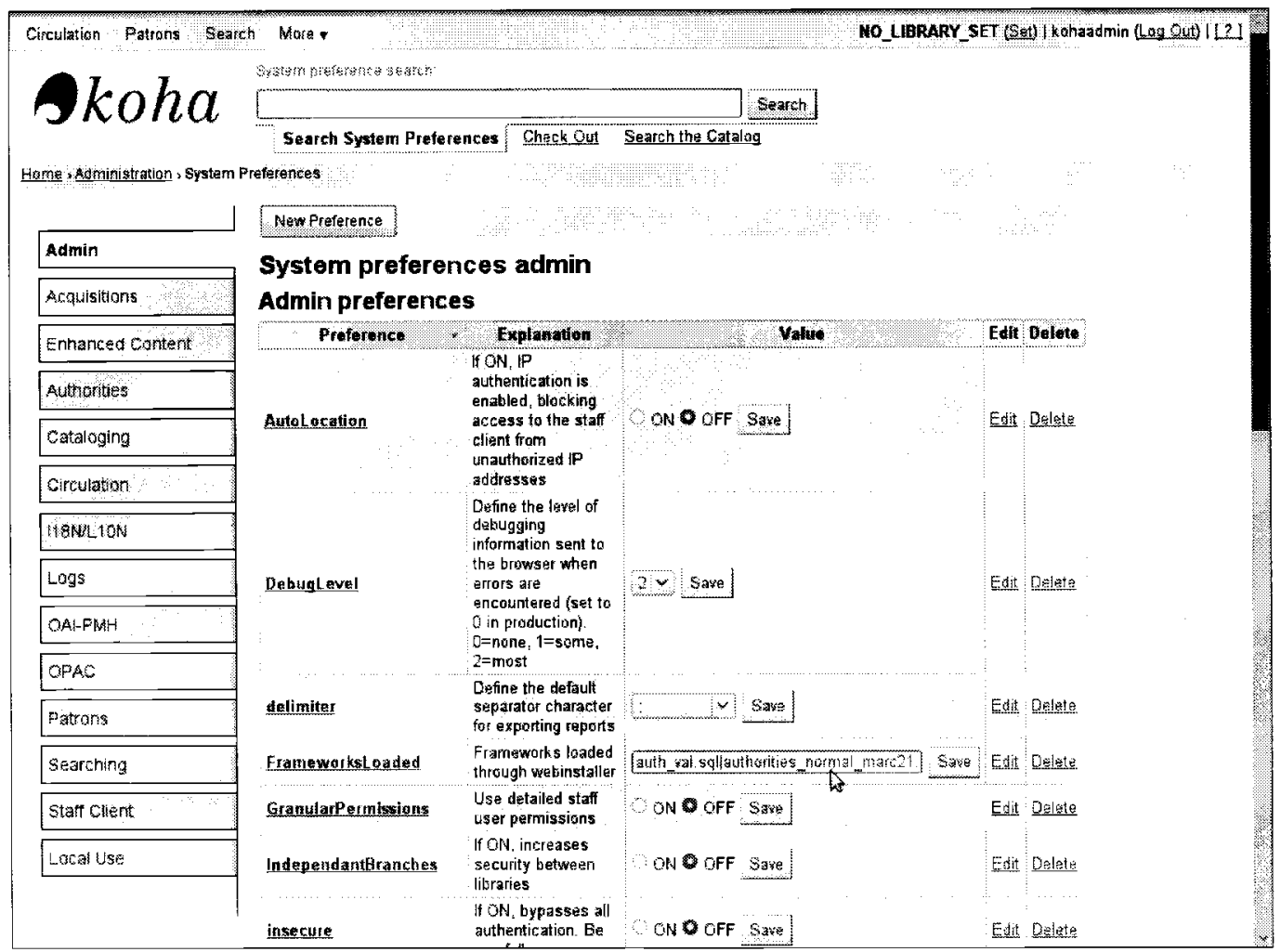

Here is a listing of security-related preferences with instructions on how to set them up:

\begin{tabular}{lllll}
\hline System preference & $\begin{array}{l}\text { System } \\
\text { preferences } \\
\text { tab }\end{array}$ & Description & $\begin{array}{l}\text { Default } \\
\text { value }\end{array}$ & Instructions \\
\hline minPasswordLength & Patrons & $\begin{array}{l}\text { The minimum } \\
\text { length of } \\
\text { OPAC and } \\
\text { staff client } \\
\text { passwords }\end{array}$ & 3 & $\begin{array}{l}\text { The longer the } \\
\text { minimum password } \\
\text { length, better the } \\
\text { security. A value of } 6 \\
\text { is reasonable. }\end{array}$ \\
\hline
\end{tabular}




\begin{tabular}{|c|c|c|c|c|}
\hline System preference & $\begin{array}{l}\text { System } \\
\text { preferences } \\
\text { tab }\end{array}$ & Description & $\begin{array}{l}\text { Default } \\
\text { value }\end{array}$ & Instructions \\
\hline IndependantBranches & Admin & $\begin{array}{l}\text { Whether } \\
\text { to increase } \\
\text { security } \\
\text { between } \\
\text { multiple } \\
\text { libraries or } \\
\text { branches setup } \\
\text { on the system }\end{array}$ & Off & $\begin{array}{l}\text { Staff with super } \\
\text { librarian privileges } \\
\text { will not see any } \\
\text { difference. } \\
\text { Other staff users } \\
\text { will not be able to } \\
\text { view patrons of } \\
\text { other libraries, they } \\
\text { will not be able to } \\
\text { edit items of other } \\
\text { libraries nor circulate } \\
\text { items of other } \\
\text { libraries. }\end{array}$ \\
\hline AutoLocation & Admin & $\begin{array}{l}\text { Whether to } \\
\text { block access } \\
\text { to the staff } \\
\text { client from } \\
\text { unauthorized } \\
\text { IP addresses }\end{array}$ & Off & $\begin{array}{l}\text { Turn "On" to block } \\
\text { access. } \\
\text { Make sure you } \\
\text { set up authorized } \\
\text { IP addresses for } \\
\text { each library. This } \\
\text { can be done from } \\
\text { Libraries, Branches } \\
\text { and Groups under } \\
\text { Administration. }\end{array}$ \\
\hline GranularPermissions & Admin & $\begin{array}{l}\text { Whether to use } \\
\text { more detailed } \\
\text { permissions } \\
\text { for staff users }\end{array}$ & Off & $\begin{array}{l}\text { Turn this On if you } \\
\text { need more granular } \\
\text { permissions when } \\
\text { setting permissions } \\
\text { for staff users. } \\
\text { More granularity } \\
\text { becomes available } \\
\text { for tools, circulation, } \\
\text { and serials modules. }\end{array}$ \\
\hline timeout & Admin & $\begin{array}{l}\text { Duration after } \\
\text { which a user's } \\
\text { session should } \\
\text { time out }\end{array}$ & 12000000 & $\begin{array}{l}\text { This is in seconds. } \\
\text { Reduce this value } \\
\text { to decrease the } \\
\text { risk of someone } \\
\text { misusing another } \\
\text { staff member's idle } \\
\text { session. }\end{array}$ \\
\hline
\end{tabular}




\section{Configuring search preferences}

The catalog search tool is available on both the OPAC and the staff client. It is the most frequently used tool. Although the default search-related system preference should work for most libraries, it might be a good idea to consider changing some of these preferences to better tailor the search to your library's needs.

The search related system preferences can found under the Searching tab.

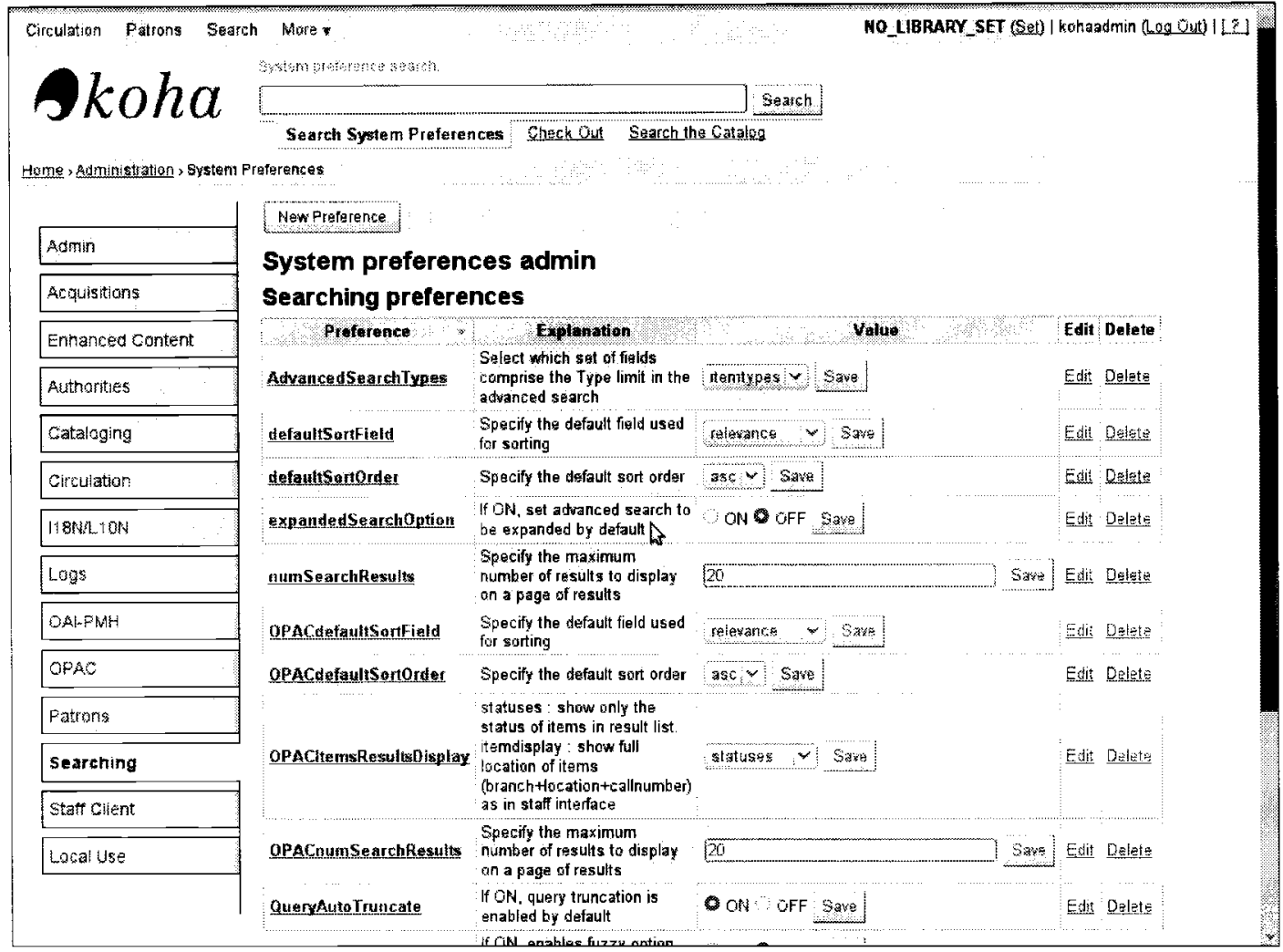


Here is the explanation of the search-related preferences along with instructions on configuring them:

\begin{tabular}{|c|c|c|c|c|}
\hline System preference & $\begin{array}{l}\text { System } \\
\text { preferences } \\
\text { tab }\end{array}$ & Description & $\begin{array}{l}\text { Default } \\
\text { value }\end{array}$ & Instructions \\
\hline AdvancedSearchTypes & Searching & $\begin{array}{l}\text { Whether } \\
\text { to use Item } \\
\text { types or } \\
\text { Collection } \\
\text { codes as } \\
\text { search } \\
\text { limits in the } \\
\text { Advanced } \\
\text { Search tool }\end{array}$ & itemtypes & $\begin{array}{l}\text { Search limits } \\
\text { allow one to } \\
\text { search within } \\
\text { item types or } \\
\text { collection codes. } \\
\text { To use collection } \\
\text { codes, your } \\
\text { records must } \\
\text { have collection } \\
\text { codes set up in } \\
\text { the collection } \\
\text { code field } 952 \$ 8 \text {. }\end{array}$ \\
\hline expandedSearchOption & Searching & $\begin{array}{l}\text { Whether } \\
\text { to display } \\
\text { additional } \\
\text { search } \\
\text { options in } \\
\text { the advanced } \\
\text { search page } \\
\text { by default } \\
\text { or only } \\
\text { when "more } \\
\text { options" are } \\
\text { clicked. }\end{array}$ & Off & $\begin{array}{l}\text { Turn "On" } \\
\text { to display } \\
\text { additional } \\
\text { options by } \\
\text { default. } \\
\text { To see what } \\
\text { additional } \\
\text { options are } \\
\text { available, click } \\
\text { on the More } \\
\text { Options link in } \\
\text { the Advanced } \\
\text { Search page on } \\
\text { the OPAC. }\end{array}$ \\
\hline QueryRemoveStopwords & Searching & $\begin{array}{l}\text { Whether to } \\
\text { remove stop } \\
\text { words from } \\
\text { search query } \\
\text { strings }\end{array}$ & Off & $\begin{array}{l}\text { If turned on, } \\
\text { the system will } \\
\text { automatically } \\
\text { remove from } \\
\text { search strings } \\
\text { words that } \\
\text { are set up in } \\
\text { Stop Words } \\
\text { under Koha } \\
\text { Administration. }\end{array}$ \\
\hline
\end{tabular}




\section{Summary}

Here is what we learned in this chapter:

- How to browse system preferences categories or to find them using the search tool

- Configuring Patrons, Acquisitions, and Serials preferences

- Configuring OPAC preferences - static content, tools for patrons, patron access control, and enhanced content

- Configuring styling and appearance on the OPAC and the staff client

- Configuring messaging, security, and search related preferences

This completes our application configuration work and we ready to use Koha. In the next chapter, we will conduct a test drive of our newly installed and configured Koha installation. 


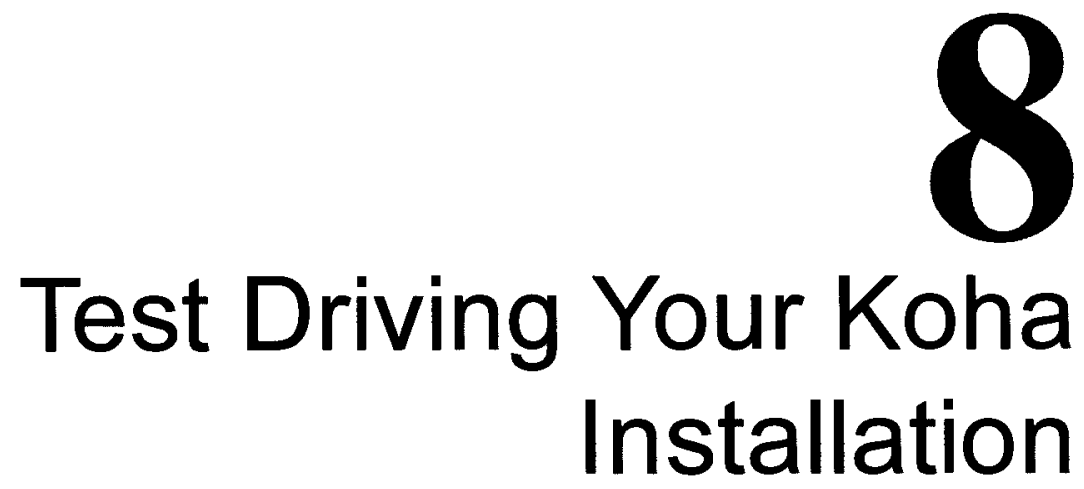

We have completed the server setup and the application configuration. We are now in a position to take our Koha installation for a test drive. We will look to complete a transaction cycle in each of the primary Koha modules:

- Patrons

- Cataloging

- Circulation

- Acquisition

- Serials

We will also test:

- The reports module

- The catalog search on the OPAC

\section{Patrons-create, search, and view patron record}

Let us first create a patron record. A patron record includes the patron's personal details such as name, date of birth, or address. Staff also need to specify the library the patron belongs to and his/her patron category. A user ID and password for use on the OPAC can also be set up. 


\section{Creating a new patron}

To create a patron record, navigate to the Patrons module using the menu bar at the top of the page and click on the New button in the Patrons home page. You will need to select the appropriate Patron Category first.

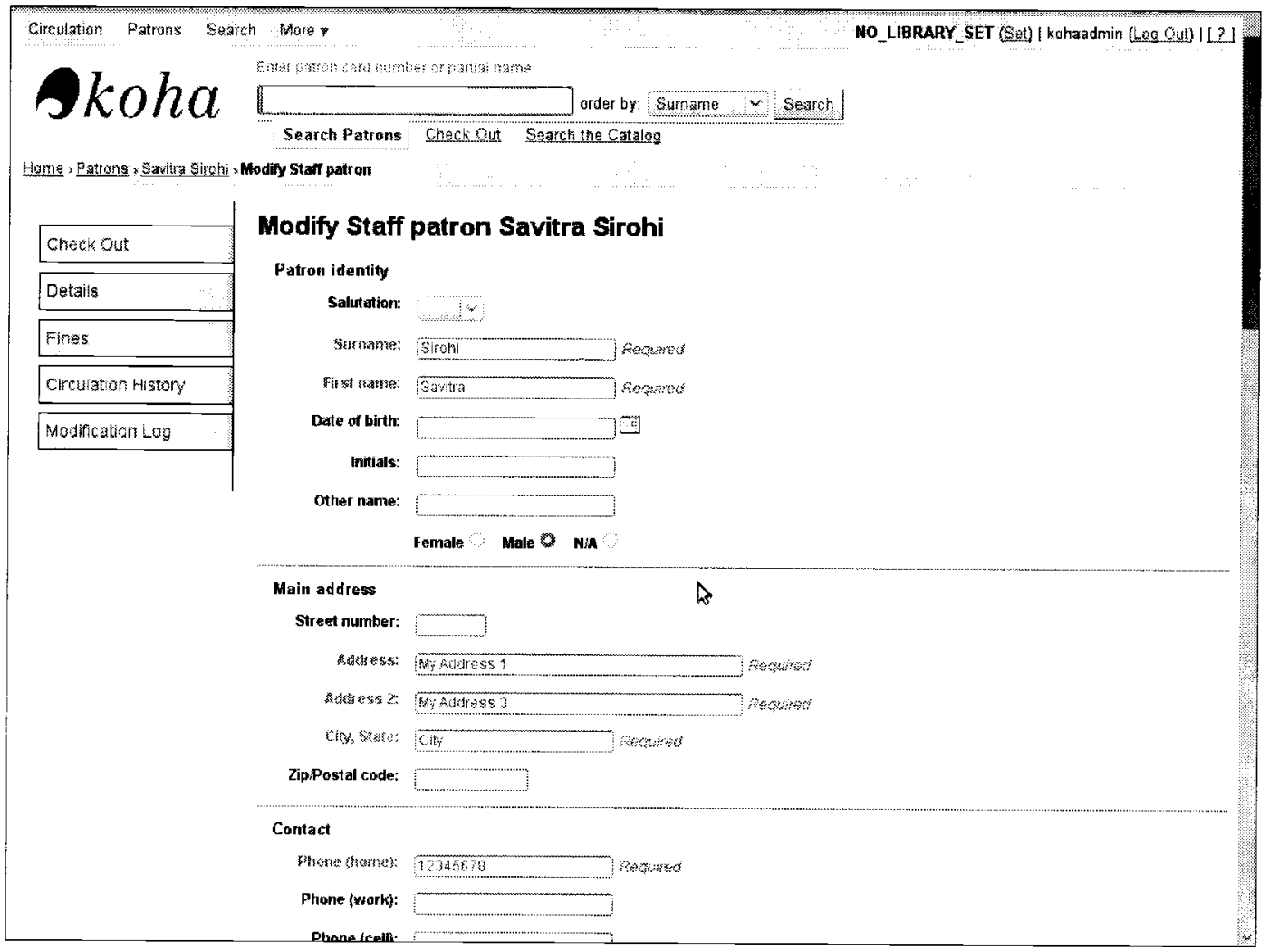

While you are creating the patron, you should verify the correctness of the following system preferences and administrative settings related to:

- Borrower's mandatory fields

- Membership expiry date calculation

- Auto card number generation

- Minimum password length 


\section{Searching for a patron}

Let us make sure the patron has been saved successfully. Use the Search Patrons tab under the search box to search for the particular patron.

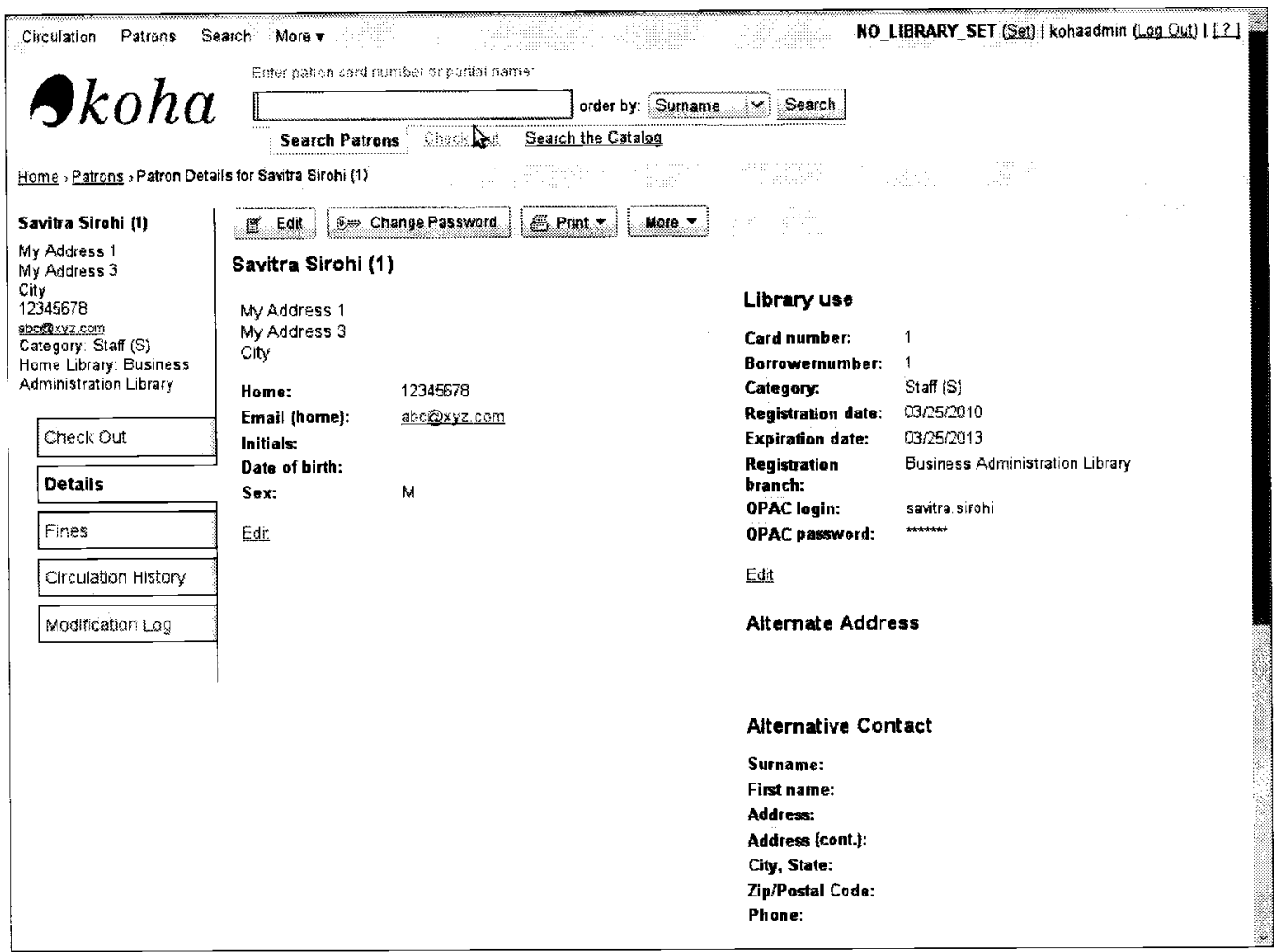

\section{Cataloging-create, search, and view bibliographic and item record}

In this section let us create a complete catalog record-a bibliographic record first, and then an item record under it. 


\section{Creating a bibliographic record}

To create a new record, navigate to the Cataloging module using the More drop-down list in the menu bar on the top of the page. Then use the New Record button. You will need to select the appropriate MARC framework first.

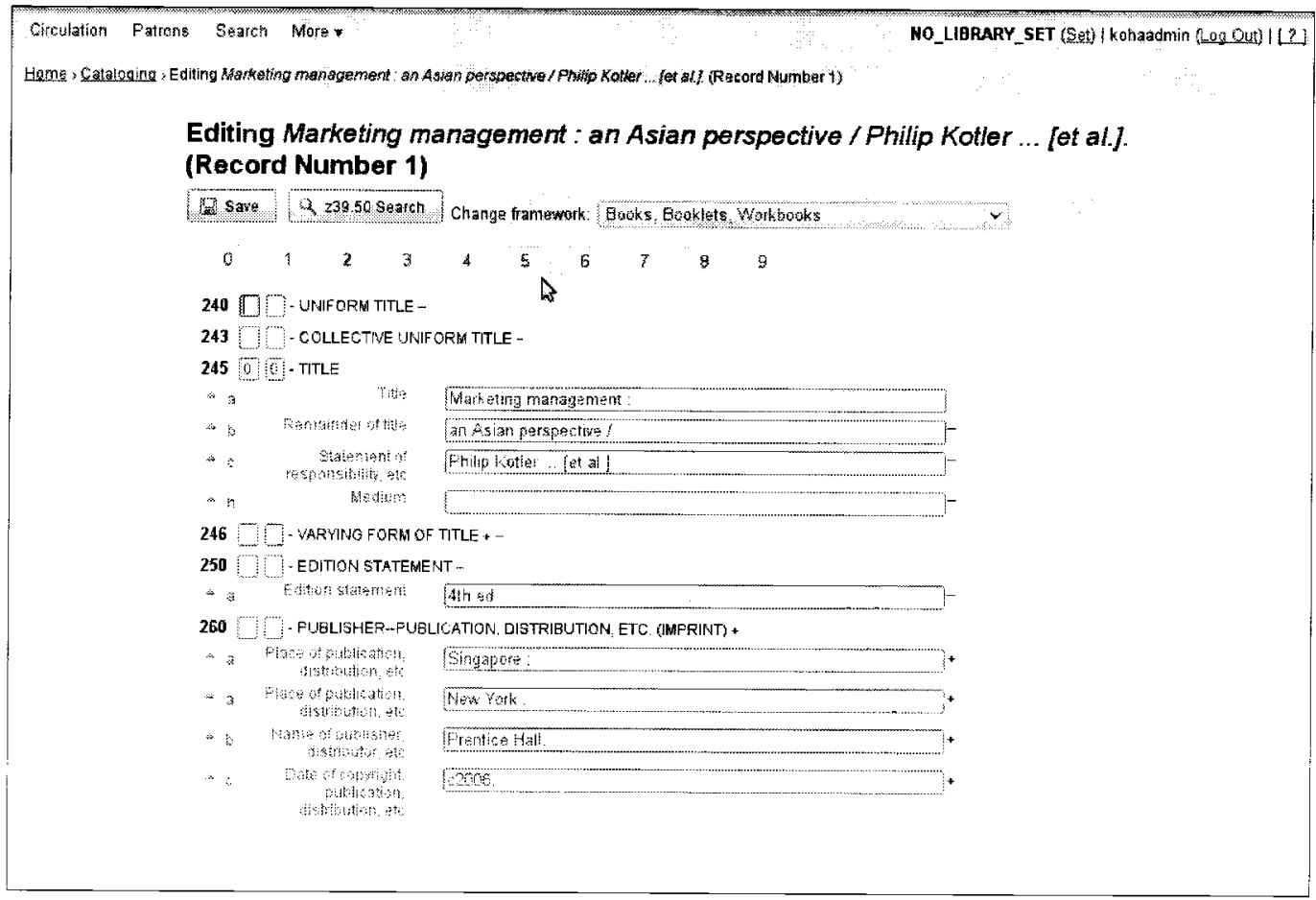

You can use the Z39.50 search feature to find and import records from the Library of Congress and other Z39.50 servers.

While you are cataloging the record, you might want to cross check your MARC framework settings:

- Fields displayed

- Mandatory fields

- Fields under Authority Control

- Fields under Authorized Values control 


\section{Creating an item record}

Once the bibliographic record is created, you will automatically move to the Add Item screen.

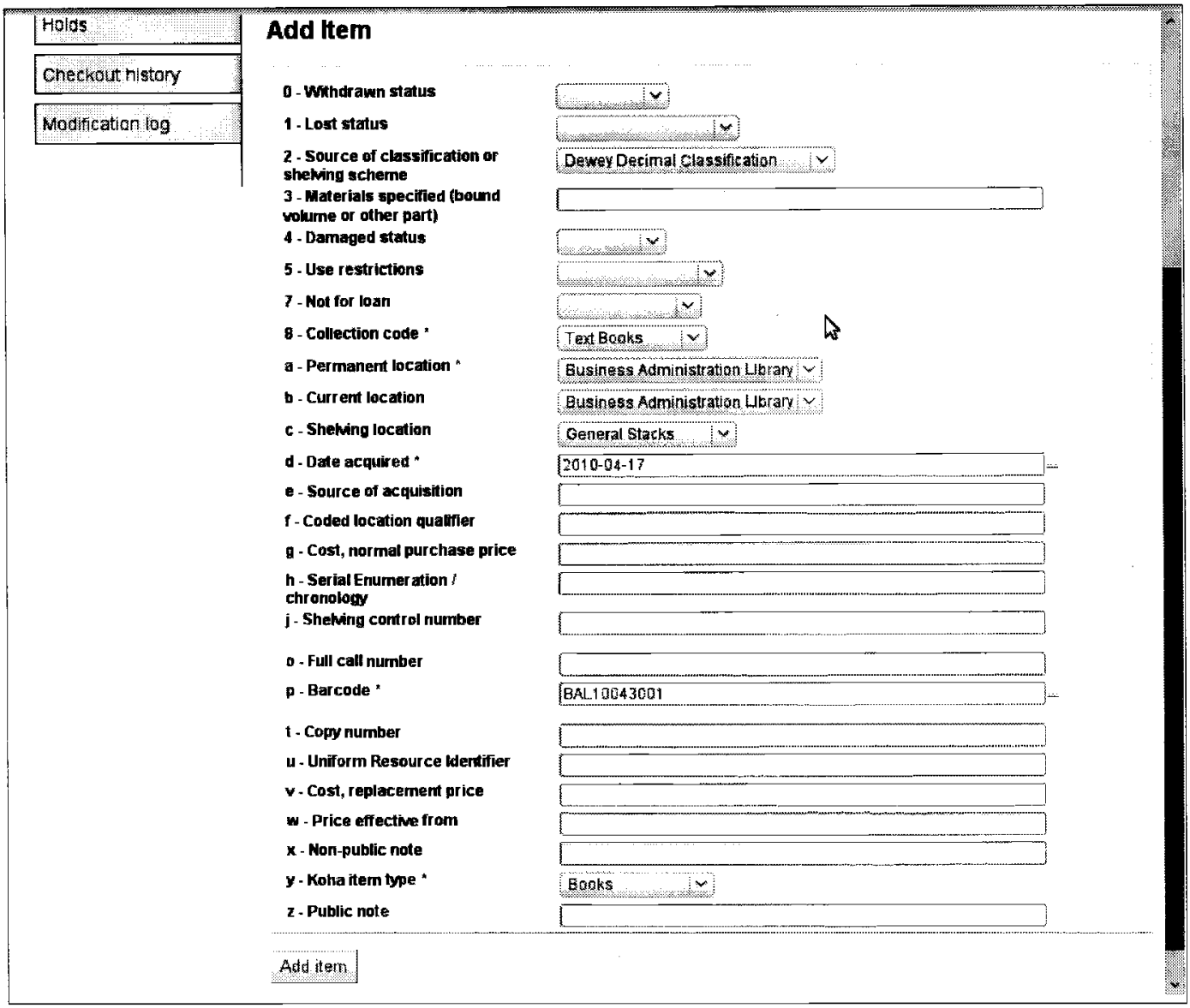

While adding the item record, you might want to cross check your MARC framework settings:

- Fields displayed

- Mandatory fields

- Fields under Authority Control

- Fields under Authorized Values control 


\section{Searching for the record}

Let us now make sure the bibliographic and item records are saved properly. Use the Search the Catalog tab under the search box to search for the record you just added.

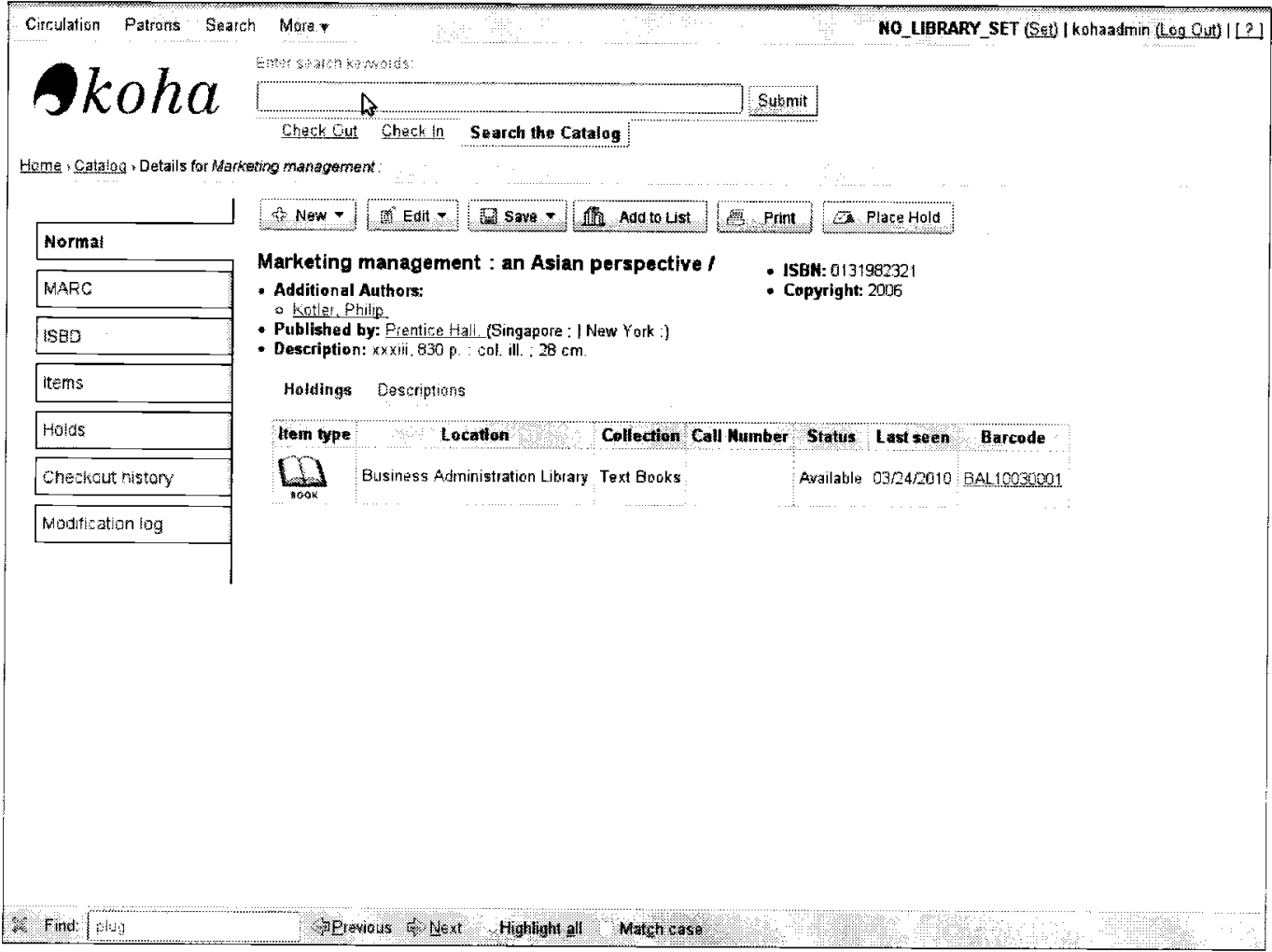

\section{Circulation-check-out, check-in, and view circulation history}

Now that we have a catalog record and a patron record, we are in a position to test circulation. We will perform a check-out operation followed by a check-in operation. 


\section{Checking out}

First navigate to the Circulation module using the menu bar on the top of the page. Then enter the name of the patron or the patron's card number in the search box. Make sure you are using the Check Out tab under the search box.

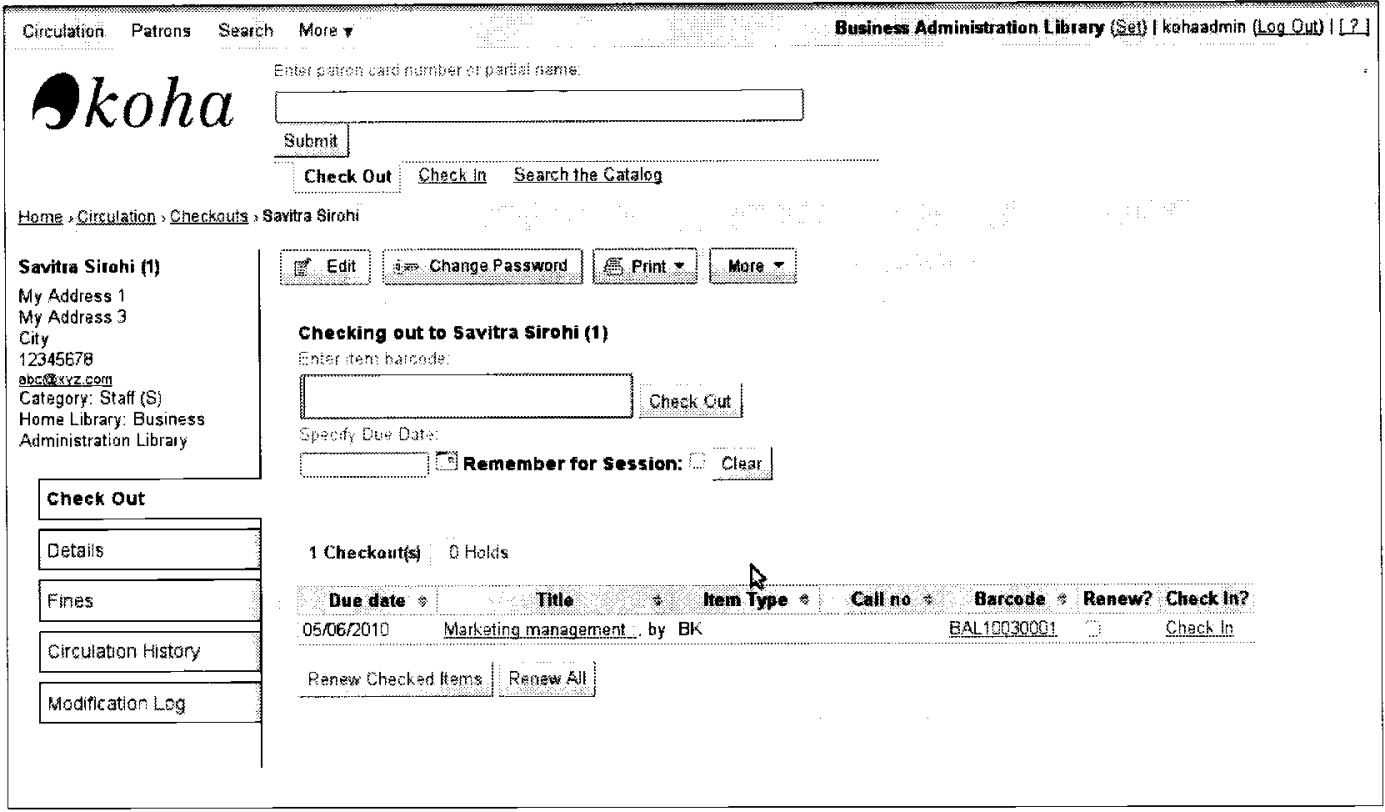

Once you click on Submit, you will enter the barcode of the item to be checked out.

During the operation you should verify that the due date is calculated in accordance with system preferences or administrative settings related to:

- Calculation of due date

- Holidays setup in the calendar 


\section{Checking in}

To check in, use the Check In tab under the search box. You will need to enter the item's barcode.

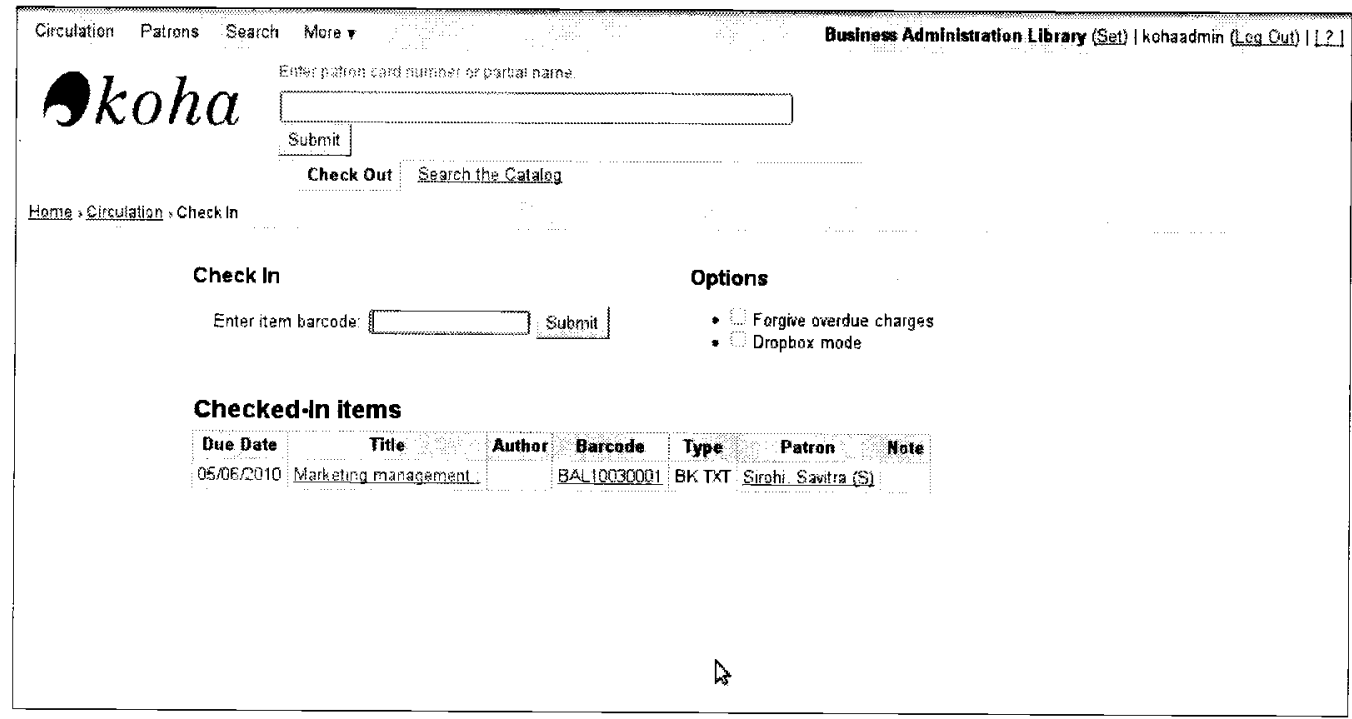

\section{Viewing circulation history}

Let us verify if the check-out and check-in operations were successful. Find the patron using the Search Patrons feature. Then click on the Circulation History tab to find the check out and check in records. 


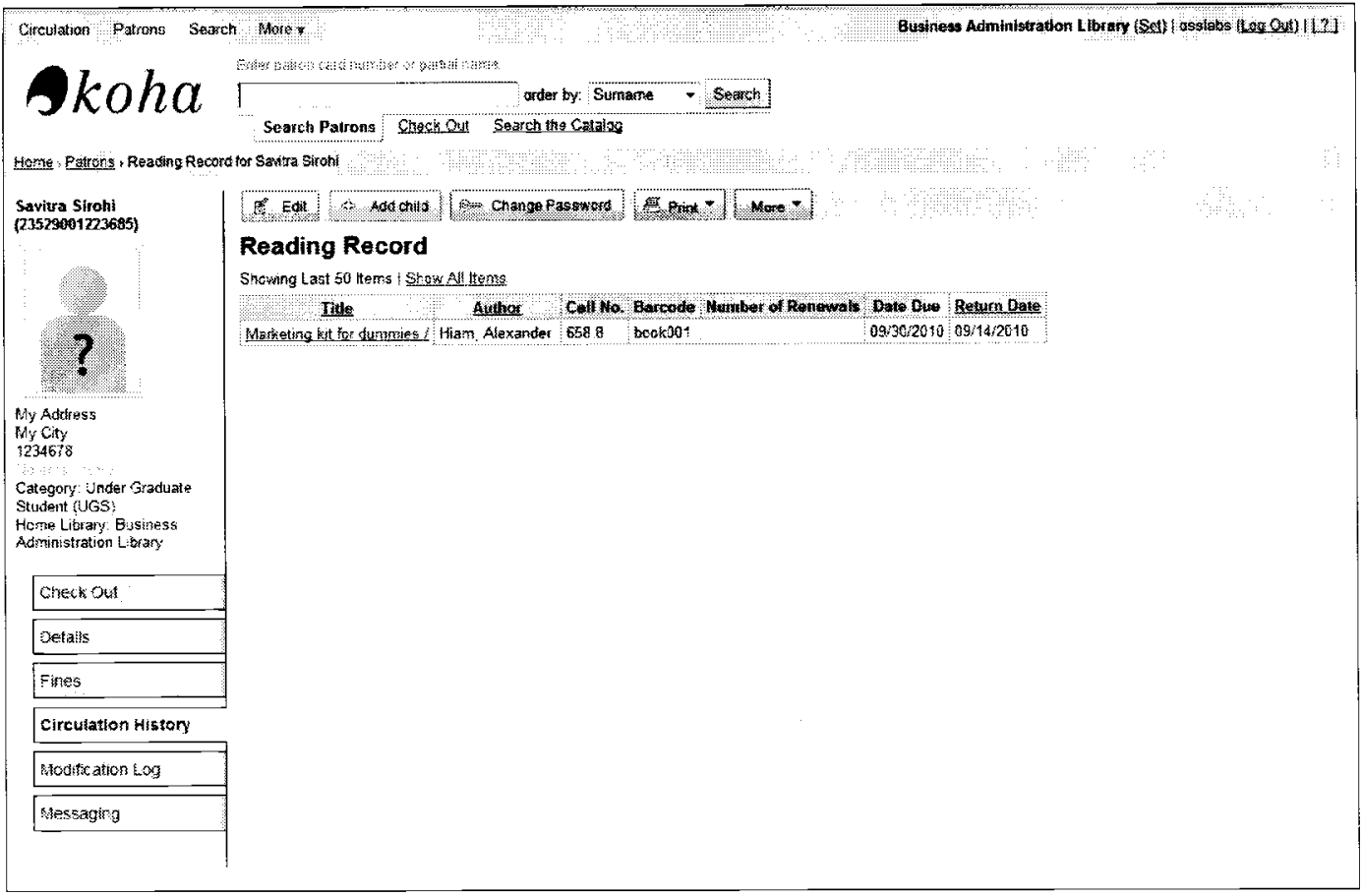

\section{Acquisitions-create an order, receive shipment, and view budget utilization}

To test the Acquisitions module we will create a budget, a vendor, and an order basket. We will then receive the shipment and finally test the impact of the order on the budget availability figures. 


\section{Creating budgets}

Navigate to the Funds and budgets section under Koha Administration. First create a Fund by entering a code, a name and optionally, indicate to the library what the fund is for. Then click on the Add Budget link. Enter the Fund and the Budget amount. Optionally, enter in the Library what the budget is for and the Start date and End date.

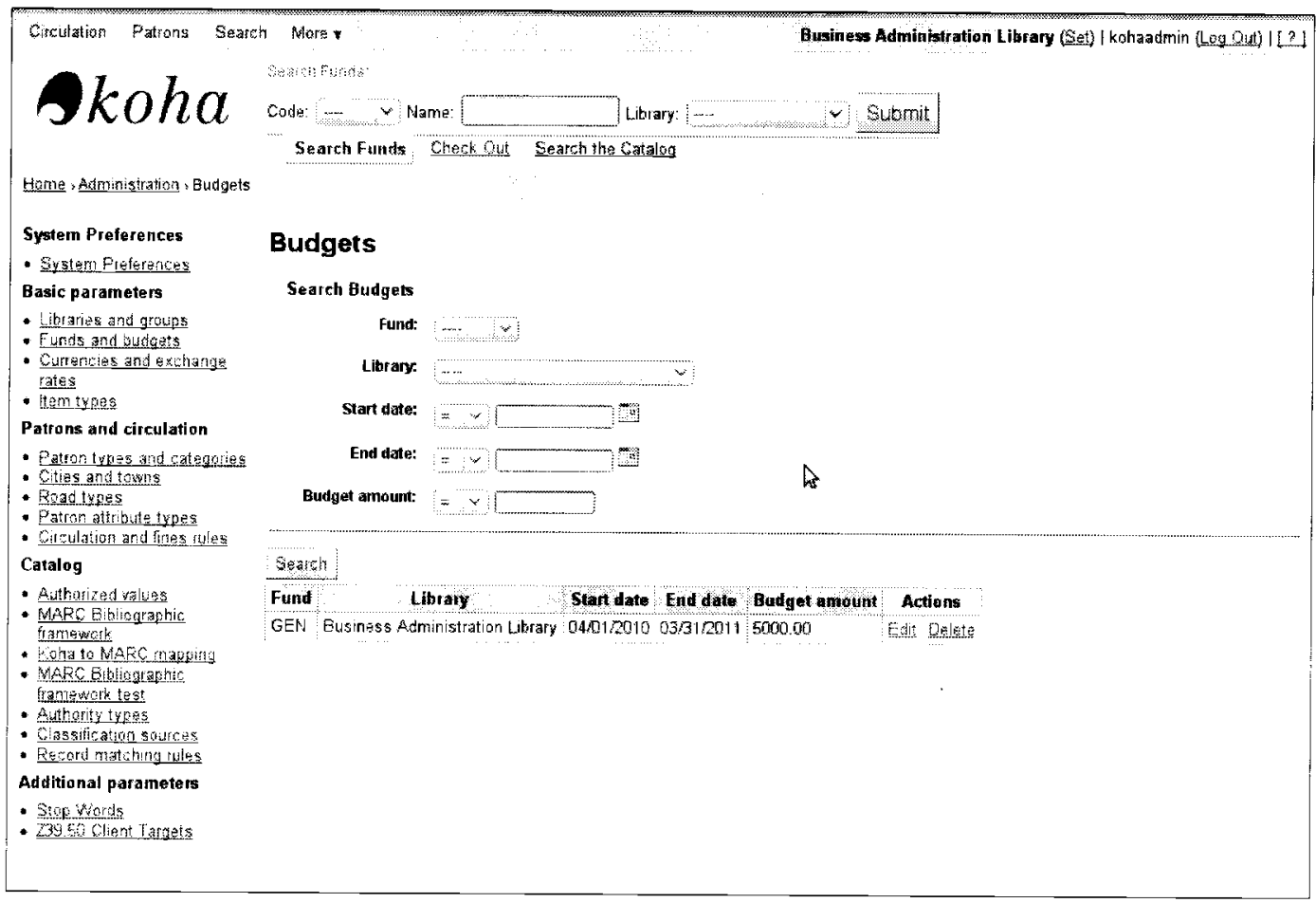

\section{Creating a vendor}

Before we create an order basket, we need to create a vendor - a book seller or a publisher. Navigate to the Acquisitions module using the More drop-down list. Then click on the New Vendor button to enter the vendor details. 


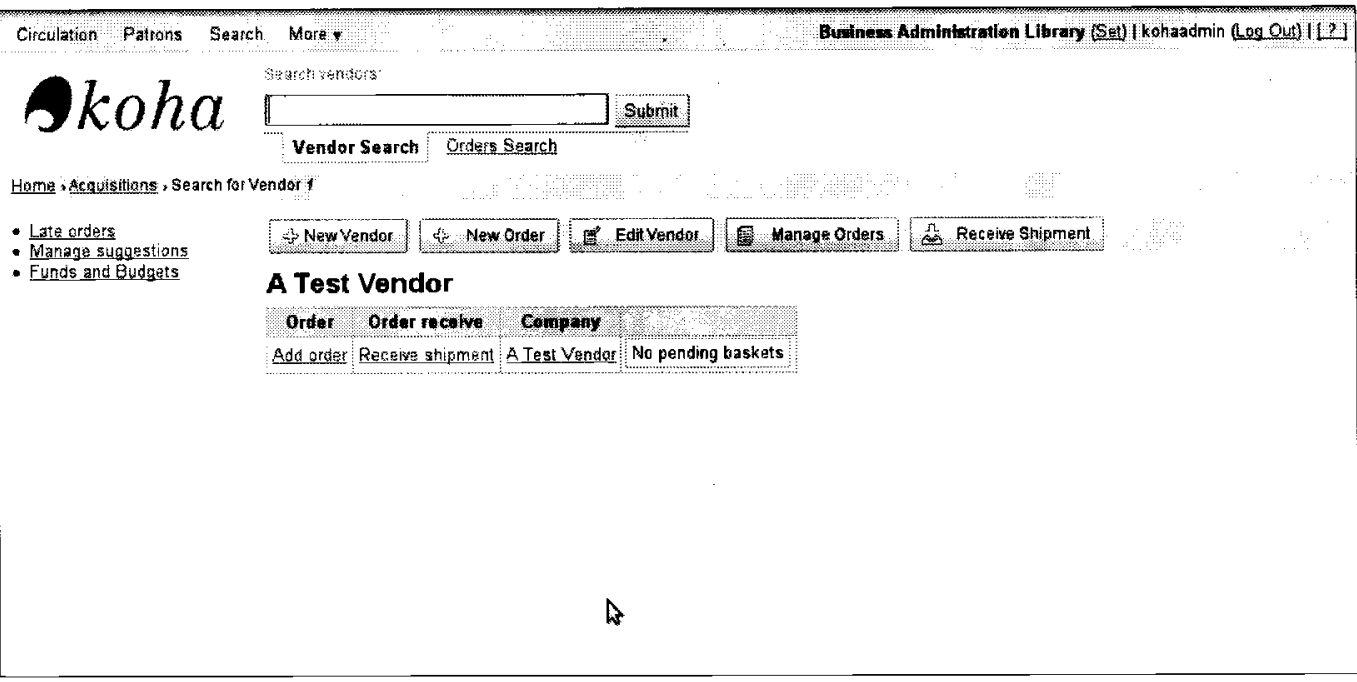

\section{Creating orders}

To create an order basket click on the New Order button on the Add order link.

Once you enter the order details you should see an order basket summary. You can modify the basket at this stage. Once the order is finalized, click on the Close this basket link.

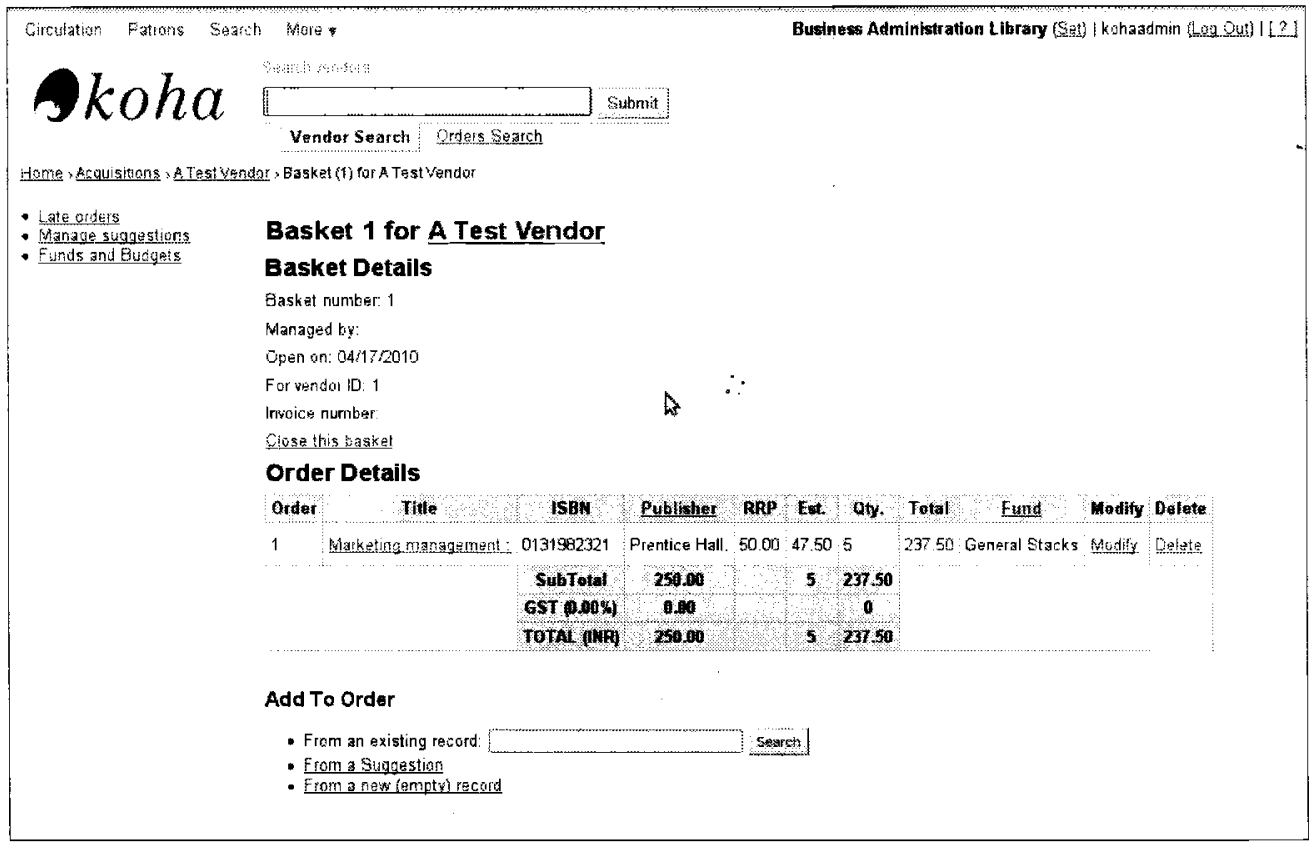




\section{Receiving shipments}

To receive a shipment, click on the Receive Shipment button.

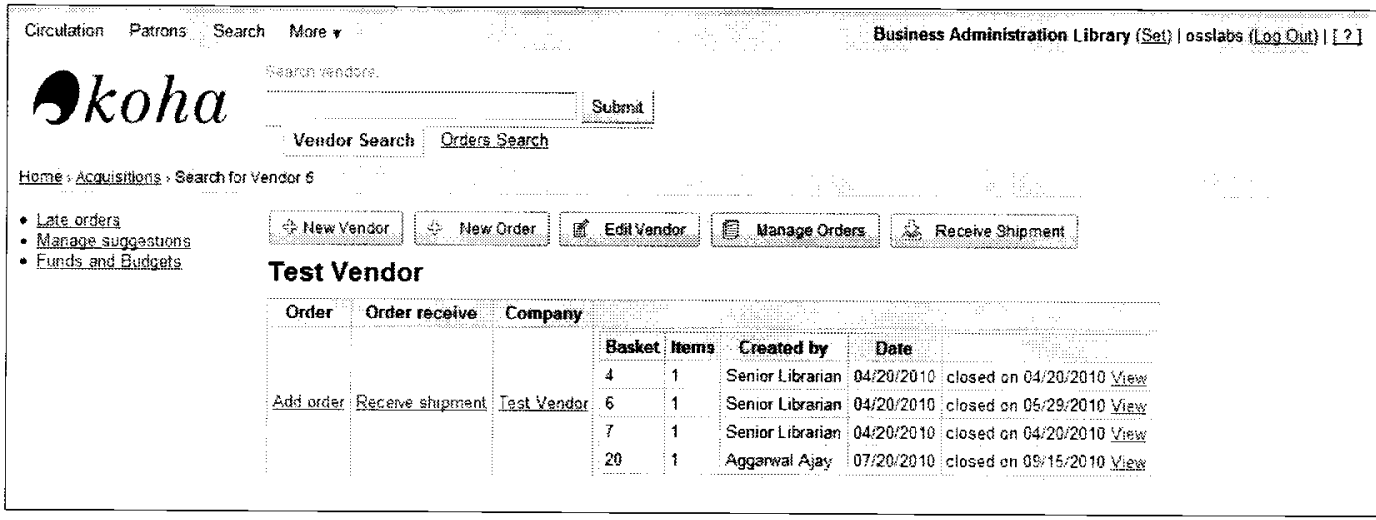

You will need to enter barcode and other details for each item in the shipment. Use the $[+]$ link above the Save button to create a new empty block for each copy. Once you accession each copy, click on Save to finish the process of receiving items.

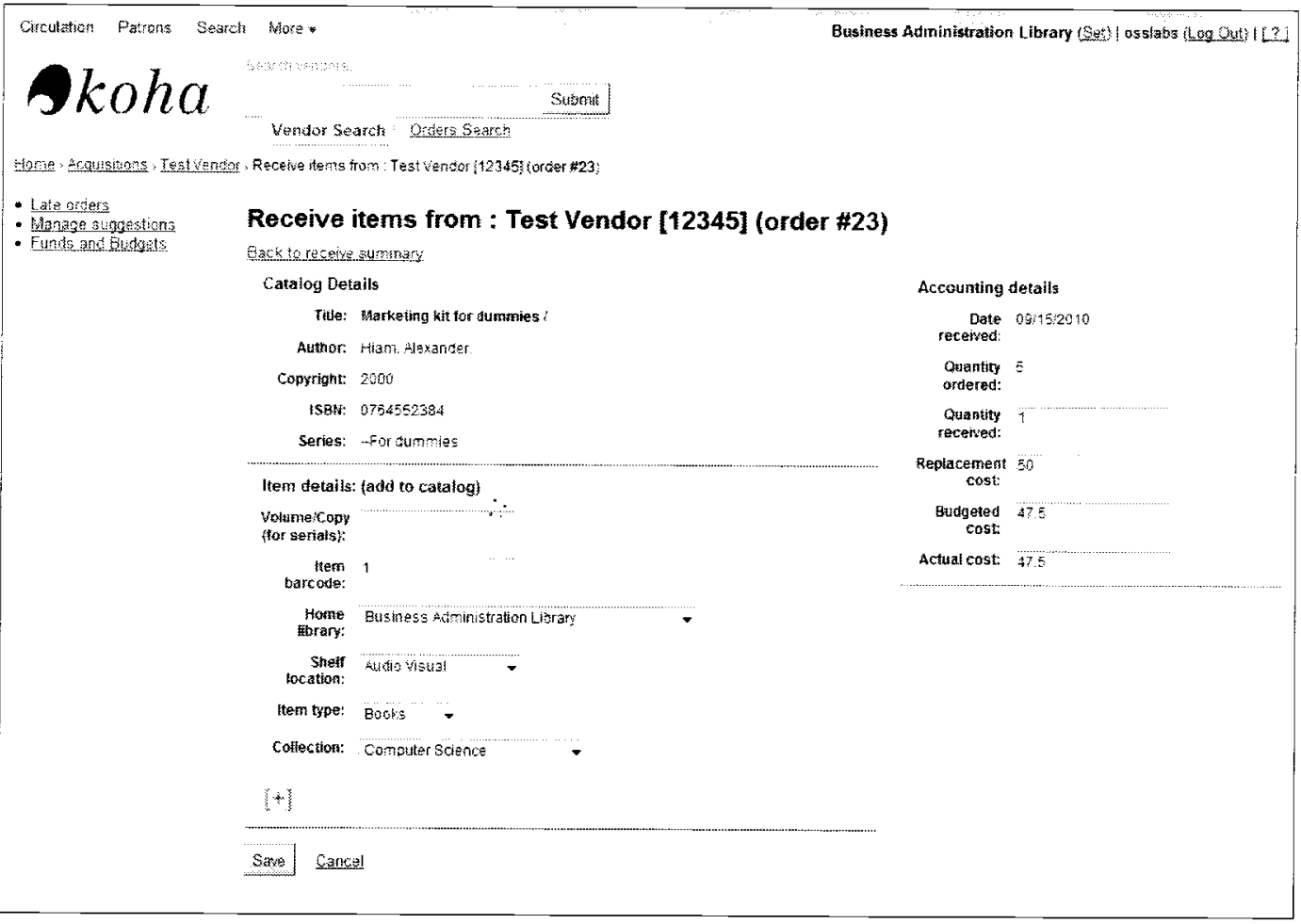




\section{Viewing budget utilization}

Finally, let us take a peek at the budget figures; the Spent and Avail amount will be automatically changed to reflect the order you just closed.

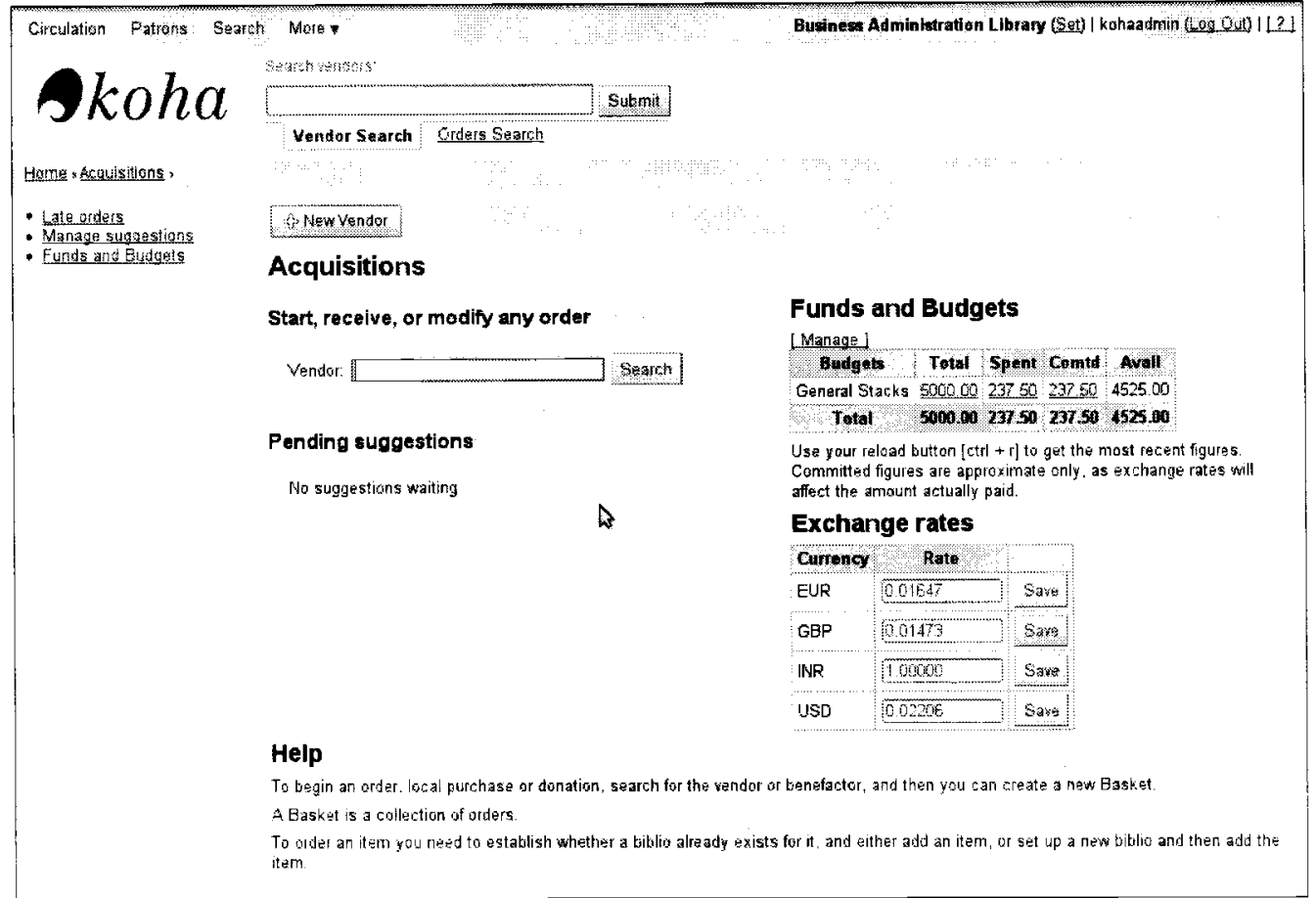

\section{Serials-creating a subscription and receiving the first issue}

Let us now test the Serials module. This module is used to manage serials or periodicals. Staff enter information about the subscription such as the vendor, the related bibliographic record, the frequency of receiving issue or numbering pattern, and subscription length. The subscription record is then used to track receipt of issues and the renewal of the subscription.

We will first create subscription and then receive the first issue for this subscription.

\section{Creating a subscription}

Navigate to the Serials module using the More drop-down list. Click on the New Subscription button to enter the subscription details. 
Fields with labels in red are mandatory.

Here are the steps to entering subscription details:

1. Select a vendor by using the Search for a vendor link

2. Use the Search for Biblio or the Create Biblio links to link a bibliographic record to the subscription

3. Choose whether you want an item record for each issue or not

4. Enter other details such as Call Number and Library the subscription belongs to

Here are steps to Serials planning:

1. Enter the First issue publication date, this is the publication date of the first issue that will arrive in the library

2. Enter the Frequency; there are several options available such as $1 /$ month or 1/week

3. Choose the Numbering pattern of the Serial

4. Enter the Starting with and Rollover at details

5. Use the Test Prediction Pattern button to test whether the pattern is correct. You should see a message No irregularities noticed.

6. Click on the Save Subscription button
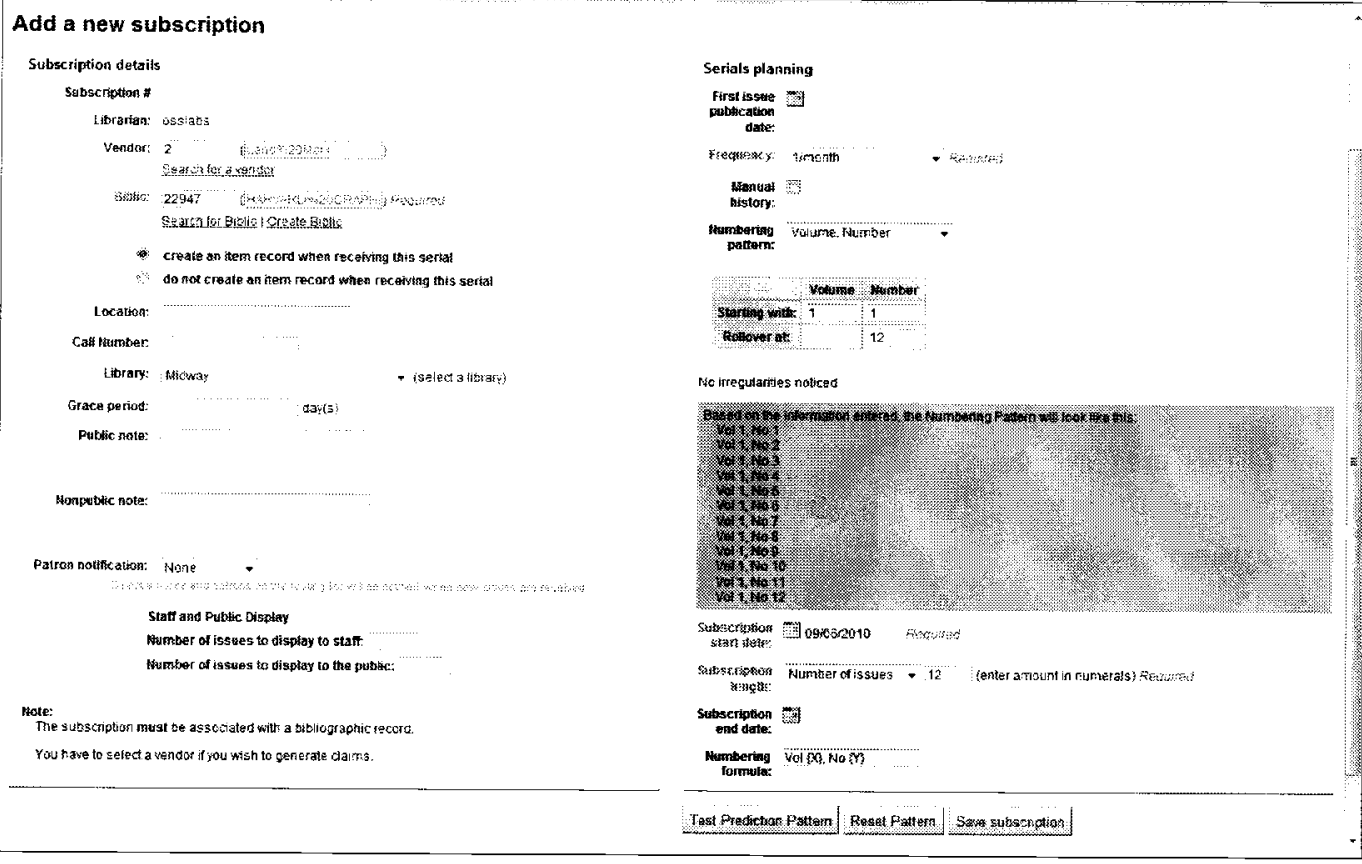


\section{Searching for the subscription}

Let us make sure that the subscription is saved successfully. Use the Search Subscriptions tab to find the record. Enter either the ISSN or the Title of the subscription and click on the Search button.

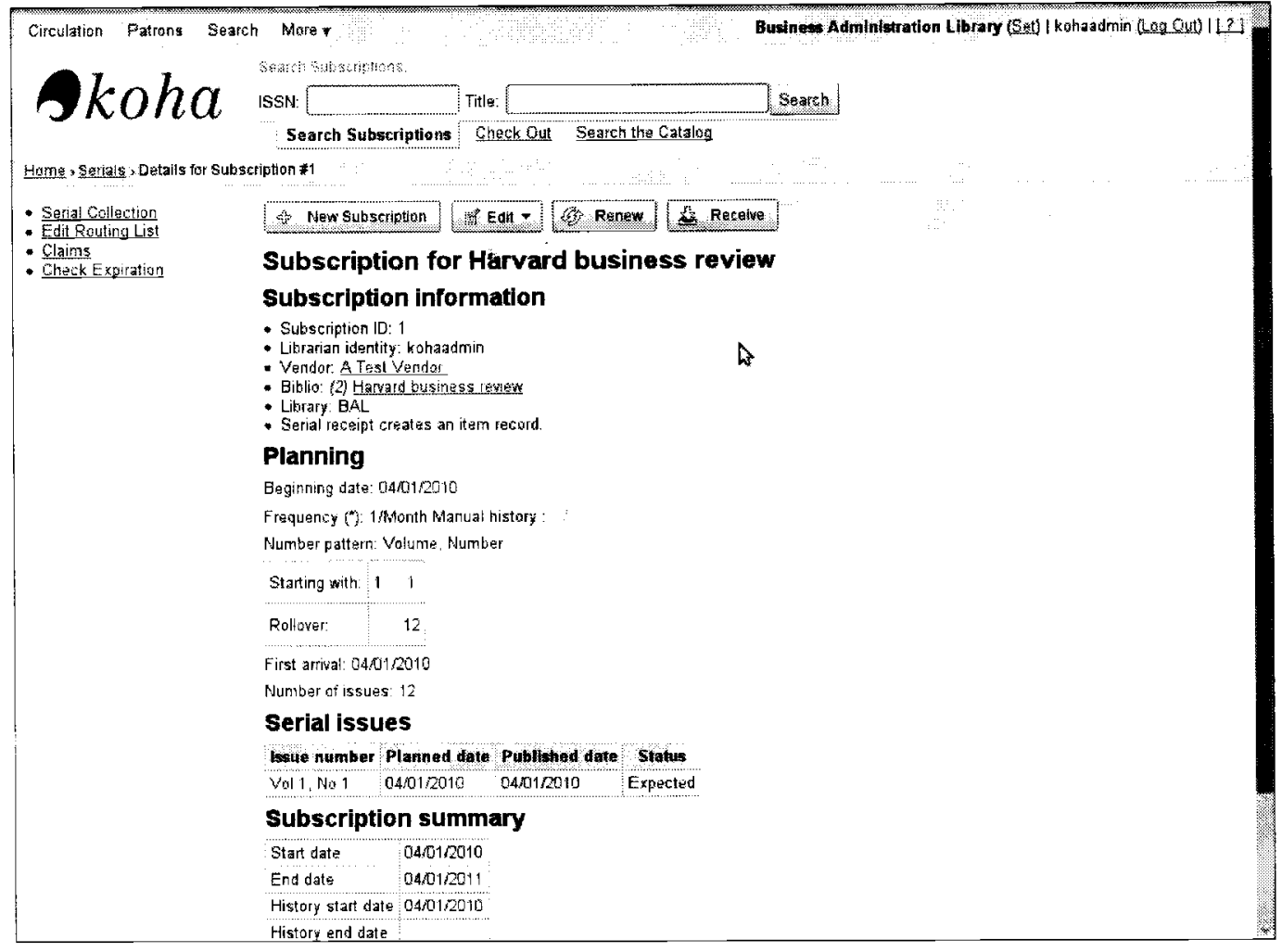




\section{Receiving an issue}

When the issue arrives in the Library, the staff needs to update the subscription record to account for this event. To receive an issue, we use the Receive button as shown in the previous screenshot.

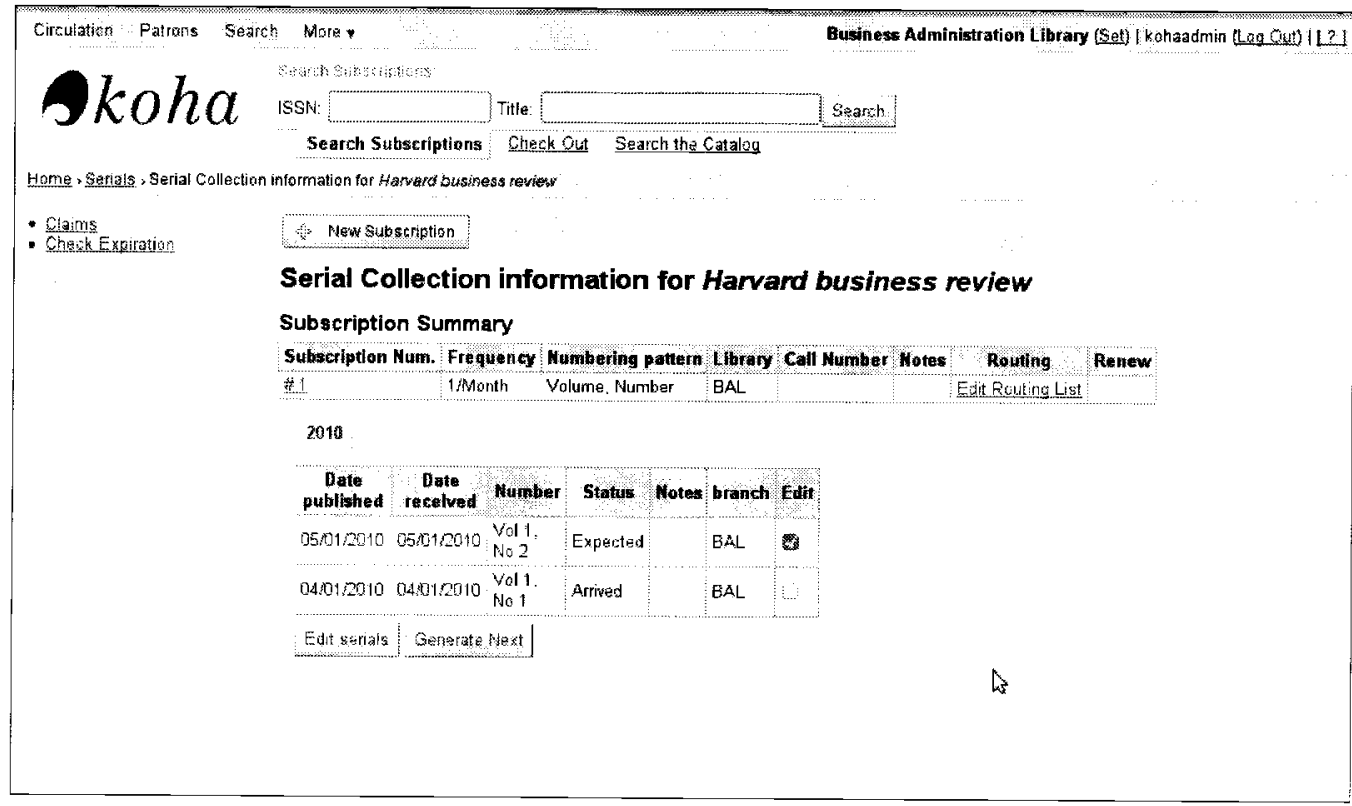

\section{Reports-creating a guided report and executing it}

Let us now test the Reports module. This module allows staff to create reports using a guided reports wizard or using SQL statements. Reports that are created can be saved and generated at a later time. This module also has statistics wizards for various functional modules and a few commonly used pre-built reports.

In this test drive we create a guided report and test its execution.

\section{Building a report}

Navigate to the Reports home page using the More drop-down list. Click on the Guided Reports link. Use the Build New button to launch the guided reports wizard. 
We go through the following steps to create the report:

1. Select the module that we want to query.

2. Choose the display format.

3. Choose a set of fields for the reports' columns.

4. Set selection criteria or limits.

5. Configure how you want data to be totaled.

6. Choose how you want the report to be ordered.

Click on the Finish button to create the report. You will need to save the report before using it.

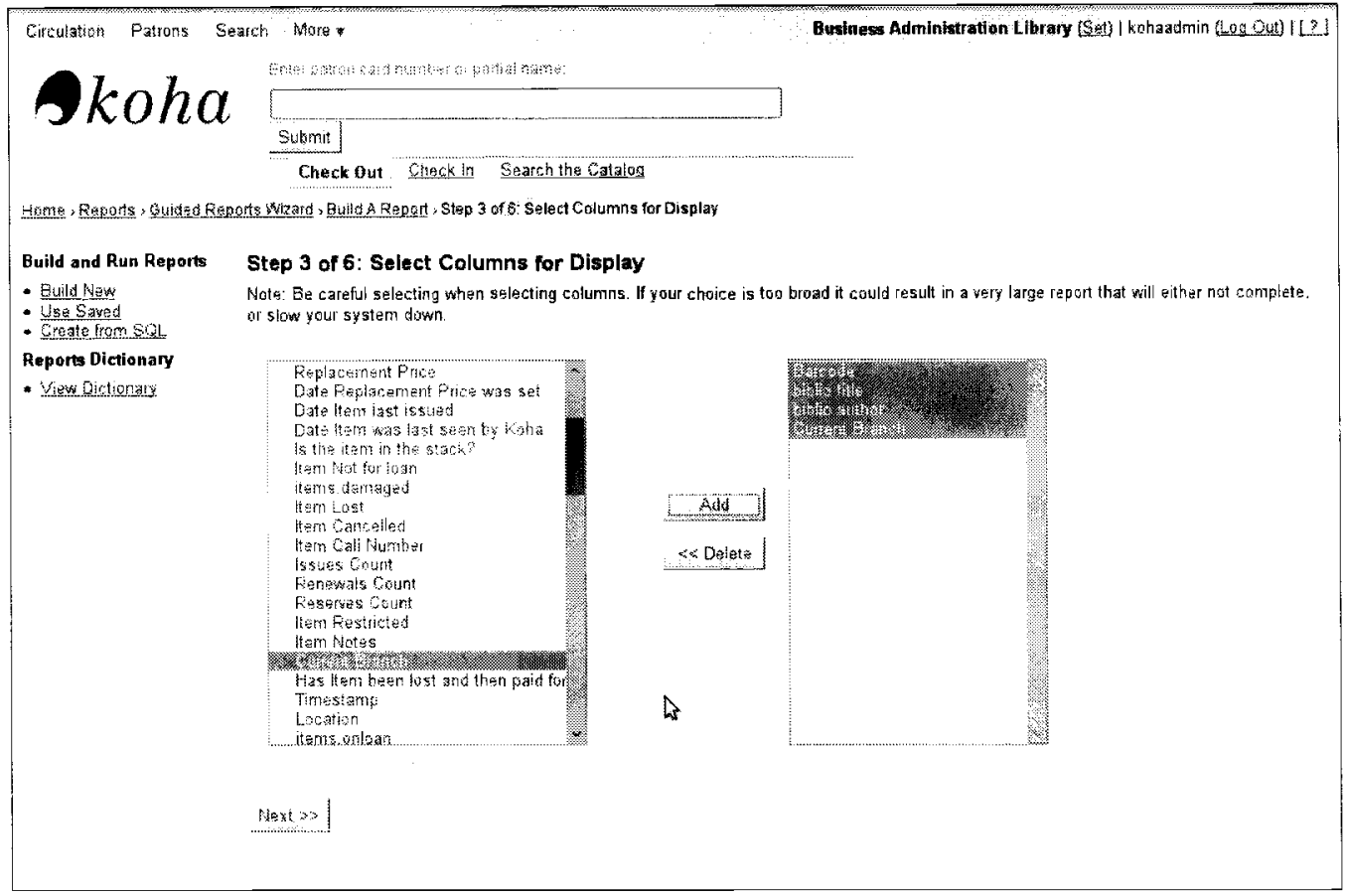




\section{Using a saved report}

To test the report you just created click on the Use Saved button on link. Click on the Run this Report link to execute the report. You also have an option of downloading the report in a comma separated format. The file can then be opened in a spreadsheet program for further analysis.

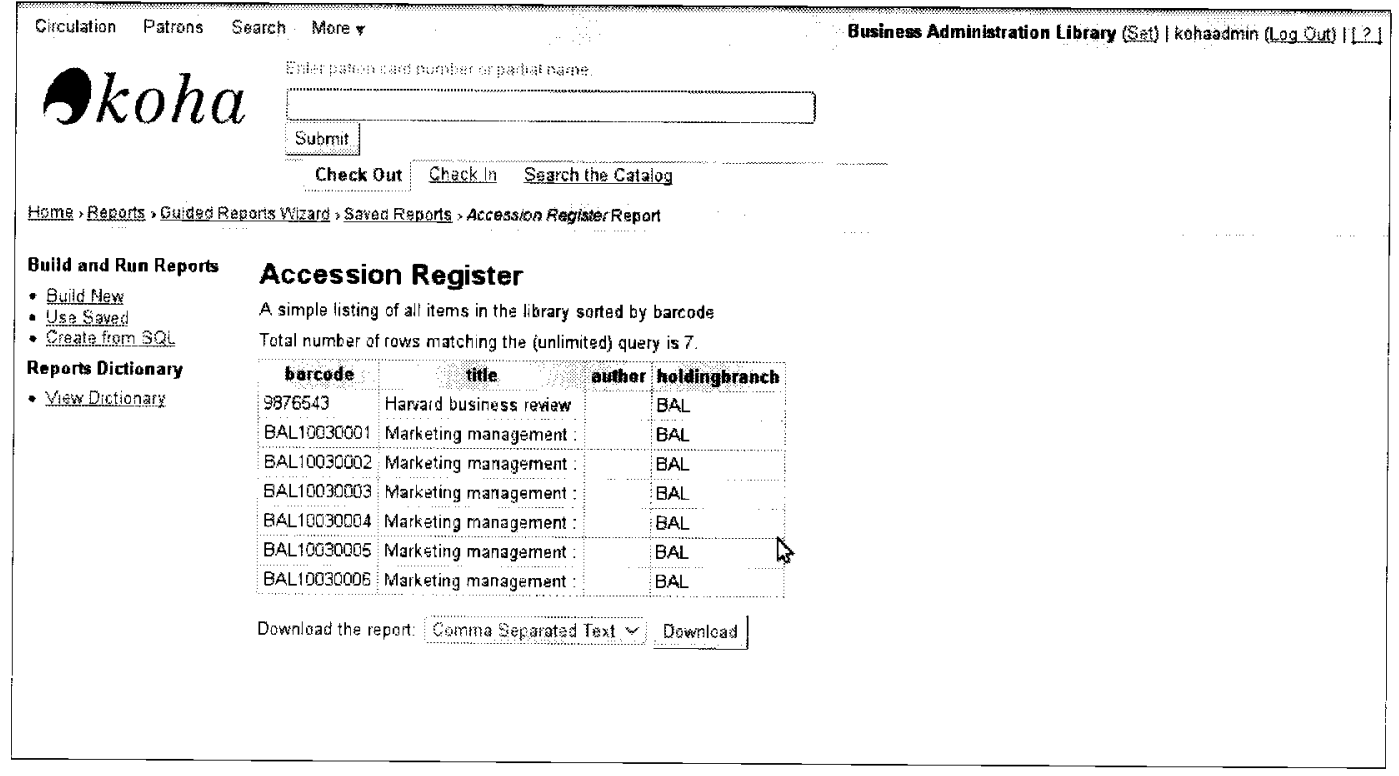

\section{OPAC_running a catalog search}

And finally let us test the catalog search feature on the OPAC. Simply type in a word or phrase related to record(s) you know are in the catalog and click on the Go button. You should see results sorted by Relevance and the Refine your search block on the left populated with Libraries, Authors, and Topics related to the search results. This test tells us that our Zebra setup is functioning well. 


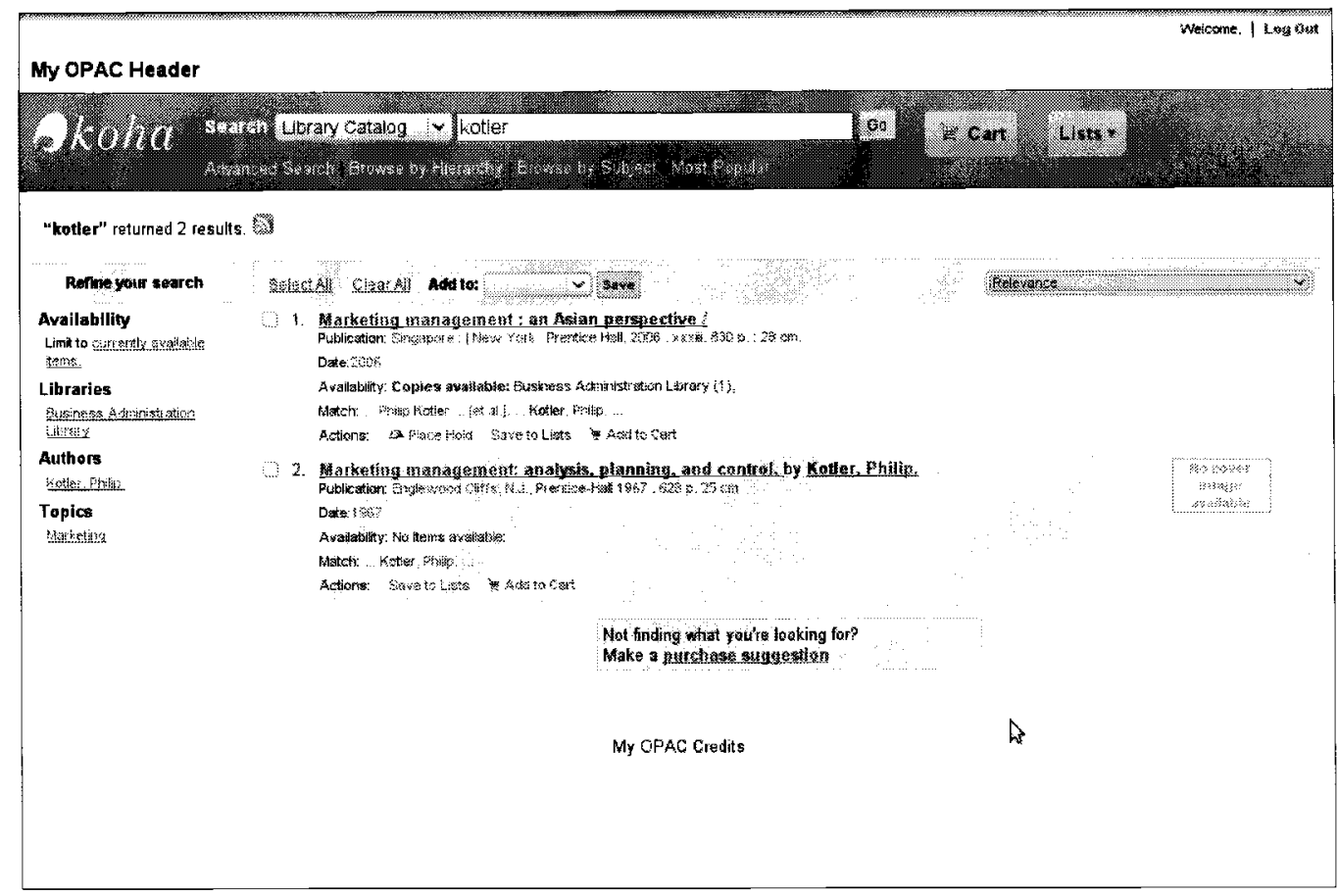

\section{Summary}

In this chapter we tested the primary Koha modules to ensure that the software installation and the server and application configuration were performed correctly.

We ran test cycles as follows:

- Patrons - create, search, and view a patron record

- Cataloging - create, search, and view a bibliographic and item record

- Circulation - check out, check in an item, and view its circulation history

- Acquisition - create an order basket, receive shipment, and view updated budget utilization

- Serials - create a subscription and receive the first issue

- Reports - create a guided report and execute it

- OPAC-executed a catalog search

In the next chapter, we will learn how to import catalog data into our Koha installation. 



\section{9 \\ Migrating Catalog Data}

Migrating catalog data from the legacy system is a prerequisite to using Koha for most libraries. The process involves exporting MARC records from the legacy system and importing them into Koha using Koha's import tools.

Migrating bibliographic data is usually easy; holdings data, however, presents a few challenges. This stems from the fact that different library systems record holdings data in different ways - fields and subfields used for an element may be different. In some cases, certain fields used in Koha may not be directly available in the holdings field.

In this chapter we will learn how to convert MARC files from legacy systems into Koha compatible files. We will learn about Koha's MARC record import tools.

\section{An orientation to migrating catalog data}

Let's start by getting a better understanding of the migration process. Here is what we will cover in this orientation section:

- The structure of MARC files that we will import into Koha

- How Koha's holdings MARC field differs from the corresponding field in other systems

- The tools we will employ to convert and import the catalog data into Koha 


\section{Understanding MARC files}

We will need to convert MARC files exported from the legacy system, which have an extension .mrc. Let's understand more about the structure of such files:

- Records: Each MARC file will contain one or more MARC records. Each MARC record contains bibliographic data and one or more holdings fields.

- Bibliographic data: Each MARC record contains bibliographic data, such as title, author, ISBN, or subject.

- Holdings fields: Information on the physical copies - such as library, barcode number, shelving location, or collection code, is recorded in a holdings field. A catalog record may have multiple holdings fields, one for each copy that is available in the library.

\section{Koha Holdings in tag 952}

Koha keeps holdings data in tag 952. We will need to make sure that the records in the import file have the data mapped to the $952 \mathrm{tag}$ and to the corresponding subfields under this tag.

You can view Koha's subfields under tag 952 in the MARC Bibliographic framework section under Koha Administration.

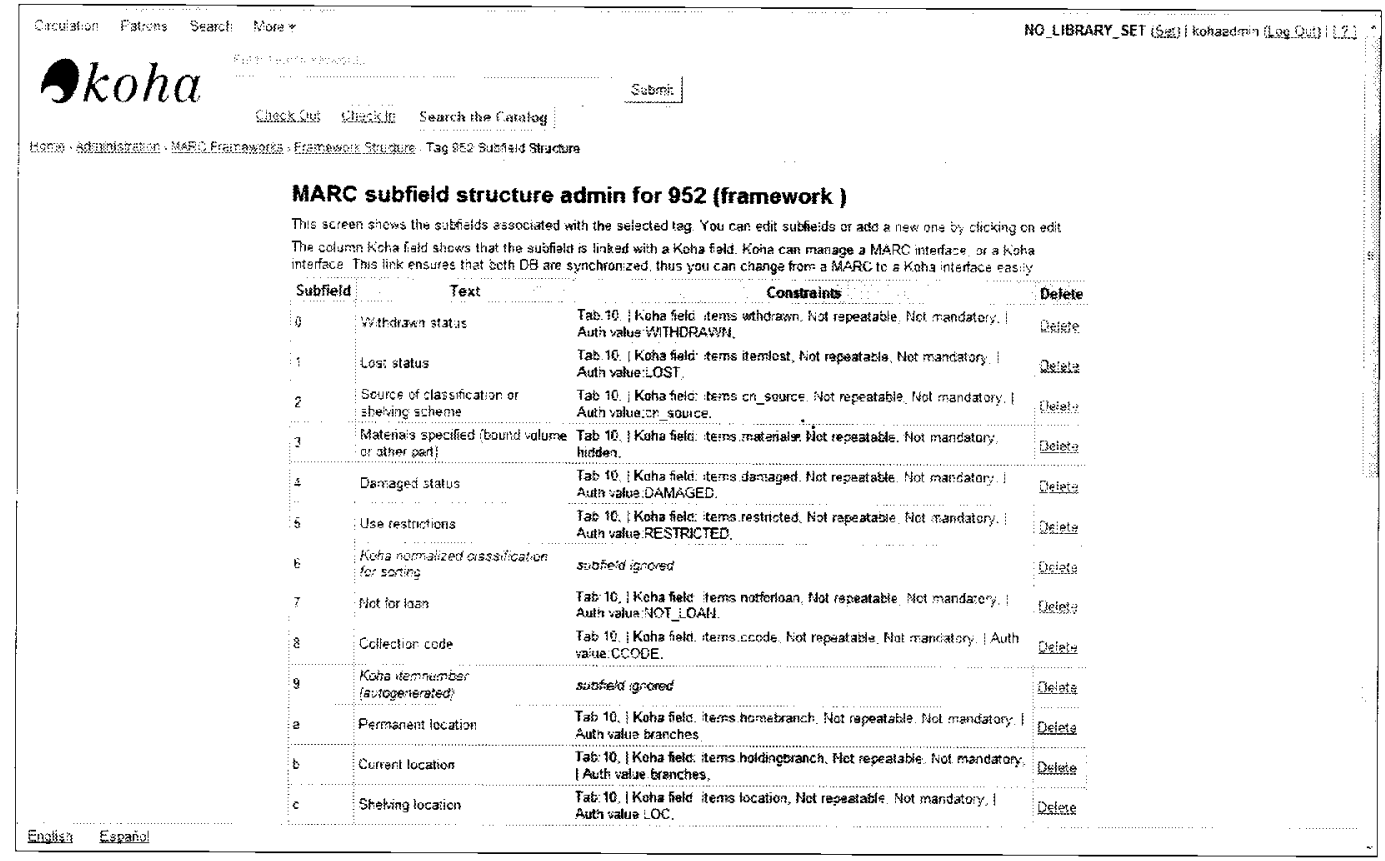


Some 952 subfields are very important from a Koha perspective. These include:

- 952\$a-Permanent location: This is the home library or branch of the particular item. It is important for circulation purposes that this subfield should have a valid library code.

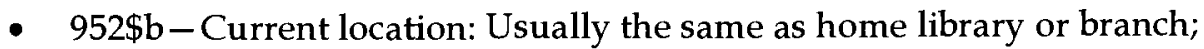
this too must have a valid library code.

- $952 \$ y-K o h a$ item type: Item types are used for setting up circulation rules. This field must have a valid item-type code.

- 952\$p-Piece designation: This is the item barcode. Circulation would not be possible without data in this subfield.

\section{Holdings in legacy systems}

It is likely that you will see these differences between Koha's holdings field and the holdings field on records exported from the legacy system:

- The holdings tag is likely to be 852 , rather than tag 952.

- Holdings subfields will differ from what Koha uses. The subfields may fully or partially comply with the Library of Congress MARC 21 holdings standards available here: http://www. loc.gov/marc/holdings/hd852. html.

- Some of the important Koha subfields may not be available-Permanent location and Current location, or Koha item type.

- Koha stores the item call number in a single subfield 952\$o, but in the legacy MARC record, you will likely find the call number broken into multiple subfields - \$h: Classification part, \$i: Item part, and \$k: Call number prefix.

\section{Import tools}

To import the data into Koha, we first convert the source MARC File into a Koha-compatible file using MARCEdit - a free MARC editor.

We then import the converted file using one of Koha's imports tools:

- bulkmarckimport.pl: A Linux command-line tool usually used to import large MARC files

- GUI import tool: A more flexible import tool available in Koha's staff client Here is more information about these tools: 


\section{MARCEdit}

A very popular tool used to view and edit MARC records, and convert them from text to MARC and vice versa. The software is free to download and use, but runs only on Windows.

MARCEdit is available for download at this link: http://people.oregonstate . edu/ reeset/marcedit/html/downloads .html.

For the purposes of migrating catalog data, we will use MARCEdit to manipulate the source file to make it suitable for importing into Koha; we will:

- Replace holdings field and subfields with ones used in Koha

- Add holdings subfields that are missing in the source MARC file

- Merge Call number-related subfields into Koha's single Call number subfield

\section{bulkmarckimport.pl}

This is a Koha program that can import MARC records from a file; it is usually used for importing files with a very large number of records. We run this program from the Linux terminal.

The program is available in the folder $/ \mathrm{misc} / \mathrm{migration}$ tools. To learn about this program, try running it with the $-\mathrm{h}$ option:

linux-4yut:/usr/share/kohaclone/misc/migration_tools \# ./bulkmarcimport. pl - - h

Small script to import bibliographic records into Koha.

\begin{tabular}{llll}
\hline $\begin{array}{l}\text { Bulkmarcimport.pl } \\
\text { option }\end{array}$ & Mandatory? & Explanation & Example \\
\hline file & Yes & $\begin{array}{l}\text { This is the full path to the MARC } \\
\text { file that you wish to import. You } \\
\text { will always need to use this option. }\end{array}$ & $\begin{array}{l}\text { home/koha/ } \\
\text { importfile. } \\
\text { mrc }\end{array}$ \\
& No & $\begin{array}{l}\text { Output more information, } \\
\text { optionally add a "1" or "2" for } \\
\text { additional information. }\end{array}$ & or $-\mathrm{v} 1$ \\
& & & or $-\mathrm{v} 2$ \\
\hline
\end{tabular}




\begin{tabular}{|c|c|c|c|}
\hline $\begin{array}{l}\text { Bulkmarcimport.pl } \\
\text { option }\end{array}$ & Mandatory? & Explanation & Example \\
\hline \multirow[t]{2}{*}{$\mathrm{fk}$} & No & $\begin{array}{l}\text { When importing records, values } \\
\text { for fields such as library code } \\
\text { ( } 952 \$ \text { a) need to be present in the } \\
\text { Koha database. }\end{array}$ & $-£ k$ \\
\hline & & $\begin{array}{l}\text { Use this option to turn off such } \\
\text { checks during imports; records } \\
\text { will be imported even if the } \\
\text { corresponding data is not present } \\
\text { in the database. }\end{array}$ & \\
\hline $\mathrm{n}$ & No & $\begin{array}{l}\text { The number of records to import } \\
\text { from a file, if not used all the } \\
\text { records are imported. }\end{array}$ & $-n 1000$ \\
\hline$\circ$ & No & $\begin{array}{l}\text { The number of records from } \\
\text { the start of the file that are to be } \\
\text { skipped. }\end{array}$ & -01000 \\
\hline \multirow[t]{2}{*}{ commit } & No & $\begin{array}{l}\text { The number of records that are } \\
\text { committed in a batch. } 50 \text { records } \\
\text { per commit is the default. }\end{array}$ & - commit 100 \\
\hline & & $\begin{array}{l}\text { If your import is too slow, you } \\
\text { might consider increasing this } \\
\text { value; however, remember that } \\
\text { if the program crashes due to a } \\
\text { certain record, all the other records } \\
\text { in the batch will be lost as well. }\end{array}$ & \\
\hline \multirow[t]{2}{*}{ t } & No & $\begin{array}{l}\text { It is useful to run a new import } \\
\text { file in the test mode initially. The } \\
\text { program does minimal processing } \\
\text { and may warn you of potential } \\
\text { problems. }\end{array}$ & $-t$ \\
\hline & & $\begin{array}{l}\text { However, remember that a } \\
\text { successful test does not mean there } \\
\text { wili.be no problem with the actual } \\
\text { import. }\end{array}$ & \\
\hline $\mathbf{s}$ & No & $\begin{array}{l}\text { Koha automatically converts any } \\
\text { MARC- } 8 \text { records to UTF- } 8 \text {. If you } \\
\text { see a problem with the format of } \\
\text { imported data in Koha screens, } \\
\text { you may want to try this option to } \\
\text { see if it yields better results. }\end{array}$ & $-s$ \\
\hline
\end{tabular}




\begin{tabular}{llll}
\hline $\begin{array}{l}\text { Bulkmarcimport.pl } \\
\text { option }\end{array}$ & Mandatory? & Explanation & Example \\
\hline c & No & $\begin{array}{l}\text { The characteristic MARC flavor of } \\
\text { records in the import file. Default } \\
\text { is MARC21. }\end{array}$ \\
& No UNIMARC & \\
& Deletes all catalog records in \\
the database prior to importing \\
the file. Be very careful with this \\
option, there is no way to recover \\
lost records.
\end{tabular}

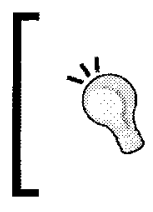

IMPORTANT: Don't use this script before you've entered and checked your MARC parameters tables twice (or more!). Otherwise, the import won't work correctly and you will get invalid data. 


\section{SAMPLE :}

$\$$ export KOHA_CONF=/etc/koha.conf

$\$$ perl misc/migration_tools/bulkmarcimport.pl-d-commit 1000 । -file/home/jmf/koha.mrc -n 3000

\section{Koha's GUI import tool}

Koha also is an end-user-friendly GUI import tool. The catalog import is executed in two steps:

- Stage MARC Records for Import: Here we load the records into a reservoir

- Manage Staged MARC records: Here we review and complete the import

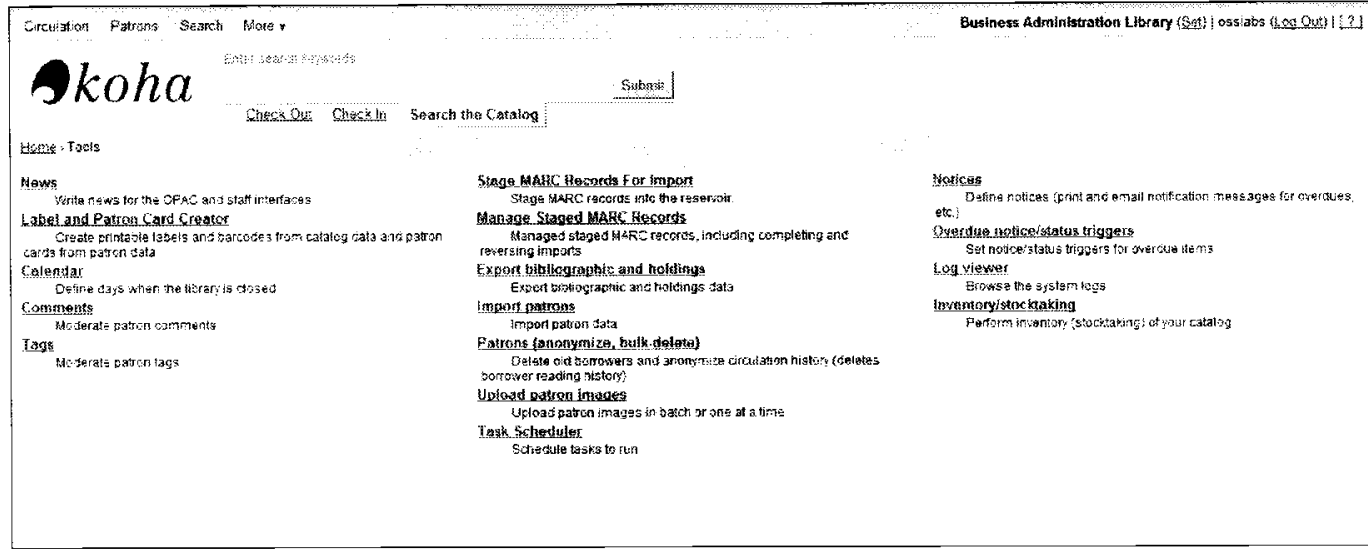

This tool is more sophisticated when compared to bulkmarcimport.pl, as it allows for:

- Review of records prior to import

- An undo import operation

- Support for record matching rules 
Record matching rules can match the incoming records to those already in the database. These rules can be used to:

- Add holdings to existing bibliographic records

- Replace bibliographic records with new ones

\section{Choosing an import tool}

Here are some pointers to help you decide which tool to employ when importing MARC files:

- In general, bulkmarcimport.pl is better when you are setting up Koha for the first time. It is faster and can handle large files.

- If you need to import new records into an existing Koha database, say when migrating data from a new branch, it is better to use the GUI tool. We can use matching rules to ensure that holdings are attached to a single parent bibliographic record.

\section{Migration process}

The process is as follows:

- Use MARCEdit to manipulate the source MARC file and make it suitable for import into Koha

- We will need to setup values in administrative fields in Koha corresponding to data in fields, such as library, item type, collection, or shelving location in the source MARC file

- Use either the bulkmarcimport.pl or the GUI import tools to import the MARC file

\section{Preparing to migrate catalog data}

Now that we have an understanding of the migration process, let's learn how to prepare for the migration. We prepare the plan in two parts; first, we determine how we will source data for the holdings subfields in Koha. Next, we decide what data we will need to setup in Koha prior to importing the MARC file. 


\section{Mapping Koha's holdings subfields to subfields in source MARC file}

In the first part of the plan, we set up a table listing all of Koha's holdings subfields. We map each subfield to a corresponding subfield in the source file. If corresponding fields for any mandatory Koha fields are not available in the source file, we will need to add data manually for such subfields while editing the file.

\begin{tabular}{|c|c|c|c|}
\hline Koha field & Mandatory & $\begin{array}{l}\text { Corresponding } \\
\text { field in ource } \\
\text { MARC file }\end{array}$ & Comments \\
\hline $\begin{array}{l}\text { 952\$8: Collection } \\
\text { code }\end{array}$ & No & $852 \$ b$ & \\
\hline $\begin{array}{l}\text { 952\$a: Permanent } \\
\text { location }\end{array}$ & Yes & $\begin{array}{l}\text { Not available } \\
\text { in source file }\end{array}$ & $\begin{array}{l}\text { MARC file has been exported by } \\
\text { Library. We will manually add this } \\
\text { tag to all records in the file. }\end{array}$ \\
\hline $\begin{array}{l}952 \$ b: \text { Current } \\
\text { location }\end{array}$ & Yes & $\begin{array}{l}\text { Not available } \\
\text { in source file }\end{array}$ & Same as Permanent location. \\
\hline $\begin{array}{l}952 \$ c: \text { Shelving } \\
\text { location }\end{array}$ & & $\begin{array}{l}\text { Not available } \\
\text { in source file }\end{array}$ & \\
\hline $952 \$ d$ : Date acquired & & $852 \$ c$ & \\
\hline $\begin{array}{l}952 \$ \text { e: Source of } \\
\text { acquisition }\end{array}$ & & $852 \$ x$ & \\
\hline $\begin{array}{l}952 \$ g: \text { Cost, } \\
\text { purchase price }\end{array}$ & & $852 \$ 9$ & \\
\hline $\begin{array}{l}952 \$ o: \text { Full call } \\
\text { number }\end{array}$ & & $\begin{array}{l}852 \$ \mathrm{~h} \text { and } \\
852 \$ \mathrm{i}\end{array}$ & \\
\hline $\begin{array}{l}952 \$ p: \text { Piece } \\
\text { designation }\end{array}$ & Yes & $852 \$ p$ & \\
\hline 952\$t: Copy number & & $\begin{array}{l}\text { Not available } \\
\text { in source file }\end{array}$ & \\
\hline $\begin{array}{l}952 \$ v \text { : Cost, } \\
\text { replacement price }\end{array}$ & & $\begin{array}{l}\text { Not available } \\
\text { in source file }\end{array}$ & \\
\hline $\begin{array}{l}952 \$ x \text { : Non-public } \\
\text { note }\end{array}$ & & $\begin{array}{l}\text { Not available } \\
\text { in source file }\end{array}$ & \\
\hline $\begin{array}{l}952 \$ y: \text { Koha's item } \\
\text { type }\end{array}$ & Yes & $\begin{array}{l}\text { Not available } \\
\text { in source file }\end{array}$ & $\begin{array}{l}\text { MARC file has been exported by } \\
\text { item type. We will manually add } \\
\text { this tag to all records in the file. }\end{array}$ \\
\hline 952\$z: Public note & & $\begin{array}{l}\text { Not available } \\
\text { in source file }\end{array}$ & \\
\hline
\end{tabular}




\section{Planning setup of administrative fields in Koha}

In the second part of the plan, we plan how to setup values in Koha's administrative fields. We need to ensure that libraries, item types, collection codes, and shelving locations in the various MARC records in the source files are setup in Koha prior to importing the file. We prepare a plan as follows:

\begin{tabular}{|c|c|c|}
\hline $\begin{array}{l}\text { Field in source } \\
\text { MARC file }\end{array}$ & $\begin{array}{l}\text { Distinct values in source } \\
\text { MARC file }\end{array}$ & $\begin{array}{l}\text { Koha's administrative fields } \\
\text { where the values need to be setup }\end{array}$ \\
\hline $\begin{array}{l}\text { Library or Branch } \\
\text { code }\end{array}$ & Lib1 & $\begin{array}{l}\text { Libraries in Libraries and Groups } \\
\text { under Koha Administration. }\end{array}$ \\
\hline \multirow[t]{5}{*}{ Item Type } & BOOK & \multirow{5}{*}{$\begin{array}{l}\text { Koha's Item types under Koha } \\
\text { Administration. }\end{array}$} \\
\hline & CD & \\
\hline & DVD & \\
\hline & $J R$ & \\
\hline & REF & \\
\hline \multirow[t]{6}{*}{ Collection Code } & Biography & \multirow{6}{*}{$\begin{array}{l}\text { Authorized values under Koha } \\
\text { Administration. Setup under } \\
\text { category - CCODE. }\end{array}$} \\
\hline & Business & \\
\hline & Fiction & \\
\hline & General & \\
\hline & History & \\
\hline & Humour & \\
\hline \multirow[t]{4}{*}{ Shelving Location } & AV & \multirow{4}{*}{$\begin{array}{l}\text { Authorized values under Koha } \\
\text { Administration. Setup under } \\
\text { category - LOC. }\end{array}$} \\
\hline & Dis & \\
\hline & New & \\
\hline & Ref & \\
\hline
\end{tabular}




\section{Migrating catalog data}

In this section, we demonstrate how to implement our migration plan. We edit the source file using MARCEdit, setup administrative fields in Koha, and then use either the bulkmarcimport.pl or the GUI import tool to complete the migration.

\section{Setting up values in Koha's administrative fields}

First, we need to make sure that we prepare the Koha database for importing the new records by setting values in administrative fields, such as library, item type, or collection code.

\section{Setting up branch codes}

The branch code(s) can be setup from Libraries and Groups page under Koha Administration.

\begin{tabular}{|c|c|c|c|c|c|c|}
\hline \multirow{4}{*}{$\begin{array}{l}\text { Cinculation Patrons Samch } \\
\text { Roh }\end{array}$} & \multicolumn{4}{|l|}{ Mors: } & \multicolumn{2}{|c|}{ NO_LIBRARY_SEI (Set) | kohaadmin (Log Out) $\mid[$ ? } \\
\hline & \multicolumn{6}{|l|}{ 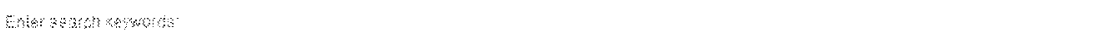 } \\
\hline & \multicolumn{6}{|l|}{, $\quad \cdots, \ldots$} \\
\hline & Chack Out chack in & \multicolumn{5}{|c|}{ Search the Catalog } \\
\hline \multicolumn{7}{|c|}{ 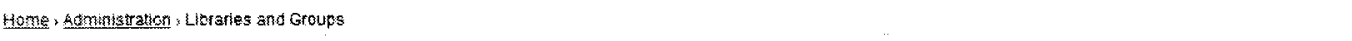 } \\
\hline \multirow{6}{*}{ 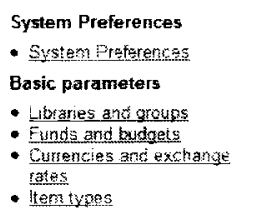 } & \multicolumn{6}{|l|}{ NowLioray / Naw Grou } \\
\hline & \multicolumn{6}{|l|}{ Libraries } \\
\hline & Name : & Code * & Address - & Propenties & & \\
\hline & Eusiness Administration Library & B*41 & (nothing extered) & & Edit Delete & \\
\hline & Connemarra Librafy & CON & (nothing entered) & & Edis Delete & \\
\hline & Engineering Library & ENGL & (nothing entered) & & Edit Delete & \\
\hline \multirow{5}{*}{ 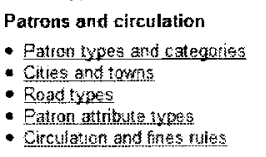 } & Last Ligraty & LAWE & (foothing entered) & & Edit Dolats & \\
\hline & Mountain Eay & MOUN & (nothing entered) & & Edit Delete: & \\
\hline & South Asiz Bussiness Schood & SAEC & Gothing entered? & & Edit Delete & \\
\hline & \multicolumn{6}{|c|}{ Group(s): Search Domain } \\
\hline & \multicolumn{6}{|l|}{ Hame Code Description : } \\
\hline \multicolumn{7}{|c|}{ No Search Domain Defined } \\
\hline - Authorized yalues & \multicolumn{6}{|l|}{ Group(s): Properties } \\
\hline \multicolumn{7}{|l|}{$\begin{array}{l}\text { - MARC Bibliographic } \\
\text { framatork } \\
\text { - Koha to MARC maning }\end{array}$} \\
\hline 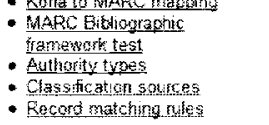 & \multicolumn{6}{|l|}{ No Properties Defined } \\
\hline \multicolumn{7}{|l|}{ Additional parameters } \\
\hline \multicolumn{7}{|l|}{ - Stop Words } \\
\hline Españ⿰纟勺 & & & & & & \\
\hline
\end{tabular}




\section{Setting up Item types}

The Item type(s) can be setup from the Item Types page under Koha Administration.

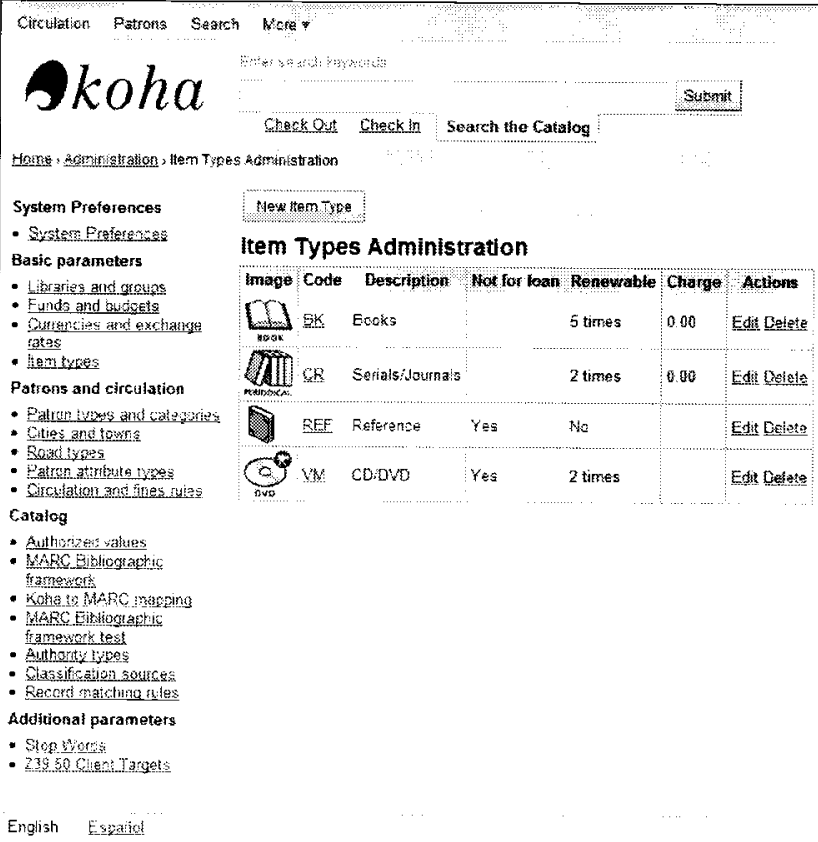




\section{Setting up collection codes}

The collection code(s) can be setup from the Authorized values page under Koha Administration. Add values to the category CCODE.

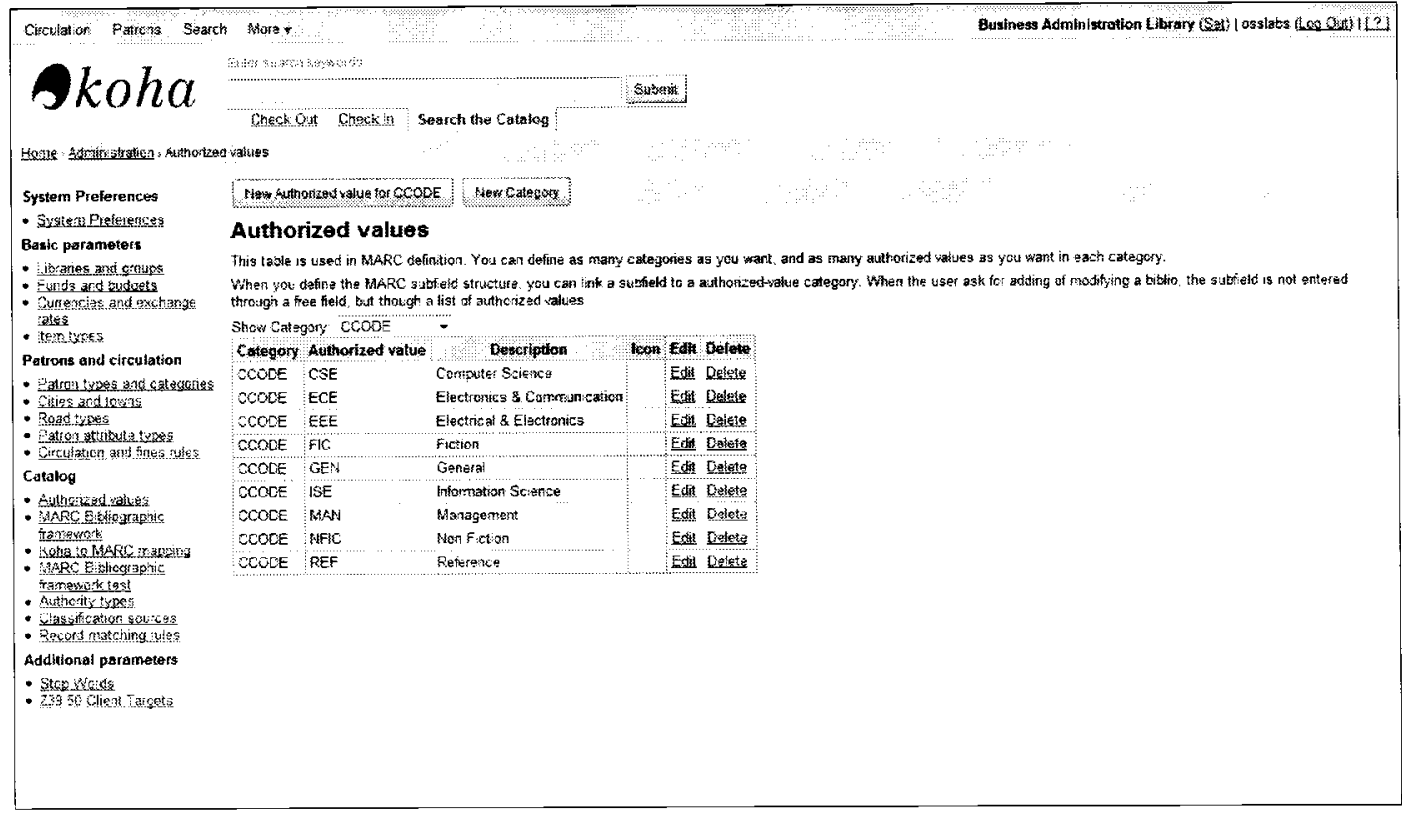




\section{Setting up shelving locations}

The item type(s) can be setup from the Authorized values page under Koha Administration. Add values to the category LOC.

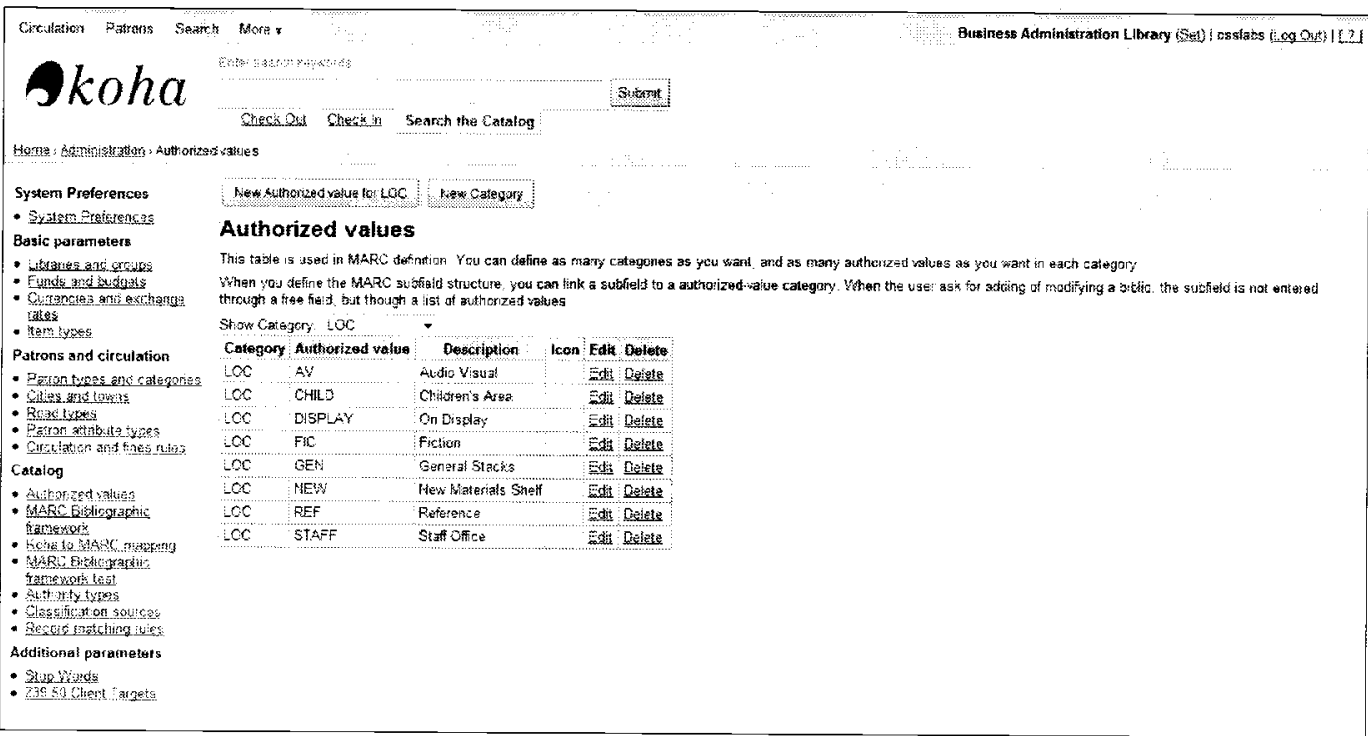

\section{Editing the source MARC file using MARCEdit}

To edit the import file, we use MARCEdit.

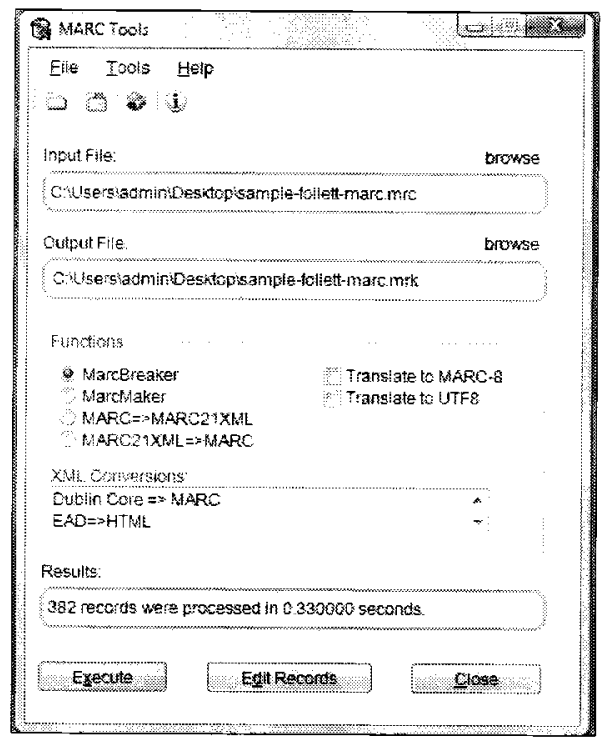


Use the MarcBreaker tool to convert the MARC file into a readable file with the extension . mrk.

Click on the Edit Records button to view the records.

Use the various options under MARCEdit's Edit and Tools menu to create the file as per Koha's standards. Here are instructions on some of the key operations you are likely to need - swapping subfields, adding a new subfield, and merging subfields:

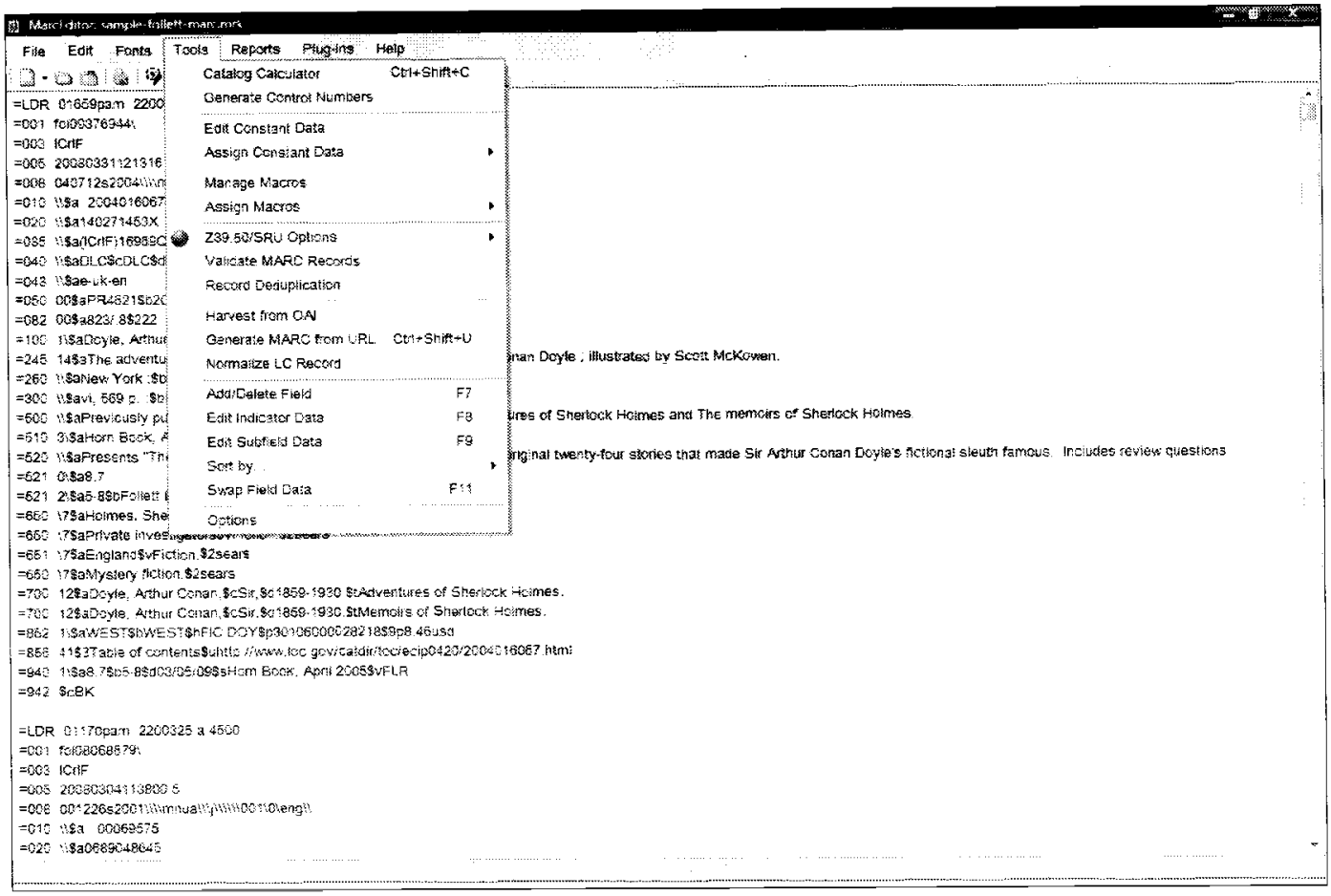




\section{Swapping subfields}

To swap fields, use the Swap Field Data tool under the Tools menu. Here are the steps to swapping subfields:

1. Specify Field and Subfield for the Original and Modified data.

2. Check Copy Source if you want to retain the original holdings field.

3. Check Add to existing field; this way you ensure that newly swapped subfields are included in the same holdings tag.

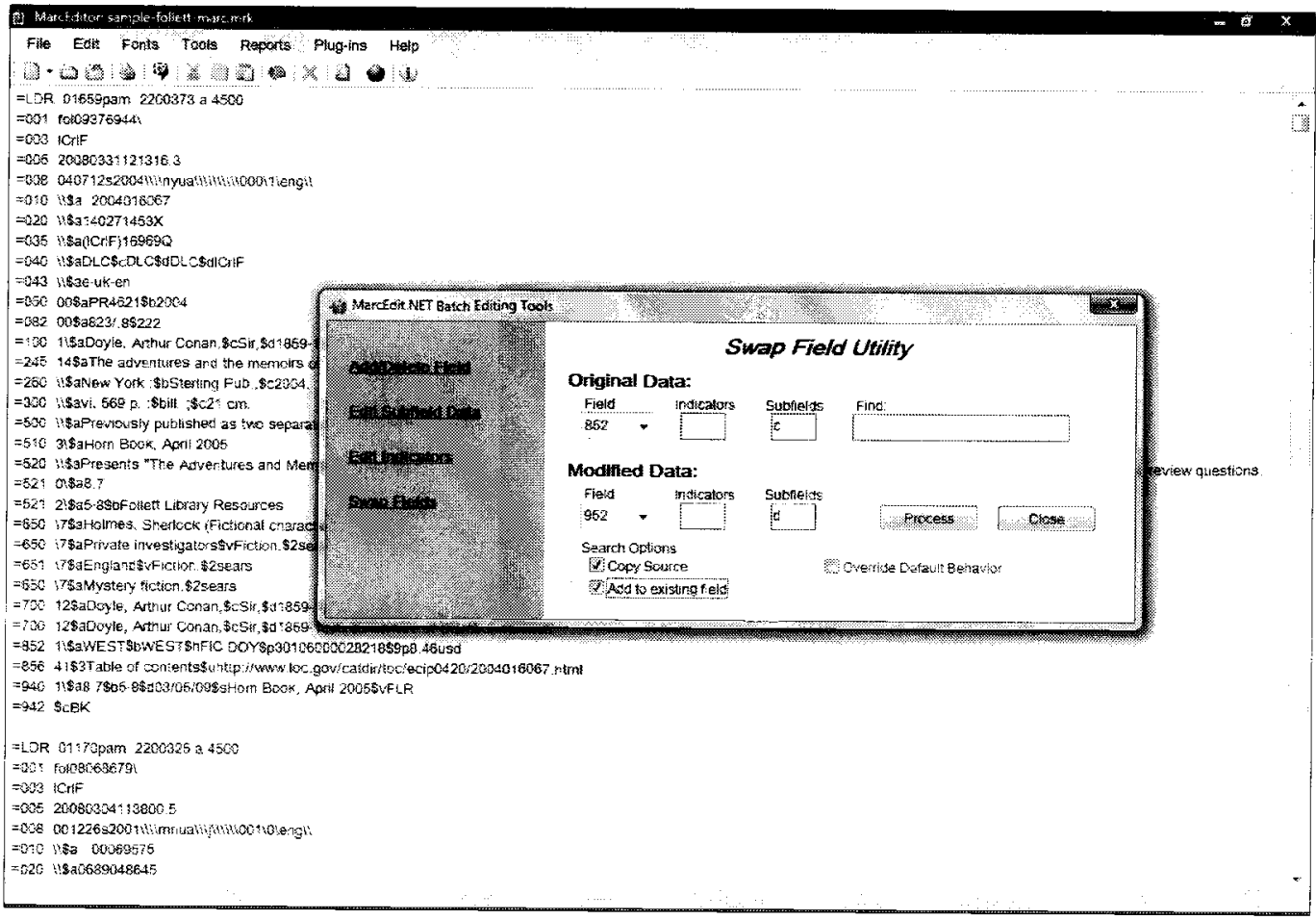




\section{Adding a new subfield}

To add a new field, use the Add/Delete Field utility under the Tools menu. Enter Field as 952, and Field data as $\backslash \backslash<$ subfield $><$ value $>$. For instance, to add a 952\$a with value LIB1, enter Field data as $\backslash \backslash \$ a L I B 1$.

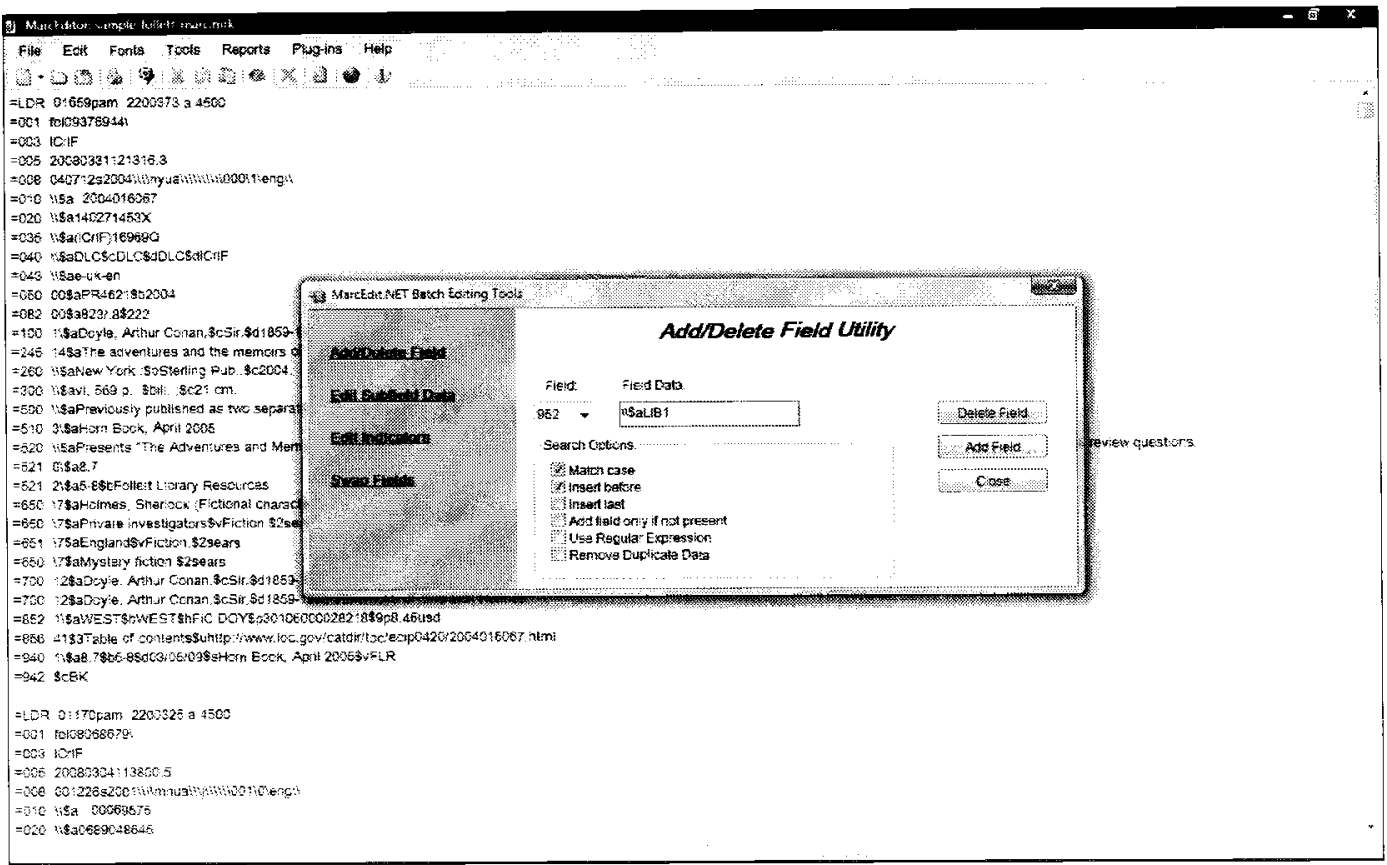

\section{Merging subfields}

To merge call number fields in the source file into a single a single call number field in Koha-952\$o, we need to use regular expressions. Here are the steps:

1. Swap each subfield in source holdings field to corresponding subfields under 952

2. Setup a regular expression find and replace that merges a set of subfields

Setting up a regular expression can be tricky, and readers are encouraged to get introduced to regular expressions first. Here is a handy introductory tutorial:

http://www.regular-expressions.info/tutorial.html 
Let's now look at a specific example-merging subfields $\$ \mathrm{~h}$ and $\$ \mathrm{i}$, with a space between the two values, into Koha's call number subfield \$o.

First, we setup a Find expression as follows:

\section{$(=952 \backslash \backslash \backslash)\left(*^{*}\right)(\backslash \$ \mathrm{~h})\left([\mathrm{a}-\mathrm{zA}-\mathrm{Z0}-9 .]^{*}\right)\left(.^{*}\right)(\backslash \$ \mathrm{i})\left([\mathrm{a}-\mathrm{zA}-\mathrm{Z0-9} .]^{*}\right)\left(.^{*}\right)$}

Here is an explanation of this expression:

- (=952 $\backslash \backslash \backslash)$ : Look for the pattern $=952 \backslash \backslash$. We have four $\backslash$ in the expression instead of two, because $\backslash$ is a special character, and we need to escape each occurrence with another $\backslash$. The round brackets store the matched string in the first back-reference field.

- (.*): Look for any string including "nothing" after the first search pattern, and stores whatever is matched into the second back-reference field.

- ( $\$$ h): Look for the subfield $\$ \mathrm{~h}$, and store it in the third back-reference field. $\$$ is a special character too and is escaped using a $\backslash$.

- ([a-zA-Z0-9. $\left.]^{*}\right)$ : Look for a string that follows $\$$ h and contains any number of small letters, capital letters, numbers, or ., and store the matched string into the fourth back reference field.

- $\left(.^{*}\right)$ : Match any string including "nothing" after the \$h subfield, and store it in the fifth back-reference field.

- ( $\$ \mathbf{i})$ : Look for the subfield $\$ \mathrm{i}$, and store it in the sixth back-reference field.

- ([a-zA-Z0-9. $\left.]^{*}\right)$ : Look for a string that follows $\$ i$ and contains any number of small letters, capital letters, numbers, or ., and store the matched string into the seventh back-reference field.

- $\left(.^{*}\right)$ : Match any string after the $\$$ i subfield, and store it into the eighth back-reference field.

And then, we setup the Replace expression as follows:

$\$ 1 \$ 0 \$ 4 \$ 72 \$ 5 \$ 8$ 
Here is an explanation of the Replace expression:

- \$1: In the replace string start with the value in the first back-reference field, the value here is $=952 \backslash \backslash$

- \$o: Append the subfield label \$o

- \$4: Append the value of the subfield $\$ \mathrm{~h}$ that is stored in the fourth back-reference field

- <space>: Append a space as a separator

- \$7: Append the value of the subfield $\$ i$ that is stored in the seventh back-reference field

- \$2: Append the text if any, before the \$h subfield; this is stored in the second back-reference field

- \$5: Append the text, if any between the $\$ \mathrm{~h}$ and $\$ \mathrm{i}$ subfields, this is stored in the fifth back-reference field

- \$8: Append the text after the $\$$ i subfield, this is stored in the eighth back-reference field

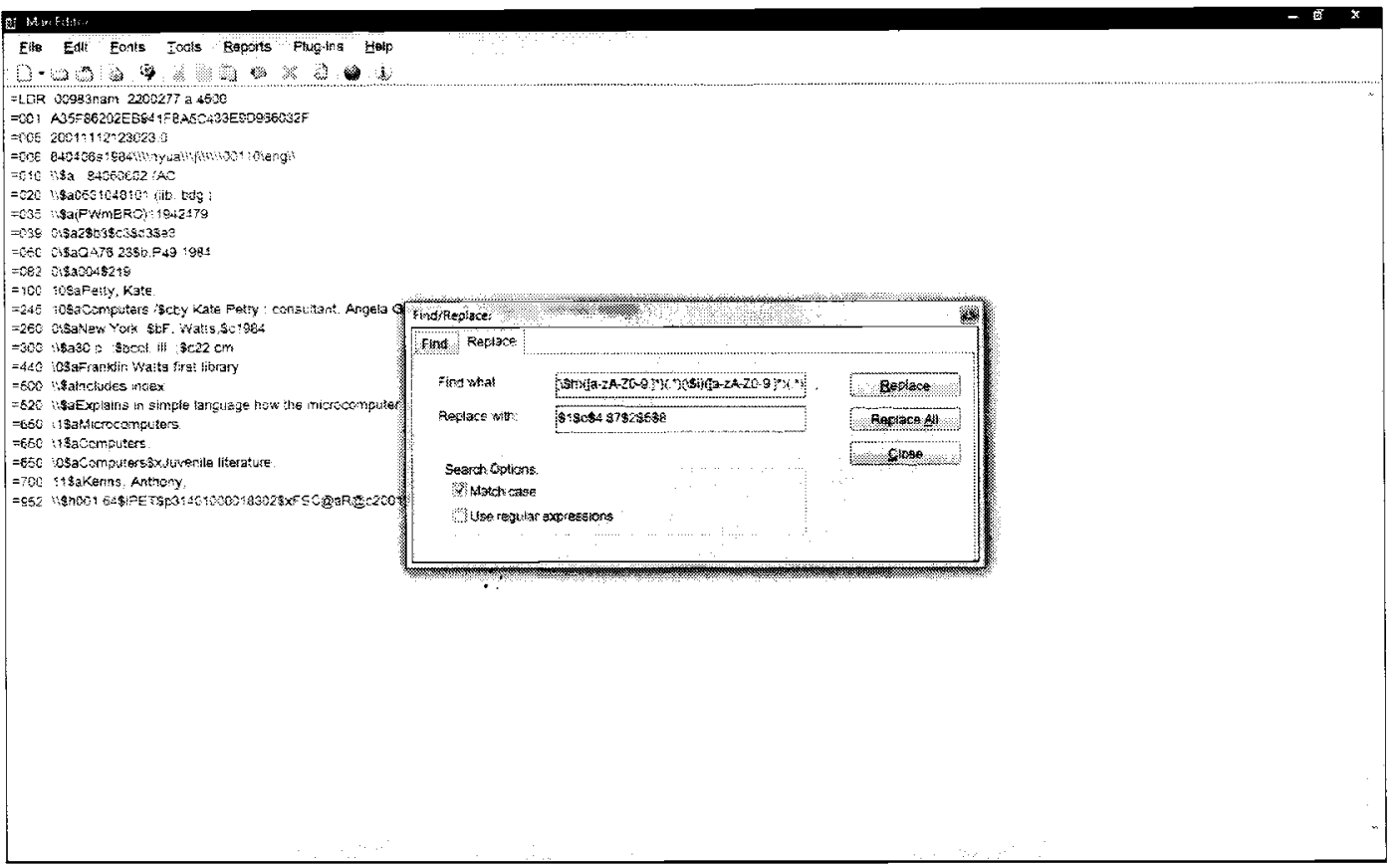


Once you are done, use the Compile File into MARC option under the File menu to create your new MARC file.

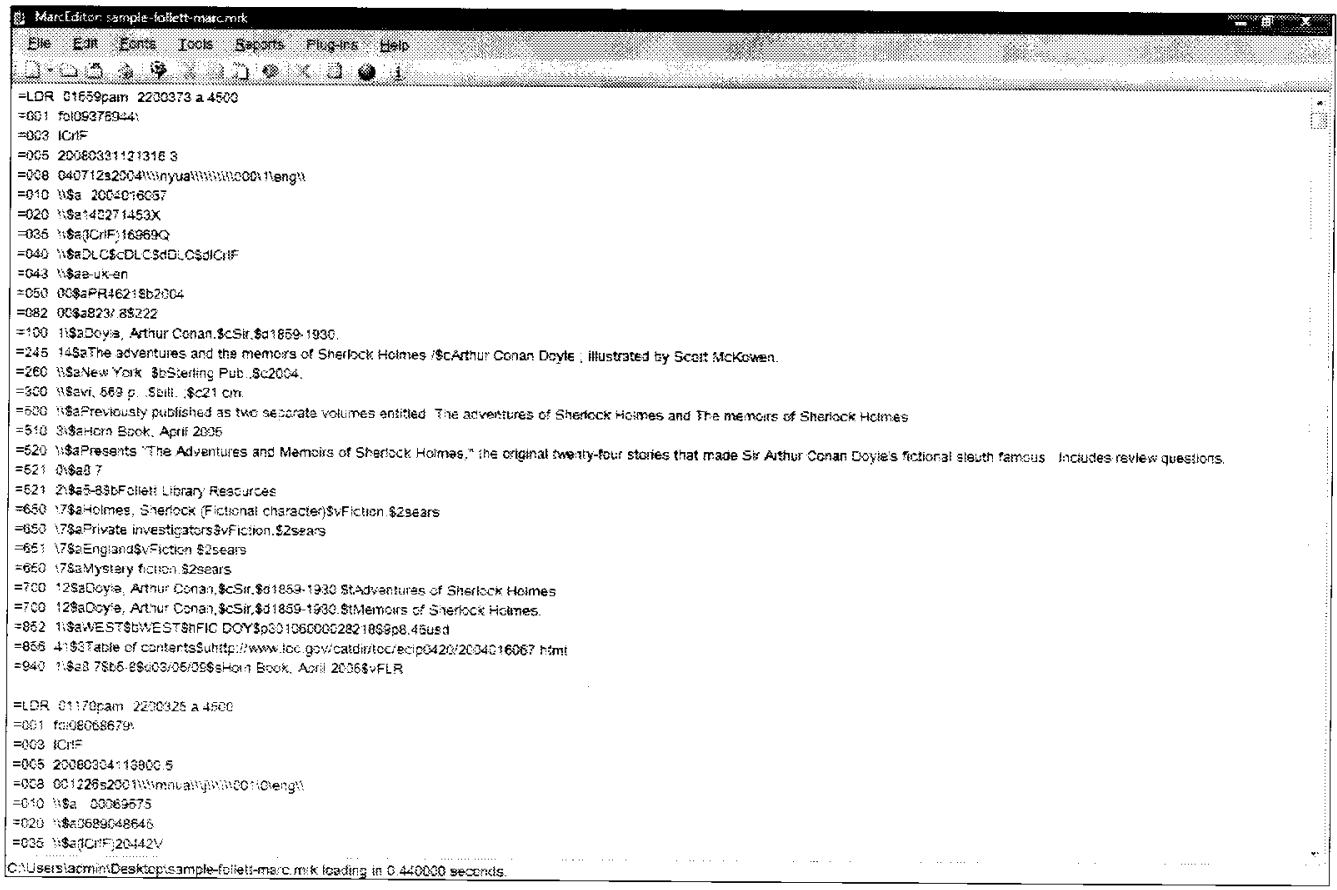

\section{Importing the MARC file}

The bulkmarcimport.pl program is the preferred way to import a large number of records. It is usually used during the initial phases of migration to Koha.

\section{Using the bulkmarcimport.pl program}

Before we run the program, let's make sure the shell environment variables are set correctly:

1inux-4yut:/usr/share/kohaclone/misc/migration_tools \# echo \$PERL5LIB /usr/share/kohaclone 1inux-4yut:/usr/share/kohaclone/misc/migration_tools \# echo \$KOHA_CONF /etc/koha-dev/etc/koha-conf . xm1

That looks ok. If you see empty variables, you can set them using these commands: 1inux-4yut:/usr/share/kohaclone/misc/migration_tools \# export PERL5IIB=/ usr/share/kohaclone

1inux-4yut:/usr/share/kohaclone/misc/migration_tools \# export kOHA_CONF=/ etc/koha-dev/etc/koha-conf .xm1 
To import a file, we run the command as follows:

linux-4yut:/usr/share/kohaclone/misc/migration_tools \#./bulkmarcimport. pl -d -file/home/koha/Download/sample-marc

deleting biblios

$300 \ldots$.

322 MARC records done in 15.4088408946991 seconds

Note the use of $-d$ option; this deletes all the data in the catalog before importing the file.

\section{Importing catalog records using the GUI tools}

You can use Koha's GUI tool to import the MARC file. Here are the steps to staging the records and managing staged records:

\section{Staging MARC records for import}

The first stage of the import process is to stage the records. Koha will import the records into a temporary storage area without changing the actual bibliographic or holdings data.

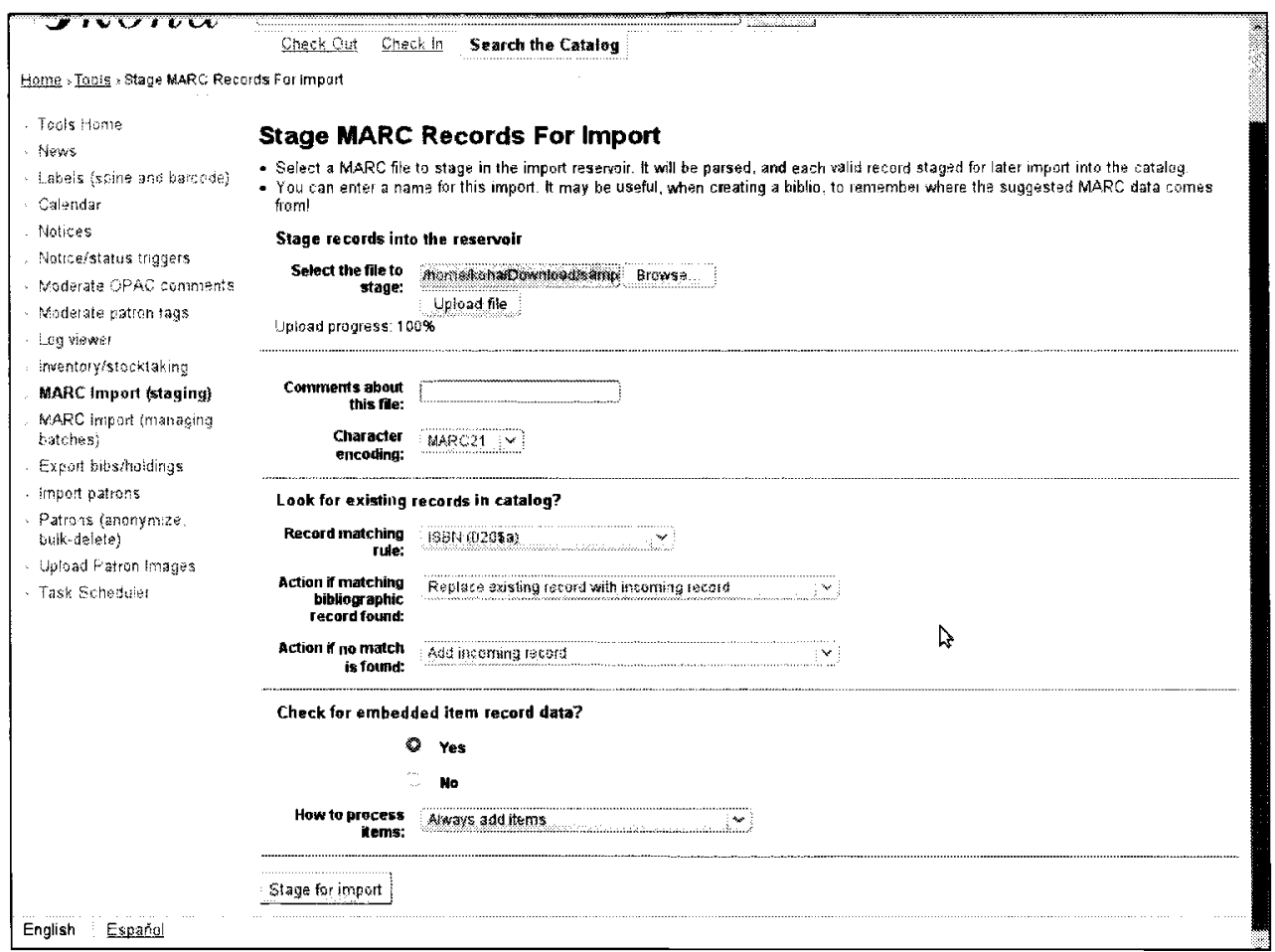


Koha comes preconfigured with two matching rules, one that matches on ISBN, and the other on ISSN. By using matching rules, you can make sure that all items or copies are grouped under the same parent bibliographic record.

Here are the steps to staging your MARC file:

1. Select the MARC file, and click on Upload to load the MARC file.

2. Select the matching rule (ISBN for books and ISSN for serials).

3. Set Action if matching bibliographic records found to ignore.

4. Set Action if no match is found to Add incoming record.

5. Say Yes to Check for embedded item record data.

6. Set How to process items to Always add items.

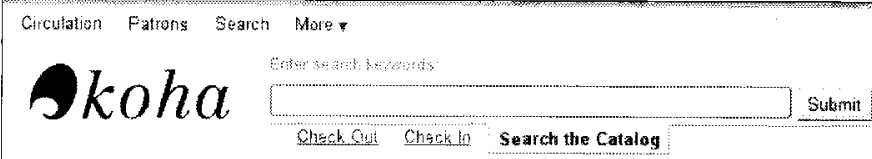

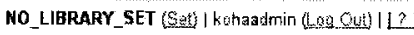

Homas , TGois ; Stage MAPC Pecords For Import

- Tools Horre

News

Labeis ispime ard batcodey

Caiendar

Nolices

Noticelstatus tiggers

- Muderato DPar conments

Mederate patron la

1.09 ine

Inventoryistucklakirio

MARC Impart (słaging)

MARE Hapen itnanoing

batches!

Expout bibsholdings

- Import pavions

Parrons iancomizas.

bulk-dalete)

Ualiad Faton lmages

Task sohedista

\section{Stage MARC Records For Import}

MARC Staging results

- 322 records in file

- O recards nót staged because af MARC entor

- 322 records staged

- 322 records with at least one match in catalog per matching rule "ISEiv"

- 322 it vern records found and staged

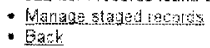

a 
At the end of the process, Koha will let you review the records before you actually import the records.

\section{Managing records}

In this step, the records will be imported into Koha's database. Simply click on the Import into Catalog button to start the process.

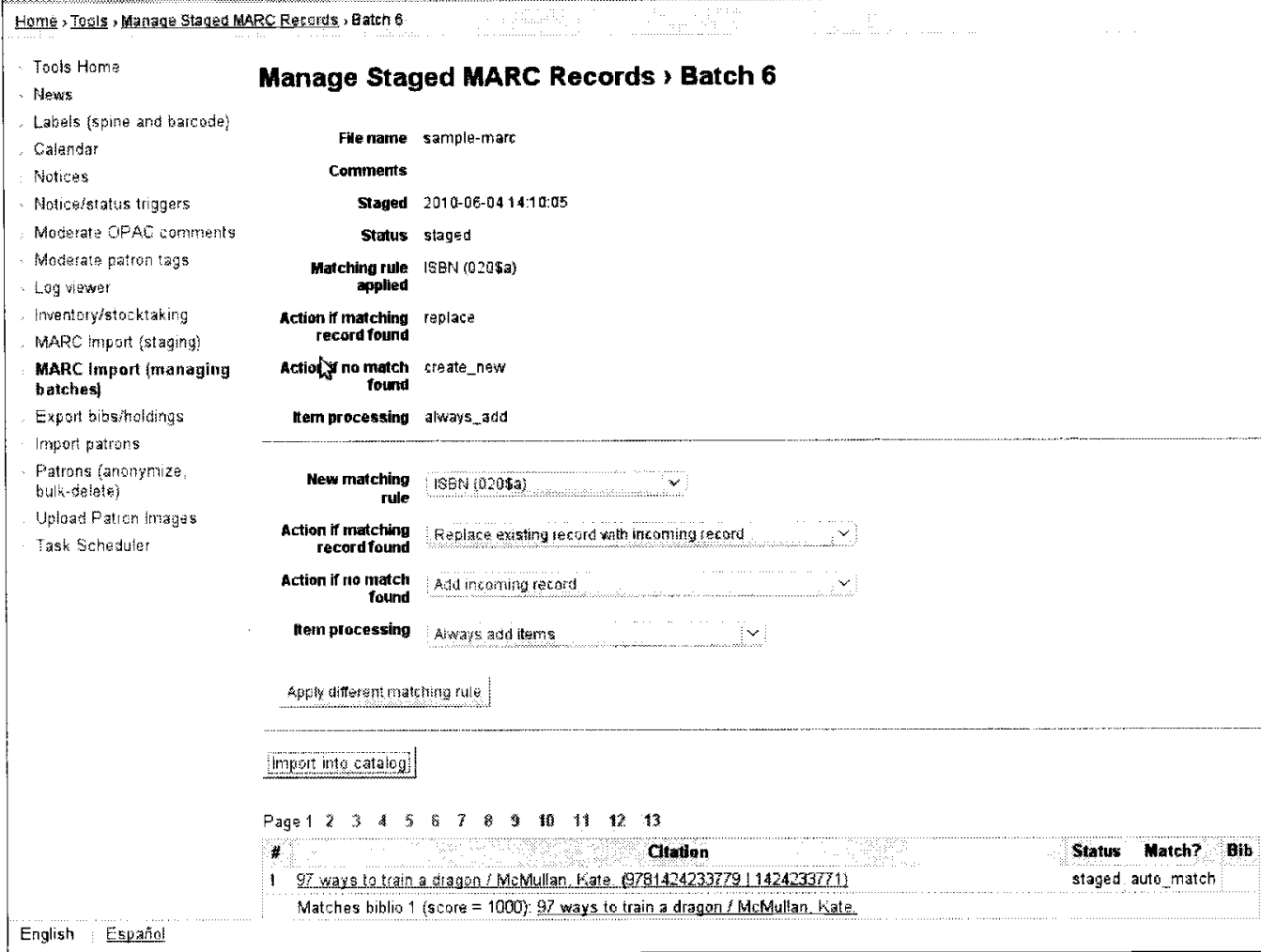


Once the import completes, you will see a summary of the import.

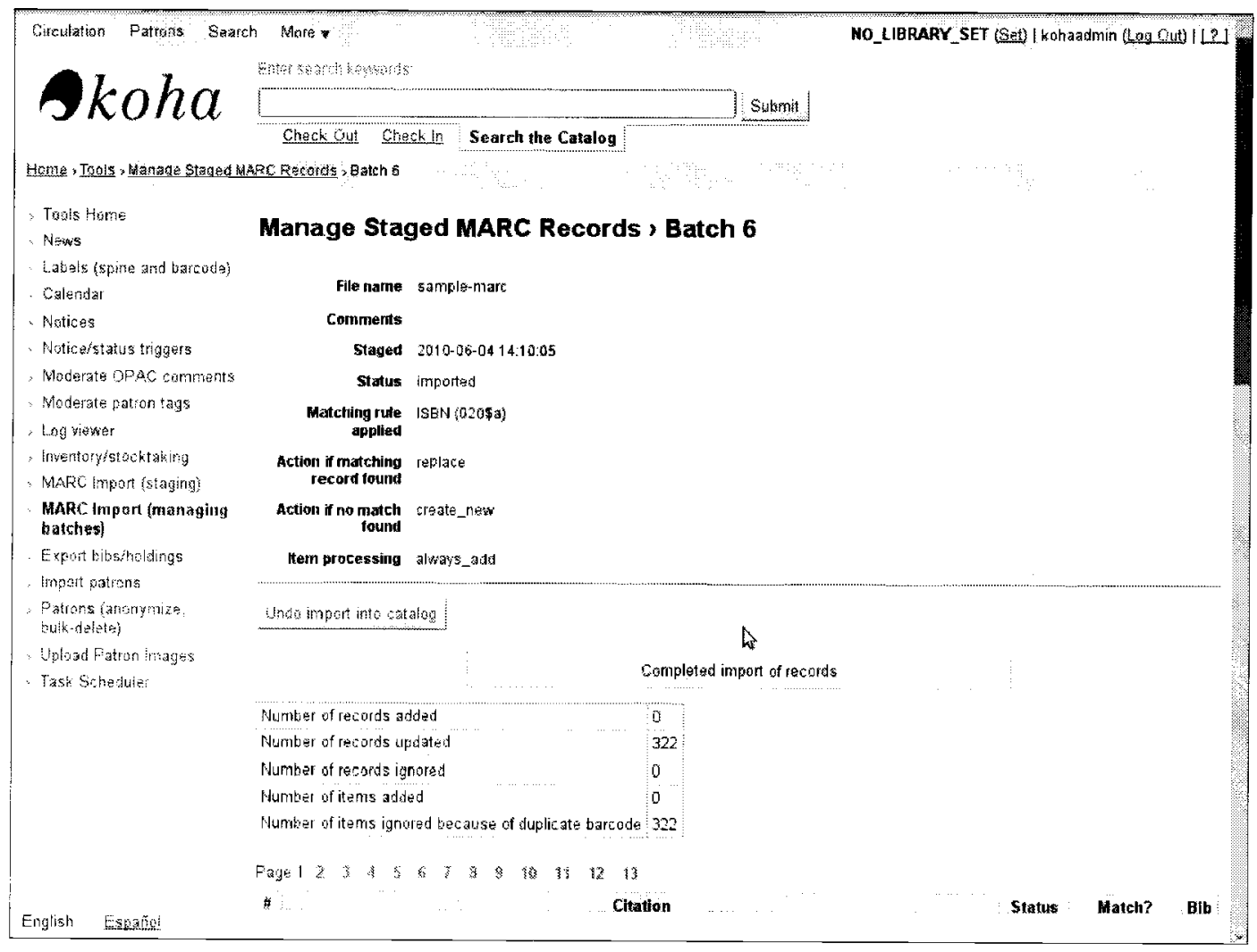

\section{Undo Import}

The great thing about the GUI tool is that it is possible to undo an import. Simply click on the Undo import into catalog button. 


\section{Summary}

Here is what we learned in this chapter on migrating catalog data from MARC compliant legacy library systems:

- Using MARCEdit to manipulate source MARC files

- Adding, merging, or swapping holdings subfields

- Setting up administrative fields in Koha prior to importing MARC files

- Using bulkmarcimport.pl and the GUI import tools

This completes the implementation section of this book. In the next chapter, we will learn how to troubleshoot installation and migration problems. 


\section{0 \\ Troubleshooting}

In this chapter, we will look at ways to troubleshoot problems with our Koha installation. If you are responsible for ensuring the availability of your Koha installation, troubleshooting is a key skill that you will need to develop. You may face problems during installation, during upgrades, or when users use the system in new ways.

We will first look at the community tools and resources available to you for help:

- Koha's Mailing lists

- Koha's IRC chat

- Koha's bug tracker

- Koha's Git repository

We will also look at ways to troubleshoot and fix some common problems:

- Apache2 web server is down

- MYSQL database server is down

- Zebra search is not returning any results

- Zebra index rebuild is not working

- Parser problems

- Over dues e-mails not working

- Fines not working

- Software bugs

- Command-line programs - environment variables not exported

- Problems with Internet Explorer 


\section{Where to get help-community resources}

There are several tools and resources that you can use to get help from the Koha community. In this section, we will point to you these resources.

\section{Koha's mailing lists}

You should join the main Koha list; this is the users list, it is very active, and is the best way to get support from the community. You can consider joining other specialized lists, depending on your interest.

You can join the lists via this page:

http://koha-community.org/support/koha-mailing-lists/.

\section{Koha Library Software Community}

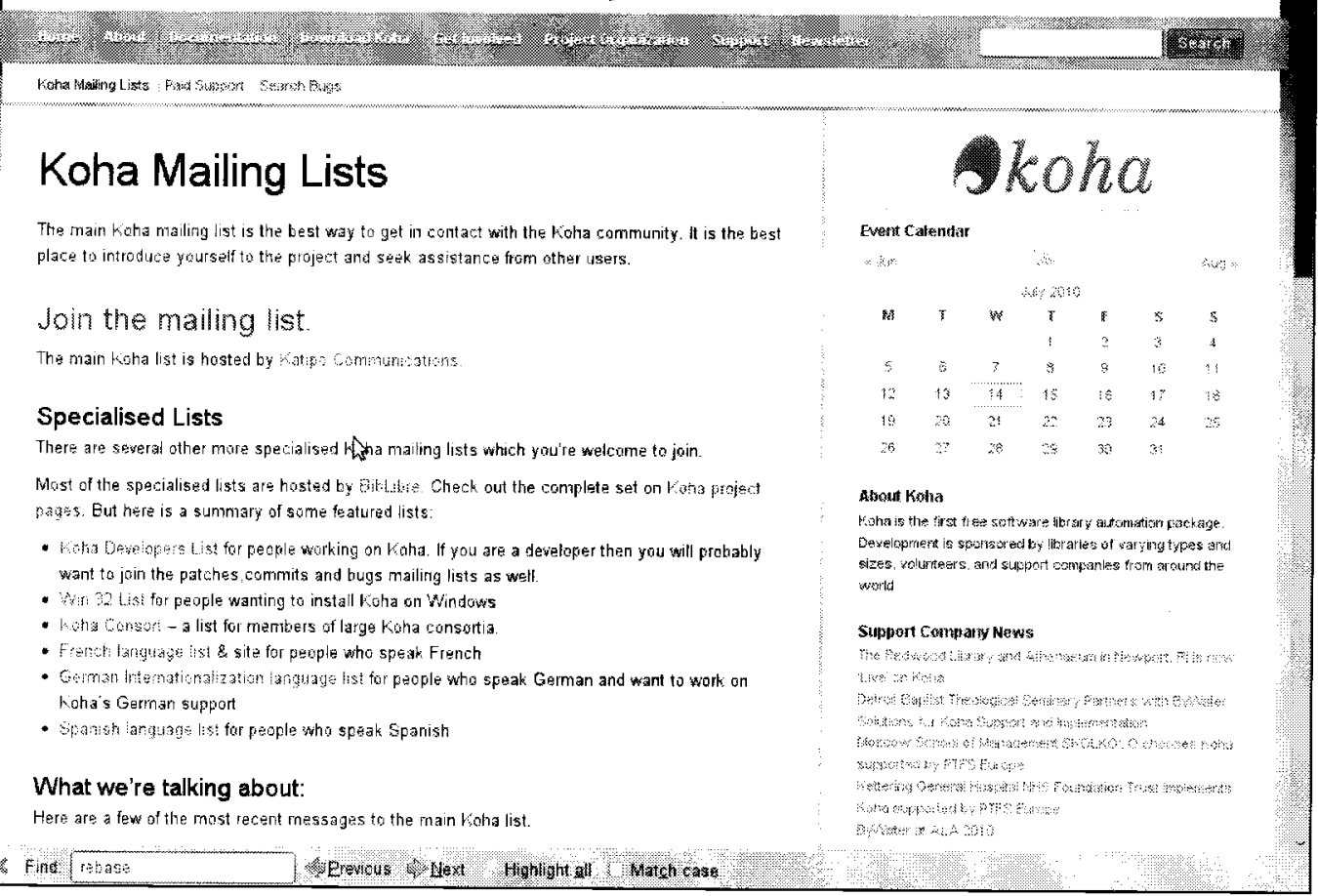




\section{Koha's IRC chat}

If you need to chat with Koha developers in real time, you should use the IRC chat. You can join the chat via this page:

http://koha-community.org/support/.

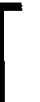

The IRC server is irc . katipo. co.nz and channel is \#koha.

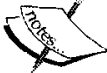

The IRC server is irc. katipo.co.nz and channel is Hkoha.

\section{Koha's bug tracker}

Koha's bug tracker is available at this URL:

http://bugs .koha-community.org/bugzilla3/.

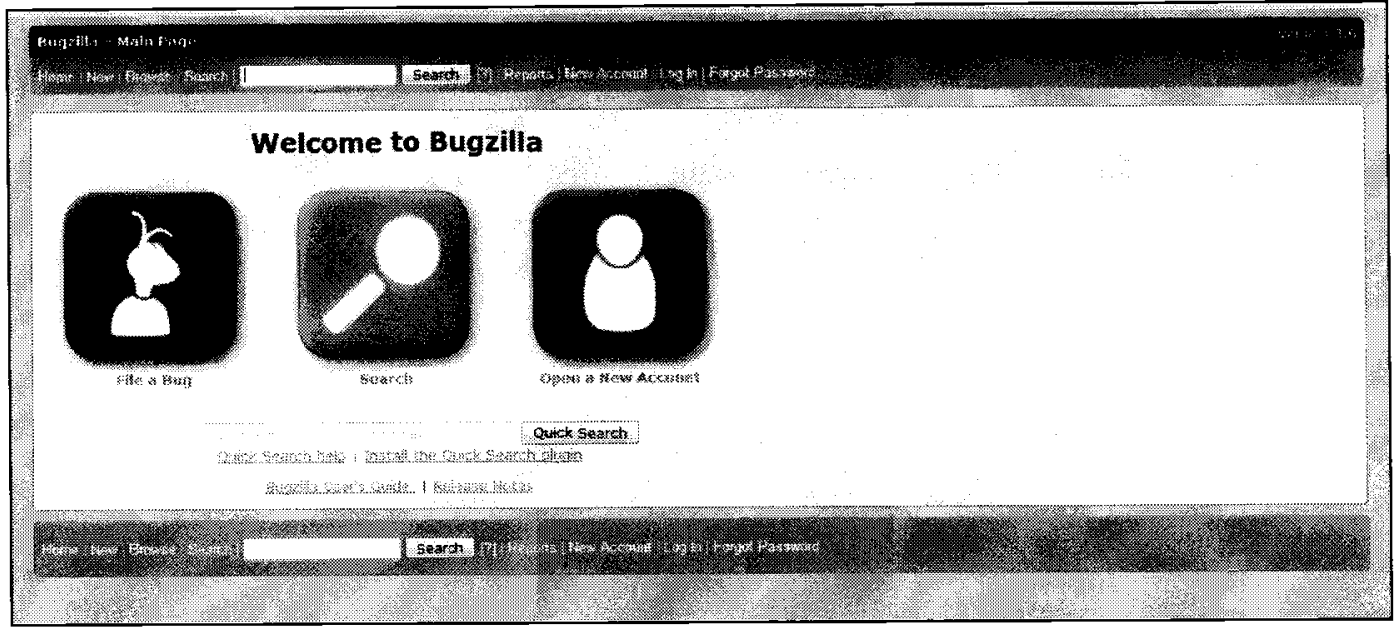

We use the bug tracker to:

- File a new bug report

- View a bug's status

- Learn about any work-around to the problem

- Download patches that fix the problem, especially if the fix is not available in Koha's Git repository 


\section{Koha's Git repository}

A web display of Koha's Git software repository is available at at:

http://git.koha-community.org/.

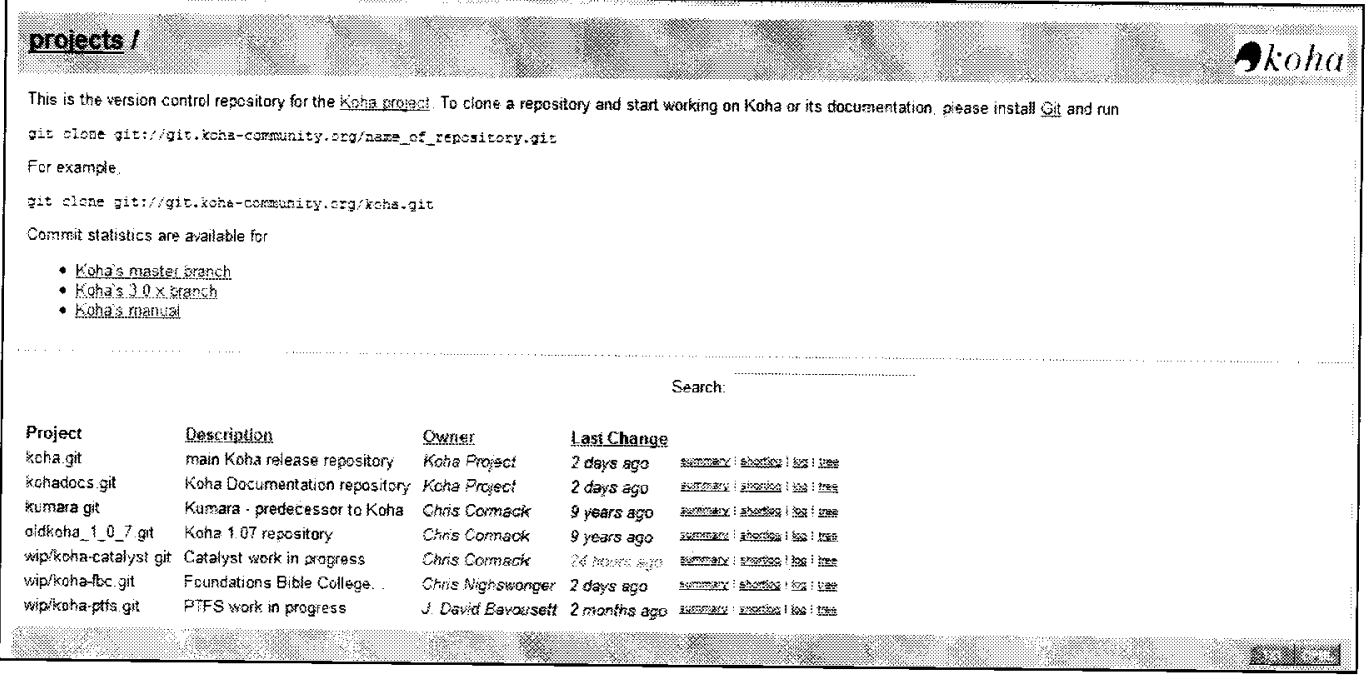

The repository can be viewed from the Linux command line, as well using Git commands.

We use the Git repository to:

- Monitor availability of patches for specific software bugs

- Download software updates

\section{Common problems}

In this section, we will look at ways to troubleshoot some common problems with a Koha installation. Other than software bugs, most other problems stem from improper server or application configuration. For each problem, we demonstrate diagnosis and rectification steps. 


\section{Apache2 web server is down}

If the Apache2 web server is down, you will not be able to connect to the server; you should see something like this.

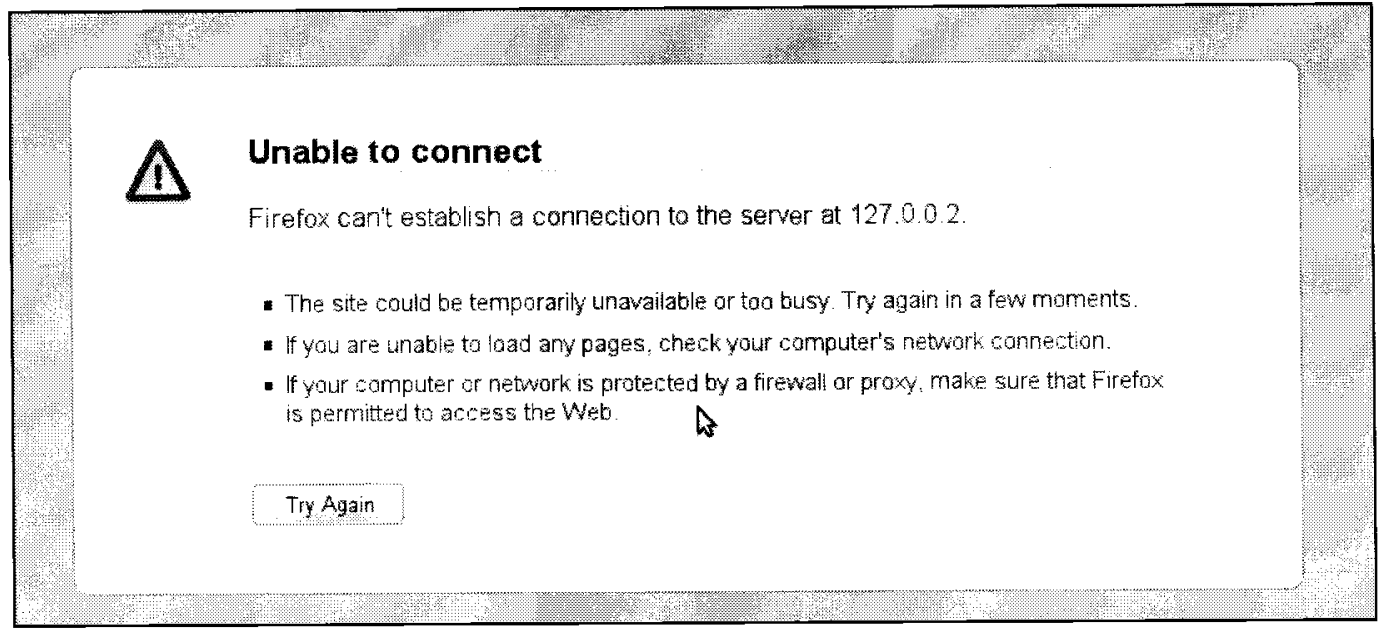

In such a situation, the first thing to check would be the status of the Apache2 server.

Let's run the command:

koha@1inux: \# sudo/etc/init.d/apache2 status

Checking for httpd2:

unused

If Apache2 is not running, run this command to bring the server up:

koha@1inux: \# sudo/etc/init.d/apache2 start

starting httpd2 (prefork)

done

A common reason for Apache2 being down, especially on openSuSE and șimilar distributions' is that the machine has been rebooted, and Apache2 has not been configured to start up at boot time.

To test if this is the case, we use the command chkconfig:

koha@1inux:/home/koha \# sudo chkconfig apache2 apache2 off 
To make sure Apache2 starts at boot, we use the chkconfig command with the on option:

koha@1inux: \# sudo chkconfig apache2 on

Let's run a test once again to see if the configuration is correct:

koha@1inux:/home/koha \# sudo chkconfig apache2 apache 2 on

There could be other reasons for the problem, of course; look at the Apache2 log files for clues. To view or track the log file, we use the tail command:

koha@1inux:/home/koha \# tail -f /var/log/apache2/error_log

\section{MySQL database server is down}

If the MySQL database server is down, you will not be able to connect to the database. You should see something like this:

\section{Koha error}

\section{The following fetal error hes occured:}

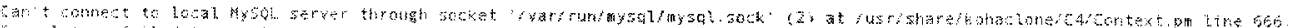

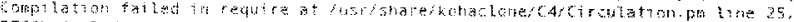

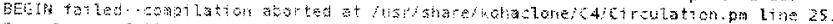

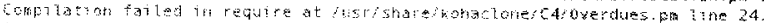

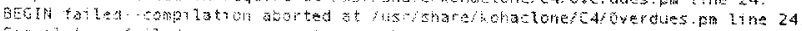

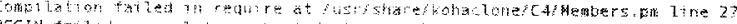

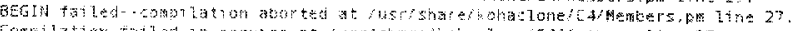

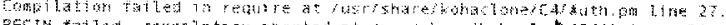

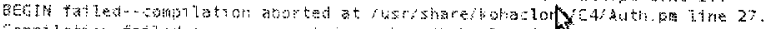

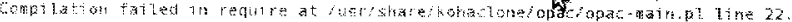

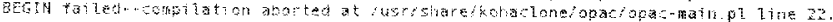

In such a situation, the first thing to check is if the MySQL database server is running or not. To test status of MySQL, we run the status command as follows:

koha@1inux: \# sudo/etc/init.d/mysq1 status

Checking for service MySQL:

unused 
The unused message above indicates that MySQL is down. To bring the database server up, we execute the start command:

koha@1inux: \# sudo /etc/init.d/mysq1 start

starting service MySQL

done

As with Apache2 on openSuSE and similar distributions, MySQL may not have been configured to start up at boot time.

To test if this is the case, we run command chkconfig:

koha@1inux:/home/koha \# sudo chkconfig mysq1 mysq1 off

To make sure MySQL starts at boot, we run chkconfig with the on option:

koha@1inux: \# sudo chkconfig mysql on

Again, just like with Apache2, let's run a test once again to make sure the configuration is correct:

koha@1inux:/home/koha \# sudo chkconfig mysq1

mysq1 on

There could be other reasons for the problem; you might want to take a look at the MySQL logs for clues:

koha@1inux:/home/koha \# tail -f /var/log/mysq1/mysq1d.1og

The messages $\log$ file is a general system log file, and may contain useful information as well:

koha@1inux:/home/koha \# tail -f /var/log/messages 


\section{Zebra search not returning any results}

Another common problem is Zebra searches don't return any results.

The No Result found message looks perfectly innocuous. Maybe you don't have a match for the search term. But if this happens for search terms you know should return results, then the first thing you should look at is the Zebra server.

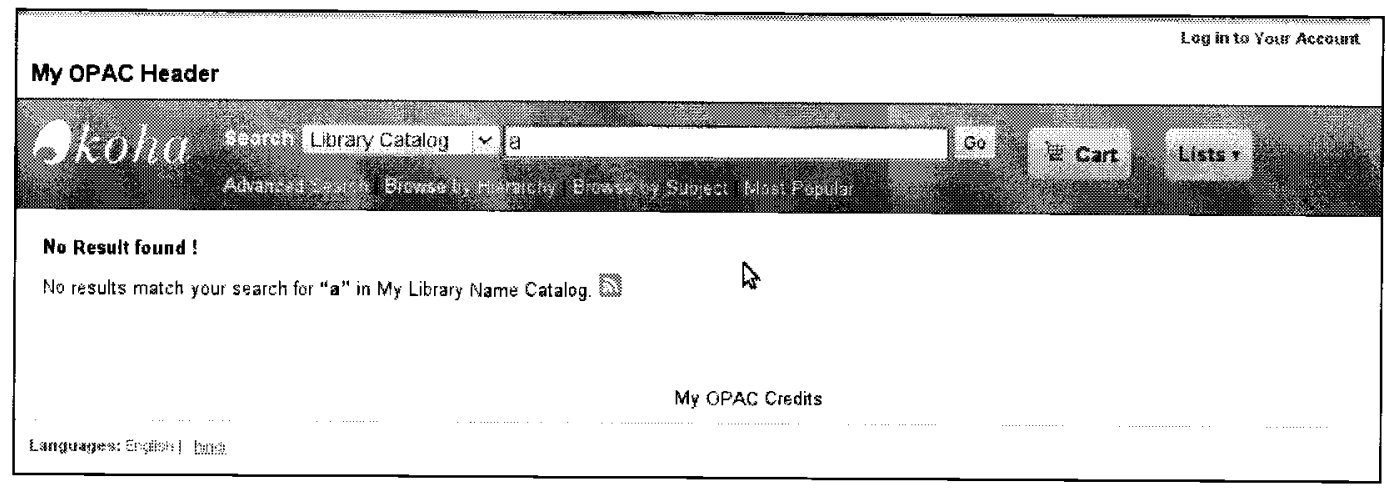

We use the ps command to see if zebrasrv is running:

koha@linux:/home/koha \# ps -eaf|grep zebra

root $20321540014: 38$ pts/0 00:00:00 grep zebra

In this case, there is no zebrasrv process. To fix the problem, we need to start up the Zebra server. We execute the zebrasrv command like this:

koha@linux:/home/koha \# zebrasrv -f/etc/koha-dev/etc/koha-conf.xml \&

Or, if we have the Zebra daemon service setup, we start the server like this:

linux-4yut:/home/koha \# sudo/etc/init.d/koha-zebra-daemon start

Let's test if the server is up, again using the ps command:

koha@linux:/home/koha \#ps -eaf|grep zebra

root $20331540014: 39$ pts/0 00:00:00 zebrasrv -f /etc/koha-

$\mathrm{dev} / \mathrm{etc} /$ koha-conf . $\mathrm{xml}$

root 20461540 0 14:39 pts/0 00:00:00 grep zebra 
The output this time tells us that there is an active zebrasrv process.

A common reason for the Zebra server being down is that it is not configured to start up when the machines reboots.

On Debian, we use the update-rc.d command to set this up:

1inux-4yut:/home/koha \# sudo update-rc.d koha-zebra-daemon defau1ts

On openSuSE, we use the chkconfig command to set this up:

koha@1inux:/home/koha \# sudo chkconfig koha-zebra-daemon on

On openSuSE, if you are not using the koha-zebra-daemon service, you can setup the zebrasrv command in the /etc/init.d/boot. local file. Edit the boot. local file:

koha@1inux: > sudo vi /etc/init.d/boot.1oca1

And add the zebrasrv command to the file somewhere near the end of the file, as follows:

/usr/bin/zebrasrv -f /etc/koha-dev/etc/koha-conf.xm1\&

There could be several reasons for the server coming down; look at the Zebra server $\log$ file for clues:

koha@1inux:/home/koha \# tail -f /etc/koha-dev/var/log/zebrasrv.log

For more information on configuring a Zebra server, see Chapter 4, Koha's Web Installer, Crontab, and Other Server Configurations.

\section{Zebra index rebuild not working}

You should know there is a problem with the rebuild process when changes to catalog items - new records, edits to records, or changes in checkout statuses do not reflect properly in search results on the OPAC and in the Staff Client.

The rebuild process may not be running due to several reasons.

If the rebuild process is setup correctly in the Crontab, you should see something like this in the messages log:

koha@1inux:/home/koha \#tail -f/var/log/messages

Jun 3 16:14:01 koha@1inux/usr/sbin/cron[4010]: (root) CMD (/home/koha) kohaclone/misc/migration_tools/rebuild_zebra.pl -b -a -z >/home/koha/ logs/zebra.log $2>\& 1$ 
If you do not see rebuild_zebra.pl executing in the log file, then you know that there is problem with the Crontab configuration.

To view how the Crontab is setup, we use the crontab command with the -1 option:

koha@1inux:/home/koha \# crontab -1

A properly configured Crontab will look something like this:

PERL5LIB=/home/koha/kohaclone

KOHA_CONF=/etc/koha-dev/etc/koha-conf . xm1

*/1 * * * * per1/home/koha/kohaclone/misc/migration_tools/rebuild zebra.p1 -b -a -z >/home/koha/logs/zebra.log $2>\& 1$

It is important to set up the environment variables PERL5LIB and KOHA_CONF in the Crontab.

For more clues, you should refer to the rebuild log file:

koha@1inux:/home/koha \# tail -f /etc/koha-dev/var/log/rebuild_zebra.log

For more information on configuring Zebra's index rebuild in the Crontab, see Chapter 4, Koha's Web Installer, Crontab, and Other Server Configurations.

\section{Parser problems}

If you are using non-English characters-Spanish or French, then the SAX parser is something you will need to have setup correctly.

A search expression matching a record that has such characters in any field will result in an error like this: 


\section{search Luprary Gatalog \& harry potter

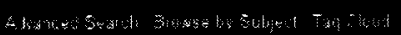

\section{Font Hats:}

In this type of situation, you should check the SAX parser setting. We do this by executing Koha's SAX parser print program /misc/sax_parser_print.pl:

koha@koha@linux: > cd /home/koha/kohaclone/misc/

koha@linux:/home/koha/kohaclone/misc \# ./sax_parser_print.pl

Koha wants something like:

XML : : LibXML : : SAX : : Parser $=$ HASH $(0 \times 81 \mathrm{fe} 220)$

You have:

XML : : L I bXML : : SAX=HASH ( $0 \times 834$ fea 4$)$

Looks bad, check INSTALL.* documentation.

The error looks bad indicates that the configured parser is not suitable for Koha use. To correct this problem, we edit the parser's initialization file:

koha@linux:/home/koha/kohaclone/misc \# vi /usr/lib/per15/vendor_ perl/5.10.0/xML/SAX/ParserDetails.ini

And, replace [XML: :SAX : : PurePerl] or [XML: :SAX : Expat], as the case may be, with [XML: : LibXML: :SAX: : Parser].

For more information on configuring the SAX parser, see Chapter 4, Koha's Web Installer, Crontab, and Other Server Configurations. 


\section{Overdues e-mail not working}

In our experience, problems related to overdue notice e-mails are fairly common. This is a more complex problem to troubleshoot, as there are a whole set of things that need to be in place.

\section{Reviewing notice triggers}

Overdue notices may not work correctly if they are not setup correctly in the Notice/status triggers section under Tools. Make sure the Letter and Delay is setup correctly for the Patron Category in question.

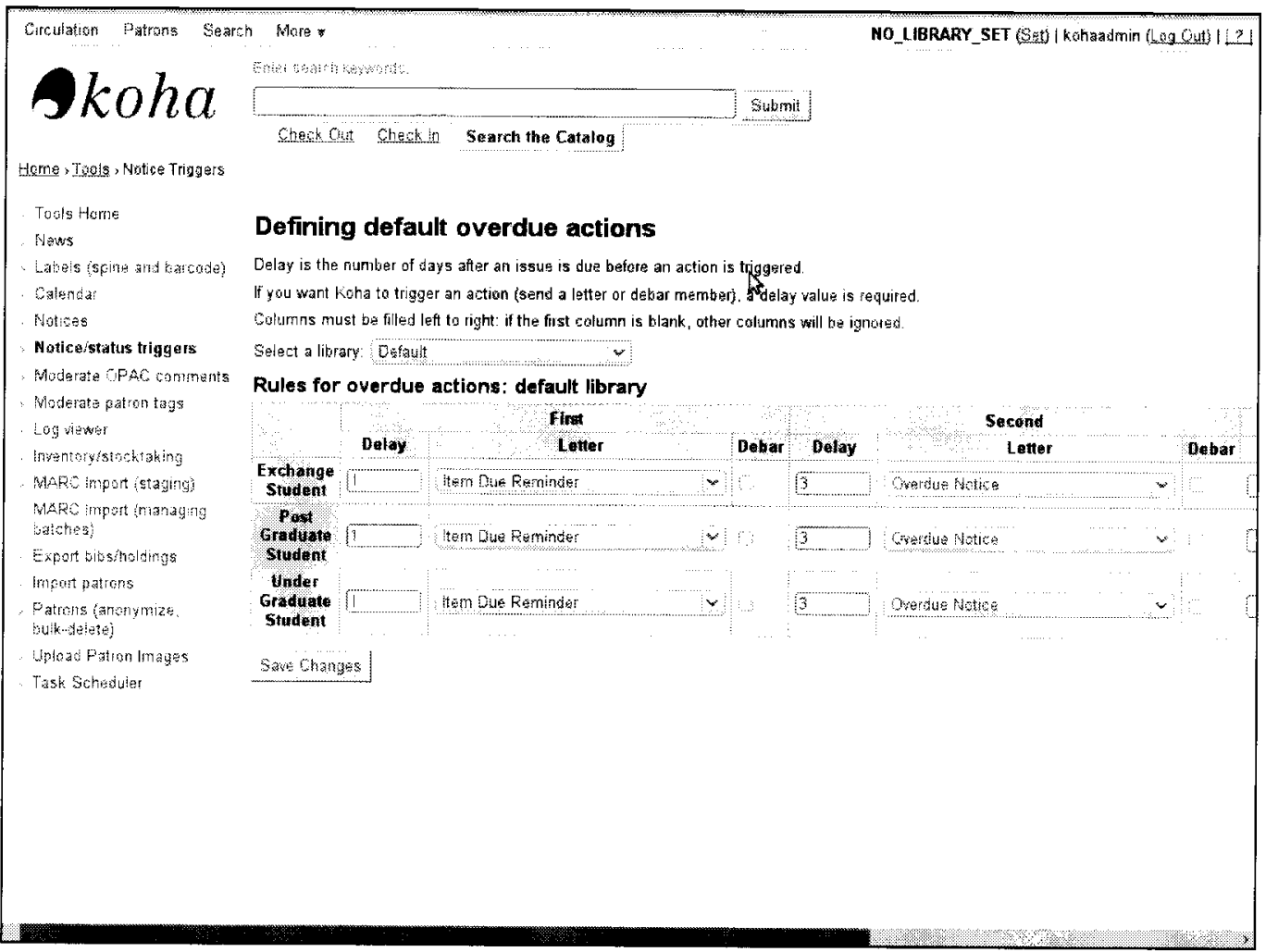

\section{Troubleshooting e-mail problems}

Next, we look at the Messaging tab of the Patron who is not receiving overdue messages. If there are messages in the Pending status, we know there is a problem with e-mailing messages, rather than generation of notices. 


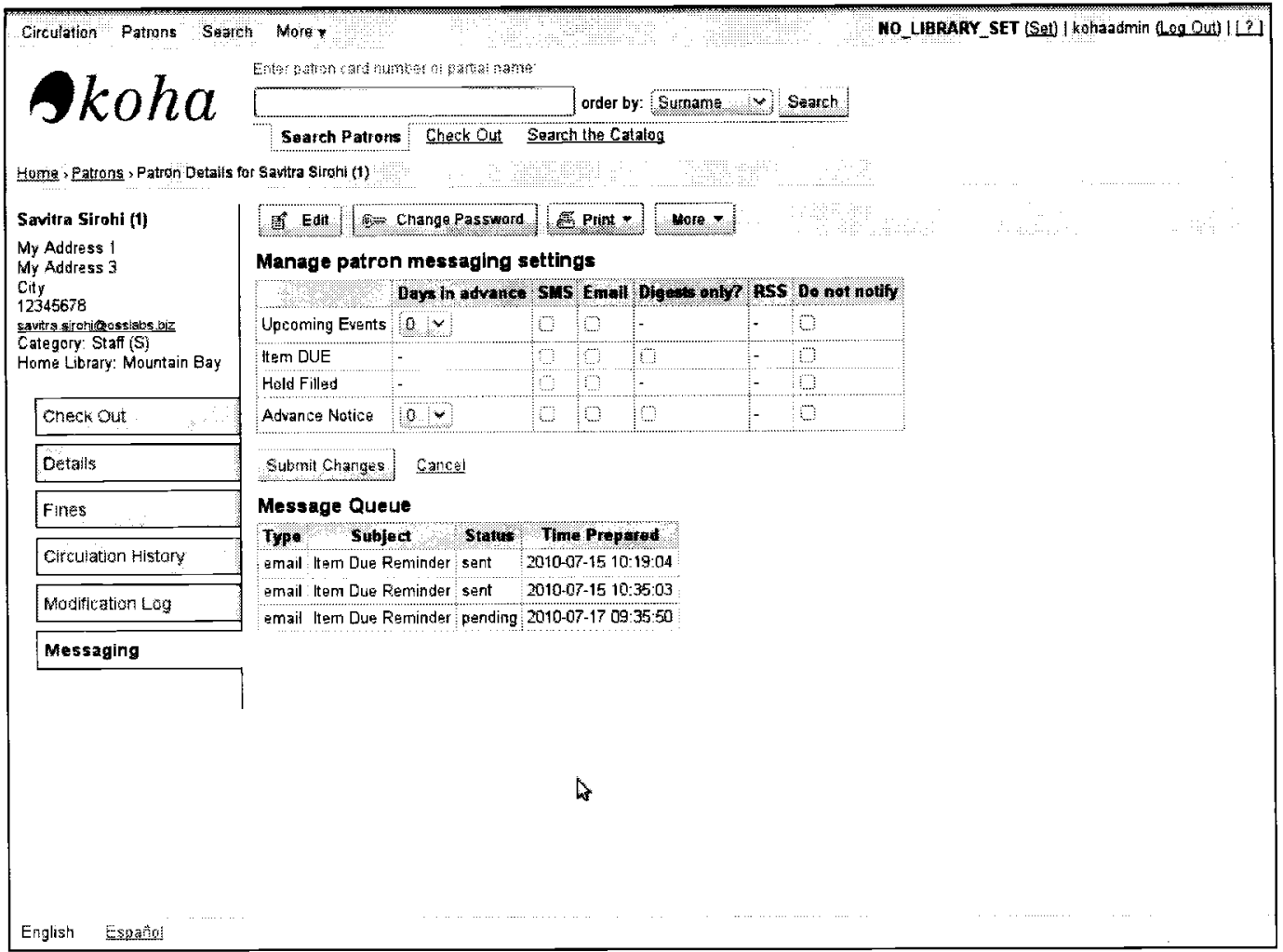

Let's first look at the status of the mail server:

koha@linux:/home/koha \# rcpostfix status

Checking for service

Postfix:

running

We should also try to send an e-mail from the Linux shell:

koha@linux:/home/koha \# mail -s "Hello Koha"

myemail@mydomain. com

EOT

If both these steps are working, we need to look at the messages log file to make sure that the cronj ob for the process_message_queue.pl program is running:

koha@linux:/home/koha \# tail -f /var/log/messages

May 31 09:55:01 koha@linux/usr/sbin/cron[8980]: (koha) CMD (perl/home/ koha/kohaclone/bin/cronjobs/process_message_queue.pl) 
To view how the Crontab is setup, we use the cront ab command with the -1 option: koha@linux:/home/koha \# crontab - I

A properly configured Crontab will have the Koha-related environment variables setup:

PERL5LIB $=/$ home $/$ koha/kohaclone

KOHA CONF $=/$ etc/koha-dev/etc/koha-conf.$x m l$

And, the cronj ob should be setup as follows:

$306 * *$ * perl/home/koha/kohaclone/bin/cronjobs/process_message_queue. pl

For more clues, run the process_message_queue.pl program from the Linux shell in verbose mode using the $-\mathrm{v}$ option:

koha@linux:/home/koha/kohaclone/misc/cronjobs \#perl process_message queue.p1 - $\mathrm{v}$

\section{Troubleshooting problems with generation of notices}

If you don't see any pending messages in the messaging tab, then there could be a problem with the Cronjob for the overdue_notices.pl program.

First, it might be a good idea to look at the messages log file to see if the program is running:

koha@inux:/home/koha \# tail -f /var/log/messages

May 31 09:45:01 koha@linux/usr/sbin/cron[8792]: (koha) CMD (perl/home/ koha/kohaclone/bin/cronjobs/overdue_notices.pl-t)

A properly configured Crontab will have the Koha-related environment variables setup, and a Cronjob for the overdue_notices.pl program:

koha@linux:/home/koha \# crontab -1

PERL5LIB=/home/koha/kohaclone

KOHA_CONF=/etc/koha-dev/etc/koha-conf.xml

‥

45 * * * perl/home/koha/kohaclone/bin/cronjobs/overdue notices.pl -t 
If the Crontab configuration is fine, try running the overdue_notices.pl program from the Linux shell for clues:

koha@1inux:/home/koha/kohaclone/misc/cronjobs \# per1 overdue_notices.p1 $-v-t$

\section{Fines not working}

Problems with fines calculations are fairly common as well.

Fines calculations may not work correctly if your fine rules are not setup correctly in the Circulation and fine rules section under Koha Administration. Make sure that the Fine Amount is setup correctly for the Patron Category and Item Type in question.

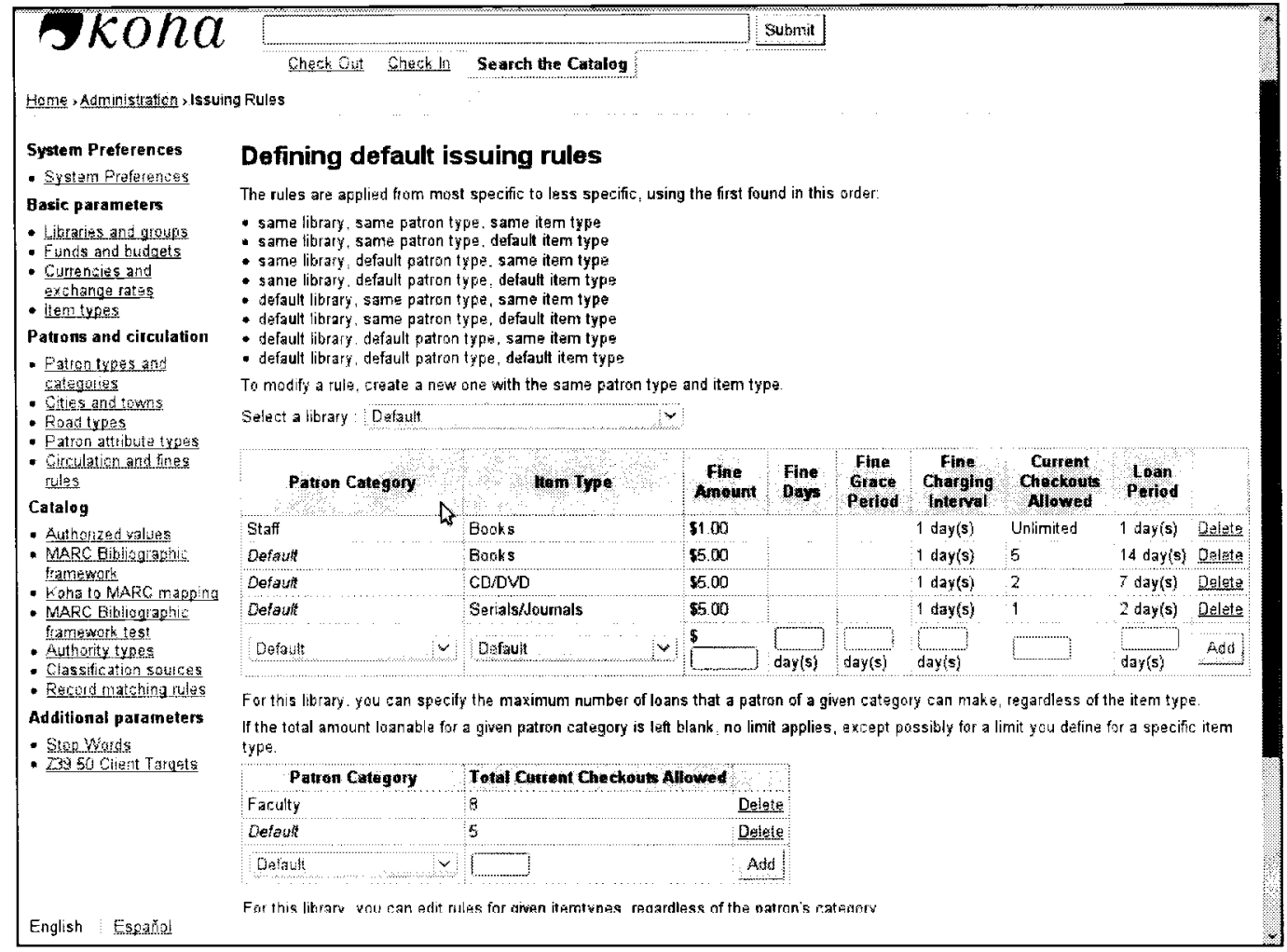

Another common mistake is to neglect to change the system preference from finesmode to production. 
You might also want to make sure that the fines.pl program is setup in the correctly in the Crontab:

koha@linux:/home/koha \# tail -f /var/log/messages

Jul 14 10:05:01 koha@linux/usr/sbin/cron[7741]: (root) CMD

perl /home/koha/kohaclone/bin/cronjobs/fines.pl)

A properly configured Crontab will have the Koha-related environment variables setup, and a Cronjob for the fines. pl program:

koha@linux:/home/koha \# crontab -1

PERI5LIB $=/$ home $/$ koha/kohaclone

KOHA_CONF $=/$ etc/koha-dev/etc/koha-conf .xml

07 * * * perl/home/koha/kohaclone/bin/cronjobs/fines.pl

For more clues, try running the fines.pl program from the Linux shell:

koha@linux:/home/koha/kohaclone/misc/cronjobs \# perl fines.pl

Fines assessment -- 2010-07-17 -- Saved to/tmp/koha_2010-07-17.log

Number of Overdue Items:

counted 1

reported 1

The program outputs information into a log file, which might contain interesting information:

koha@linux:/home/koha/kohaclone/misc/cronjobs \#vi/tmp/koha_2010-07$17 . \log$

cardnumber categorycode surname firstname email phone
address citystate itemnumber barcode date_due
days_overdue fine

$1 \quad s$

12345678

2010-07-14
Sirohi Savitra myemail@mydomain.com

My Address 1

3
1

3
30108000050959 


\section{Software bugs}

Sometimes, you may come across software bugs. You can raise such issues in Koha's bug tracker. Often, you will find that someone has already raised a bug report, and a fix is available as well.

Here is an example of a bug report on the tracker:

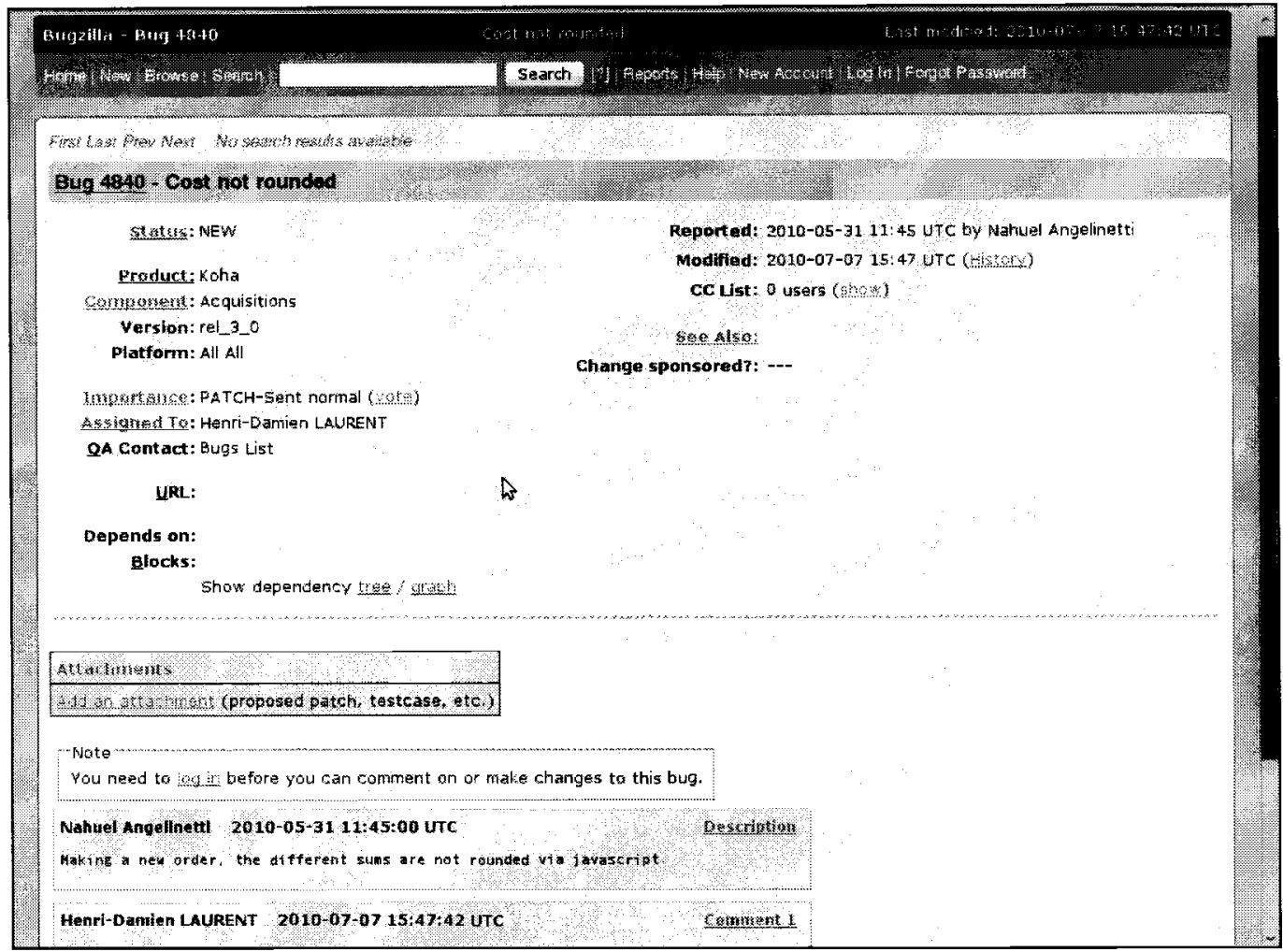


If a bug fix is available, and if Koha's release manager has pushed the fix into the repository, you will find the patch in Koha's Git repository.

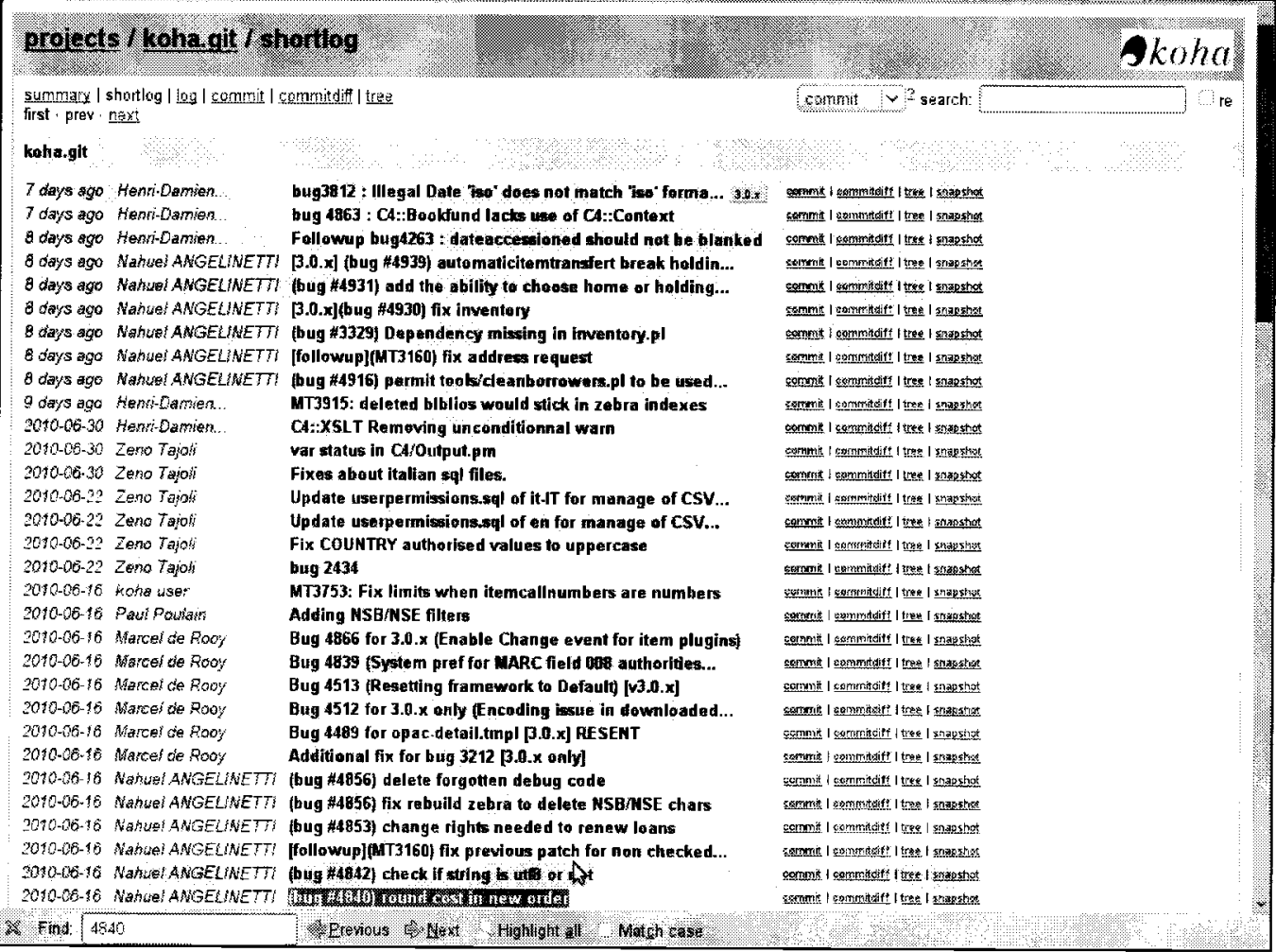

To apply the fix to our installation, we use the git pull command, something like this:

koha@linux:/home/koha/kohaclone \# git pull origin $3.0 . x$

This command will pull the bug fix, along, with all the other changes in the repository since the last pull. We will learn more about git pull in the next chapter, Chapter 11, Updating Software. 
If a bug fix is available, but has not been pushed into the Koha repository, you can download the patch from the bug reports, and try to apply it yourself. To apply a patch, we use the command git apply:

koha@linux:/home/koha/kohaclone \# git apply name-of-patch.patch

\section{Command line programs-environment variables not exported}

If you don't have Koha's environment variables set up correctly for the Linux shell, you will see errors like this when running command-line programs, such as bulkmarcimport.pl:

1i85-160:/home/koha/kohaclone/misc/migration tools \# perl bulkmarcimport. pl $--h$

Can't locate C4/Context.pm in @INC (@INC contains: /usr/lib/per15/5.10.0/ i586-linux-thread-multi /usr/lib/perl5/5.10.0/usr/lib/perl5/site perl/5.10.0/i586-linux-thread-multi /usr/lib/per15/site_perl/5.10.0/ usr/lib/perl5/vendor_perl/5.10.0/i586-linux-thread-multi /usr/lib/perl5/ vendor_perl/5.10.0/usr/lib/per15/vendor_perl .) at bulkmarcimport.pl line 21 .

BEGIN failed--compilation aborted at bulkmarcimport.pl line 21 .

To avoid this problem, we need to export the KOHA_CONF and PERL5LIB environment variables:

koha@linux:/home/koha/kohaclone \# export KOHA_CONF=/etc/koha-dev/etc/ koha-conf . $x \mathrm{cml}$

koha@linux:/home/koha/kohaclone\# export PERL5LIB=/home/koha/kohaclone

To set these up to be persistent across sessions, we add these lines to the /etc/bash . bashrc file in Debian, and to the /etc/bash.bashrc.local file in openSuSE. 


\section{Problems with Internet Explorer}

Some Koha screens may not display properly in Microsoft's Internet explorer:

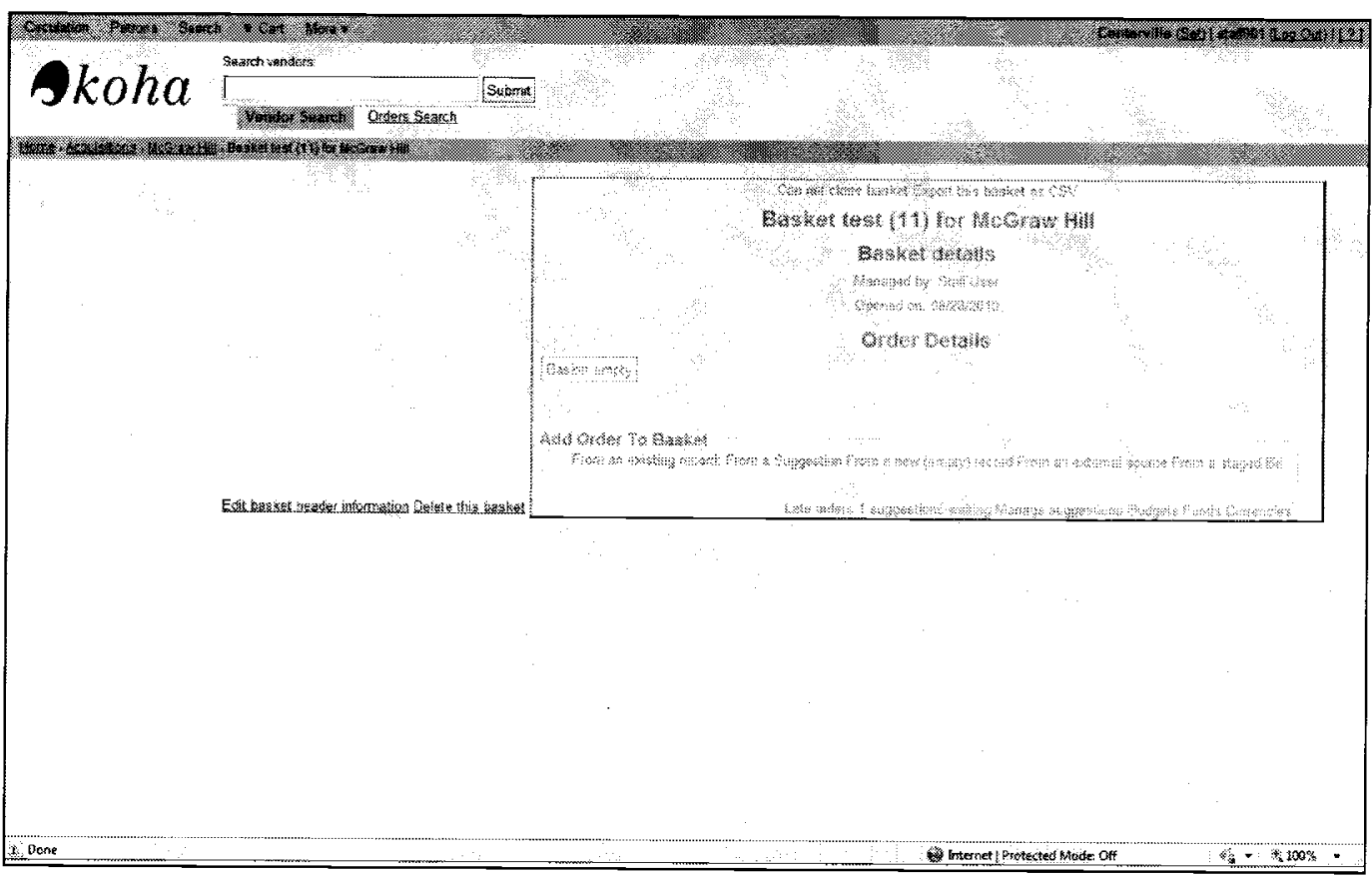

You can try looking for a fix in the Koha bug tracker or in its Git repository. It is best, however, if you use Firefox, Chrome, or other browsers; things should be just fine on those. 


\section{Summary}

In this chapter, we learned how to troubleshoot application problems. Koha's community tools - mailing lists, IRC chat, Git repository, and bugs repository are a great help.

To get you started on Koha troubleshooting skills, we walked you through troubleshooting tasks for some common problems with Apache2, MySQL, and Zebra.

We learned how to tackle more complex problems related to overdue notices e-mails, fines, and finding and applying bug fix patches.

We also learned the importance of exporting Koha's environment variables, and of setting up the SAX parser correctly.

In the next chapter, we will learn how to download and install software updates. 



\section{1 \\ Updating Software}

The Koha software is always changing, almost every day. These changes contain bug fixes, minor revisions to existing features, and entirely new features. You should keep the software updated to benefit from these changes.

Even if the new versions do not contain changes of interest to you, it is good practice to keep the software updated. If your version falls too far behind the current version, the update process to the latest version is likely to be very difficult.

In this chapter we learn how to download and install software updates. We cover the chapter in two steps - an orientation followed by a demonstration of the process.

\section{Orientation to updating software}

Before we can update the Koha software, let us learn about Koha's software versions and how to choose the version to upgrade to. In this section we also learn about the components of a software update, and how to install each component of the update properly.

\section{Understanding Koha's software versions}

To choose which new version to upgrade to, let us first understand how the Koha software is organized. 


\section{Branches}

At any given point Koha has at least two main software branches:

- Stable: This branch is older and is considered stable or bug free for the most part. Only bug fixes are allowed on this branch.

- Development: This branch is where new features are developed. This branch is ahead of the stable branch, meaning it has all the features of the stable branch and the new features in development.

\section{Heads}

Both branches - stable and development have heads. A heads is the tip of the branch, pointing to the latest change made in that branch.

At the time of writing of this chapter, there are two heads available in Koha's Git repository.

- 3.0.x: This is the tip of the stable branch

- master: This is the tip of the development branch

\section{Tags}

Both branches have multiple tags. Tags point to specific points in a branch's change history. For instance we see these tags related to the stable branch:

- v3.00.06: This is the latest stable branch

- v3.00.05: An earlier version of the 3.0.x branch

- v3.00.04: An earlier version of the 3.0.x branch

- v3.00.03: An earlier version of the 3.0.x branch

And these tags are available for the development branch:

- v3.02.00-beta: This is the 3.02 branch in the beta testing stage

- v3.03.00-alpha: This is the 3.02 branch when released for alpha testing 


\section{Choosing a version to update to}

We can choose to move to the head of the stable branch or the head of the development branch or to any tag in one of these branches.

Here are some pointers to help you decide:

- On production servers, we upgrade to the latest stable tag in the stable branch

- To take an early look at new features being developed, switch to the alpha or beta tag in the development branch, if available

- If you want to take a look at the very latest version of the software, switch to head of the development branch

\section{Understanding components of software updates}

When bugs are fixed or new features are added in Koha, different types of files and programs can change such as these:

- Perl, Java script, HTML, CSS, and other types of files in kohaclone folder

- Tables, columns, constraints, indexes, system preferences, and other types of changes in Koha's database

- Indexes and properties in Zebra configuration files

- Directives in Koha's Apache2 configuration files

\section{An overview of the installation process}

To ensure that software updates are installed properly, we need to follow these steps:

- Download software updates: We can download updates using Git. Git automatically detects our current version and downloads updates from Koha's online repository.

- Switch to a specific software version: Depending on our purposes, we will choose a version that we want to upgrade to.

- Install Perl module prerequisites: The new version of the software may depend on new Perl modules; we will need to install these.

- Install the new version of Koha: We will install the new Koha version using the make utility; this process is similar to that of a fresh Koha install. 
- Configure Apache2: The new version of the software may have an updated Apache 2 configuration file. We will need to configure this new file.

- Upgrade the database: We will use Koha's web installer to upgrade the database to the new version.

- Rebuild Zebra indexes: The new software version may contain updates to Zebra configuration files. To have these changes reflected in search results, we will need to do a full rebuild of Zebra's indexes.

- Restart Zebra server: To load new Zebra configurations we will have to restart zebrasrv.

\section{Updating the software}

Now that we have an understanding of how to update the software, let us go ahead and execute the update process.

\section{Downloading updates using git pull command}

To download software updates, we use the git pul l command. Before we do that let us check what branch we are on at this time by using the git branch command:

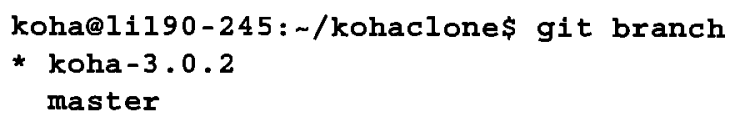

This * in the output above indicates that we are on the 3.0 .2 version, which at the time of writing is an older version on Koha's stable branch.

Let us also check the branches on the online Koha repository, by using the git branch command with the $-r$ (for remote branch) option:

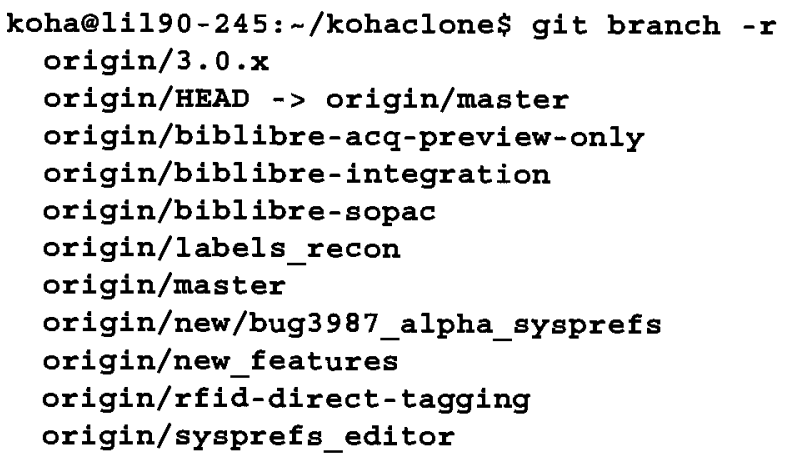


Of the several branches listed in the output above, two are of immediate interest to us-origin/3.0.x and origin/HEAD or origin/master. Origin/3.0. $\mathrm{x}$ is the stable branch while origin/HEAD or origin/master is the development branch.

If we are on a production server and we are interested only in updates for the stable branch, we will run the git pull command pointing to the stable branchorigin/3.0.x:

koha@lil90-245: / kohaclone\$ git pull origin $3.0 . x$

If we are on a test machine, and we want to upgrade to the development branch for development of test purposes, we run the git pull command pointing to the development branch-origin/master:

koha@li190-245: /kohaclone\$ git pull origin master

Once the command is executed your Koha server has the latest updates available in the kohaclone folder.

\section{Switching to a new software version}

Now we need to decide which version of the software to use, this of course depends on what your purpose of upgrading is.

First let us take a look at the tags that are available. To determine this, we use the command git tag:

koha@li190-245: /kohaclone\$ git tag

We see several tags, at the bottom of the list; you should see tags for the $3.0 . \mathrm{x}$ branch, something like this:

v3.00.03

v3.00.04

v3.00.05

v3.00.06

And at the very bottom, tags for the master branch, which is currently versioned 3.02.xx:

v3.02.00-alpha

v3.02.00-alpha2

v3.02.00-beta 
To switch to the master or the head of the branch, we run the git checkout command as follows:

koha@1i190-245: /kohaclone\$ git checkout master

We see from the output of the git tag command that the latest tag or version in Koha's stable branch is version v3.00.06. To switch to this version, we would run the git checkout command with the $-\mathrm{b}$ option and with a label for the new branch and the tag as parameters:

koha@11190-245:-/kohaclone\$ git checkout -b <label for the new branch> $<$ tag pointing to the version>

The -b option creates a new branch with the specified label and points the branch to the software version specified by the tag. This command would be executed like this:

koha@1i190-245: /kohaclone\$ git checkout -b koha-3.0.6 v3.00.06

To switch to tag 3.02 .00 -beta on the development branch, we would run the git checkout command as follows:

koha@1i190-245: / kohaclone\$ git checkout -b koha-3.02-beta v3.02.00-beta

To test if you have switched branches successfully, use the git branch command:

koha@1i190-245:-/kohaclone\$ git branch

* koha-3.02-beta

master

\section{Installing the new software version}

Once we have switched to the software version we want to use, we will install the new Koha version in the same way that we do a fresh Koha install. The reader should refer to Chapters 1 and 2 for help with these steps.

\section{Running the Makefile.PL program}

First we run the Makefile.PL program. As this is a software update and not a fresh install, we need to make sure we enter configuration details corresponding to the current installation:

1inux-4yut:/usr/share/kohaclone \# per1 Makefile.PL

We chose the dev installation mode during our initial installation; make sure we choose the same here:

Installation mode (dev, single, standard) [standard] dev 
Set the configuration directory to the directory configuration directory of the current installation:

Configuration directory: [/home/koha/koha-dev]

Make sure to specify the current database name here:

Please specify the name of the database to be used by Koha [koha]

Specify the MySQL user that has privileges over the database:

Please specify the user that owns the database to be used by Koha [kohaadmin]

Specify the password of this MySQL user:

Please specify the password of the user that owns the database to be used by Koha [katikoan] katikoan

If you are using Zebra, say yes here:

Insta11 the zebra configuration files? (no, yes) [yes]

For other questions, the default value should be fine. Simply press the Return key to proceed to the next step.

\section{Installing Perl modules}

The Makefile. PL step above may end with warnings on missing Perl module prerequisites:

[Mon Jun 14 16:12:27 2010] Makefile.PL: Warning: prerequisite IPC: :Cmd 0.46 not found. We have 0.401 .

[Mon Jun 14 16:12:30 2010] Makefile.PL: Warning: prerequisite Text: : CSV: : Encoded 0.09 not found.

Writing Makefile for koha

1inux-4yut:/usr/share/kohaclone \#

We will need to install these missing modules using the package manager or the CPAN shell. Refer to Chapter 1 for more information on how to install Perl modules.

\section{Completing Koha installation}

Once all Perl modules are installed successfully, we finish the installation of the new version by running the rest of the make commands:

koha@11190-245: / kohaclone\$ make

koha@1i190-245: / kohaclone\$ make test

koha@11190-245:-/kohaclone\$ sudo make insta11 


\section{Configuring Apache2}

Installation of the new Koha version will overwrite Koha's Apache2 configuration file-/etc/koha-dev/etc/koha-httpd. conf. This is why we will need to configure Apache 2 once again. Refer to Chapter 2 for more information on how to configure Apache2.

\section{Upgrading the database}

Once we have Apache2 configured we navigate to Koha's staff client to launch Koha's web installer. Here we use the kohaadmin MySQL user to log on.

\section{Okoha \\ CPEN-SOLREE WFTEGRATEO EIBAARY SYSTEM}

Welcome to the Koha Web Installer

Before we begin, please verify you have the correct

credentials to continue. Please log in with the username

and password given to you by your systems

adrhnizatrator and located in your kona-conf . $\times \mathrm{ml}$

configuration file.

Please enter your username and password:

Username:

Password:

Login»

Once we log in, we see a database upgrade message. In this step the installer will upgrade the database to match the new version of the software. 


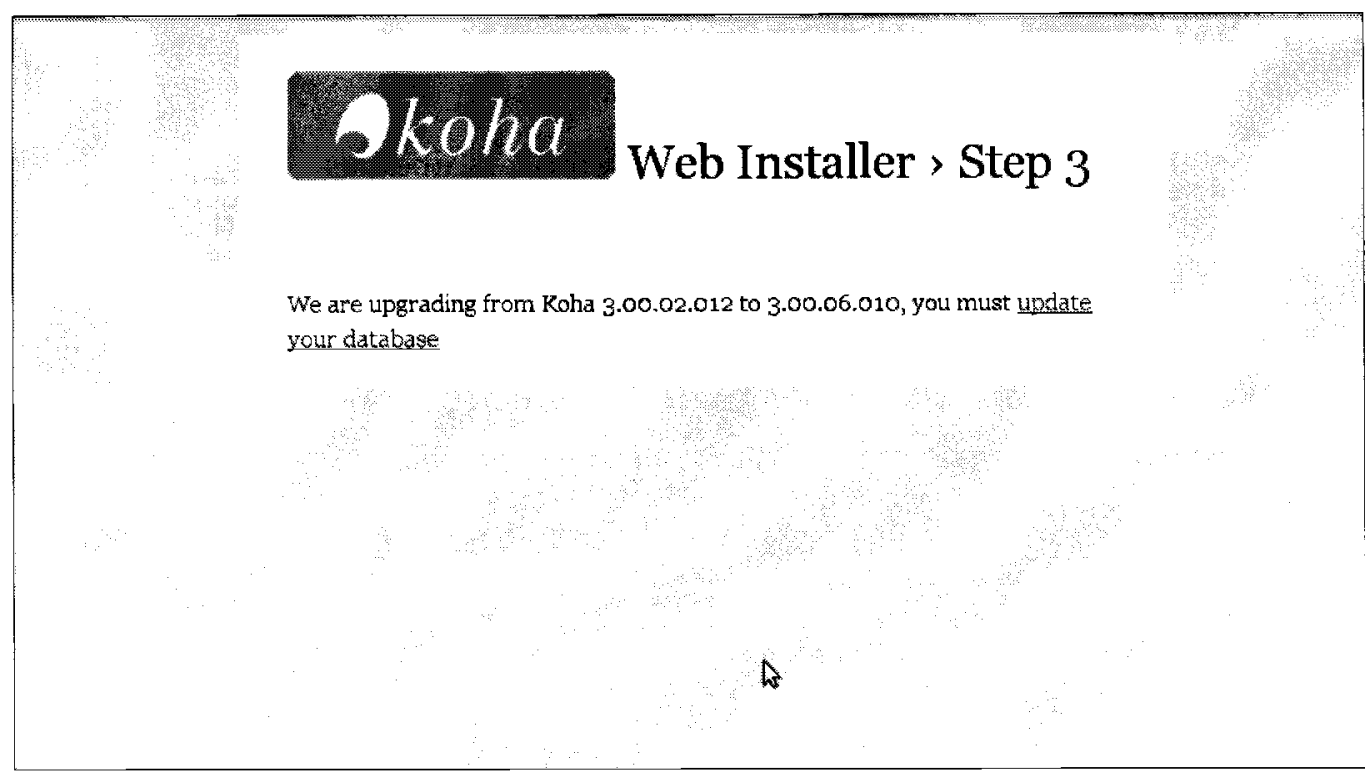

Once the database upgrade finishes, you should be able to log in to the new version of Koha.

\section{Zebra-rebuilding indexes and restarting the server}

As a final step we need to do a full rebuild of Zebra indexes in line with the new Zebra configuration files. We also restart zebrasrv to load the new configurations.

\section{Rebuilding Zebra indexes}

We run the rebuild_zebra.pl program with the $-r$ option to do a full rebuild:

Linux-4yut:/usr/share/kohaclone \# ./misc/migration_tools/rebuild_zebra.pl -b $-a-r-v$

Restart Zebrasrv

\section{Restarting zebrasrv}

To restart zebrasrv, we restart the Zebra daemon as follows:

linux-4yut:/home/koha \# sudo/etc/init.d/koha-zebra-daemon restart 


\section{Summary}

Here is what we learned in this chapter on updating software:

- Using git pull command to download software updates

- Using git branch command to switch to a specific software version

- Installing the new Koha version using the Make utility

- Upgrading the database using Koha's web installer

- Rebuilding Zebra indexes using new Zebra configuration files

- Restarting Zebra server to load new configurations

In the next chapter, we will learn about a related topic - how to make your own modifications to the Koha software. 


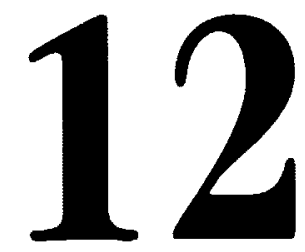

\section{Customizing Koha Software}

Most serious Koha users will want to customize the software to suit their needs, perhaps to modify the styling or appearance or to tweak a certain page to show additional information. If you have the skills, you can even take on more serious work, such adding new features.

It is best to share the code you create by sending patches to Koha's release manager. Koha's license requires that we share any enhancements we make. Another reason to share the code is that if your changes are included in upcoming releases, you don't have to do the work of retrofitting your changes into the new version.

In this chapter, we learn how to customize Koha code. We start with an orientation, and then use a specific example to demonstrate how to implement and share software changes.

\section{An orientation to customizing Koha software}

Let's first get an understanding on how to go about customizing software. We will learn about the skills required, the organization of Koha's application folder and its database, and the process of making the software changes using Git, Koha's version-control system. 


\section{Skills needed}

Here is a quick overview of the skills needed to customize Koha. If you want to modify styling and appearance, HTML and CSS skills should suffice. If you want to work on more complex features, you will likely need JavaScript, Perl, and SQL skills as well:

- HTML: Koha runs in a browser, basic HTML skills are required if you want to make changes to Koha's screens

- CSS: Size, fonts, position, or colors on Koha screens are controlled via CSS files

- JavaScript: JavaScript adds interactivity to web pages; in Koha, JavaScript is used for tasks such as validating keyed data or building menus

- Perl: Koha's scripting language. If you need to work outside of basic styling and appearance changes, you will need Perl skills

- SQL: Along with Perl, you will need SQL skills to access or modify data in the database

\section{Understanding Koha's application folder}

To be able to make changes to the software, we need to understand the structure of Koha's application folder-how the folders are organized, what they contain, and how the different file types are related to each other.

\section{Top level folders}

Here is a description of the some of the important folders in the kohaclone folder:

- C4: This folder contains Koha's Perl modules. These Perl modules are shared libraries, containing subroutines that are used by various Perl scripts throughout the Koha application.

- etc: This folder contains Apache2, Zebra, and Koha's configuration files.

- installer: This folder contains Koha's web installer files, including those that install or upgrade the Koha database.

- koha-tmpl: This folder contains files related to staff client and OPAC screens.

- Perl scripts: Koha's Perl scripts are organized by function in folders, such as acqui - for acquisitions, circ-for circulations, or misc-for various command-line and Crontab programs. 


\section{Template files}

Let's take a closer look at the koha-tmpl file; this folder contains files and folders related to Koha's screens:

- The koha-tmpl folder contains two folders-opac-tmpl for the OPAC, and intranet-tmpl for the staff client

- The OPAC and staff client template folder each contains a theme folder named prog

- The theme folder in turn contains a language folder - en or $f r$, depending how you installed Koha

- Within the language folder, you will find a set of folders $j s$-containing JavaScript files, includes - header, footer, masthead and other include files, $\mathrm{lib}$ - external display-related libraries, such as yui and jquery, modules template files that display Koha's pages and css - stylesheets

\section{Relationships between different types of files}

Let's understand how Perl scripts, Perl modules, and template files are related:

- Perl scripts call or use subroutines in Perl modules. To use a subroutine, the Perl script must first load the module using the Use statement, like this: use $\mathrm{C} 4:$ : Items;

- Perl scripts, especially those that are used in Koha screens, have one or more template files associated with them. To see which template file is associated, look for statements such as this:

= get_template_and_user (\{template_name $=>$ "cataloguing/additem. tmpl",

- Template files include header or footer types of include files using a statement such as this:

$<$ !-- TMPL_INCLUDE NAME="doc-head-open. inc" -->

- CSS and JavaScript files are usually included in template files via the include file doc-head-close.inc 


\section{Understanding Koha's database}

We also need to understand how Koha's database is organized. This will help us make software changes that require access to the database or that require updates to be made to it. In this section we take a quick look at how to browse the database; we also list some of the important tables.

\section{Browsing Koha's database}

Let's start by logging in to MySQL. First, we use the use command to switch to Koha's database:

mysql> use koha

Database changed

We use the show tables command to view a listing of all tables in the database:

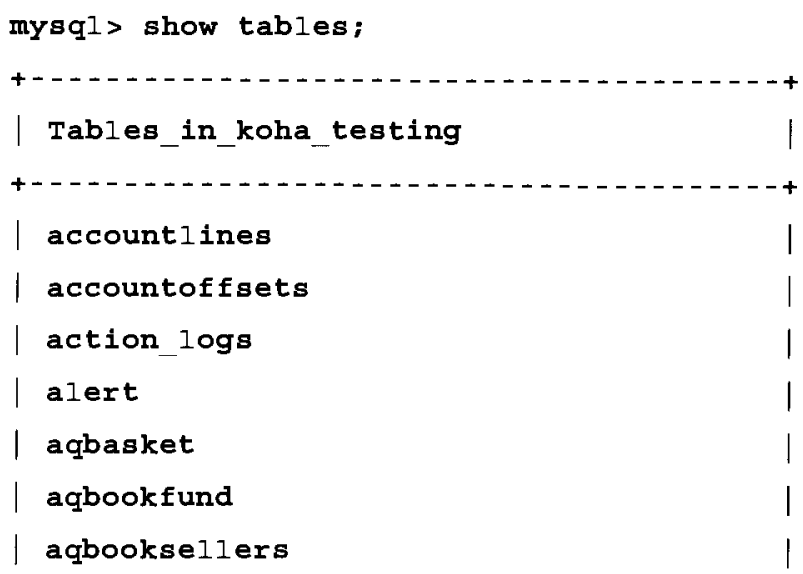

To view how a particular table organized, we use the describe command:

mysql> describe borrowers;

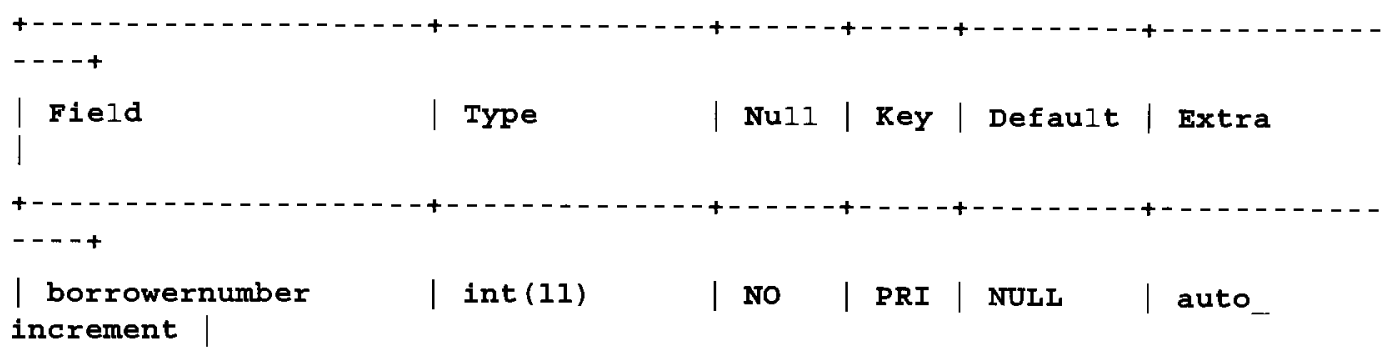
increment | 


\begin{tabular}{|c|c|c|c|c|}
\hline cardnumber & varchar (16) & YES & UNI & NULI \\
\hline surname & mediumtext & NO & & NULI \\
\hline firstname & text & YES & & NUIL \\
\hline
\end{tabular}

\section{An overview of important Koha tables}

Here is a quick overview of some of the important tables in Koha, categorized by function.

\section{Cataloguing}

The following three tables are key Cataloguing related tables:

- biblio: Contains bibliographic data such as title or author.

- biblioitems: Also contains bibliographic data; there is one-to-one correspondence between records in biblio and biblioitems tables.

This table stores the MARC record in the field marcxml

- items: Contains holdings records.

\section{Circulation}

Here is a listing of important circulation-related tables:

- issues: Contains current checkouts

- old_issues: Contains items that have been checked in

- reserves: Contains open hold requests

- old_reserves: Contains hold requests that are cancelled or fulfilled

\section{Patrons}

Here are two key patrons-related tables:

- borrowers: Contains patron records

- accountlines: Contains data on patrons fines and other dues 


\section{Administration}

Administrative setting and data are stored in the following tables:

- libraries: Libraries participating in the system

- itemtypes: Item types are used in circulation rules

- categories: Patron categories

- issuingrules: Circulation and fine rules

- systempreferences: Global system preferences

- aqbookfund: Funds, budgets are created under funds

- aqbudget: Budgets under each fund

\section{Serials}

Serials data is captured in the following tables:

- subscription: Subscription information such as frequency, numbering pattern, start and end dates

- subscriptionhistory: Table that tracks missing and received issues

- serial: Table connecting bibliographic records and subscriptions

- serialitems: Items under a serial record

\section{Acquisitions}

Acquisitions-related data is captured under these tables:

- aqbasket: Contains order baskets

- aqbooksellers: Table containing vendor records

- aqorders: Contains orders within a basket

- aqorderdeilivery: Contains records of shipments received

- aqorderbreakdown: Contains information on budget utilization against each order

\section{Koha's database structure}

Here is a useful diagram of the database structure including key tables, their columns, and relationships between the tables:

http://wiki.koha-community.org/wiki/File: Kohastructure.png. 


\section{Using Git to manage software changes}

It is highly recommended that the software changes be managed using Git.

Some of the benefits of using Git are:

- Make changes safely in a separate development branch

- Undo changes easily, even if changes are to a large number of files

- Automatically merge your changes with those available in Koha's online repositories

- Share your changes with others, including Koha's release manager

Here is a listing of some Git commands we will use:

- git checkout: To create a development branch.

- git add: Add one or more changed files to a commit.

- git commit: Records the changes along with a description or comment entered by the committer.

- git format - patch: Creates a patch-a file that contains all the changes in a single file. The patch can then be shared with others, including Koha's release manager. The release manager may choose to include the patch in upcoming versions of the software.

- git send-email: Sends an e-mail to Koha's release manager with the patch.

- For more information on Git commands, refer to these links: http://git-scm.com/documentation.

\section{Understanding the software customization process}

And finally, here is how we go about making a change:

- Creating a branch: As a first step, we use the git checkout command to create and switch to a new development branch. We can create one or more commits in this branch.

- Changing application files: We change one or more files using vi or other editors. These files may be Perl modules, Perl scripts, JavaScript, CSS, or template files.

- Making database changes: We make database changes in MySQL scripts in the installer folder. 
- Changing configuration files: We make changes to Koha, Apache2, or Zebra configuration files in the etc folder.

- Creating a commit: Once all the changes related to a feature have been made, we commit the changes using the git commit command. The commit may consist of a single file or several files, but all files should be logically related.

- If we have changed any of configuration files in the etc folder, we install them using the Makefile. PL, make, and make install set of commands. These commands will install the new files in Koha's configuration folder, /etc/koha-dev/etc/.

- Changing the database: If we have made any database changes, we install these using Koha's web installer. The web installer runs automatically when we navigate to the staff client.

- Creating a patch: Once the changes are tested, we can use the git format patch command to create a patch. The patch can be sent to Koha's release manager, or to others using the git send-email command.

\section{Customizing Koha software-an example}

Let's take a look at a specific example to understand how to modify Koha code.

Let's say we want to add the Google Indic Transliteration tool to the masthead on the OPAC. This tool transliterates text in the source language to a destination language selected from a drop-down list. The transliterated expression can be then be used as a search expression.

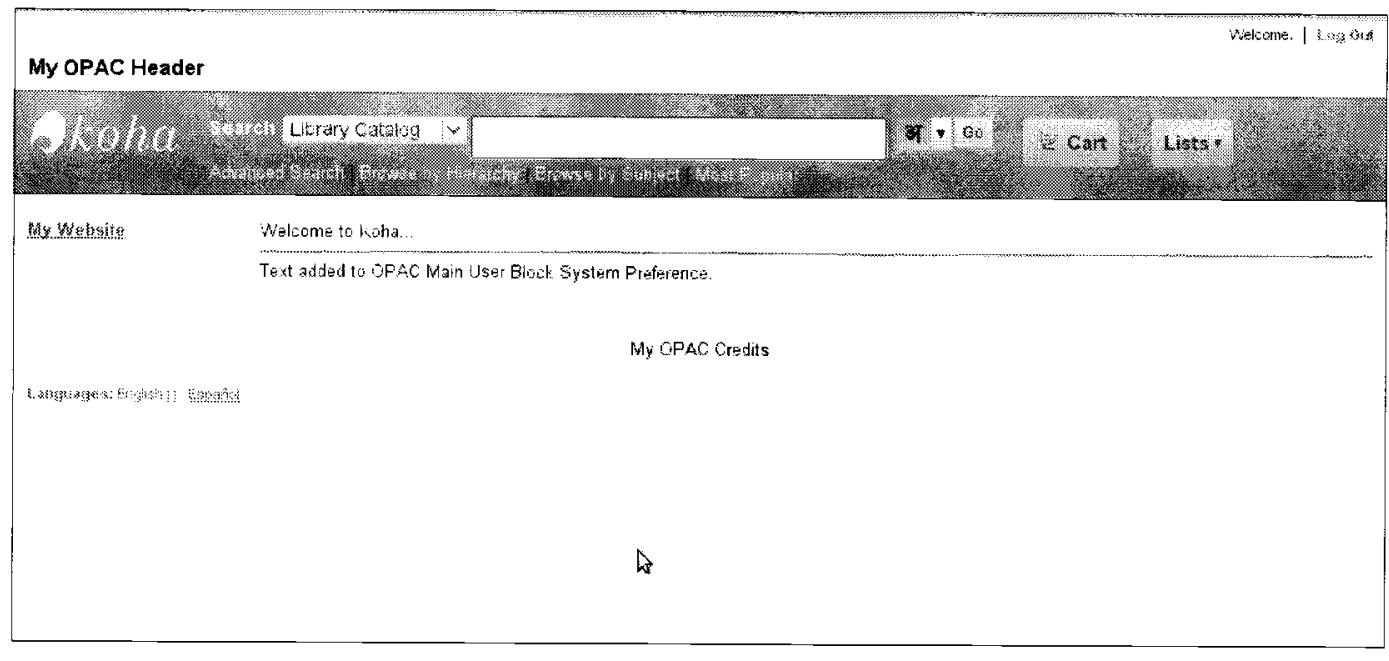


This feature requires the following changes:

- Modify the CSS file to position the transliteration control

- Modify the search box on the masthead to accept input in the source language

- Add the language selector drop-down list to the right of the search box

- Include a Google-provided JavaScript file; the transliteration is performed by this file

- Add a new system preference to control the availability of the tool

\section{Creating a development branch}

Let's first create a development branch in which to work by creating a copy of the master branch:

Koha@linux:/home/koha/kohaclone \# git checkout -b mydevel master

This command creates a copy of the master branch, and switches to using this new branch.

\section{Making CSS changes}

To position the control via CSS, we edit the opac.css file in the koha-tmpl/opactmpl/prog/en/css folder:

koha@linux:/home/koha/kohaclone \#vi koha-tmpl/opac-tmpl/prog/en/Css/ opac.css

We add this block for the transliteration control to the CSS file:

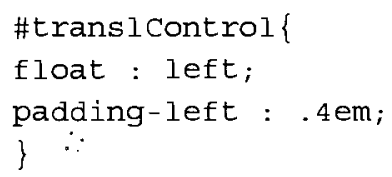

\section{Creating a new JavaScript file}

We create the new Google-provided JavaScript file in the folder koha-tmpl /opactmpl/prog/en/js. Open an empty new file using the vi command:

koha@linux:/home/koha/kohaclone \# vi koha-tmpl/opac-tmpl/prog/en/js/ googleindictransliteration.js 
And add the contents of the transliteration file to the file:

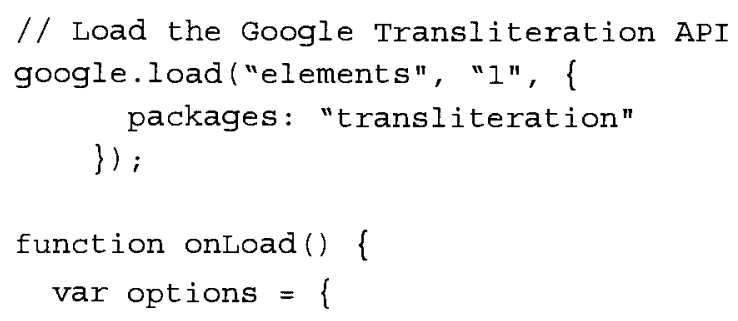

\section{Loading the Transliteration JavaScript file}

Next, we add a block to load the transliteration JavaScript file. We add this block to the doc-head-close. inc file in the koha-tmpl/opac-tmpl/prog/en/includes folder. The doc-head-close. inc file is included in all OPAC pages, so we can be sure that our new JavaScript will be loaded in all pages.

koha@linux:/home/koha/kohaclone \# vi koha-tmpl/opac-tmpl/prog/en/ includes/doc-head-close.inc

We add this block to the include file:

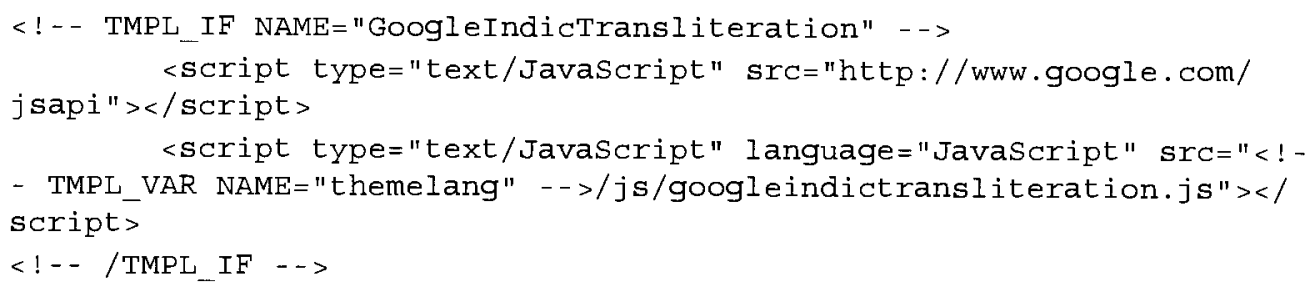

Note the use of this if condition in the block above:

<! - - TMPL_IF NAME="GoogleIndicTransliteration" -->

This loads the Transliteration JavaScript only if a system preference

GoogleIndicTransliteration is set to On.

\section{Creating a system preference}

Next, we create a system preference that will be used to control whether the transliteration tool will be displayed or not. The system preference once installed will look like this: 


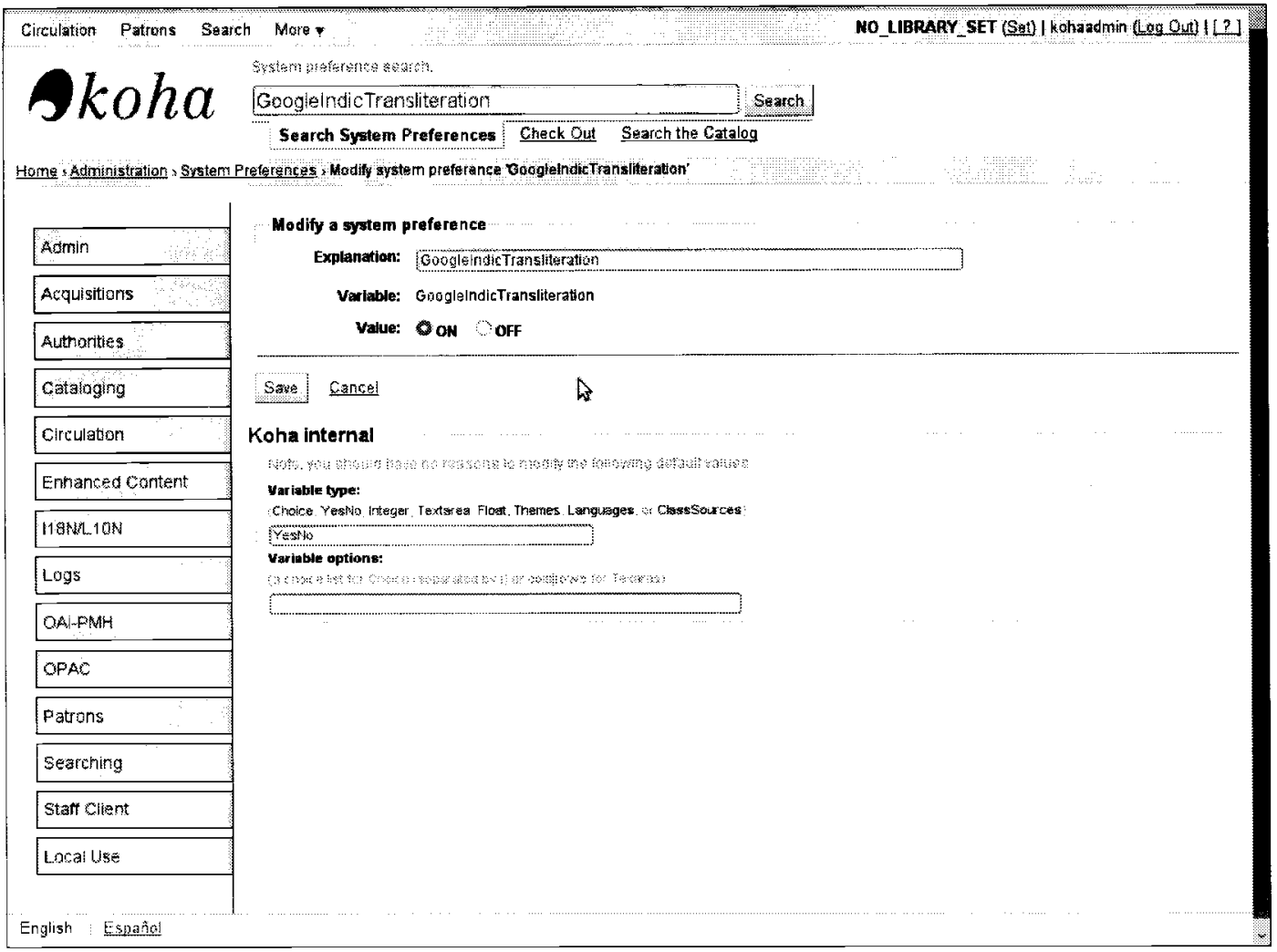

We will need to modify the database install and update scripts.

First, let's edit the sysprefs.sql file in the installer/data/mysql/en/mandatory/ folder:

koha@1inux:/home/koha/kohaclone \# vi installer/data/mysql/en/ mandatory/sysprefs.sql

We add this block to the file:

INSERT INTO systempreferences (variable, value, explanation, options, ty pe) VALUES ('GoogleIndicTransliteration','0','Allow display of Google Indic Transliteration Tool in the OPAC Masthead', NULL, 'YesNo');

The sysprefs.sql file is called from Koha's web installer. It is used to insert system preferences along with a description and a default value. This file is used only for fresh installations.

To make sure the new system preference is added when someone upgrades their Koha version, we need to add the following lines in the updatebase $30 . \mathrm{pl}$ file in the folder/installer/data/mysq1/: 
koha@linux:/home/koha/kohaclone \# vi installer/data/mysql/ updatedatabase $30 . \mathrm{pl}$

We add a block as follows at the bottom of the file. The field \$DBversion is important; Koha's web installer, when deciding whether to upgrade the Koha database, checks if the database's current version is below the highest \$DBversion value indicated in this file. If it is below this number, it initiates the database upgrade process.

Set the $\$ D B v e r s i o n$ by incrementing the last 3 digits of the number in the previous block in the file. So if the last block in the file starts with this line:

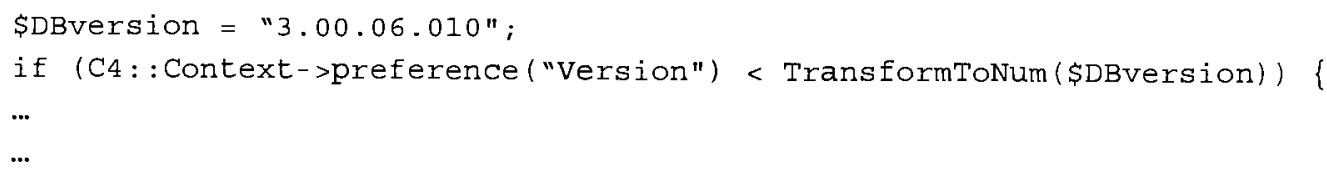

We create our new block as follows:

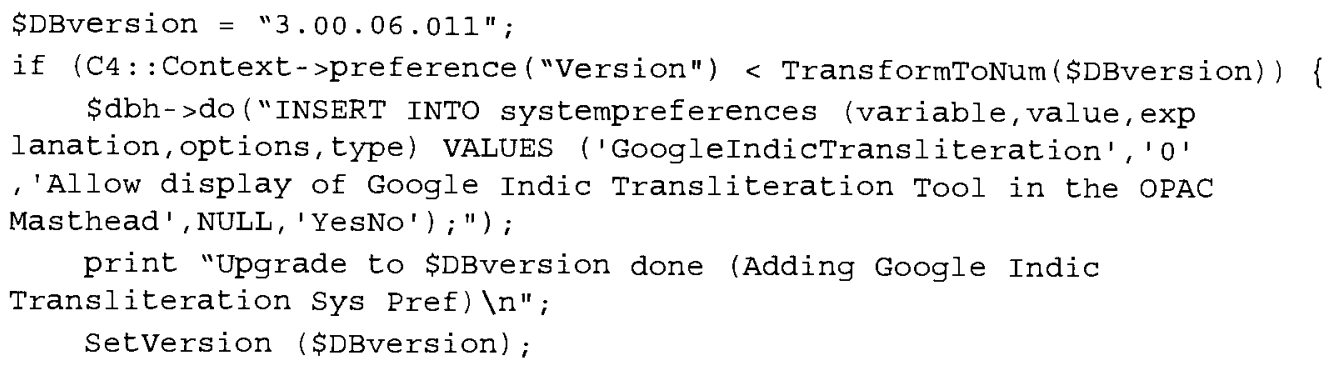

And finally, we edit the systempreferences.pl in the folder admin. This file controls the tab in which this new preference will be displayed in the Global System preferences module in Koha.

koha@linux:/home/koha/kohaclone \# vi admin/systempreferences.pl

Add this line to show this preference in the OPAC tab in the Global System Preferences module in Koha:

$$
\text { \$tabsysprefs }\{\text { XSLTResultsDisplay }\}=\text { "OPAC"; }
$$




\section{Adding the transliteration tool to the display template}

Next, we add the code to display the transliteration control on the OPAC pages. We add this block of code to the masthead.inc file in the folder koha-tmpl / opac-tmpl / $\mathrm{prog} / \mathrm{en} / \mathrm{includes} /$. The mast head. inc file is included in all OPAC pages that have the Search tool on the top. Let's edit the file:

koha@1inux:/home/koha/kohaclone \# vi koha-tmpl/opac-tmp1/prog/en/ includes/masthead.inc

And, add this block of code:

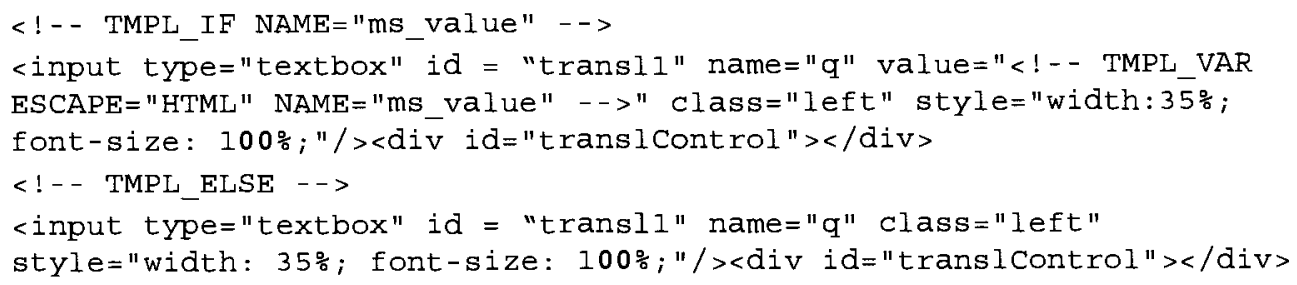

\section{Editing the Perl scripts to enable the system preference}

And finally, we need a mechanism to look up the value (on or off) of the system preference in the database, and pass that value to the template files. We edit the opac-main.pl file in the folder opac:

koha@1inux:/home/koha/kohaclone \# vi opac/opac-main.p1

And add this block of code somewhere near the bottom of the file:

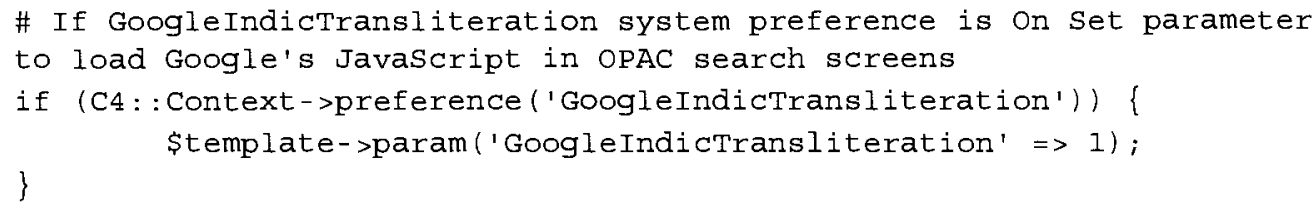

Do the same in the opac-search.pl in the folder opac. 


\section{Committing changes}

We will use Git to commit the changes we have just made. First, let's check what files are modified using the git status command:

koha@linux:/home/koha/kohaclone \# git status

\# On branch koha-3.0.2

\# Changed but not updated:

\# (use "git add <file>..." to update what will be committed)

\# (use "git checkout -- <file>..." to discard changes in working directory)

\#

\# modified: admin/systempreferences.pl

\# modified: installer/data/mysql/en/mandatory/sysprefs.sql

\# modified: installer/data/mysql/updatedatabase30.pl

\# modified: koha-tmpl/opac-tmpl/prog/en/Css/opac.css

\# modified: koha-tmpl/opac-tmpl/prog/en/includes/doc-head-

Now, we add the specific files we want in the patch using the git add command: koha@linux:/home/koha/kohaclone \# git add admin/systempreferences.pl koha@linux:/home/koha/kohaclone \# git add installer/data/mysql/en/ mandatory/sysprefs.sql

koha@linux:/home/koha/kohaclone \# git add installer/data/mysql/ updatedatabase $30 . \mathrm{pl}$

Once we have added all the files, we use the git commit command to make the commit:

koha@linux:/home/koha/kohaclone \# git commit

The command prompts for user input; here we add a description of the commit:

This adds the Google Indic Transliteration tool to the OPAC masthead.

\# Please enter the commit message for your changes. Lines starting

\# with '\#' will be ignored, and an empty message aborts the commit.

$\#$ 
\#

$\#$

\# On branch mydevel

\# Changes to be committed:

\# (use "git reset HEAD <file>..." to unstage)

$\#$

\# modified: admin/systempreferences.pl

\# modified: installer/data/mysql/en/mandatory/sysprefs.sql

Save the comment by using : wq, and the command should exit with a message such as this:

[mydevel 4727d7c] This adds the Google Indic Transliteration tool to the OPAC masthead.

9 files changed, 55 insertions(+), 3 deletions(-)

create mode $100644 \mathrm{koha-tmpl/opac-tmpl/prog/en/js/}$

googleindictransliteration.js

To check if the commit was successful, we use the git log command:

koha@linux:/home/koha/kohaclone \# git log

The output should display our commit on the top:

commit $4727 d 7 c a 977 b 032 f 08 f 0 b 67 a 6 d 0 b 9 c 778$ fdd386e

Author: root <root@linux-4yut.site>

Date: Tue Jun 15 16:55:342010+0530

This adds the Google Indic Transliterater to the OPAC masthead.

\section{Create a patch using Git}

Now, let's say we have tested this change, and want to share it with others or send it to the Koha release manager for inclusion in upcoming Koha releases. To do this, we create a patch using the command git format-patch:

koha@linux:/home/koha/kohaclone \# git format-patch origin/master 
Note the use of the word master in the command above; this indicates that the patch should be created against the master branch. By doing this, we ensure that the patch can be applied on the master.

The command should exit by creating a single file containing all the changes:

0001 -This-adds-the-Google-Indic-Transliterater-to-the-OPA.patch

Let's take a look at this file:

koha@linux:/home/koha/kohaclone \# cat 0001-This-adds-the-Google-Indic-

Transliterater-to-the-OPA.patch

The first few lines contain information, such as from, date and subject:

From 4727d7ca977b032f08f0b67a6d0b9c778fdd386e Mon sep 17 00:00:00 2001

From: root <root@linux-4yut.site>

Date: Tue, 15 Jun $201016: 55: 34+0530$

Subject: [PATCH] This adds the Google Indic Transliteration tool to the OPAC masthead

The section below the information block gives a summary of the changes in terms of the files changes, and the number lines added or deleted:

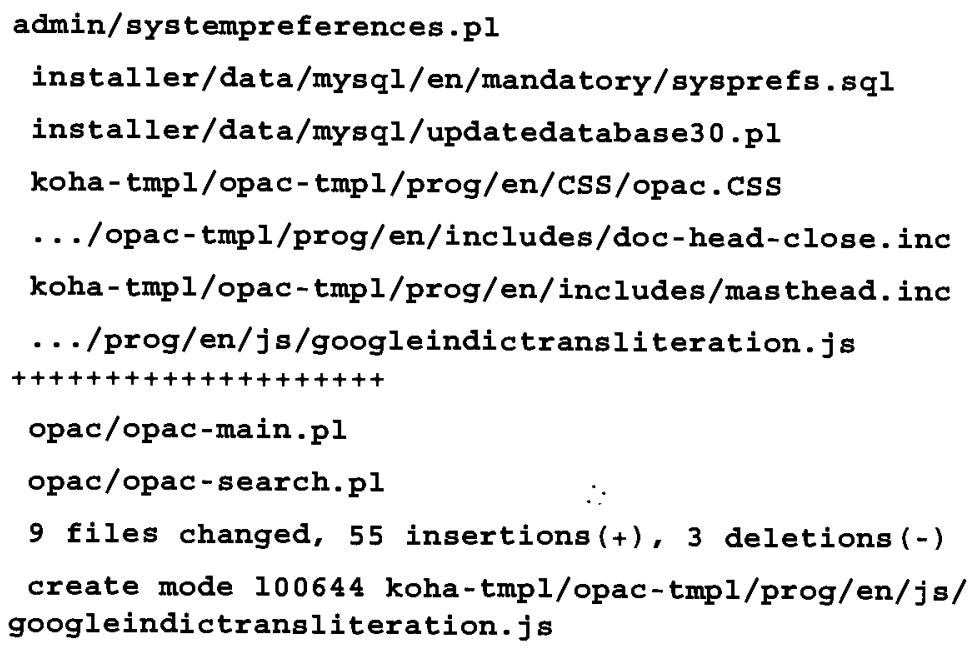

And then, there blocks for each file that is changed; lines that are added are prefixed with $\mathbf{a}+$ sign, and those that are deleted are prefixed with a - sign.

diff--git a/opac/opac-search.pl b/opac/opac-search.pl

index $7 \mathrm{a} 0 \mathrm{e} 3 \mathrm{c} 8 . \mathrm{d} 67 \mathrm{dae} 7100755$

-. a/opac/opac-search.pl 


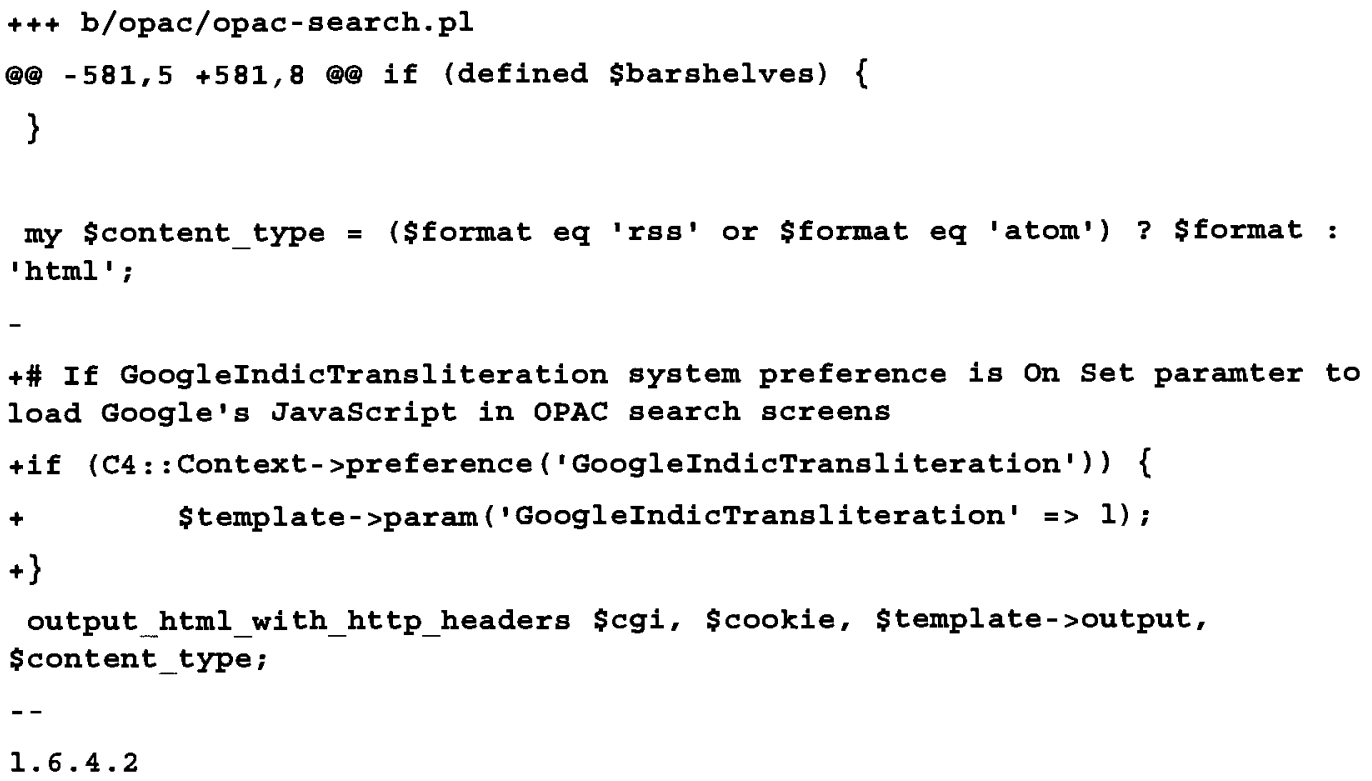

\section{Sending the patch to Koha's release manager}

To share your code, you can send the patch to the koha-patches list; Koha's release manager will then take a look at your code, and if it meets quality standards, include it in the appropriate branches.

To send the patch, first we setup our name and e-mail in Git:

koha@linux:/home/koha/kohaclone \# git config --global user.name "firstname lastname"

koha@linux:/home/koha/kohaclone \# git config --global user.email "myemail@mydomain.com"

To e-mail the patch, use the git send-email command:

koha@linux:/home/koha/kohaclone \# git send-email 0001-This-adds-theGoogle-Indic-Transliterater-to-the-OPA.patch

The command will prompt for input; to the question who should the emails be sent to, enter the e-mail address koha-patches@lists .koha-community.org:

Who should the emails be sent to? koha-patches@lists.koha-community.org 


\section{Summary}

In this chapter on customizing Koha software, we learned about:

- The organization of Koha's application folder

- The structure of Koha's database

- How to make changes to configuration, database, and application files

- How to commit changes using Git

- How to generate patches using Git

- How to send patches to others using Git

In the next and final chapter, we will cover advanced topics, such as LDAP authentication, internationalization, and exposing the catalog to the outside world via the Z39.50 protocol. 


\section{3 \\ Advanced Topics}

In this final chapter, we will learn about setting up some less widely used but nevertheless important features of Koha. These features are:

- Creating and using one's own matching rules for catalog imports

- Authenticating users against an LDAP server

- Setting up custom OPAC interfaces for each library in your Koha installation

- Setting up Koha screens in other languages

- Publishing the catalog via Z39.50 protocol 


\section{Creating and using matching rules for use during catalog imports}

Koha's default installation includes two record matching rules for use during catalog imports - one based on ISBN and the other for matching on ISSN. We can also create our own matching rules from the Record Matching Rules section under Koha Administration.

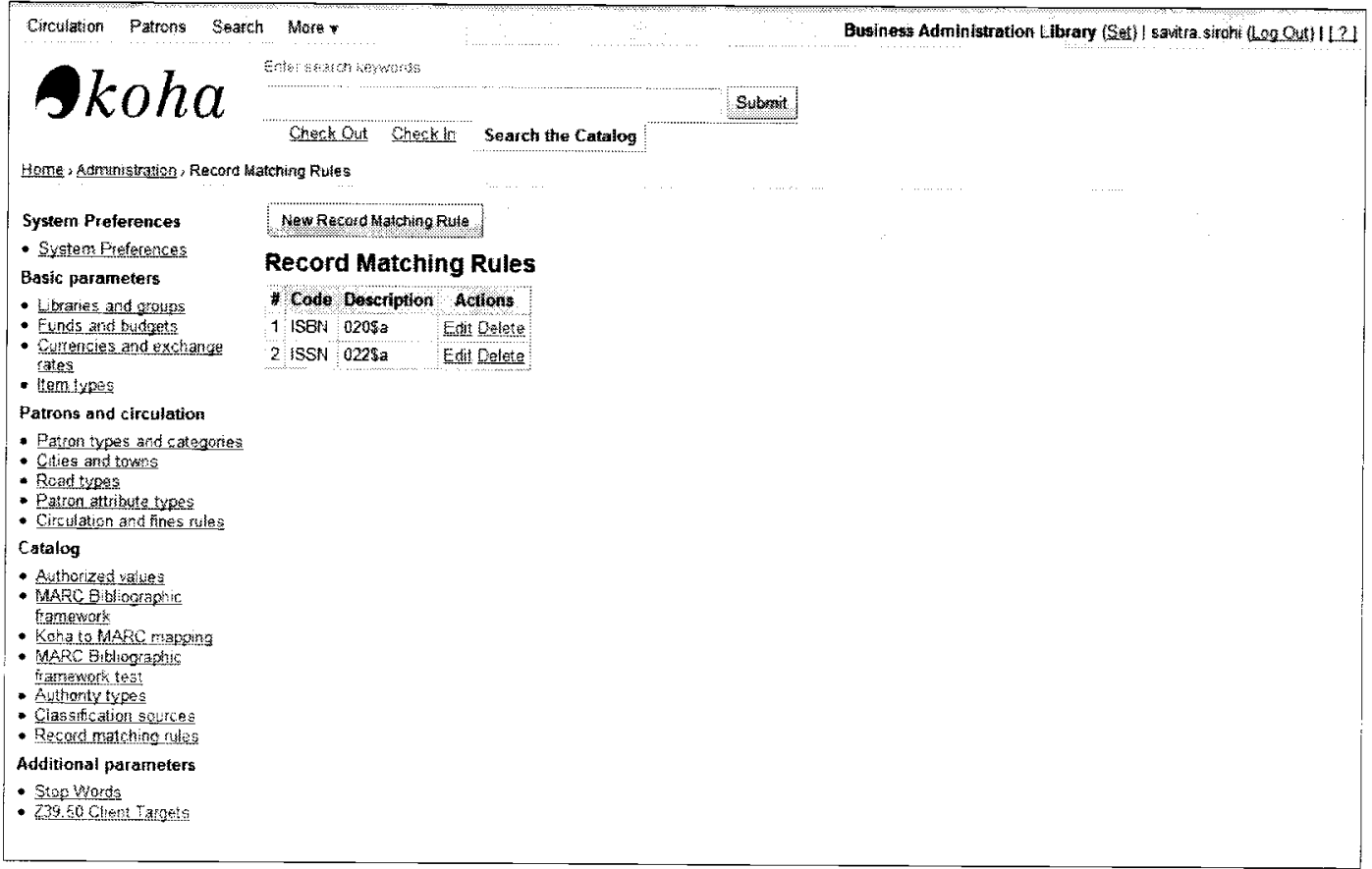


To create a new rule we use the New Matching Rule button.

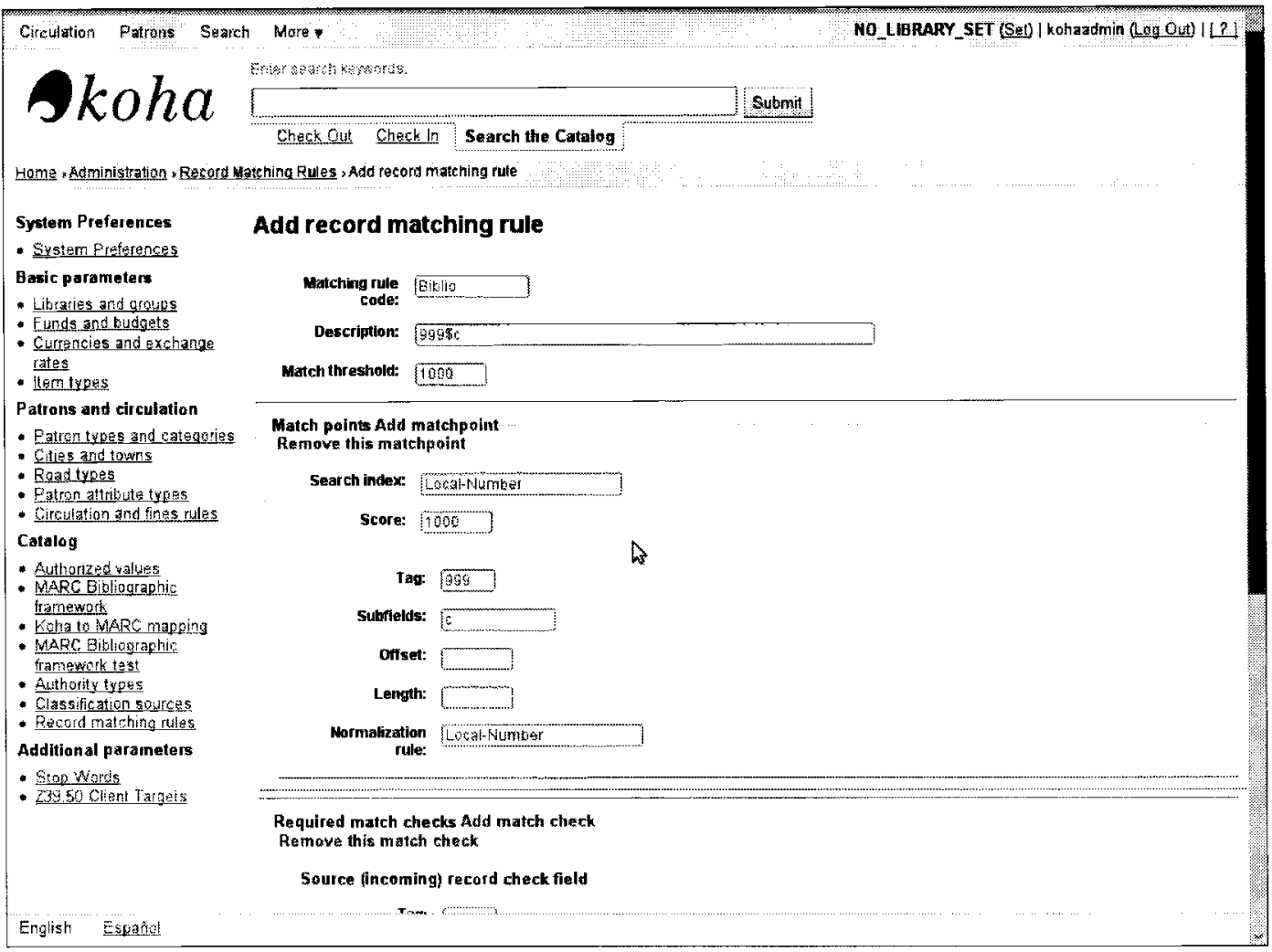

\section{Understanding matching rules}

Here are key points to note on creating matching rules:

- Match points: We will create one or more match points. Each match point refers to a catalog field that the incoming records in the import file and the existing records in the database are matched on. The match point could refer to fields such as Control number, Biblio number, or Title.

- Match threshold: Each matching rule has a threshold that must be crossed during the matching process for a record pair to be considered successfully matched.

- Score: Each match point in a matching rule is assigned a score. During the matching process if a pair of record is matched on the particular match point, the matched pair is assigned the corresponding score. The sum of scores across all match points must be greater than the Match threshold. 
- Match checks: Optionally 1 or more match checks can be created for each matching rule. These checks compare a field in the incoming record to the same or different field in the records in the database. Think of these as an additional check to ensure records are correctly matched. For instance, if you have a match point on Title, you might want a match check based on author.

- Search index: This is the Zebra index that is used to match the records. See section Determining search indexes below for more information.

- Tag and Subfield: These refer to the MARC tag that the match point is based on.

- Offset: This refers to the number of characters of the match string that should be ignored when matching, the offset applies from the left of the string.

- Length: This refers to the number of characters of the match string that should be considered for matching. Using Offset and Length, we can match records based on certain parts of the values in MARC fields or subfields.

- Normalization Rule: This field is not used in the processing, and it does not matter what is entered here. Additional capabilities using different normalization rules may be added in newer versions of Koha.

\section{Determining search indexes}

We determine the search index by looking at two Zebra's configuration files-ccl . properties and records.abs. If an index is present in both files, it can be used in matching rules.

Let us say we wanted to update our bibliographic records after a cleanup, we could create a matching rule based on Koha's biblionumber database field. This is a unique number assigned to each bibliographic record and is stored in tag 999\$c in the MARC record.

Let us take a look at Zebra's record.abs file in the folder /etc/koha-dev/etc/ zebradb/marc_defs/marc2l/biblios/:

linux-4yut:/usr/share/kohaclone/misc/migration_tools \# vi /etc/koha-dev/ etc/zebradb/marc_defs/marc21/biblios/record.abs

If we run a search on tag $999 \$ c$, we find that the search index for this tag is Local Number:

\# Koha Local-Use Biblio Indexes

melm $999 \$ c$ Local-Number: $n$, Local-Number : w, Local-Number : s 
Next we look at the file ccl .properties stored in the folder/etc/koha-dev/etc/ zebradb/:

1inux-4yut:/usr/share/kohaclone/misc/migration_tools \# vi /etc/koha-dev/ etc/zebradb/ccl.properties

If we run a search on the index Local-number, we find an entry as follows:

Loca1-number $1=12$

sn Local-number

The index Local-number is present in both these files and we can use it in the Search index field in matching rules.

\section{More information and examples}

For more information and examples on matching rules, refer to Koha community documentation on this topic, available at:

http: //koha-community.org/documentation/3-2-manual/x3735\#AEN4 124.

\section{Using LDAP with Koha}

If your organization uses an LDAP (Lightweight Directory Access Protocol) server for user authentication, it makes sense to configure Koha to integrate with it. This way you don't have to maintain users and passwords in two places, the LDAP server and in Koha.

This is how Koha works with LDAP:

- When a user logs into Koha, the password entered by the user is verified against the password maintained on the LDAP server.

- We can configure Koha such that when a user logs in for the first time, his / her patron category, branch, address, and other such information is copied over into Koha.

- We can configure Koha such that if a user's LDAP record is updated, the updated information is copied over into Koha when the user next logs into Koha.

- We can map fields in the LDAP database to fields in Koha. This way we can make sure LDAP data is copied into Koha correctly.

It is fairly simple to configure Koha to use LDAP; let us take a look at a general example followed by the specific case of configuration for Microsoft Active Directory. 


\section{Configuring LDAP}

To configure Koha to use LDAP, we edit the /etc/koha-dev/etc/koha-conf .xml file and add an LDAP block similar to this:

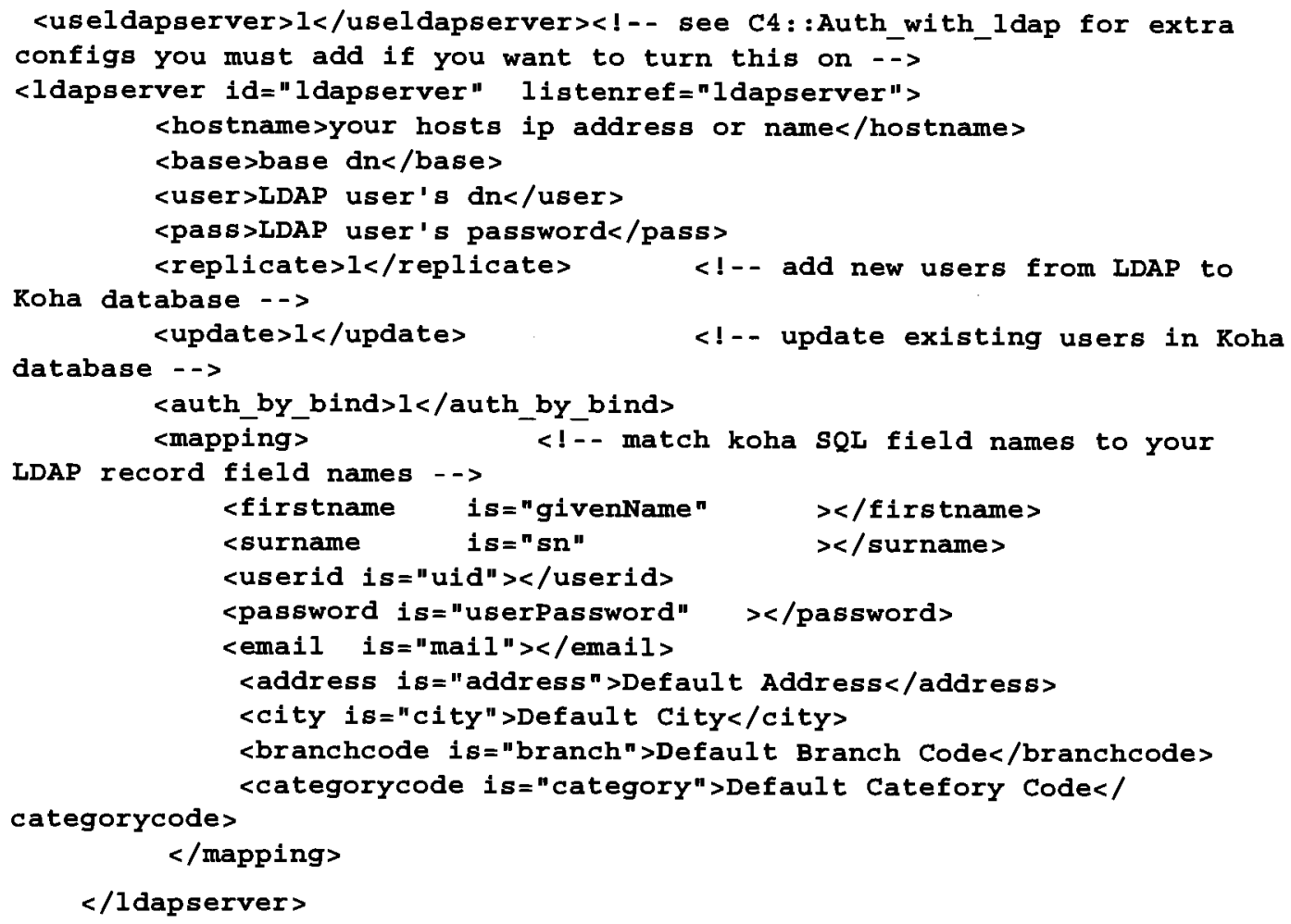

Here is how we configure the LDAP block:

1. Add the LDAP server block before these tags: </config></yazgfs $>$ in the koha-conf.xml file.

2. Set the <useldapserver > tag to 1 to turn LDAP authentication on, set it to 0 to turn it off.

3. Enter the LDAP server's host name or IP address in the tag <hostname >.

4. Enter the LDAP server's base DN in the tag < base>.

5. In the tag <user $>$ enter the DN of an LDAP user with browse privileges to the base DN.

6. Enter the LDAP user's password in the tag <pass >.

7. Set < replicate > tag to 1 if you want to create new users in Koha from the LDAP server. If this is set to 0 , the user record must exist in Koha. 
8. Set <update $>$ tag to 1 if you want updates to user records on the LDAP server to update user records in Koha as well.

9. The fields listed in the <mapping > block refer to fields in the borrowers tables in Koha.

10. The fields listed in the <mapping $>$ block must include all mandatory fields in the borrowers table except the field borrowernumber. Mandatory fields in the table are-surname, address, city, branchcode, and categorycode (patron category code).

11. The fields listed in the <mapping > block should include other Koha fields that have data in corresponding fields in the LDAP record. This way you can get useful data such as e-mail address or phone number from the LDAP record into Koha.

12. The name following is = refers to the corresponding field in the LDAP server.

13. For each field you can specify a default value in case the LDAP server does not have any value for that field.

\section{Microsoft Active Directory}

If you need to integrate Koha with Microsoft Active Directory, you may need to change the following in the LDAP block in the file /etc/koha-dev/etc/koha-conf . $\mathrm{xml}$ to get things to work:

- Set tag <auth_by_bind > to 1, like this:

<auth_by_bind $>1</$ auth_by_bind $><!--$ set to 1 to authenticate by binding instead of password comparison, e.g., to use Active Directory - $\rightarrow$

- Set the is attribute for userid to sAMAccountName instead of UID. sAMAccountName is the corresponding uid field in Active Directory. 


\section{Setting permissions}

If you use LDAP, you must set permissions for each individual staff user in Koha. To set permissions use the Set Permissions option under the More menu available in the details page for a patron.

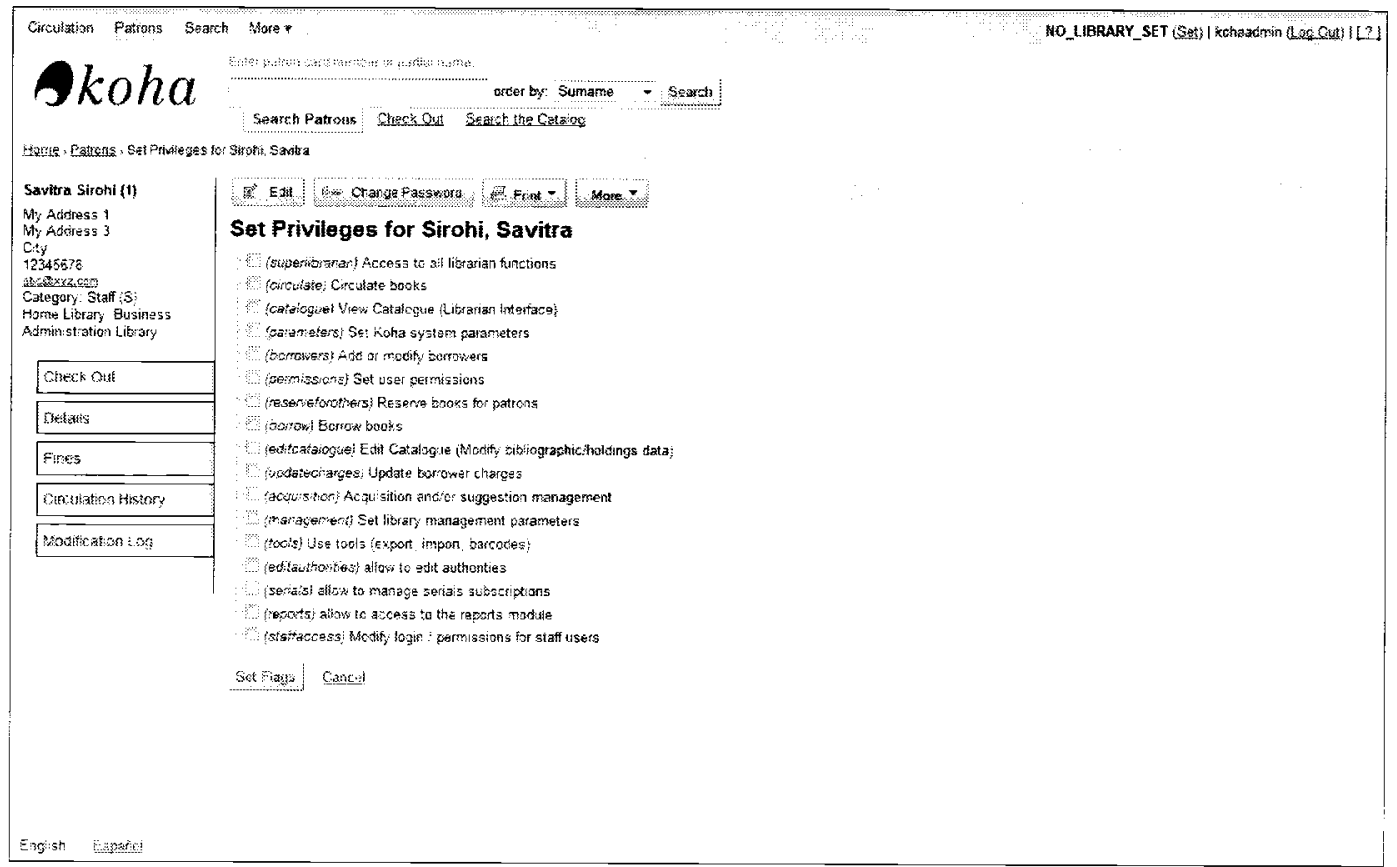

\section{Multiple OPAC interfaces}

If you have multiple libraries or branches on the same Koha installation, you might want to use the multiple OPAC interfaces feature of Koha.

We use this feature to:

- Create a customized OPAC interface for each library

- Each OPAC interface can have its own logo, colors, fonts, and so on.

- Search is limited to the particular library

Here are the steps to doing this:

1. Edit the Apache 2 koha-httpd. conf file and create a virtual host block for each library or branch. 
2. You will need domain names for each branch, for example, branchl . mykohalibrary.org, branch2 . mykohalibrary.org.

3. In each virtual host, repeat this stanza, change the values of environment variables OPAC_CSS_OVERRIDE and OPAC_SEARCH_LIMIT appropriately.

SetEnV OPAC_CSS_OVERRIDE branchl.cSS

SetEnv OPAC_SEARCH_LIMIT branch:branchl

SetEnV OPAC_LIMIT_OVERRIDE 1

4. Create the corresponding style sheet files in the folder: /koha-tmpl/opac-tmpl/prog/en/css/branchl.css

If we had two branches, we would have two Apache2 virtual hosts as follows:

\#\# OPAC Virtual Host for Branchl

$<$ VirtualHost *:80>

ServerAdmin webmaster@linux-4yut

DocumentRoot /usr/share/kohaclone/koha-tmpl

ServerName branchl.mykohalibrary.org

$\cdots$

-

\# Repeat this virtualhost stanza changing the following environment vars to

\# create multiple OPAC interfaces with custom css and/or search limits: SetEnv OPAC_CSS_OVERRIDE branchl.css

SetEnv OPAC_SEAR̄CH_LIMIT branch:branchl

SetEnv OPAC_LIMIT_OVERRIDE 1

$</$ VirtualHost $>$

\#\# OPAC Virtual Host for Branch2

$<$ virtualHost *:80>

ServerAdmin webmaster@linux-4yut

DocumentRoot /usr/share/kohaclone/koha-tmpl

ServerName branch2.mykohalibrary.org

-

$\cdots$

\# Repeat this virtualhost stanza changing the following environment vars to

\# create multiple OPAC interfaces with custom css and/or search limits:

SetEnv OPAC_CSS_OVERRIDE branch2.css

SetEnv OPAC_SEARCH_LIMIT branch:branch2

SetEnv OPAC_LIMIT_OVERRIDE 1

$</$ virtualHost $>$ 


\section{Installing new languages}

If you need to have Koha OPAC and staff client screens in another language, you will need to install the particular language. Here are the steps involved:

1. Install Perl module prerequisite Locale : : PO.

2. Check availability of the corresponding language files in the Koha folder.

3. Create new folders for the new language in the appropriate OPAC and staff client folders.

4. Use Koha's program - tmpl_process2 .pl to install the new language.

5. Enable the new language via Koha's system preferences module.

As an example let us install the Spanish language.

\section{Install Locale::PO module}

We need the Perl module Locale: : Po before we can install the new language. We use CPAN to install this module:

koha@lil90-245: /kohaclone\$ cpan Locale: :PO

\section{Creating language templates for the OPAC}

First let us locate the Spanish language files in the kohaclone folder. The language files have an extension . po and are found in the misc/translator folder:

koha@li190-245: /kohaclone \$cd misc/translator/

koha@li190-245: /kohaclone/misc/translator \$ ls *ES*.po

es-ES-i-opac-t-prog-v-3000000.po

es-ES-i-staff-t-prog-v-3000000.po

To create the language templates for the OPAC, first we create a new directory for the new language in the koha-tmpl/opac-tmpl/prog/folder:

koha@lil90-245:-/kohaclone/misc/translator \# mkdir ../../koha-tmpl/opactmpl/prog/es

We then use the tmpl_process $3 . p 1$ program to install the new language. The program is executed as follows:

koha@li190-245: /kohaclone/misc/translator \# perl tmpl process3.pl install - $i$ <path to the English language folder> -o <path to the new language folder> $-s$ <path to the po file of the new language> $-r$ 
We would install the Spanish language file for the OPAC in this fashion:

koha@li190-245: /kohaclone/misc/translator \# perl tmpl_process3.pl install - 1 .././koha-tmpl/opac-tmpl/prog/en/ -o .././/koha-tmpl/opactmpl/prog/es/ -s po/es-ES-i-opac-t-prog-v-3000000.po -r

\section{Creating language templates for the staff client}

In a similar fashion, we can create the language templates for the staff client. First we create the folder for Spanish language, this time in the / koha-tmpl/intranettmpl / prog/ folder:

linux-4yut:/usr/share/kohaclone/misc/translator \# mkdir .././koha-tmpl/ intranet-tmpl/prog/es

And then we use the tmpl_process3.pl program to install the new language:

linux-4yut:/usr/share/kohaclone/misc/translator \# perl tmpl_process3. pl install -i ../../koha-tmpl/intranet-tmpl/prog/en/ -o .././koha-tmpl/ intranet-tmpl/prog/es/ -s po/es-Es-i-staff-t-prog-v-3000000.po -r

\section{System preferences}

Once the language is installed, don't forget to enable these from the I18N/L10N (short form of Internationalization and Localization) block in the Global System Preferences section under Koha Administration. 
Here are the system preferences you will need to change:

- language: Use this preference to enable the new language for the staff client

- opaclanguages: Use this preference to enable the new language for the OPAC

- opaclangaugesdisplay: Choose whether you want to display a language selection bar on the OPAC

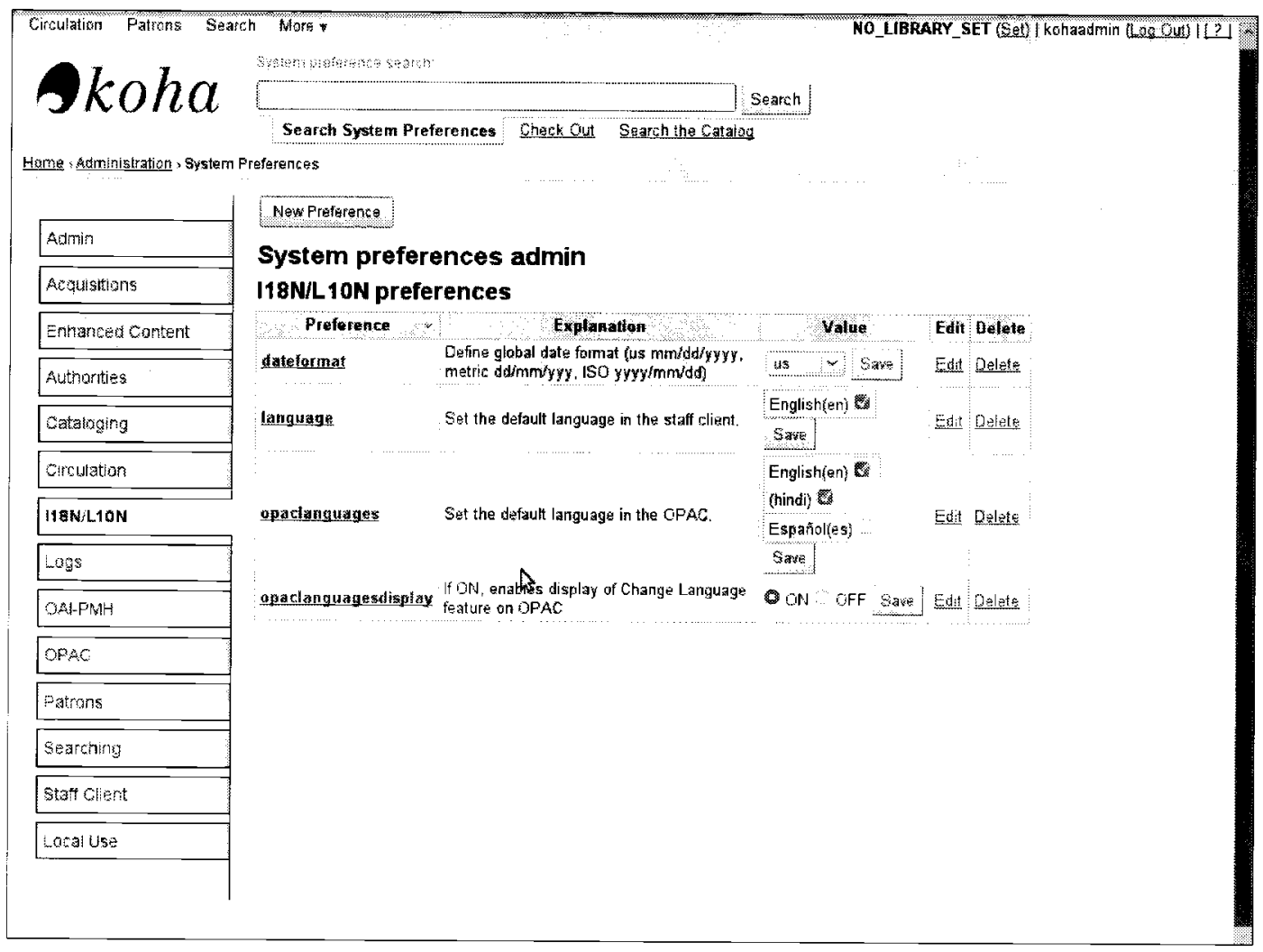

\section{Testing the new language}

Once the system preferences are set correctly, you should see the new language in the language selection bar at the bottom of the page in the OPAC and the staff client. 


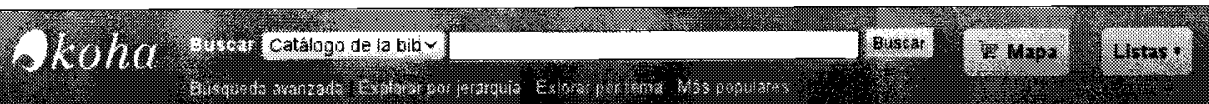

Mus Whatito

Welcome to Koha.

Taxt added to OFAC Main User Black System Preference.

t

My OPAC Credits

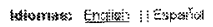

\section{Setting up a public Z39.50 server}

With Koha you can publish your catalog records to the outside world via the Z39.50 protocol. This will allow any Z39.50 compliant client software to search and copy records from your catalog. Some applications of this feature are:

- Allow other libraries to copy records from your catalog

- Include your catalog data in results of a Z39.50 compliant federated search tool in use in your organization

Configuring your Koha to be a Z39.50 server is not that hard; we cover the steps below.

We edit the koha-conf .xml file to configure the public Z39.50 server:

koha@li190-245: /kohaclone\$ vi /etc/koha-dev/etc/koha-conf.xml

\section{Configuring the listen directive}

The listen directive controls the network protocol, the IP address and the port that our public server will be available on.

To set up the listen directive for the public server, remove the comment tags on the listen directive for the public server:

$<$ !-- public server runs on tcp -->

<listen id="publicserver" >tcp:@:9999</listen>

The @ symbol signifies all IP addresses, so the public Z39.50 server will listen on any and all IP addresses on the machine. You can set up a specific IP address here if you like, something like:

$<$ !-- public server runs on tcp -->

<listen id="publicserver" >tcp:192.168.1.123:9999</listen> 
The 9999 after the colon in the lines above is the port the server will listen on. You can change this as well, to something like this:

<!-- public server runs on tcp -->

<1isten id="publicserver" >tcp:192.168.1.123:7090</1isten>

\section{Configuring the server directive}

Next we add a server directive. This directive essentially sets up a new Zebra server. As part of this directive we configure things such as the location of Zebra indexes folders, location of Zebra's bibliographic configuration files, the MARC record syntax to be used, or the location of the style sheets to be used for transforming the records.

The simplest thing to do is to model our new server on the existing bibliographic server block already configured in the koha-conf .xml file:

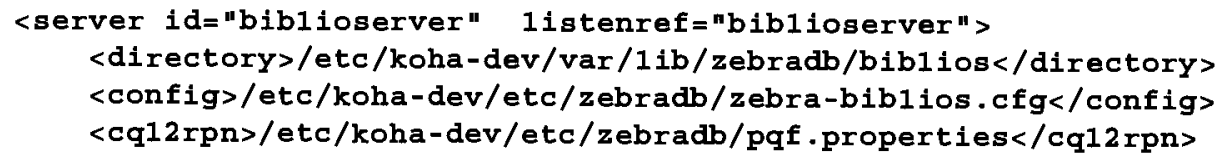

Once we copy this block, we replace the name biblioserver with publicserver, like so:

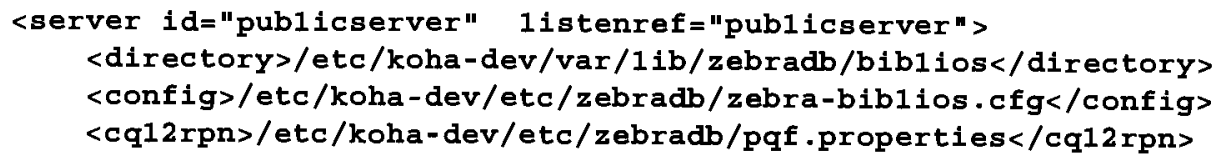

\section{Configuring the serverinfo directive}

And finally we configure the serverinfo directive. This directive controls the location to a Zebra configuration file and the username and password that allows access to the Zebra indexes.

Again, it is best to model the new serverinfo directive on the corresponding directive for the bibliographic server:

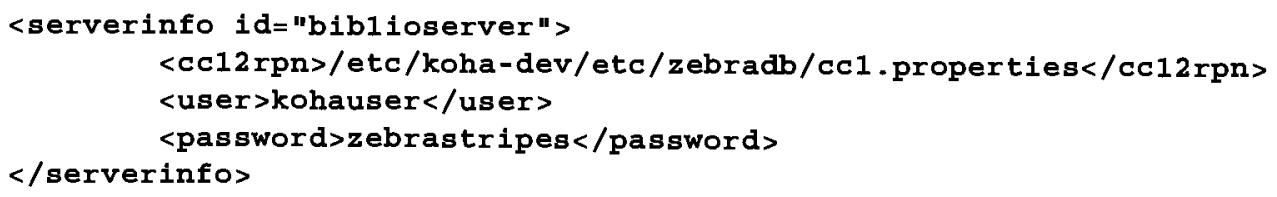


We just copy this block above and replace the ID biblioserver with publicserver, like so:

<serverinfo id="publicserver"> <ccl2rpn>/etc/koha-dev/etc/zebradb/ccl.properties</ccl2rpn> <user>kohauser</user> $<$ password>zebrastripes</password>

$</$ serverinfo $>$

\section{Restarting the Zebra server}

To make sure the Zebra server uses the updated configurations we have just performed, we restart zebrasrv:

linux-4yut:/home/koha \# sudo/etc/init.d/koha-zebra-daemon restart

\section{Summary}

In this final chapter we looked at some advanced features of Koha:

- The ability to create one's own record matching rules gives us a powerful way to import new records and to update and maintain the catalog.

- Many large organization use LDAP to maintain users and passwords. Koha can talk to any LDAP server including Microsoft Active Directory. The configuration is simple; however, attention must be paid to the replicate, update, and the mapping fields.

- To setup customized OPACs for each library or branch that share a Koha system, we set up separate Apache2 virtual hosts for each branch. For each virtual host we set up the corresponding domain name, the name of the stylesheet file, and the branch code.

- To install additional languages, we learned how to use the tmpl_process 3 . pl program to install language files.

- Setting up a Z39.50 server allows us to share our catalog with others and to include it in other Z39.50 solutions such as federated search. 


\section{Index}

\section{Symbols}

-a parameter 46

-b parameter 46

-d parameter 46

--help parameter 47

-k parameter 46

-munge-config parameter 1

-nosanitize parameter 47

-noxml parameter 46

-r parameter 46

-s parameter 46

-v parameter 47

-w parameter 47

-x parameter 46

-y parameter 47

-z parameter 46

\section{A}

\section{acquisitions module}

about 117

budgets, creating 158

budget utilization, viewing 161

functions 117

orders, creating 159

shipments, receiving 160

testing 157

vendor, creating 158

acquisitions preferences

configuring 117

Apache2

about 23

configuration 23

configuration folder 25 configuring 61

features 23

Koha default Apache2 file 26

Koha virtual hosts 26

name based or IP based virtual hosts 24

reference link 24

virtual host configuration 27

virtual hosts 24

Apache 2 configuration

about 27

plan 27

prerequisites 31

Apache2 configuration plan

about 27

hostname with two ports 28

IP address with two ports 29

standalone machine 30

two host names 28

two IP addresses 30

Apache2 web server configuring 31

Apache2 web server configuration about 31

Apache2, restarting 33-35

Koha virtual hosts, enabling 33

listener, configuring 32

OPAC virtual host, editing 32

rewrite module. enabling 32

staff client virtual host, editing 33

symbolic link, creating to

koha-httpd.conf 31

Authority Control

about 69

Authority Types 70

bibliographic fields 70

system preferences control 70 
Authorized values

about 71,72

fields 72

key points 73

B

Bulkmarcimport.pl, options

c 174

commit 173

d 174

file 172

fk 173

idmap 174

m 174

n 173

o 173

s 173

t 173

v 172

$\times 174$

y 174

bulkmarcimport.pl program

using 188, 189

bulkmarckimport.pl 172

C

c, Bulkmarcimport.pl option 174

calendar

about 99

configuring 100, 101

due date calculations 99

editing 100

fine calculation 99

holidays 99

system preferences, editing 101

catalog data migration

about 179

administrative field values, setting up 179

bulkmarcimport.pl program, using 188

catalog records, importing using GUI tools 189

MARC file, importing 188

source MARC file, editing 182, 183

catalog data, migration process about 176

holdings data in tag 952170,171 holdings, in legacy systems 171

import tool, selecting 176

MARC files, converting 170

preparing for 176

tools, importing 171

cataloging 67

cataloging configuration plan implementation

about 77

authorities system preferences, configuring 78

Authority Types, configuring 79

authorized values categories, configuring 80

authorized values, editing 80,81

special Authorized Values 81

cataloging configuration tools, Koha

about 68

Authority Control 69

Authorized values 71,72

MARC frameworks 68,69

cataloging module

bibliographic record, creating 152

configuration plan 73

item record, creating 153

record, searching for 154

testing 151

catalog records

importing, GUI tools 189

managing 191, 192

catalog records, importing

MARC records, staging 189-191

circulation and fine rules

about 97

creating 98

identifying 98

circulation module

about 91

checking in 156

checking out 155

circulation history, viewing 156

testing 154

commit, Bulkmarcimport.pl option 173

community resources, Koha

about 10

Koha bug tracker 197

Koha Git repository 198 
Koha IRC chat 197

Koha mailing lists 196

components, software updates 219

configuration, Apache2 web server. See

Apache2 web server configuration

configuration folder, Apache2 25

configuration plan, Apache2. See Apache2 configuration plan

configuration plan, cataloging module

Authority Control rules, identifying 73, 76

fields to control, identifying 76

frequently cataloged types of material, identifying 74

implementing 77

mandatory fields, identifying 75

MARC field sets, identifying 74

preparing 73

configuration problems, Apache2 troubleshooting 35

CPAN

about 9,10

URL 9

CPAN installations troubleshooting 18

CPAN shell

about 9

configuring 15

crontab

configuring 58

editing 58

crontab configuration, Koha

about 58

advance notices, generating 59

crontab, editing 58

e-mail messages, sending 59

environment variables, setting up 58

fines, calculating 59

overdue notices, generating 59

Zebra indexes, rebuilding 60

crontab examples 60

D

d, Bulkmarcimport.pl option 174 database

upgrading 224
E

enhanced content, OPAC preferences configuring 128

environment variables

KOHA_CONF environment variable 63

PERL5LIB environment variable 64 persistent environment variables 64 setting up, for Linux shell 63

E

fields and subfields, MARC frameworks advanced constraints 88 editing 85,86

field or subfield, making mandatory 88 hidden fields and subfields 88

labels of fields or subfields, editing 88

file, Bulkmarcimport.pl option 172

fk, Bulkmarcimport.pl option 173

G

general preferences, Koha

configuring 138

messaging preferences, configuring 138,139

search preferences, configuring 145

security preferences, configuring 142

Git

about 9

URL 9

git branch command 220

git checkout command 222

Git commands

git add 233

git checkout 233

git commit 233

git format -patch 233

git send-email 233

git pull command 220

git tag command 221

global system preferences module, Koha 112

GUI import tool 175,176 
H

holds preferences

configuring 107

editing 107

idmap, Bulkmarcimport.pl option 174

imports tools, Koha

about 171

bulkmarckimport.pl 172

GUI import tool 175

MARCEdit 172

installation

Zebra 41

installation packages, Koha installation

Debian/Ubuntu package lists 14

Perl modules 13, 14

system packages 13

installation tools, Koha

CPAN shell 9

Git 9

make utility 9

package manager 9

IP based virtual hosts 24

Item types

about 94

creating 96

identifying 95

K

Koha

Apache2, auto-starting 61

cataloging configuration tools 68

cataloging module 67

circulation module 91

community resources 196

crontab, configuring 58

features 245

general preferences, configuring 138

global system preferences module 112

heads 218

installing, with Zebra 42

matching rules 247

matching rules for use during catalog imports, creating 246, 247 matching rules for use during catalog imports, using 246, 247

multiple OPAC interfaces 252,253

MySQL, auto-starting 61

new languages, installing 254

OPAC preferences, configuring 122

search indexes, determining 248, 249

software branches 218

software stack installation 16

styling and appearance, configuring 132

system preferences 111

tags 218

transactional modules, configuring 113

using, without Zebra 48, 49

version, selecting 219

web installer, executing 51

working with LDAP 249

XML SAX parser, configuring 62

Zebra related components 40

Zebra server, auto-starting 61

Koha 3.0 user manual

URL 113

Koha 3.2 manual

URL 113

Koha administrative fields

branch codes, setting up 179

collection codes, setting up 181

item types, setting up 180

shelving locations, setting up 182

Koha application folder structure about 228

relationships, between files 229

template files 229

top level folders 228

Koha architecture 8

Koha bug tracker 197

kohaclone folder

c4 228

etc 228

installer 228

koha-tmpl 228

Perl scripts 228

Koha community documentation

URL 249

KOHA_CONF environment variable setting up 63 
Koha database

about 230

acquisitions related data 232

administration 232

browsing 230

Cataloguing related tables 231

circulation related tables 231

Koha tables, overview 231

patrons related tables 231

serials data 232

structure 232

Koha default Apache2 file 26

Koha features

about 91

calendar 99

circulation and fine rules 97

Item types 94

notices 102

patron categories 91

system preferences 107

Koha Git repository 198

Koha installation

branch, checking out 12

common problems 198

completing 21

configuring 20

installation packages list, preparing 12

Koha, cloning 11

Koha, downloading 11

orientation 7

preparing for 11

repositories or sources, setting up 14,15

server prerequisites 11

troubleshooting 198

Koha IRC chat 197

Koha mailing lists 196

Koha's architecture 8

Koha software

customizing 227

updating 217

versions 217

Koha software customization

application folder structure, understanding 228

changes, committing using Git 240, 241

CSS changes, making 235

database, organizing 230 example 235

Git used 233

new JavaScript file, creating 235

orientation 227

patch, creating using Git 241

patch, sending to Koha release manager 243

Perl scripts, editing 239

skills required 228

software customization process 233, 234

system preference, creating 236-238

transliteration JavaScript file, loading 236

transliteration tool, adding to display template 239

Koha virtual hosts 26

Koha web installer

executing $52,53,56$

functions 52

Koha, launching 57, 58

optional settings 54

L.

LDAP, using with Koha about 249

LDAP, configuring 250, 251

Microsoft Active Directory 251

permissions, setting 252

Linux distribution

selecting 10

M

m, Bulkmarcimport.pl option 174

Makefile.PL program

running 222

make utility $9 \therefore$

MARCEdit

about 172

download link 172

MARC file

importing 188

MARC frameworks

about 54,68, 69

configuring 83

fields, editing 85

list, editing 83 
new framework, creating 84

subfields, editing 85

matching rules

understanding 247,248

matching rules for use during catalog imports

creating 246, 247

using 246,247

messaging preferences, Koha

AutoEmailOpacUser 140

AutoEmailPrimary Address 141

configuring 138, 139

EnhancedMessagingPreferences 140

migration process preparation, catalog data administrative fields setup, planning 178

holdings subfields, mapping to subfields in source MARC file 177

multiple OPAC interfaces 252

MySQL

configuring 61

MySQL database, Koha

setting up 19

\section{$\mathbf{N}$}

n, Bulkmarcimport.pl option 173

name based virtual hosts 24

new languages

installing, in Koha 254

new software version installation

about 222

Koha installation, completing 223

Makefile.PL program, running 222

Perl modules, installing 223

notices

about 102

due and overdue notices, configuring 103 editing 104

notices triggers, editing 106

0

o, Bulkmarcimport.pl option 173

Online Public Access Catalog (OPAC) 111 about 122

catalog search, running 166

functions 122
OPAC preferences

configuring 122

enhanced content, configuring 128, 129

patron access control, configuring 126

static content, configuring 122, 123

tools for patrons, configuring 124, 125

OPAC styling and appearance

configuring 133

OPAC styling related preferences

opaclayoutstylesheet 134

opacstylesheet 135

opacthemes 134

OPACUserCSS 135

XSLTDetailsDisplay 135

XSLTResultsDisplay 136

optional settings, Koha web installer

MARC frameworks 54

other data 55,56

orientation, Koha installation

about 7

installation tools 8

Koha architecture 8

Kohavs community resources 10

Linux distribution, selecting 10

Linux packages, recommending 10

packages, installing 8

overdue notice e-mails issues

e-mail problems, troubleshooting 206-208 notice triggers, reviewing 206

troubleshooting problems, with generation of notices 208

$\mathbf{P}$

package manager 9

patron access control, OPAC preferences

$\because$ configuring 126

patron categories

about 91

creating 93

examples, for different library types 93

identifying 92

patrons module

about 114

functions 114

patron, creating 149,150 
patron, searching for 151

testing 149

patrons preferences

autoMemberNum 116

BorrowerMandatory Field 115

borrowerRelationship 116

configuring 114

ExtendedPatronAttributes 115

memberofinstitution 117

patronimages 117

PERL5LIB environment variable setting up 64

Perl modules

installing 223

installing, CPAN used 17

persistent environment variables setting up 64

prerequisites, Apache2 configuration

about 31

DNS 31

host names 31

IP addresses 31

open Firewall ports 31

public Z39.50 server

listen directive, configuring 257

server directive, configuring 258

serverinfo directive, configuring 258

setting up 257

Zebra server, restarting 259

$\mathbf{R}$

rebuild_zebra.pl

about 41,46

examples 47

indexes, creating or recreating 48

options 47

rebuild indexes, scheduling in Crontab 48

reports module

guided report, creating 164, 165

saved report, using 166

testing 164

$\mathbf{S}$

s, Bulkmarcimport.pl option 173

search indexes

determining 248, 249 search preferences, Koha

AdvancedSearchTypes 146

configuring 145

expandedSearchOption 146

QueryRemoveStopwords 146

security preferences, Koha

AutoLocation 144

configuring 142

GranularPermissions 144

IndependantBranches 144

minPasswordLength 143

timeout 144

serials module

about 119

functions 119

issue, receiving 164

subscription, creating 161

subscription, searching for 163

testing 161

serials preferences

configuring 119

RenewSerialAddsSuggestion 121

RoutingSerials 120

SubscriptionHistory 121

software changes managing, Git used 233

software customization process steps 233,234

software stack installation, Koha about 16

CPAN installations, troubleshooting 18

Koha installation, completing 21

Koha installation, configuring 20

MySQL database, setting up 19

packages, installing from Linux prompt 16

packages, installing with dselect 17

packages, installing with package manager 16

packages, installing with shell scripts 16

Perl modules, installing with CPAN 17

software updates

Apache2, configuring 224

database, upgrading 224, 225

downloading, git pull command used 220

installation process 219

new software version, installing 222

orientation 217 
switching, to new software version 221

source MARC file

editing, MARCEdit used 182, 183

new subfield, adding 185

subfields, merging 185, 186, 188

subfields, swapping 184

Spanish language, installing in Koha

example 254

language templates, creating for OPAC 254,255

language templates, creating for staff client 255

language, testing 256

Locale $^{\star \star} \mathrm{PO}$ module, installing 254

system preferences 255

special Authorized Values

about 81

Item Types 82

library 82

staff client styling and appearance

configuring 136

staff client styling related preferences intranetstylesheet 138

template 137

static content, OPAC preferences

configuring 122, 123

styling and appearance, Koha

configuring 132

OPAC styling and appearance, configuring 133

staff client styling and appearance, configuring 136

system preferences, Koha

about 111

global system preferences module 112

online documentation 113

using 113

system preferences, OPAC preferences

GoogleJackets 130

LibraryName 123

OPACAmazonCoverImages 130

OPACAmazonEnabled 130

OPACAmazonSimilarItems 130

OpacAuthorities 125

opacbookbag 125

OPACFRBRizeEditions 131

opaccredits 123 opacheader 124

OpacMainUserBlock 124

OpacNav 124

OpacPasswordChange 127

OpacRenewalAllowed 127

OPACShelfBrowser 126

opacsmallimage 124

OpacTopissue 126

opacuserlogin 127

PINSEISBN 132

RequestOnOpac 128

reviewson 128

suggestion 128

TagsEnabled 132

TagsModeration 132

ThingISBN 132

virtualshelves 126

XISBN 132

$\mathbf{T}$

t, Bulkmarcimport.pl option 173

top level folders, Koha application folder structure 228

transactional modules

acquisitions module 117

acquisitions preferences, configuring

117,119

configuring 113

patrons module 114

patrons preferences, configuring 114-116

serials module 119

serials preferences, configuring 119-121

troubleshooting

Apache2 web server is down 199

command line programs 213

fines not working 209, 210

MySQL database server is down 200, 201

overdue notice e-mails 206

parser problems 204, 205

problems with IE 214

software bugs 211, 212

Zebra index rebuild not working 203, 204

Zebra search not returning any results 202, 203

troubleshooting, Apache2 configuration problems 
about 35

incorrect or missing directory directive 36 listener not setup 37

rewrite module not enabled 36 unable to connect to MySQL 36

\section{V}

v, Bulkmarcimport.pl option 172 virtual host configuration 27 virtual hosts, Apache2 24

\section{$\mathbf{X}$}

x, Bulkmarcimport.pl option 174

XML SAX parser

configuring 62

XSLT style sheets 133

$Y$

y, Bulkmarcimport.pl option 174

$\mathbf{Z}$

\section{Zebra}

about 39

features 39

installing 41

testing 42
Zebra indexes

rebuilding 225

Zebra installation

about 41

Koha, installing with Zebra 42

Zebra packages, installing 41

Zebra packages

installing 41

Zebra related components, Koha

about 40

rebuild_zebra.pl 41

Zebrasrv 40

Zebra server

restarting 259

configuring 61

zebrasrv

invoking, with Koha's configuration file 43

restarting 225

Zebrasrv 40

zebrasrv command

running 43

zebrasrv daemon

about 44

on Debian or Ubuntu 44

on openSuSE 45,46

Zebra, testing

about 42

rebuild_zebra.pl, running 46

zebrasrv daemon, running 44

zebrasrv program, running 43 


\section{[PACKT] \\ open source ${ }^{2}$ \\ community experience distilled}

\section{Thank you for buying Koha 3 Library Management System}

\section{About Packt Publishing}

Packt, pronounced 'packed', published its first book "Mastering phpMyAdmin for Effective MySQL Management" in April 2004 and subsequently continued to specialize in publishing highly focused books on specific technologies and solutions.

Our books and publications share the experiences of your fellow IT professionals in adapting and customizing today's systems, applications, and frameworks. Our solution based books give you the knowledge and power to customize the software and technologies you're using to get the job done. Packt books are more specific and less general than the IT books you have seen in the past. Our unique business model allows us to bring you more focused information, giving you more of what you need to know, and less of what you don't.

Packt is a modern, yet unique publishing company, which focuses on producing quality, cutting-edge books for communities of developers, administrators, and newbies alike. For more information, please visit our website: www packtpub. com.

\section{About Packt Open Source}

In 2010, Packt launched two new brands, Packt Open Source and Packt Enterprise, in order to continue its focus on specialization. This book is part of the Packt Open Source brand, home to books published on software built around Open Source licences, and offering information to anybody from advanced developers to budding web designers. The Open Source brand also runs Packt's Open Source Royalty Scheme, by which Packt gives a royalty to each Open Source project about whose software a book is sold.

\section{Writing for Packt}

We welcome all inquiries from people who are interested in authoring. Book proposals should be sent to author@packtpub.com. If your book idea is still at an early stage and you would like to discuss it first before writing a formal book proposal, contact us; one of our commissioning editors will get in touch with you.

We're not just looking for published authors; if you have strong technical skills but no writing experience, our experienced editors can help you develop a writing career, or simply get some additional reward for your expertise. 


\section{Join Packt!}

Work at the Leading Edge of IT Publishing

We're looking for good people to join our Team in Mumbai. We enjoy what we do, and here's why you might also:

- Intellectually rewarding work

- Innovative and creative company

- Work at the cutting edge of the technology driven publishing

- Dynamic, open and professional culture

- High staff involvement

- Day job - 40 hours a week with flexibility; Sat/Sun off

- MNC; among top 12,000 global websites

- Not a BPO operation

- Permanent employment (not contract)

- Explicit recognition in published books

\section{Work at Packt:}

\section{Content Development - A creative, exciting opportunity}

Content creation at Packt is a sophisticated process of content engineering. The team at Packt conceives the title ideas, and in tandem with experts it develops the books. As a part of the content development team at Packt, you work directly on draft book manuscripts from skilled authors around the world.

\section{Sales and Marketing - Innovation at work}

We are one of the very few leading publishers in IT who have a direct model of publishing. Our sales and marketing team is looking for innovative minds to develop and execute new ways of marketing and selling our books to a global audience working at the cutting edge of the current web marketing techniques.

\section{Candidate Profile:}

For all roles, you must have excellent communication skills, good command over English, keen observation and eye for detail, strong analytical skills, expressive ability and an interest in IT and technologies in general.

Candidates with a good science or engineering education have been particularly successful in the content development roles. For other roles, a good degree with a technical bend of mind is found to be useful.

\section{Opportunities Available:}

\section{Content Development Team}

- Development editors

- Technical editors

- Title Information editors

- Project managers

- Production co-ordinators

- Proofreaders

- Indexers If you are interested in working with us, please contact us by email at mumbaijobs@packtpub.com or by phoning us at 0225698 7682/3/4.

\section{We are currently hiring.}


Shroff / Packt Publishing

\section{6 .NET Compact Framework 3.5}

9789350231340

9788184049367

9789350233016

9788184045802

9789350230077

9788184042436

9789350231739

9788184042443

9788184047776

9789350232460

9789350231487

9788184046700

9789350232040

9788184049923

9788184049206

9788184045772

9788184049152

9789350231517

9788184049183

9788184046717

9789350230114

9788184047769

9789350232071

9789350232088 .

9788184046175

9788184048773

9788184046724

9788184044621

9788184047752

9788184048902

9788184049022

9788184047615

9789350231746

Beginner's Guide, 456 Pgs

Development, 544 Pages

Yii1.1 and PHP5, 372 Pages

Alfresco 3 Enterprise Content

Apache JMeter, 144 Pages

Microsoft Platform, 552 Pages

Asterisk Gateway Interface 1.4

and 1.6 Programming, 224 Pgs

AsteriskNOW, 212 Pages
Data Driven Applications, 492 Pages

3CX IP PBX Tutorial, The, 234 Pages

3D Game Development with Microsoft Silverlight 3:

3D Graphics with XNA Game Studio 4.0, 300 Pages

Active Directory Disaster Recovery, 256 Pages

ADempiere 3.4 ERP Solutions, 468 Pages

Advanced Microsoft Content Management Server

Agile Web Application Development with

Ajax and PHP: Building Responsive Web Applications, 288 Pages

Management Implementation, 604 Pgs

Alfresco 3 Web Content Management, 448 Pages

Alfresco 3 Web Services, 444 Pages

Alfresco Developer Guide, 560 Pages

Amazon SimpleDB Developer Guide, 260 Pages

Apache CXF Web Service Development, 340 Pages

Apache Geronimo 2.1: Quick Reference, 420 Pages

Apache Maven 2 Effective Implementation, 460 Pages

Apache MyFaces 1.2 Web Application Development, 416 Pgs

Apache MyFaces Trinidad 1.2: A Practical Guide, 296 Pages

Apache OFBiz Development: The Beginner's Tutorial, 476 Pgs

Apache Roller 4.0 - Beginner's Guide, 392 Pages

Apache Struts 2 Web Application Development, 384 Pages

Application Development for IBM WebSphere Process

Server 7 and Enterprise Service Bus 7, 556 Pages

Applied Architecture Patterns on the

ASP.NET 3.5: Application Architecture and Design, 263 Pages

ASP.NET 3.5 Content Management

System Development, 288 Pages

ASP.NET 3.5 Social Networking, 584 Pages

ASP.NET Data Presentation Controls Essentials, 258 Pages

ASP.NET MVC 1.0 Quickly, 260 Pages

Asterisk 1.4: The Professional's Guide, 288 Pages

Asterisk 1.6: Build feature-Rich Telephony

systems with Asterisk, 244 Pages

$\begin{array}{rrr}\text { Zehoo } & \mathbf{2 0 1 0} & 750.00 \\ \text { Landis } & \mathbf{2 0 1 0} & \mathbf{3 5 0 . 0 0} \\ & & \\ \text { Hillar } & 2009 & 675.00 \\ \text { James } & 2011 & \mathbf{4 5 0 . 0 0} \\ \text { Rommel } & 2008 & 325.00 \\ \text { mungkas } & 2010 & 700.00 \\ & & \\ \text { Ying } & 2005 & 475.00\end{array}$

Winesett $\quad 2010 \quad 550.00$

Darie $2008 \quad 250.00$

Shariff $2009 \quad 875.00$

Shariff $2011 \quad 675.00$

Lucidi $\quad 2010 \quad 675.00$

Potts $\quad 2010 \quad 525.00$

Chaganti $2010 \quad 400.00$

Balani $2010 \quad 350.00$

Chillakuru $2009 \quad 625.00$

Haili $2008 \quad 225.00$

Ching $2009 \quad 700.00$

Kummel $\quad 2010 \quad \mathbf{6 2 5 . 0 0}$

Thomas $2009 \quad 450.00$

Howell $2010 \quad 475.00$

Romero $\quad 2010 \quad 600.00$

Newton $2009 \quad 400.00$

Chandrasekaran $\quad 2011 \quad 825.00$

Seroter $\quad 2010 \quad \mathbf{8 2 5 . 0 0}$

Thakur $2008 \quad 300.00$

Christianson $2009 \quad 425.00$

Siemer $\quad \mathbf{2 0 1 0} \quad \mathbf{5 5 0 . 0 0}$

Kanjilal $2007 \quad 325.00$

Balliauw $2009 \quad 300.00$

Carpenter $\quad 2009 \quad 425.00$

Merel $\quad 2009 \quad 375.00$

Simionovich $2009 \quad 325.00$

Simionovich $2010 \quad 325.00$ 
9788184049671

9788184049688

9789350232095

9789350233597

9789350232101

9788184042382

9789350232484

9789350231609

9789350232477

9788184049091

9789350232118

9788184048858

9789350232491

9788184046014

9789350232422

9788184042412 9789350230602

9789350230039

9789350231715

9789350232507

9788184042405

9788184048797

9788184042467

9788184042474

9788184042320

9788184042399

9788184042245

9788184043907

9788184047783

9788184048889

9788184045734

$\mathbf{9 7 8 9 3 5 0 2 3 2 1 2 5}$

9788184044607

9789350232514

9788184046731

9789350232521

9789350233122

9789350231531

9789350233139

9788184049060

9789350231616

9788184043891

9788184045727

9789350232132
Backbase 4 RIA Development, 490 Pages

Beginning OpenVPN 2.0.9, 360 Pages

BIRT 2.6 Data Analysis and Reporting, 368 Pages

BlackBerry Enterprise Server for Microsoft ${ }^{\circledR}$ Exchange, 196 Pgs

BlackBerry Java Application Development:

Beginner's Guide, 380 Pages

BPEL Cookbook, 186 Pages

BPEL PM and OSB operational management with Oracle

Enterprise Manager $10 \mathrm{~g}$ Grid Control, 256 Pages

Blender 2.49 Scripting, 300 Pages

Blender 3D 2.49 Architecture, Buildings, and Scenery, 380 Pages

Blender 3D 2.49 Incredible Machines, 320 Pages

Blender 3D Architecture, Buildings, and Scenery, 340 Pages

Building Enterprise-Ready Telephony

Systems with sipXecs 4.0, 320 Pages

Building job sites with Joomla!, 244 Pages

Building Process Driven SOA using BPMN and BPEL, 333 Pages

Building SOA-Based Composite Applications

Using NetBeans IDE 6, 312 Pages

Building Telephony Systems with Asterisk, 178 Pages

Building Telephony Systems with OpenSER, 332 Pages

Building Telephony Systems with OpenSIPS 1.6, 288 Pages

Building Websites with DotNetNuke 5, 344 Pages

Building Websites with Expression Engine 2, 336 Pages

Building Websites with Joomla!, 342 Pages

Building Websites with Joomla! 1.5, 388 Pages

Building Websites with Mambo: A Step by Step Tutorial, 250 Pages

Building Websites with Microsoft Content Management Server, 638 Pgs

Building Websites with PHP - Nuke, 322 Pages

Building Websites with VB.NET and DotNETNuke 4, 338 Pages

Business Process Execution Language

for Web Services, 2/ed, 374 Pgs

Business Process Management with JBoss jBPM, 220 Pgs

C\# 2008 \& 2005 Threaded Programming:

Beginner's Guide, 410 Pgs

Cacti 0.8 Network Monitoring, 136 Pages

CakePHP Application Development, 336 Pages

Catalyst 5.8: the Perl MVC Framework, 252 Pages

Catalyst Accelerating Perl Web Application Development, 202 Pgs

ChronoForms 1.3 for Joomla! site Cookbook, 384 Pages

CISSP in 21 Days, 324 Pages

Cloning Internet Applications with Ruby, 344 Pages

CMS Design Using PHP and jQuery, 348 Pages

CMS Made Simple 1.6: Beginner's Guide, 372 Pages

Cocos2d for iPhone 0.99 Beginner's Guide, 376 Pages

Codelgniter 1.7, 304 Pages

Codelgniter 1.7 professional development, 304 Pages

Codelgniter for Rapid PHP Application Development, 262 Pages

ColdFusion 8 Developer Tutorial, 404 Pages

ColdFusion 9 Developer Tutorial, 396 Pages
Emde Boas

Feilner

2010

725.00

Ward

2010

550.00

Desai

2010

550.00

300.00

Foust

Blanvalet

2010

575.00

2006

200.00

$\begin{array}{rrr}\text { Bharadwaj } & 2011 & 375.00 \\ \text { Anders } & 2010 & 450.00 \\ \text { Brito } & 2011 & 575.00 \\ \text { Brito } & 2009 & 475.00 \\ \text { Brito } & 2010 & \mathbf{5 0 0 . 0 0} \\ & & \\ \text { Picher } & 2009 & 475.00 \\ \text { Dhar } & 2011 & \mathbf{3 7 5 . 0 0} \\ \text { Juric } & 2008 & 400.00\end{array}$

Jennings

Gomillion

2011

475.00

Goncalves

2005

200.00

Goncalves

$2010 \quad 500.00$

Washington

2010

425.00

Murphy

Graf

Graf

2010

525.00

2011

2006

500.00

350.00

Graf

2010

575.00

Ying

2005

275.00

Paterson

2004

550.00

350.00

Egan

350.00

Mathew

Cumberlidge

2004

375.00

250.00

$\begin{array}{rrr}\text { Hillar } & 2009 & 425.00 \\ \text { Kundu } & 2009 & 200.00 \\ \text { Bari } & 2008 & 425.00 \\ \text { John } & \mathbf{2 0 1 0} & 375.00 \\ \text { Rockway } & 2007 & 275.00 \\ \text { Janes } & 2011 & \mathbf{5 7 5 . 0 0} \\ \text { Srinivasan } & 2009 & 350.00 \\ \text { Sheong } & \mathbf{2 0 1 1} & \mathbf{5 2 5 . 0 0} \\ \text { Verens } & \mathbf{2 0 1 1} & \mathbf{5 2 5 . 0 0} \\ \text { Hauschildt } & \mathbf{2 0 1 0} & \mathbf{5 5 0 . 0 0} \\ \text { Ruiz } & \mathbf{2 0 1 1} & \mathbf{5 7 5 . 0 0} \\ \text { Blanco } & 2009 & 450.00 \\ \text { Griffith } & \mathbf{2 0 1 0} & \mathbf{4 5 0 . 0 0} \\ \text { Upton } & 2007 & 325.00 \\ \text { Farrar } & 2008 & 475.00 \\ \text { Farrar } & \mathbf{2 0 1 0} & \mathbf{6 0 0 . 0 0}\end{array}$




$$
\text { ISBN }
$$

9789350232149 9788184042368

9788184042313

9789350230916

9788184042290

9788184048810

9789350231647

9789350231821

9789350231753

9788184042283

9788184043969

9788184049565 9789350232538

9788184048407

9788184044706

9789350231357

9788184048872

9788184047691

9789350232545

9789350231296

9788184048223

9788184048926

9788184048841

9789350232552

9789350232569

9789350232996

9789350231425

9788184046762

9788184046168

9788184045307

9789350232576

9788184048803

9788184042306

9788184046212 9788184048933

9789350231524

9788184046069

9789350233054

9788184049213

9788184048643
Compiere 3, 232 Pages

Configuring IPCop Firewalls:

Closing Borders with Open Source, 244 Pgs

Creating your MySQL Database:

Practical Design Tips and Techniques, 108 Pages

CUPS Administrative Guide: A practical tutorial to installing, managing, and securing this powerful printing system, 256 Pgs

Designing and Implementing Linux Firewalls and QOS

Using Netfiler, Iproute, NAT and L7 - Filter, 288 Pages

Django 1.0 Web Site Development, 280 Pages

Django 1.1 Testing and Debugging, 440 Pages

Django 1.2 e-commerce, 252 Pages

Documentum 6.5 Content Management Foundations, 424 Pages

DNS in Action: A Detailed and Practical Guide to DNS

Implementation, Configuration and Adminstration, 198 Pages

Documentum Content Management Foundations: EMC Proven

Professional Certification Exam E20-120 Study Guide, 284 Pages

Domino 7 Application Development, 228 Pages

DotNetNuke 5.4 Cookbook, 440 Pages

Drools JBoss Rules 5.0 Developer's Guide, 328 Pages

Drupal 5 Themes, 262 Pages

Drupal 6 Attachment Views, 300 Pages

Drupal 6 Content Administration, 204 Pages

Drupal 6 JavaScript and juery, 344 Pages

Drupal 6 Panels Cookbook, 228 Pages

Drupal 6 Performance Tips, 246 Pages

Drupal 6 Search Engine Optimization, 288 Pages

Drupal 6 Site Blueprints, 280 Pages

Drupal 6 Social Networiking, 316 Pages

Drupal 7, 424 Pages

Drupal 7 First look, 296 Pages

Drupal 7 Module Development, 428 Pages

Drupal E-commerce with Ubercart 2.X, 372 Pages

Drupal for Education and E.Learning, 408 Pages

DWR Java AJAX Applications, 232 Pages

EJB 3 Developer Guide, 277 Pages

EJB 3.0 Database Persistence with

Oracle Fusion Middleware 11g, 456 Pages

Elgg Social Networking, 204 Pages

Enhancing Microsoft Content Management Server

with ASP.NET 2.0, 226 Pages

Entity Framework Tutorial, 2321 Pages

Expert Cube Development with

Microsoft SQL Server 2008 Analysis Services, 364 Pages

Expert PHP 5 Tools, 476 Pages

Expert Python Programming, 376 Pages

Ext GWT 2.0: Beginner's Guide, 332 Pages

Ext JS 3.0 Cookbook, 380 Pages

eZ Publish 4: Enterprise Web Sites Step-by-Step, 296 Pages
Pretorius $\quad 2010 \quad 350.00$

Dempster $\quad 2006 \quad 275.00$

Delisle $\quad 2006 \quad 125.00$

Shah $\quad 2010 \quad 375.00$

Gheorghe $\quad 2006 \quad 300.00$

Hourieh $2009 \quad 1000.00$

Tracey $\quad 2010 \quad 650.00$

Legg $2010 \quad 375.00$

Kumar $\quad 2010 \quad 625.00$

Dostalek $2006 \quad 225.00$

Kumar $\quad 2007 \quad 350.00$

McCarrick $2010 \quad 350.00$

Kurphy $2011 \quad 650.00$

Bali $2009 \quad 500.00$

Shreves $2007 \quad 325.00$

Green $\quad 2010 \quad \mathbf{4 5 0 . 0 0}$

Green $2009 \quad 300.00$

Butcher $2009 \quad 525.00$

Patel $2011 \quad 350.00$

Holowaychuk $2010 \quad 375.00$

Finklea $\quad 2009 \quad 425.00$

Ogunjobi $\quad 2009 \quad 425.00$

Peacock $2009 \quad 475.00$

Mercer $2011 \quad 625.00$

Noble $2011 \quad 450.00$

Garfield $2011 \quad 650.00$

Papadongonas $2010 \quad 550.00$

Fitzgerald $\quad 2010 \quad 375.00$

Salkosuo $\quad 2008 \quad 300.00$

Sikora $\therefore 2008 \quad 275.00$

Vohra $2011 \quad 675.00$

Sharma $2008 \quad 1000.00$

Harbar $2006 \quad 250.00$

Kanjilal $\quad 2008 \quad 300.00$

$\begin{array}{rrr}\text { Webb } & 2009 & 550.00 \\ \text { Merkel } & \mathbf{2 0 1 0} & \mathbf{7 2 5 . 0 0} \\ \text { Ziade } & 2008 & 450.00 \\ \text { Vaughan } & \mathbf{2 0 1 1} & \mathbf{5 0 0 . 0 0} \\ \text { Ramon } & 2009 & 575.00 \\ \text { Fullone } & 2009 & 450.00\end{array}$


9789350233023 Facebook Graph API Development with

Flash Beginners Guide, 332 Pages

9789350231630 Firebug 1.5: Editing, Debugging, and Monitoring Web Pages, 232 Pages

9789350232156 Flash 10 Multiplayer Game Essentials, 344

9789350232583

9788184049077

9788184048940

9789350232163

9789350230046

9788184042429

9789350231654

9789350231494

9788184048612

9789350230060

9789350231869

9789350234073

9789350234105

9788184043884

9788184049084

9789350231302

9789350232002

9789350230886

9789350231722

9788184048391

9789350231074

9789350232590

9789350232606

9788184049930

9789350232613

9788184049237

9788184049244

9789350232620

9789350231661

9789350231791

9788184044089

9788184046182

9789350232187

9789350232637

9789350232644

9788184049954
Flash Multiplayer Virtual Worlds, 420 Pages

Flash with Drupal, 388 Pages

Flex 3 with Java, 312 Pages

FreeSWITCH 1.0.6, 328 Pages

Funambol Mobile Open Source, 280 Pages

GDI + Custom Controls with Visual C\# 2005, 276 Pages

Getting Started with Audacity 1.3, 228 Pages

Getting Started with Oracle BPM Suite 11gR1 -

A Hands-On Tutorial, 544 Pages

Getting Started with Oracle SOA Suite $11 \mathrm{~g}$

R1-A Hands-On Tutorial, 496 Pages

GlassFish Administration, 288 Pages

GlassFish Security, 304 Pages

Google App Engine Java and GWT

Application Development, 492 Pages

Google Web Toolkit 2 Application

Development Cookbook, 256 Pages

Google Web Toolkit: GWT Java Ajax Programming, 248 Pages

Grails 1.1 Web Application Development, 332 Pages

Grok 1.0 Web Development, 316 Pages

Groovy for Domain-Specific Languages, 320 Pages

Hacking Vim 7.2, 252 Pages

High Availability MySQL Cookbook, 284 Pages

IBM Cognos 8 Planning, 428 Pages

IBM Cognos 8 Report Studio Cookbook, 280 Pages

IBM InfoSphere Replication Server and

Data Event Publisher, 352 Pages

IBM Lotus Notes 8.5 User Guide, 304 Pages

IBM Lotus Notes and Domino 8.5.1, 336 Pages

IBM Lotus Sametime 8 Essentials: A User's Guide, 292 Pages

IBM WebSphere eXtreme Scale 6, 296 Pages

ICEfaces 1.8: Next Generation Enterprise

Web Development, 296 Pgs

Implementing SugarCRM 5.x, 360 Pages

iReport 3.7, 244 Pages

IT Inventory and Resource Management with OCS

Inventory NG 1.02, 268 Pages

Java EE 5 Development using GlassFish

Application Server, 426 Pages

Java EE 5 Development with NetBeans 6, 404 Pages

Java EE 6 with GlassFish 3 Application Server, 496 Pages

JavaFX 1.2 Application Development Cookbook, 336 Pages

JavaScript Testing Beginner's Guide, 280 Pages

JBoss AS 5 Development, 420 Pages

$\begin{array}{rrr}\text { Williams } & 2011 & 500.00 \\ & & \\ \text { Luthra } & 2010 & 350.00 \\ \text { Hirematada } & 2010 & 525.00 \\ \text { Makzan } & 2011 & 625.00 \\ \text { Tidwell } & 2009 & 575.00 \\ \text { Kore } & 2009 & 525.00 \\ \text { Minessale } & 2010 & 500.00 \\ \text { Fornari } & 2010 & 425.00 \\ \text { Serban } & 2006 & 300.00 \\ \text { Hiitola } & 2010 & 350.00 \\ & & \cdot \\ \text { Buelow } & 2010 & 825.00 \\ & & \\ \text { Buelow } & 2009 & 750.00 \\ \text { Kou } & 2010 & 425.00 \\ \text { Kalali } & 2010 & 450.00 \\ & & \\ \text { Guermeur } & 2011 & 750.00 \\ & & \\ \text { Ahammad } & 2011 & 400.00 \\ \text { Chaganti } & 2007 & 300.00 \\ \text { Dickinson } & 2009 & 500.00 \\ \text { Guardia } & 2010 & 475.00 \\ \text { Dearle } & 2010 & 475.00 \\ \text { Schulz } & 2010 & 375.00 \\ \text { Davies } & 2010 & 425.00 \\ \text { Riaz } & 2009 & 650.00 \\ \text { Sanghani } & 2010 & 425.00\end{array}$

Chatterjee

$2011 \quad 525.00$

Hooper $2011 \quad 450.00$

Rosen $2010 \quad 500.00$

Scott $2011 \quad 450.00$

Chaves $2009 \quad 450.00$

Eschen $2009 \quad 450.00$

Magana $2011 \quad 550.00$

Ahammad $2010 \quad 375.00$

Antal $\quad 2010 \quad 400.00$

Heffelfinger $\quad 2007 \quad 450.00$

Heffelfinger $2008 \quad 400.00$

Heffelfinger $\quad 2010 \quad 750.00$

Valdimir $\quad 2011 \quad 500.00$

Eugene $\quad 2011 \quad 425.00$

Marchioni $\quad 2010 \quad 625.00$ 


\begin{tabular}{|c|c|c|c|c|}
\hline ISBN & Title & Author & Year & Price \\
\hline 9789350233146 & JBoss AS 5 Performance Tuning, 320 Pages & Marchioni & 2011 & 475.00 \\
\hline 9788184048230 & JasperReports 3.5 for Java Developers, 368 Pages & Heffelfinger & 2009 & 550.00 \\
\hline 9789350232170 & JasperReports 3.6 Development Cookbook, 408 Pages & Siddiqui & 2010 & 600.00 \\
\hline 9788184049442 & JasperReports for Java Developers, 348 Pages & Heffelfinger & 2010 & 1200.00 \\
\hline 9788184047738 & JBoss Drools Business Rules, 308 Pages & Browne & 2009 & 450.00 \\
\hline 9788184047707 & JBoss Portal Server Development, 280 Pages & Rao & 2009 & 400.00 \\
\hline 9788184049268 & JBoss RichFaces 3.3, 324 Pages & Filocamo & 2009 & 475.00 \\
\hline 9788184047790 & JBoss Tools 3 Developers Guide, 410 Pages & Leonard & 2009 & 625.00 \\
\hline 9788184049947 & jBPM Developer Guide, 376 Pages & Salatino & 2010 & 550.00 \\
\hline 9788184045345 & JDBC 4.0 and Oracle JDeveloper for J2EE Development, 446 Pgs & Vohra & 2008 & 500.00 \\
\hline 9788184048360 & Joomla! $1.5 x$ Customization, 288 Pages & Chapman & 2009 & 425.00 \\
\hline 9789350231500 & Joomla! 1.5 Beginner's Guide, 386 Pages & Tiggeler & 2010 & 575.00 \\
\hline 9789350231326 & Joomla! 1.5 Multimedia, 380 Pages & Walker & 2010 & 575.00 \\
\hline 9788184048605 & Joomla! 1.5 SEO, 332 Pages & Dinther & 2009 & 500.00 \\
\hline 9789350231807 & Joomlal 1.5 Site Blueprints, 268 Pages & Ogunjobi & 2010 & 400.00 \\
\hline 9788184047646 & Joomla! 1.5 Template Design, 286 Pages & Silver & 2009 & 425.00 \\
\hline 9789350232200 & Joomla! 1.5 Templates Cookbook, 244 Pages & Carter & 2010 & 375.00 \\
\hline 9788184044690 & Joomla! Accessibility, 156 Pages & Connor & 2007 & 250.00 \\
\hline \multirow[t]{2}{*}{9788184044584} & Joomla! Cash Money-making weapons for your Joomla! & & & \\
\hline & websiteBrandon, 182 Pages & Dawson & 2007 & 300.00 \\
\hline 9788184049251 & JSF 1.2 Components, 412 Pages & Hlavats & 2009 & 500.00 \\
\hline 9788184049299 & Joomla! 1.5 Content Administration, 216 Pages & Porst & 2009 & 325.00 \\
\hline 9788184049282 & Joomla! 1.5 Development Cookbook, 364 Pages & Kennard & 2009 & 550.00 \\
\hline 9789350232194 & Joomla! 1.5 JavaScript jQuery, 300 Pages & Blanco & 2010 & 450.00 \\
\hline 9788184047653 & Joomla! E-Commerce with VirtueMart, 480 Pages & Sarkar & 2009 & 725.00 \\
\hline 9789350232217 & Joomla! Social Networking with JomSocial, 196 Pages & Boateng & 2010 & 300.00 \\
\hline 9788184049275 & Joomla! with Flash, 264 Pages & Sarkar & 2009 & 400.00 \\
\hline 9788184049220 & jQuery 1.3 with PHP, 252 Pages & Verens & 2009 & 375.00 \\
\hline 9789350230015 & jQuery 1.4 Reference Guide, 340 Pages & Chaffer & 2010 & 500.00 \\
\hline 9788184043952 & jQuery Reference Guide, 268 Pages & Swedberg & 2007 & 325.00 \\
\hline 9788184047561 & jQuery UI 1.6: The User Interface Library for jQuery, 444 Pgs & Wellman & 2009 & 675.00 \\
\hline 9788184049305 & jQuery UI 1.7: The User Interface Library for jQuery, 396 Pgs & Wellman & 2009 & 600.00 \\
\hline 9788184049251 & JSF 1.2 Components, 412 Pages & Hlavats & 2009 & 625.00 \\
\hline 9789350232033 & JSF 2.0 Cookbook, 404 Pages & Leonard & 2010 & 600.00 \\
\hline \multirow[t]{2}{*}{9789350232651} & Kentico CMS 5 Website Development: & & & \\
\hline & Beginner's Guide, 320 Pages & Robbins & 2011 & 475.00 \\
\hline 9789350233849 & Koha 3 Library Management System, 302 Pages & Gupta & 2011 & 450.00 \\
\hline 9788184046557 & Learning Drupal 6 Module Development, 332 Pages & Butcher & 2010 & 375.00 \\
\hline 9788184046816 & Learning Ext JS, 332 Pages & Anderson & 2009 & 350.00 \\
\hline 9788184045369 & Learning Facebook Application Development, 240 Pages & Hayder & 2008 & 300.00 \\
\hline 9788184042337 & Learning Jakarta Struts 1.2, 222 Pages & Wiesner & 2005 & 225.00 \\
\hline 9788184043921 & Learning Joomla! 1.5 Extension Development, 178 Pages & LeBlanc & 2007 & 250.00 \\
\hline 9788184047806 & Learning jQuery 1.3, 460 Pages & Chaffer & 2009 & 700.00 \\
\hline 9788184043976 & Learning jQuery, 384 Pages & Chaffer & 2010 & 425.00 \\
\hline 9788184043877 & Learning PHP Data Objects, 188 Pages & Poppel & 2007 & 225.00 \\
\hline 9788184047813 & Learning SQL Server 2008 Reporting Services, 540 Pgs & Krishnaswamy & 2009 & 525.00 \\
\hline 9789350230473 & Learning the Yahoo! User Interface library, 384 Pages & Wellman & 2010 & 575.00 \\
\hline 9789350232224 & Least Privilege Security for Windows 7, Vista, and XP, 468 Pages & Smith & 2010 & 700.00 \\
\hline 9788184048254 & Liferay Portal 5.2 Systems Development, 556 Pages & Yuan & 2009 & 825.00 \\
\hline 9789350230466 & Liferay Portal 6 Enterprise Intranets, 700 Pages & Yuan & 2010 & $1,050.00$ \\
\hline
\end{tabular}


9788184044638 LINQ Quickly A practical guide to programming Language

Integrated Query with C\#, 254 Pages

9788184049312 Linux E-mail, 380 Pages

9789350230909 Linux Thin Client Networks Design and Deployment:

A quick guide for System Administrators, 184 Pages

9788184044737 Lotus Notes Domino 8 Upgrader's Guide, 278 Pages

9788184048346 LWUIT 1.1 for Java ME Developers, 368 Pages

9789350230084 Magento 1.3: PHP Developer's Guide, 360 Pages

9789350231432 Magento 1.3: Sales Tactics Cookbook, 300 Pages

9789350233085 Magento 1.4 Development Cookbook, 276 Pages

9788184049107 Magento Beginner's Guide, 308 Pages

9789350231333 Mahara 1.2 E-Portfolios: Beginner's Guide, 268 Pages

9788184044713

9788184044539

9788184044676

9788184042252

Managing eZ Publish Web Content Management Projects, 322 Pgs

Managing Software Development with Trac and Subversion, $122 \mathrm{Pgs}$

Mastering Joomla! 1.5 Extension \& Framework Development, 490 Pgs

Mastering Mambo E-Commerce, Templates, Module

Development, SEO, Security and Performance, 306 Pages

9788184044003 Mastering OpenLDAP: Configuring, Securing and

Integrating Directory Services, 484 Pages

9788184047820

9788184042351

9788184049336

Mastering Oracle Scheduler in Oracle 11g Databases, 244 Pgs

Mastering PHPMyAdmin 2.8 for Effective

MySQL Management, 316 Pages

9789350230008

9789350231548

Matplotlib for Python Developers, 312 Pages

Maximize Your Investment: 10 Key Strategies for Effective

Packaged Software Implementations, 236 Pages

9788184043853

MediaWiki 1,1: Beginner's Guide, 364 Pages

Microsoft AJAX Library Essentials: Client-side

ASP.NET AJAX 1.0 Explained, 300 Pages

9789350233092 Micros oft Azure: Enterprise Application Development, 256 Pgs

9789350230091 Microsoft Dynamics AX 2009 Development Cookbook, 360 Pgs

9788184049541 Microsoft Dynamics AX 2009 Programming:

Getting Started, 352 Pgs

9789350232231

Microsoft Dynamics GP 2010 Cookbook, 332 Pages

9789350231982

9789350232668

9789350233603

9788184049343

9789350232248 9789350230787

9789350231708

Microsoft Dynamics NAV 2009 Application Design, 504 Pages

Microsoft Dynamics NAV Administration, 216 Pages

Microsoft Enterprise Library 5.0, 288 Pages

Microsoft Office Live Small Business:

Beginner's Guide, 260 Pages

Microsoft Silverlight 4 and SharePoint 2010 Integration, 344 Pgs

Microsoft Silverlight 4 Business Application Development:

Beginners Guide, 420 Pages

9789350232972

Micros oft Silverlight 4 Data and Services Cookbook, 484 Pgs

Microsoft SQL Azure Enterprise Application

Development, 428 Pages

9789350232255 Microsoft Visio 2010 Business Process

Diagramming and Validation, 352 Pages

9789350232262 Microsoft Windows Workflow Foundation 4.0 Cookbook, 284 Pgs

9788184049695 Middleware Management with Oracie Enterprise Manager

Grid Control 10g R5, 336 Pages

9788184045338

Mobile Web Development, 238 Pages

$\begin{array}{rrr}\text { Kumar } & 2007 & 325.00 \\ \text { Haycox } & 2009 & 575.00 \\ & & \\ \text { Richards } & 2010 & 275.00 \\ \text { Speed } & 2007 & 325.00 \\ \text { Sarkar } & 2009 & 550.00 \\ \text { Huskisson } & 2010 & \mathbf{4 0 0 . 0 0} \\ \text { Rice } & 2010 & \mathbf{4 5 0 . 0 0} \\ \text { Ferdous } & 2011 & \mathbf{4 2 5 . 0 0} \\ \text { Rice } & 2009 & 450.00 \\ \text { Kent } & 2010 & \mathbf{4 0 0 . 0 0} \\ \text { Bauer } & 2007 & 375.00 \\ \text { Murphy } & 2007 & 200.00 \\ \text { Kennard } & 2007 & 500.00 \\ & & \\ \text { Hauser } & 2005 & 325.00 \\ & & \\ \text { Butcher } & 2007 & 450.00 \\ \text { Rood } & 2009 & 475.00 \\ & & \\ \text { Delisle } & 2004 & 350.00 \\ \text { Tosi } & 2009 & 475.00\end{array}$

Beaubouef

$2010 \quad 350.00$

Rahman $\quad 2010 \quad 550.00$

Darie $\quad 2007 \quad 300.00$

Dudley $2011 \quad 375.00$

Pocius $\quad 2010 \quad 550.00$

Dalen $\quad 2010 \quad 525.00$

Polino $2010 \quad 500.00$

Brummel $2010 \quad 750.00$

Oberoi $2011 \quad 325.00$

Joshi $2011 \quad 425.00$

Pitre $\quad 2009 \quad 400.00$

Hillar $\quad 2010 \quad 525.00$

Albert $\quad 2010 \quad 625.00$

Cleeren $\quad 2010 \quad 725.00$

Krishnaswamy $2011 \quad 650.00$

$\begin{array}{rrr}\text { Parker } & 2010 & \mathbf{5 2 5 . 0 0} \\ \text { Zhu } & 2010 & \mathbf{4 2 5 . 0 0}\end{array}$

Maheshwari $\quad 2010 \quad 500.00$

Mehta $2008 \quad 300.00$ 


\begin{tabular}{|c|c|c|c|c|}
\hline ISBN & Title & Author & Year & Price \\
\hline 9788184049169 & ModSecurity 2.5, 288 Pages & Mischel & 2009 & 425.00 \\
\hline 9788184049121 & MODx Web Development, 284 Pages & John & 2009 & 425.00 \\
\hline 9788184045710 & Moodle 1.9 E-Learning Course Development, 388 Pages & Rice IV & 2008 & 450.00 \\
\hline 9789350232286 & Moodle 1.9 English Teacher's Cookbook, 312 Pages & Hillar & 2010 & 475.00 \\
\hline 9789350231623 & Moodle 1.9 Extension Development, 328 Pages & Moore & 2010 & 400.00 \\
\hline 9789350231999 & Moodle 1.9 for Design and Technology, 296 Pages & Taylor & 2010 & 450.00 \\
\hline 9788184048636 & Moodle 1.9 for Second Language Teaching, 532 Pages & Stanford & 2009 & 800.00 \\
\hline \multirow[t]{2}{*}{9788184047639} & Moodle 1.9 for Teaching 7-14 Year Olds: & & & \\
\hline & Beginner's Guide, 240 Pgs & Cooch & 2009 & 3500.00 \\
\hline 9789350232279 & $\begin{array}{l}\text { Moodle } 1.9 \text { for Teaching Special Education Children } \\
\text { (5-10 Year Olds): Beginner's Guide, } 332 \text { Pages }\end{array}$ & Olsen & 2010 & 500.00 \\
\hline 9788184049190 & Moodle 1.9 Math, 272 Pages & Wild & 2009 & 400.00 \\
\hline 9788184047684 & Moodle 1.9 Multimedia, 276 Pages & Pedro & 2009 & 425.00 \\
\hline 9789350230022 & Moodle 1.9 Teaching Techniques, 220 Pages & Nash & 2010 & 325.00 \\
\hline 9789350233153 & Moodle 1.9 Testing and Assessment, 400 Pages & Myrick & 2011 & 600.00 \\
\hline 9789350230893 & Moodle 1.9 Theme Design: Beginner's Guide, 312 Pages & Gadsdon & 2010 & 475.00 \\
\hline 9789350232842 & Moodle 2.0 First Look, 284 Pages & Mary & 2011 & 425.00 \\
\hline 9788184046854 & Moodle Administration, 380 Pages & Büchner & 2009 & 425.00 \\
\hline 9788184046861 & Moodle Course Conversion: Beginner's Guide, 320 Pages & Wild & 2009 & 350.00 \\
\hline 9788184044591 & Moodle Teaching Techniques, 194 Pages & Rice IV & 2007 & 275.00 \\
\hline 9789350230053 & MooTools 1.2 Beginner's Guide, 284 Pages & Gube & 2010 & 425.00 \\
\hline 9789350232675 & MySQL 5.1 Plugin Development, 296 Pages & Golubchik & 2011 & 450.00 \\
\hline 9789350231449 & MySQL Admin Cookbook, 384 Pages & Schneller & 2010 & 575.00 \\
\hline 9789350232682 & MySQL for Python, 448 Pages & Lukaszewski & 2011 & 675.00 \\
\hline 9789350231456 & NetBeans Platform 6.9 Developer's Guide, 296 Pages & Petri & 2010 & 450.00 \\
\hline 9789350232293 & Nginx HTTP Server, 356 Pages & Nedelcu & 2010 & 525.00 \\
\hline 9789350231852 & NHibernate 2.x Beginner's Guide, 284 Pages & Cure & 2010 & 425.00 \\
\hline 9788184045703 & Object-Oriented JavaScript, 360 Pages & Stefanov & 2008 & 375.00 \\
\hline 9788184044546 & Object-Oriented Programming with PHP5, 274 Pages & Hayder & 2007 & 350.00 \\
\hline \multirow[t]{3}{*}{9788184044010} & ODP.NET Developer's Guide: Oracle Database $10 \mathrm{~g}$ & & & \\
\hline & Development with Visual Studio 2005 and the Oracle Data & & & \\
\hline & Provider for .NET, 328 Pages & Pulakhandam & 2007 & 425.00 \\
\hline 9789350234082 & OGRE 3D 1.7 Beginner's Guide, 308 Pages & Kerger & 2011 & 500.00 \\
\hline \multirow[t]{2}{*}{9788184042238} & Open VPN Building and Integrating Virtual & & & \\
\hline & Private Networks, 274 Pgs & Feilner & 2006 & 300.00 \\
\hline 9789350232699 & OpenCart 1.4 Beginner's Guide, 244 Pages & Yilmaz & 2011 & 375.00 \\
\hline 9789350233832 & OpenCms 7 Development, 300 Pages $\quad \therefore$ & Liliedahl & 2011 & 450.00 \\
\hline 9789350233160 & OpenSceneGraph 3.0: Beginner's Guide, 420 Pages & Wang & 2011 & 625.00 \\
\hline 9789350232705 & OpenStreetMap, 256 Pages & Bennett & 2011 & 400.00 \\
\hline 9789350231463 & OpenX Ad Server: Beginner's Guide, 304 Pages & Yilmaz & 2010 & 450.00 \\
\hline \multirow[t]{2}{*}{9788184047844} & Oracle $10 \mathrm{~g} / 11 \mathrm{~g}$ Data and Database & & & \\
\hline & Management Utilities, $436 \mathrm{Pgs}$ & Madrid & 2009 & 675.00 \\
\hline \multirow[t]{2}{*}{9789350232309} & Oracle 11g R1/R2 Real Application & & & \\
\hline & Clusters Handbook, 684 Pages & Prusinski & 2010 & $1,025.00$ \\
\hline 9788184049992 & Oracle $11 \mathrm{~g}$ Streams Implementer's Guide, 356 Pages & McKinnell & 2010 & 525.00 \\
\hline 9789350233030 & Oracle APEX 4.0 Cookbook, 336 Pages & Zoest & 2011 & 500.00 \\
\hline \multirow[t]{2}{*}{9789350231975} & Oracle Application Express 3.2: & & & \\
\hline & The Essentials and More, 652 Pages & Geller & 2010 & 975.00 \\
\hline 9788184048919 & Oracle Application Express Forms Converter, 176 Pages & Bos & 2009 & 275.00 \\
\hline
\end{tabular}


9789350234099 Oracle Business Intelligence:

\section{0}

9789350231579

\section{1}

9788184047660

9789350232712

9789350231968

9788184046076

9789350231098

9789350231067

9788184047837

9788184049978

9789350231234

9788184048629

9788184048421

9788184048384

9788184045796

9788184044720

9788184043914

9788184049176

9789350230497

9788184049145

9789350232729

9789350230480

9789350230121

9788184047721

9789350233177

9788184043945

9788184048582

9788184044096

9789350230107

9789350232736

9789350231838

9789350231814

9788184048377

9789350232316

9789350230879

9789350232866

9789350232446

9789350234181

9789350232019

9789350232323

9788184047745

9788184044645

Plone 3 Intranets, 312 Pages

Plone 3 Multimedia, 380 Pages

Plone 3 Theming, 328 Pages
The Condensed Guide to Analysis and Reporting, 196 Pages

Oracle Coherence 3.5, 412 Pages

Oracle Database $11 \mathrm{~g}$ - Underground Advice for

Database Administrators, 356 Pages

Oracle E-Business Suite R12 Supply

Chain Management, 300 Pages

Oracle Essbase 9 Implementation Guide, 448 Pages

Oracle Fusion Middleware Patterns, 228 Pages

Oracle JRockit: The Definitive Guide, 596 Pages

Oracle Modernization Solutions, 435 Pages

Oracle Siebel CRM 8 Installation and Management, 580 Pgs

Oracle SOA Suite 11g R1 Developer's Guide, 724 Pages

Oracle SOA Suite Developer's Guide, 656 Pages

Oracle SQL Developer 2.1, 500 Pages

Oracle Universal Content Management Handbook, 360 Pages

Oracle User Productivity Kit 3.5, 544 Pages

Oracle VM Manager 2.1.2, 248 Pages

Oracle Warehouse Builder 11g Getting Started, 368 Pages

Oracle Web Services Manager, 238 Pages

osCommerce Webmaster's Guide to Selling Online, 428 Pages

OSWorkflow: A guide for Java developers and architects to

integrating open-source Business Process Management, 212 Pgs

Papervision3D Essentials, 432 Pages

Pentaho 3.2 Data Integration: Beginner's Guide, 500 Pages

Pentaho Reporting 3.5 for Java Developers, 388 Pages

PHP 5 CMS Framework Development - 2led, 424 Pages

PHP 5 CMS Framework Development, 352 Pages

PHP 5 E-commerce Development, 450 Pages

PHP and script.aculo.us Web 2.0 Application Interfaces, 272 Pgs

PHP jQuery Cookbook, 344 Pages

PHP Oracle Web Development: Data processing,

Security, Caching, XML, Web Services, and Ajax, 396 Pages

PHP Team Development, 192 Pages

PHP Web 2.0 Mashup Projects, 306 Pages

Plone 3 for Education, 216 Pages

Plone 3 Products Development Cookbook, 396 Pages

Plone 3.3 Site Administration, 248 Pages

Pluggable Authentication Modules: The Definitive Guide to

PAM for Linux SysAdmins and C Developers, 128 Pages

PostgreSQL 9 Administration Cookbook, 372 Pages

PostgreSQL 9.0 High Performance, 476 Pages

Practical Data Analysis and Reporting with BIRT, 320 Pages

PrestaShop 1.3 Beginner's Guide, 316 Pages

PrestaShop 1.3 Theming Beginner's Guide, 320 Pages

Processing XML documents with Oracle JDeveloper $11 \mathrm{~g}, 388 \mathrm{Pgs}$

Professional Plone Development, 422 Pages

\begin{tabular}{|c|c|c|}
\hline Vasiliev & 2011 & 300.00 \\
\hline Seovic & 2010 & 625.00 \\
\hline Sims & 2010 & 525.00 \\
\hline Siddiqui & 2011 & 450.00 \\
\hline Anantapantula & 2009 & 675.00 \\
\hline Gaur & 2011 & 350.00 \\
\hline Hirt & 2010 & 975.00 \\
\hline Laszewsk & 2008 & 475.00 \\
\hline Hansal & 2010 & 875.00 \\
\hline Reynolds & 2010 & $1,075.00$ \\
\hline Wright & 2009 & 925.00 \\
\hline Harper & 2010 & 750.00 \\
\hline Khanine & 2010 & 550.00 \\
\hline Manuel & 2009 & 825.00 \\
\hline Singh & 2009 & 375.00 \\
\hline Griesemer & 2009 & 550.00 \\
\hline Lakshminarayanan & 2008 & 300.00 \\
\hline Gurevych & 2007 & 450.00 \\
\hline Diego & 2007 & 275.00 \\
\hline Winder & 2009 & 650.00 \\
\hline Roldan & 2010 & 750.00 \\
\hline Gorman & 2009 & 575.00 \\
\hline Brampton & 2011 & 625.00 \\
\hline Brampton & 2010 & 525.00 \\
\hline Peacock & 2010 & 550.00 \\
\hline Rao & 2009 & 400.00 \\
\hline Joshi & 2011 & 525.00 \\
\hline Vasiliev & 2007 & 450.00 \\
\hline Abeysinghe & 2009 & 300.00 \\
\hline Chow & 2007 & 325.00 \\
\hline Rose & 2010 & 325.00 \\
\hline Alba & 2011 & 475.00 \\
\hline Gross & 2010 & 575.00 \\
\hline Giménez & 2010 & 600.00 \\
\hline Williams & 2009 & 500.00 \\
\hline Clark & 2010 & 375.00 \\
\hline Geisshirt & 2010 & 225.00 \\
\hline Riggs & 2011 & 550.00 \\
\hline Smith & 2011 & 725.00 \\
\hline Ward & 2011 & 500.00 \\
\hline Horton & 2010 & 475.00 \\
\hline Hashim & 2011 & 475.00 \\
\hline Vohra & 2009 & 575.00 \\
\hline Aspeli & 2007 & 425.00 \\
\hline
\end{tabular}




\begin{tabular}{|c|c|c|c|c|}
\hline ISBN & Title & Author & Year & Price \\
\hline 9788184044652 & 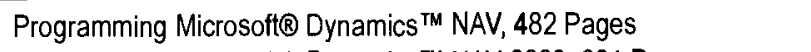 & Studebaker & 2007 & 475.00 \\
\hline 9788184049329 & Programming Microsoft@ Dynamics ${ }^{\mathrm{TM}}$ NAV 2009, 624 Pgs & Studebaker & 2009 & 750.00 \\
\hline \multirow[t]{2}{*}{9788184045291} & Programming Windows Workflow Foundation: Practical WF & & & \\
\hline & Techniques and Examples using XAML and C\#, 256 pages & Allen & 2008 & 300.00 \\
\hline \multirow[t]{2}{*}{9788184043983} & Project Management with dotProject: Implement, Configure, & & & \\
\hline & Customize, and Maintain your DotProject Installation, 232 Pages & Jordan & 2007 & 300.00 \\
\hline 9789350233047 & Python 2.6 Text Processing Beginners Guide, 388 Pages & McNeil & 2011 & 575.00 \\
\hline 9789350232330 & Python 3 Object Oriented Programming, 412 Pages & Phillips & 2010 & 625.00 \\
\hline 9789350232989 & Python Geospatial Development, 516 Pages & Westra & 2011 & 775.00 \\
\hline 9789350232743 & Python Multimedia, 300 Pages & Sathaye & 2011 & 450.00 \\
\hline 9788184049961 & Python Testing: Beginner's Guide, 260 Pages & Arbuckle & 2010 & 300.00 \\
\hline \multirow[t]{2}{*}{9788184043938} & Qmail Quickstarter: & & & \\
\hline & Install, Set Up and Run your own Email Server, 152 Pages & Wheeler & 2007 & 225.00 \\
\hline 9788184045352 & Quality Assurance for Dyanmics AX-Bassed ERP Solutions, 181 Pgs & Gupta & 2008 & 250.00 \\
\hline 9789350230282 & Quickstart Apache Axis2, 188 Pages & Jayasinghe & 2010 & 275.00 \\
\hline 9789350232347 & Refactoring with Microsoft Visual Studio 2010, 384 Pages & Ritchie & 2010 & 575.00 \\
\hline 9788184049701 & RESTful Java Web Services, 262 Pages & Sandoval & 2010 & 400.00 \\
\hline 9788184046199 & RESTful PHP Web Services, 223 Pages & Abeysinghe & 2008 & 300.00 \\
\hline \multirow[t]{2}{*}{9788184042269} & RSS and Atom: Understanding and Implementing & & & \\
\hline & Content Feeds and Syndication, 282 Pages & Wittenbrink & 2005 & 325.00 \\
\hline 9788184044577 & Ruby on Rails Enterprise Application Development, 530 Pages & Smith & 2007 & 525.00 \\
\hline 9788184045314 & Ruby on Rails Web Mashup Projects, 280 Pages & Sheong & 2008 & 350.00 \\
\hline 9788184047868 & SAP Business ONE Implementation, 324 Pages & Niefert & 2009 & 475.00 \\
\hline 9788184049114 & Sakai Courseware Management, 508 & Berg & 2009 & 750.00 \\
\hline 9788184047592 & Scratch 1.4: Beginner's Guide, 268 Pages & Badger & 2009 & 400.00 \\
\hline 9789350233184 & Scribus 1.3.5: Beginner's Guide, 360 Pages & Gemy & 2011 & 550.00 \\
\hline 9788184047578 & Seam 2.x Web Development, 302 Pages & Salter & 2009 & 450.00 \\
\hline 9789350233238 & Selenium 1.0 Testing Tools: Beginners Guide, 240 Pages & Burns & 2011 & 350.00 \\
\hline 9789350232453 & Selling Online with Drupal e-Commerce, 272 Pages & Peacock & 2011 & 400.00 \\
\hline \multirow[t]{2}{*}{9789350231081} & Service Oriented Architecture: & & & \\
\hline & An Integration Blueprint, 248 Pages & Schmutz & 2010 & 375.00 \\
\hline 9788184045765 & SharePoint Designer Tutorial, 190 Pages & Poole & 2008 & 250.00 \\
\hline 9789350232750 & Silverlight 4 User Interface Cookbook, 286 Pages & Cipan & 2011 & 425.00 \\
\hline \multirow[t]{2}{*}{9789350231692} & SketchÜ 7.1 for Architectural Visualization: & & & \\
\hline & Beginner's Guide, 412 Pages & Jongh & 2010 & 625.00 \\
\hline \multirow[t]{2}{*}{9788184048896} & Small Business Server 2008 Installtion, & & & \\
\hline & Migration, and Configuration, 412 Pages & Overton & 2009 & 625.00 \\
\hline 9788184042375 & Smarty PHP Template Programming and Applications, 256 Pages & Maia & 2006 & 275.00 \\
\hline \multirow[t]{2}{*}{9788184046045} & SOA Cookbook: Design Recipes for Building & & & \\
\hline & Better SOA Processes, 273 Pgs & Havey & 2008 & 350.00 \\
\hline 9788184047714 & SOA Patterns with BizTalk Server 2009, 406 Pages & Seroter & 2009 & 600.00 \\
\hline 9789350233009 & Software Testing using Visual Studio 2010, 408 Pages & Subashni & 2011 & 600.00 \\
\hline 9788184043860 & SOA and WS-BPEL, 250 Pages & Vasiliev & 2007 & 350.00 \\
\hline 9788184046205 & SOA Governance, 231 Pages & Biske & 2008 & 300.00 \\
\hline 9788184045376 & Service Oriented Java Business Integration, 438 Pages & Binildas & 2008 & 500.00 \\
\hline 9788184045758 & Service Oriented Architecture with Java, 196 Pages & Binildas & 2008 & 250.00 \\
\hline 9788184044553 & SOA Approach to Integration, 384 Pages & Sarang & 2008 & 400.00 \\
\hline 9788184048353 & Solr 1.4 Enterprise Search Server, 344 Pages & Smiley & 2009 & 525.00 \\
\hline 9788184047851 & Spring 2.5 Aspect Oriented Programming, 332 Pages & Dessi & 2009 & 600.00 \\
\hline 9788184049138 & Spring Persistence with Hibernate, 465 Pages & Seddighi & 2009 & 700.00 \\
\hline
\end{tabular}




\begin{tabular}{|c|c|c|c|c|}
\hline ISBN & Title & Author & Year & Price \\
\hline 9789350231784 & Spring Python 1.1, 272 Pages & Turnquist & 2010 & 400.00 \\
\hline 9789350231876 & Spring Security 3, 428 Pages & Mularien & 2010 & 650.00 \\
\hline 9788184047585 & Spring Web Flow 2 Web Development, 274 Pages & Luppken & 2009 & 400.00 \\
\hline \multirow[t]{2}{*}{9788184044560} & SQL Server Integration Services Using & & & \\
\hline & Visual Studio 2005, 322 Pages & Krishnaswamy & 2007 & 375.00 \\
\hline 9788184045321 & Swing Extreme Testing, 328 Pages & Lavers & 2008 & 375.00 \\
\hline 9788184048599 & Symfony 1.3 Web Application Development, 232 Pages & Bowler & 2009 & 350.00 \\
\hline 9788184044669 & Tapestry 5 Building Web Applications, 272 Pages & Kolesnikov & 2008 & 325.00 \\
\hline 9789350232354 & Tcl 8.5 Network Programming, 596 Pages & Kocjan & 2010 & 900.00 \\
\hline \multirow[t]{2}{*}{9789350232767} & The Business Analyst's Guide to Oracle & & & \\
\hline & Hyperion Interactive Reporting 11, 236 Pages & Cody & 2011 & 350.00 \\
\hline 9788184049985 & Tomcat 6 Developer's Guide, 424 Pages & Chetty & 2010 & 625.00 \\
\hline 9788184048865 & Trixbox CE 2.6, 348 Pages & Garrison & 2009 & 525.00 \\
\hline 9789350232774 & Troux Enterprise Architecture Solutions, 256 Pages & Reese & 2011 & 375.00 \\
\hline 9789350231845 & TYPO3 4,2 E-Commerce, 220 Pages & Karlsons & 2010 & 325.00 \\
\hline 9789350231319 & TYPO3 4.3 Multimedia Cookbook, 232 Pages & Osipov & 2010 & 350.00 \\
\hline 9788184042450 & TYPO3: Enterprise Content Management, 626 Pages & Altmann & 2005 & 525.00 \\
\hline 9788184046038 & TYPO3: Extension Development, 237 Pages & Dulepov & 2008 & 300.00 \\
\hline 9788184042276 & UML 2.0 in Action: A Project - Based Tutorial, 248 Pages & Grassle & 2005 & 200.00 \\
\hline 9788184042344 & Understanding TCP $/ \mathrm{P}, 482$ Pages & Dostalek & 2006 & 350.00 \\
\hline \multirow[t]{2}{*}{9789350232781} & Unity 3D Game Development by & & & \\
\hline & Example Beginner's Guide, 408 Pages & Creighton & 2011 & 600.00 \\
\hline 9788184049374 & Unity Game Development Essentials, 320 Pages & Goldstone & 2009 & 475.00 \\
\hline 9789350232439 & User Training for Busy Programmers & Rice & 2011 & 275.00 \\
\hline 9789350231685 & VirtualBox 3.1: Beginner's Guide, 356 Pages & Romero & 2010 & 525.00 \\
\hline \multirow[t]{2}{*}{9788184043990} & Visual SourceSafe 2005 Software Configuration & & & \\
\hline & Management in Practice, 406 Pages & Serban & 2007 & 475.00 \\
\hline 9788184047608 & VSTO 3.0 for Office 2007 Programming, 264 Pages & Thangaswamy & 2009 & 400.00 \\
\hline 9788184046885 & WCF Multi-tier Services Development with LINQ, 392 Pages & Liu & 2010 & 425.00 \\
\hline \multirow[t]{2}{*}{9789350232026} & WCF 4.0 Multi-tier Services Development with & & & \\
\hline & LINQ to Entities, 356 Pages & Liu & 2010 & 525.00 \\
\hline \multirow[t]{2}{*}{9788184048414} & WebSphere Application Server 7.0 & & & \\
\hline & Administration Guide, 348 Pgs & Robinson & 2009 & 425.00 \\
\hline 9788184047622 & WordPress 2.7 Complete, 300 Pages & Silver & 2009 & 450.00 \\
\hline 9788184047677 & WordPress 2.7 Cookbook, 324 Pages & Jung & 2009 & 475.00 \\
\hline 9788184049664 & WordPress 2.8 Theme Design, 300 Pages & Silver & 2010 & 450.00 \\
\hline 9789350232361 & WordPress 2.8 Themes Cookbook, 320 Pages & Ohrn & 2010 & 475.00 \\
\hline 9789350231470 & WordPress 2.9 E-Commerce, 292 Pages & Bondari & 2010 & 450.00 \\
\hline 9789350232798 & WordPress 3 Site Blueprints, 308 Pages & Wallace & 2011 & 375.00 \\
\hline 9789350232804 & WordPress 3.0 JQuery, 322 Pages & Silver & 2011 & 475.00 \\
\hline 9789350231678 & WordPress and Flash 10x Cookbook, 276 Pages & Spannagle & 2010 & 425.00 \\
\hline 3788184049350 & WordPress MU 2.8: Beginner's Guide & Harrison & 2009 & 425.00 \\
\hline 3788184046052 & WordPress for Business Bloggers, 359 Pages & Thewlis & 2008 & 425.00 \\
\hline 3788184046021 & WordPress Theme Design, 229 Pages & Silver & 2008 & 300.00 \\
\hline 789350232811 & WordPress Top Plugins, 260 Pages & Corbin & 2011 & 400.00 \\
\hline \multirow[t]{2}{*}{9789350232828} & WS-BPEL 2.0 for SOA Composite Applications with & & & \\
\hline & Oracle SOA Suite 11g, 624 Pages & Juric & 2011 & 575.00 \\
\hline 789350233078 & wxPython 2.8 Application Development Cookbook, 320 Pages & Precord & 2011 & 475.00 \\
\hline 788184044683 & Xen Virtualization, 148 Pages & Chaganti & 2007 & 225.00 \\
\hline
\end{tabular}


9789350232835 XNA 4.0 Game Development by Example:

\section{YUI 2.8 Learning the Library, 416 Pages}

9789350231555 Zabbix 1.8 Network Monitoring, 436 Pages

9788184045741 Zen Cart E-Commerce Application Development, 318 Pages

9788184048575 Zend Framework 1.8 Web Application Development, 388 Pages

9788184044614 Zimbra Implement, Administer and Manage, 222 Pages

9788184045789 Zenoss Core Network and System Monitoring, 282 Pages

$\begin{array}{rrr}\text { Jaegers } & 2011 & 650.00 \\ \text { Barreiro } & \mathbf{2 0 1 0} & \mathbf{6 2 5 . 0 0} \\ \text { Olups } & \mathbf{2 0 1 0} & \mathbf{6 5 0 . 0 0} \\ \text { Sarkar } & 2008 & 375.00 \\ \text { Pope } & 2009 & 575.00 \\ \text { Resnick } & 2008 & 300.00 \\ \text { Badger } & 2008 & 350.00\end{array}$

US EDITIONS:

9781904811114

9781904811251

9781904811138

9781904811022

9781904811923

9781847190901

9781904811060

9781904811862

9781904811909

9781904811015

9781904811374

9781904811299

9781904811794

9781904811442

9781904811213

9781904811121

9781904811077

9781904811633

9781904811459
Alfresco Enterprise Content Management Implementation, 360 Pages

Building and integrating Virtual Private Networks with Openswan, 360 Pages

Building Online Communities with phpBB 2, 360 Pages

Building Websites with Plone, 416 Pages

cPanel User Guide and Tutorial, 208 Pages

Deep Inside osCommerce: The Cookbook, 400 Pages

Domino 7 Lotus Notes Application Development, 228 Pages

ImageMagick Tricks: Web Image Effects from the Command

Line and PHP, 232 Pages

JasperReports: Reporting for Java Developers, 344 Pages

Learning eZ publish 3: Building Content Management

Solutions--Leaders of the $\mathrm{eZ}$ publish community guide you

through this complex and powerful PHP-based Content

Management System, 329 Pages

Linux Email: Setup and Run a Small Office Email

Server using PostFix. Courier. ProcMail, SquirrelMail.

ClamAV and SpamAssassin, 316 Pages

Moodie E-Learning Course Development, 256 Pages

PHP Programming with PEAR, 292 Pages

PHPEclipse: A User Guide, 228 Pages

Programming Windows Workflow Foundation; Practical

WF Techniques and Examples using XAML and $\mathrm{CH}, 300$ Pages

SpamAssassin: A Practical Guide to Integration and Configuration. 240 Pages McDonald

SSL VPN: Understanding, evaluating and planning secure;

web-based remote access, 212 Pages

Upgrading to Lotus Notes and Domino 7, 340 Pages

User Training for Busy Programmers, 92 Pages
Borgermans

2004 US\$59.99

Taylor

Rice

Stephan

Chow

Allen

Steinberg

Speed

Rice
2005 US\$ 39.99

2006 US\$ 39.99

2006 US\$39.99

2006 US $\$ 29.99$

2006 US\$ 44.99

2004 US\$39.99

2004 US\$ 49.99

2006 US\$59.99

2005 US\$ 12.99

- TITLES RELEASED AFTER January 2010 ARE MARKED IN BOLD. 


\section{For Wholesale enquiries contact:-}

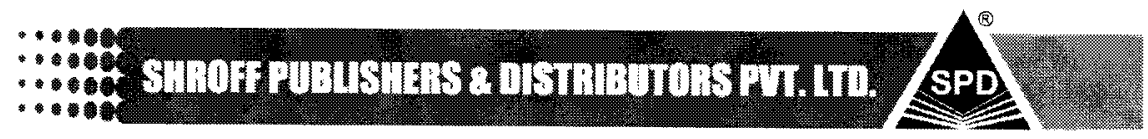

C-103, TTC Industrial Area, MIDC, Pawane, Navi Mumbai - 400705.

Tel: (91 22) 41584158 • Fax: (91 22) 41584141 •E-mail: spdorders@shroffpublishers.com

\section{Branches:-}

Bangalore

7, Sharada Colony, Basaveshwarnagar,

$8^{\text {th }}$ Main, Bangalore 560079

Tel: (91 80) 41287393 - Fax: 41287392

E-mail: spdblr@shroffpublishers.com

Kolkata

$7 B$ Haati Bagan Road,

CIT Paddapukur, Kolkata - 700014

Tel: (91 33) $22849329 / 7954$ • Fax: 28350795

E-mail: spdkol@shroffpublishers.com
Delhi

Basement, 2/11 Ansari Road,

Daryaganj, New Delhi - 110002

Tel: (91 11) $23243337 / 8$ • Fax: 23243339

E-mail: spddel@shroffpublishers.com

\section{RESIDENT REPRESENTATIVES}

Chennai Mobile : 9710936664 / 9884193326 E-mail: spdchennai@shroffpublishers.com

Hyderabad Mobile : 09885059050 E-mail: jayashanker@shroffpublishers.com

Pune Mobile : 09619439607 E-mail: dinesh@shroffpublishers.com

\section{For retail enguiries contact:}

\section{GOMPUTEP}

Computer Bookshop (I) Pvt. Ltd.

Kitab Mahal Bldg., Ground Floor, Next to Central Bank of India.

190. Dr. D. N. Road, Fort, Mumbai 400001

Tel: (91 22) $66317922 / 23 / 24$ • Fax: 22623551

E-mail: cbs@vsnl.com

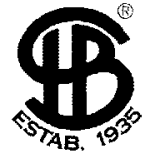

Sterling Book House

181, Dr. D. N. Road, Fort, Mumbai - 400001.

Tel. : (91-22) 22676046,22659599 • Fax : 22623551

E-mail ; sbh@vsnl.com•www.sterlingbookhouse.com
Mumbaì

36. M. A. Sarang Marg,

Tandel Street South) Dongri, Mumbai-400 009

(91-22) 66107595 - Telefax: 66107596

E-mail:spddongri@shroffpublishers.com 


\section{Koha 3 Library Management System}

Koha is the first full-featured open source library management system that is widely used for efficiently managing libraries. However, setting up and maintaining Koha is no walk in the park. It is not as straightforward as setting up the other popular LAMP applications.

This practical guide provides all the essential information that is needed to make the task of installing and configuring Koha seem simple and easy. It demonstrates how to set up Koha and its various aspects installation, configuration, application administration, and data migration. It also covers troubleshooting, software maintenance, software customization, and other advanced topics.

Written in a practical style, this book uses the Linux shell in many chapters, demonstrating the execution of commands and their output. All chapters are written in a way that makes them applicable to various Linux distributions. By the end of this book, you will have gained the knowledge to get the most out of your Koha installation.

\section{Who this book is written for}

This book is aimed at Linux system administrators who need to install and maintain Koha. If you are a system administrator who wants to set up an open source integrated library system, then this book is for you. It will also be useful for system administrators who require help with specific aspects of implementing Koha.

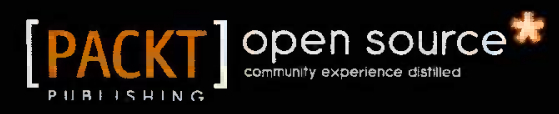

"Community Experience Distilled"
What you will learn from this book

Set up and configure Koha as per your needs and requirements

Install, configure, and test drive the Zebra Search Engine to improve the searching capabilities of your Koha application

- Configure the Cataloging module to make finding and evaluating items in a library amazingly simple for patrons

Migrate catalog data from other systems into Koha

Configure the circulation module by mapping your library's policies to rules and preferences in Koha

- Tons of pointers for troubleshooting common problems that arise with your Koha installation

- Beef up your knowledge of advanced topics such as LDAP integration and Internationalization

- Set up your Koha server as a Z39.50 server to share your catalog with the outside world

- Customize your software and share it with the community
Packt Publishing

Birmingham - Mumbai

www.packtpub.com
For sale in the Indian Subcontinent (India, Pakistan, Bangladesh, Sri Lanka, Nepal, Bhutan, Maldives) only. Illegal for sale outside of these countries.

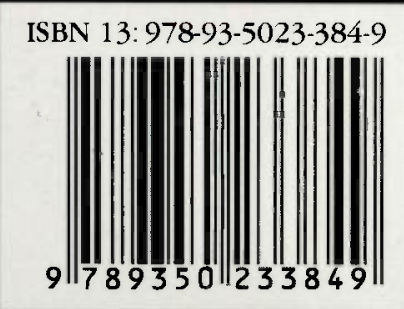

